\title{
Fish against thrombosis? : dietary fish and cardiovascular risk profile
}

Citation for published version (APA):

van Houwelingen, A. C. (1988). Fish against thrombosis? : dietary fish and cardiovascular risk profile. [Doctoral Thesis, Maastricht University]. Rijksuniversiteit Limburg.

https://doi.org/10.26481/dis.19881209ah

Document status and date:

Published: 01/01/1988

DOI:

10.26481/dis.19881209ah

Document Version:

Publisher's PDF, also known as Version of record

\section{Please check the document version of this publication:}

- A submitted manuscript is the version of the article upon submission and before peer-review. There can be important differences between the submitted version and the official published version of record.

People interested in the research are advised to contact the author for the final version of the publication, or visit the DOI to the publisher's website.

- The final author version and the galley proof are versions of the publication after peer review.

- The final published version features the final layout of the paper including the volume, issue and page numbers.

Link to publication

\footnotetext{
General rights rights.

- You may freely distribute the URL identifying the publication in the public portal. please follow below link for the End User Agreement:

www.umlib.nl/taverne-license

Take down policy

If you believe that this document breaches copyright please contact us at:

repository@maastrichtuniversity.nl

providing details and we will investigate your claim.
}

Copyright and moral rights for the publications made accessible in the public portal are retained by the authors and/or other copyright owners and it is a condition of accessing publications that users recognise and abide by the legal requirements associated with these

- Users may download and print one copy of any publication from the public portal for the purpose of private study or research.

- You may not further distribute the material or use it for any profit-making activity or commercial gain

If the publication is distributed under the terms of Article $25 \mathrm{fa}$ of the Dutch Copyright Act, indicated by the "Taverne" license above, 
FISH AGAINST THROMBOSIS?

Dietary fish and cardiovascular risk profille 



\title{
FISH AGAINST THROMBOSIS?
}

\section{Dietary fish and cardiovascular risk profile}

\author{
PROEFSCHRIFT
}

ter verkrijging van de graad van doctor

aan de Rijksuniversiteit Limburg te Maastricht, op gezag van de Rector Magnificus prof.dr. F.I.M. Bonke, volgens het besluit van het College van Dekanen, in het openbaar te verdedigen op vrijdag, 9 december 1988 om 16.00 uur

door

Adriana Cornelia van Houwelingen

geboren te Dordrecht 
promotor:

co-promotor:

beoordelingscommissie: prof.dr. R. Reneman

prof.dr. M.J. Crawford

dr. J.A. Schouten

prof.dr. P.B. Soeters

prof.dr. F. Sturmans

Het verschijnen van dit proefschrift werd mede mogelijk gemaakt door financiële steun van de Stichting Het Scholten Cordes. Fonds, de Nederlandse Hartstichting en de Jan Dekkerstichting \& dr. Ludgardine Bouwmanstichting.

Ontwerp omslag: Kees Ruissen.

Druk: Groenevelt bv, Landgraaf. 


\section{CONTENTS}

Publications

CHAPTER 1

Introduction

CHAPTER 2

Habitual fish consumption, fatty acids of serum phospholipids and platelet function

\section{CHAPTER 3}

Comparison between the habitual intake of polyunsaturated fatty acids from fish and their concentrations in serum lipid fractions

\section{CHAPTER 4}

Effect of a moderate fish intake on blood pressure, bleeding time, hematology and clinical chemistry in healthy males

\section{CHAPTER 5}

A controlled study on the effects of a fish enriched diet on serum lipids and apoproteins

\section{CHAPTER 6}

Effect of a moderate fish intake on platelet aggregation in human platelet rich plasma

\section{CHAPTER 7}

Dietary fish, and platelet aggregation and ATP release in human blood 


\section{CHAPTER 8}

Influence of dietary fish on eicosanoid metabolism in male volunteers

\section{CHAPTER 9}

Effect of a moderate fish intake on coagulation parameters in healthy males

CHAPTER 10

A moderate fish intake increases plasminogen activator inhibitor type-1 in human volunteers

\section{CHAPTER 11}

General discussion and some concluding remarks

Summary

Samenvatting

Woorden van dank

Curriculum vitae 


\section{Publications}

This thesis is mainly based on the following papers:

- Houwelingen AC v, Stegen J, Kromhout D, Lezenne Coulander C de, Hornstra G. Habitual fish consumption, fatty acid composition of serum phospholipids and platelet function. Atherosclerosis 1988: in press. (CHAPTER 2).

- Houwelingen AC v, Kester ADM, Hornstra G. Comparison between the habitual intake of polyunsaturated fatty acids from fish and their concentrations in serum lipid fractions. Eur J Clin Nutr 1988: accepted. (CHAPTER 3).

- Houwelingen AC v, Nordøy A, Beek E v d, Houtsmuller U, Metz M d, Hornstra G. Effect of a moderate fish intake on blood pressure, bleeding time, hematology, and clinical chemistry in healthy males. Am J Clin Nutr 1987; 46: 424-436. (CHAPTER 4).

- Houwelingen AC v, Zevenbergen JH, Groot PHE, Hornstra G. A controlled study on effects of a fish enriched diet on serum lipids and apoproteins. 1988; Submitted. (CHAPTER 5).

- Houwelingen AC v, Hennissen AAHM, Verbeek-Schippers F, Simonsen T, Kester ADM, Hornstra G. Effect of a moderate fish intake on platelet aggregation in human platelet rich plasma. Thromb Haemostas 1988: 59: 507-513. (CHAPTER 6).

- Houwelingen AC v, Kester ADM, Hornstra G. Effect of a moderate fish intake on platelet aggregation and ATP-release in human blood. 1988; Submitted. (CHAPTER 7).

- Hornstra G, Houwelingen AC v. Influence of dietary fish on eicosanoid metabolism in male volunteers. To be submitted. (CHAPTER 8).

- Muller AD, Houwelingen AC v, Dam-Mieras MCE v, Bas BM, Hornstra G. Effect of a moderate fish intake on coagulation in healthy males. 1988; Submitted (CHAPTER 9).

- Emeis JJ, Houwelingen AC v, Hoogen CM v d, Hornstra G. A moderate fish intake increases plasminogen activator inhibitor type-1 in human volunteers. 1988; Submitted. (CHAPTER 10). 



\section{CHAPTER 1}

\section{INTRODUCTION}

According to the definition of the World Health Organization, atherosclerosis is a variable combination of changes in the intima of arteries involving focal accumulation of lipids and complex carbohydrates with blood and its constituents, accompa nied by fibrous tissue formation, calcification and associated changes in the media. Impaired circulation and ischemia occur when atherosclerotic lesions and thrombi obstruct the flow of blood. Atherosclerosis is the most important cause of cardiovascular disease, which is the leading cause of death in Western industrialized countries.

Since the beginning of this century an association has been suggested between nutrition and atherosclerosis. The Russian investigator Ignatowski fed rabbits contaminated meat in order to discover the cause of diarrhea which plaqued Russian soldiers. By coincidence he observed that the intima of the aorta of the rabbits showed atherosclerotic lesions, and so this study became one of the first in which atherosclerosis was produced experimentally in an animal model (1). Moreover, a relation between cardiovascular disease and nutrition was put forward.

International studies showed that in some populations atherosclerosis is rare, whereas in others it is the most common cause of death. It has been proposed that this inequality results from differences in nutrition. Epidemiological studies have shown a much lower prevalence of atherosclerosis in Greenland Eskimos and Arctic populations than in populations in Western Europe $(2,3)$. Arctic populations consume more protein and less carbohydrate than Western populations. They consume equivalent amounts of fat. The fatty acid compositions of these fats, however, are different. The Eskimos' intake of saturated fatty acids is less than half of that of Danes, while the consumption of both mono- and polyunsaturated fatty acids is much higher (4). The polyunsaturated fatty acids consumed by Danes are mainlly of the n-6 type - characteristic for terrestrial plants - while Eskimos consume mainly the very long-chain ( $>C 20$ ) polyunsaturated fatty acids of the $n-3$ type from marine animals. On the basis of this observation it was suggested that the consumption of lipids of marine origin contribute to the low incidence of atherosclerosis (4). Thereafter, many attempts have been made to correlate fish consumption with mortality from coronary heart disease. In several studies a negative relationship was found (5-9); on other occasions, however, no significant correlations could be observed at all (10-14). 
The relation between cardiovascular mortality rates and dietary composition in 15 different countries was investigated by Renaud (13). No significant influence was observed for the consumption of fish. For vegetable oil, however, a significant negative correlation was found, as well as a significant positive one for dairy fat. In another international study the association between fish consumption and mortality from cardiovascular disease disappeared when adjustments were made for the effects of other foods (5). Moreover, the results in this study were very strongly influenced by one set of data collected in Japan.

Not only on an international level, but even within one country significant relations between dietary fish and cardiovascular disease are observed. In Japan the mortality due to ischemic heart disease is lower among fishermen with a high fish consumption compared to farmers (15). In Norway a dose response relation with the lowest risk for those who had a high fish consumption was reported by Norell et al (8). Other data obtained in Norway $(16,17,18)$ to support the 'fish hypothesis" may simply point to a protective effect of food shortage. In two other studies $(11,14)$ the absence of a significant correlation between fish consumption and cardiovascular mortality has been suggested to be due to the rather high habitual fish consumption of the group with the lowest fish intake (19). In addition, in a coastal community in Northern Norway, a higher mortality from coronary heart disease was observed compared with an inland community which had a 2.5 times lower fish consumption (20).

In studies performed within one city it was found that in the Dutch town of Zutphen an inverse relation exists between fish consumption and 20-year mortality from coronary heart disease (7). Comparable results were reported by Shekelle in the Western Electric Study in Chicago (9). On the other hand, during a 12-year followup study which was recently performed among women in Gothenburg, Sweden, no significant correlation between intake of fish and the incidence of ischemic heart disease was found (12).

Although the results of these epidemiological studies are ambiguous and inconclusive with respect to the relation between fish consumption and cardiovascular disease, they have prompted many intervention trials to study the effects of $n-3$ fatty acids on the cardiovascular risk profile. A careful screening of the available literature revealed that many of the beneficial effects of fish were obtained in intervention studies which had several serious shortcomings in their design. Methods to monitor compliance with the treatment were often absent. Moreover, there was an enormous variability in quantities and types of dietary supplementation. Volunteers have consumed fatty fish, fish oils, fish oil concentrates or purified timnodonic acid (20:5 $\mathrm{n}-3)$. In all these studies the amount of timnodonic acid given varied from 50 milligrams (21) to more than 10 grams a day (22). The duration of supplementation varied from one dose (23) to repeated doses given for over four years (24). Most of 
the trials were conducted with healthy adults of either or both sexes as subjects. Elderly people and patients requiring chronic hemodialysis, or with diabetes, serum lipid abnormalities, peripheral vascular disease, ischemic heart disease, angina, myocardial infarction, or hypertension have also been included. Due to the different kinds of volunteers in intervention trials, it is very difficult to get an overall impression of the putative beneficial effects of fish in relation to prevention of cardiovascular disease. Therefore, comparison of these studies is very difficult. Moreover, many of the intervention studies performed lacked a proper control group, as a consequence of which their results cannot be interpreted correctly.

In this thesis first the hypothesis that habitual fish consumption might be related to coronary heart disease through an effect on bleeding time, platelet functions and fibrinolysis was tested in a selection of the study population, which belonged to the Dutch cohort of the Seven Countries Study (Chapter 2 and 3).

Furthermore we performed a well-controlled intervention study in which the effect of a reasonable amount of dietary fish on a number of risk indicators of ischemic heart and vessel disease was investigated. The amount of fish chosen was thought to be a feasible amount for a Western population, taking into account the average habitual fish consumption. Chapter 4 contains a detailed description of the experimental design.

To test the efficacy of a fish-enriched diet and to study the mechanism of action, a number of variables that have been implicated in the epidemiology and etiology of atherosclerosis have been investigated.

Blood pressure is strongly related to cardiovascular mortality (25), and any change in blood pressure may be expected to change the cardiovascular risk. Epidemiological data concerning the relation between dietary fish and blood pressure are very weak (26-32). The effects of supplementation with dietary fish on blood pressure are presented in Chapter 4.

Blood platelets also play an important role in the onset and progress of cardiovascular disease $(33,34)$. The tendency of platelets to become activated is of great importance for the development of atherosclerosis (35). Bleeding time is considered to reflect the interaction between platelets and vessel wall in vivo (36). Epidemiological observations in Greenland Eskimos $(29,37)$ and in a Japanese fish-eating population (30) showed significantly prolonged bleeding times. This prolonged bleeding tendency might be related to their low cardiovascular mortality in comparison to Europeans. In addition bleeding time was significantly shorter in patients having a myocardial infarction compared with patient having chest pain but no infarction (38). Data on bleeding time in relation to a fish enriched diet are given in Chapter 4.

Of the various risk factors for atherosclerosis, serum lipids play a central role (39). It has been observed that total serum cholesterol and VLDL and LDL cholesterol 
concentrations are positively associated with subsequent incidence of heart disease, whereas HDL cholesterol concentrations are negatively associated with cardiovascular risk which is enhanced by an increase in the ratio of total to HDL cholesterol (40-43). Raised triglyceride concentrations in serum have also been associated with an increased risk of ischemic heart disease $(44,45)$. Our results with respect to the effects of dietary fish on serum lipids, fatty acid composition of serum and apoproteins are presented in Chapter 5.

The importance of in-vivo platelet aggregation as a risk factor for cardiovascular disease is poorly documented. Studies performed after myocardial infarction or in angina pectoris patients demonstrated that platelet aggregation may be enhanced or unaltered $(46,47,48)$. Platelets of Greenland Eskimos and Japanese fishermen (30, 49) were less reactive in platelet rich plasma in comparison to those of Caucasian Danes and Japanese farmers. In vitro platelet functions in relation to a diet containing a moderate amount of fish are described in Chapter 6 and 7.

As prostanoids are important in the regulation of hemostasis, thrombosis and blood pressure and may play a role in the development and progress of ischemic cardiovascular disease (50), the effects of a fish-enriched diet on prostanoid formation and metabolism were also investigated. Results are given in Chapter 8 .

Blood coagulation is stimulated by activated platelets $(51,52,53)$. In addition, thrombin, which is formed as a consequence of vascular injury, is a potent activator of blood platelets $(54,55)$. In fact, thrombin is essential for the initiation of the local platelet thrombus $(56,57)$. The end product of the coagulation cascade, fibrin, is part of the contents of the atherosclerotic plaque (58). Consequently blood coagulation is expected to play an important role in cardiovascular disease. Furthermore, oral anticoagulants appeared to be effective in the secondary prevention of myocardial infarction $(59,60)$. The results of our intervention study on blood coagulation are described in Chapter 9.

The fibrinolytic system has also been implicated in the development of atherosclerosis $(61,62)$. An impaired fibrinolytic system, e.g. by an increase of plasminogen activator inhibitor, has been associated with cardiovascular and thrombo-embolytic disease $(63,64,65)$. Fibrinolytic parameters in relation to dietary fish are presented in Chapter 10 .

Finally, in the general discussion (Chapter 11) the results obtained with diets enriched with $\mathrm{n}-3$ fatty acids are discussed in the context of the putative beneficial effects on cardiovascular risk. Moreover the influence of marine diets on other aspects of human health are briefly discussed. 


\section{References}

1. Ignatowski A. Über den Einfluss der Animal Nahrung auf den Kaninchen organismus. Ber d K milmed Akad zu St Petersburg Bd 16, 1908.

2. Editorial: Eskimo diets and disease. Lancet 1983; i: 1139-1141.

3. Bang HO, Dyerberg J. Lipid metabolism and ischemic heart disease. In: Draper HH (ed). Advanced Nutrition Research. Vol 3. Plenum Press, New York 1980: 1-22.

4. Bang HO, Dyerberg J, Sinclair HM. The composition of the Eskimo food in north western Greenland. Am J Clin Nutr 1980; 33: 2657-2661.

5. Crombie LK, McLoone P, Smith WCS, Thomson M, Tunstall Pedoe H. International differences in coronary heart disease mortality and consumption of fish and other food stuffs. Eur Heart $\mathrm{I}$ $1987 ; 8: 560-563$.

6. Knox EG. Food and diseases. Brit J Prev Soc Med 1977; 31: 71-80.

7. Kromhout D, Bosschieter EB, Lezenne Coulander $\mathbf{C}$ de. The inverse relation between fish consumption and 20-year mortality from coronary heart disease. New Engl J Med 1985; 312: 1205-1209.

8. Norell SE, Albohm A, Feychting M, Pedersen NL. Fish consumption and mortality from coronary heart disease. Brit Med J 1986; 293: 426

9. Shekelle RB, Paul O, MacMillan Shryrock A, Stamler J. Fish consumption and mortality from coronary heart disease. New Engl J Med 1985; 313: 820.

10. Armstrong BK, Mann JI, Adelstein AM, Eskim F. Commodity consumption and ischaemic heart disease mortality with special reference to dietary practices. J Chron Dis $1975 ; 28: 455-469$.

11. Curb JD, Reed DM. Fish consumption and mortality from coronary heart disease. New Engl J Med $1985 ; 313: 821-822$.

12. Lapidus L, Andersson H, Bengtsson C, Bosaeus I. Dietary habits in relation to inciclence of cardiowascular disease and death in women: a 12-year follow-up of participants in the population study of women in Gothenburg, Sweden. Am J Clin Nutr 1986; 44: 444-448.

13. Renaud S. Personal communication.

14. Vollset SE, Heuch I, Bjelke E. Fish consumption and mortality from coronary heart disease. New Engl J Med 1985; 313: 820-821.

15. Kimura N. Changing patterns of coronary heart disease, stroke, and nutrient intake in Japan. Prev Med 1983; $12: 222-227$.

16. Strom A. Examination into the diet of Norwegian families during the war years 1942-1945. Acta Med Scand (Suppl) $1948 ; 214: 1-47$.

17. Strom A, Jensen RA. Mortality from circulatory diseases in Norway 1940-1945. Lancet 1951; i: 126-129.

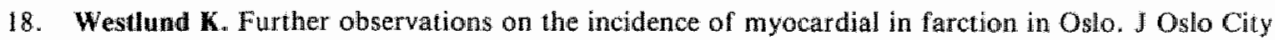
Hosp 1965; 15: 201-231. 
19. Kromhout D. Fish consumption and mortality from coronary theart disease. New Eng J Med 1985; 313: 824 .

20. Simonsen T, Vartun A, Lungmo V, Norddy A. Coronary heart disease, serum lipids and dietary fish in two communities in Nothern Norway. Acta Med Scand 1987:222: 237-245.

21. Driss $\mathbf{F}$, Dareet $\mathbf{P}$, Lagarde $\mathbf{M}$, Vericel $\mathbf{E}_{*}$ Velardo B, Guichardant $\mathbf{M}$, Dechananne $\mathbf{M}$. Polyunsaturated fary acids: Drugs or food: Wid Rev Nutr Diet 1984; 43: 170-173.

22. Jakubowski JA, Ardlie NG. Evidence for the mechanism by which eicosapentaenoic acid inhibits human platelet aggregation and secretion. Implications for the prevention of vascular disease. Thromb Res 1979\% 16: 205-217.

23. Nord Ay , Lagarde M. Renaud S. Platelets during alimentary hyperlipaemia induced by cream and cod liver oil. Eur J Clin Invest $1984 ; 14: 339-345$.

24. Ferretti A, Flanagan VP, Reeves. VB. Occurrence of prostaglandin E3 in human urine as a result of marine oil ingestion: gas chromatographicmass spectrometric evidence. Biochim Bioptays Acta 1988; $959: 262-268$.

25. Kannel WB. Role of bloodpressure in cardiovascular morbidity and mortality. Progr Cardiovasc Dis $1974 ; 17: 1-28$.

26. Bjerager P, Kromann N, Thygesen K, Harwald B. Blodtryk hos grønlaendere. Ugeskr Laeg 1980; 142: $2278-2280$.

27. Dahl LK. Salt intake and salt need. New Engl J Med 1958; 258: 1152-1157.

28. Ehrströ̀m MCh. Medical studies in North Greenland 1948-1949. VI Blood pressure, hypertension and arteriosclerosis in relation to food and mode of living. Acta Med Scand $1951 ; 140: 416-422$.

29. Jørgensen KA, Nielsen AH, Dyerberg J. Hemostatic factors and renin in Greenland Eskimos on a high eicosapentaenoic acid intake. Acta Med Scand 1986; 219: 473-479.

30. Hiral A, Terano T, Saito H, Tamura Y, Ysohida S. Eicosapentaenoic acid and platelet function in Japanese. In: Lovenberg $W$, Yamori $Y$ (eds). Nutritional prevention of cardiovascular disease. Academic Press, London 1984: 231-239.

31. Kangawa Y, Nishizawa M, Suzuki M, Miyatake T, Hamamoto T, Goto K, Motonaga E, Izumikawa H, Hirata $\mathbf{H}$, Ebihara A. Eicosapolyenoic acid of serum lipids of Japanese islanders with low inci. dence of cardiovascular diseases. I Nutr Sci Vitaminol 1982; 28: 441-453.

32. Rohinson D, Day J. Low plasma triglyceride levels in lake dwelling East African tribesmen - A fushy story. Int J. Epidem 1986; 15: 183\%187.

33. Chandler AB. Arterial thrombosis, platelets and atherogenesis. In: Hornstra $\mathrm{G}$. Dietary fats, prostanoids and arterial thrombosis. Martinus Nijhoff Publishers, The Hague 1982: 1-14.

34. Ross, R. Glomset JA. The pathogenesis of atherosclerosis. N Engl J Med 1976; 295: 369-377.

35. Trylor TG, Gibney MJ, Morgan JB. Haemostatic function and polyunsaturated fatty acids. Lancet 1979; ii: 1378.

36. Nieuwenhuis HK, Sixma JJ. Bleeding time measurements. In: Harker LA, Zimmerman TS (eds). Measurements of platelet function. Churchill Liwingstone, Edinburgh 1983: 26-45. 
37. Dyerberg J, Bang HO. Haemostatic function and platelet polyunsatured fatty acids in Eskimos. Lancet $1979 ; \mathrm{ii}: 433-435$.

38. Milner PC, Martin JF. Shortened bleeding time in acute myocardial infarction and its relation to

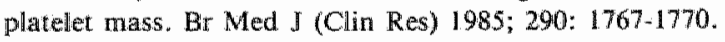

39. Assimann G. Lipid metabolism and atherosclerosis. Schattauer Verlag GmbH Stuttgart 1982: 1-13.

40. Kannel BW, Castelli WP, Gordon T, MeNamara PM. Serum cholesterol lipoprotiein and the risk of coronary heart disease. The Framingham study. Ann Intern Med 1971; 74: 1-12.

41. Castelli WP. Epidemiology of coronary heart disease: the Framingham study. Am J Med 1984; 76 : $4-12$.

42. Levy RT, Blum CB, Schaeter EJ. The composition, structure and metabolism of high density lipoprotein. In: Greten $H$ (ed). Lipoprotein metabolism. Springer-Verlag, New York 1976: 56.

43. Miller ME, Anagnostou A, Ley B, Marshall P. Steiner M. Effect of fish oil concentrate on hemorrheological and hemostatic aspects of diabetes mellitus: a preliminary study. Thromb Res 1987; 47. $201-21.4$.

44. Carlson LA, Böttiger LE. Ischaemic hearti clisease in relation to lactual values of plasma trigiycer. ides and cholesterol. Lancet 1972; i: 865-868.

45. Åberg $\mathbf{H}$, Lithell $\mathbf{H}$, Selinus I, Hedstrand H. Serum triglycerides are a risk factor for myocardial infarction but not for angina pectoris. Results from a 10-year follow-up of Uppsala primary preventive study. Atherosclerosis 1985; 54: 89-97.

46. Weiss HJ. Platelets, pathophysiology and antiplatelet drug therapy. Alan R Liss Inc, New York 1982: 76-94.

47. Kinlough-Rathbone RL, Packham MA, Mustard JG. Platelet aggregation. In: Measurements of platelet function. Harker LA, Zimmerman TS (eds). Churchill Libingstone, Edinburgh 1983: 64-91.

48. Hornstra G. The filtragometer in thrombosis research. In: Day HJ, Holmsen $\mathrm{H}$, Zucker MB (eds). Platelet function testing. DHEW Publication (no NIH 78-1087). US Department of health, education and wellfare. Public Health Serwice, National Institute of Health 1978: 416-427.

49. Hirai A, Hamzaki T, Terano T, Nishikawa T, Tamura $\mathbb{Y}$, Kumagai A, Sajiki J. Eicosapentaenoic acid and platelet function in Japanese. Lancet 1980; ii: $1132-1133$.

50. Marcus AJ. The eicosanoids in biology and medicine. J. Lipid Res 1984; 25: 1511-1516.

51. Bevers EM, Rosing J, Zwaal RFA. Platelets and coagulation. In: Macintyre DE, Gordon J (ecls), Platelets in biology and pathology. Volune III. Elsevier Science Publishers, BV, Biomedical Division, Amsterdam 1987: 127:160.

52. Fantl P, Ward HA. The thromboplastic component of intact blood is present in masked form. Aust J Expt. Biol Med Sci 1958; 36: 499-504.

53. Walsh PN, Griffin JH. Contribution of human platelets to the proteolytic activation of blood coagulation factor XII and XI. Blood 1981; 57:106-118.

54. Dawey MG, Lüscher EF. Actions of thrombin and other coagulant and proteolytic enzymes on blood platelets. Nature 1967; 216: 857-858. 
55. Majeras PW, Tollefsen DM, Shumain MA. The interaction of platelets with thrombin. In: Gordon IL (ed). Platelets in biology and pathology. Volume 1. Elsevier, North Holland Biomedical Press, Ansterdam 1976: $241-260$.

56. Ardlie NG, Han P. Enzymatic basils for platelet aggregation and release: the significance of the 'platelet atmosphere' and the relationship between platelet function and biood coagulation. Brit $J$ Hatratol 1974; 26: 331-356.

57. Hornstra G. Platelet-vessel wall interaction: role of blood clotting. Phil Trans R Soc Lond B 1981; 294: $335-371$.

58. Woolf N. Pathology of atherosclerosis. Chapter 10: Thrombosis and atherosclerosis. Butterworth Scientific, London 1982: 217-259.

59. Loeliger EA, Hensen A, Kroes F, Dijk LM van "Fekkes $\mathbf{N}$, Jonge $\mathbf{H}$ de, Hemker HC. A double blind trial of long-term anticoagulant treatment after myocardial infarction. Acta Med Scand 1967; 182: $549-566$.

60. Vries WA de, Tijssen JPG, Loeliger EA, Roos J. A double-blind trial to assess long-term anticoagulant therapy in elderly patients after myocardial infarction. Lancet 1980; ii: 989-994.

61. Astrup T. Fibrinolysis: an overview. In: Davidson JF, Rowan RM, Desnoyers PS (eds). Progress in chemical fybrinolysis and thrombolysis. Raven Press, New York 1978: 1-57.

62. Bachunann R. Fibrinolysis. In: Verstraete $M$, Vermylen J, Lynen $R_{*}$ Arnout $J$ (eds). Thrombosis and Haemostasis 1987. University Press, Leuwen 1987: 227-265.

63. Hamsten A, De Faire U, Walldius G, Dahllen G, Szamosi A, Landou C, Blombäck M, Wiman B. Plasminogen activator inhibitor is plasma-risk factor for recurrent myocardial infarction. Lancet 1987; ît: $3-8$.

64. Hamsten A, Wiman B, De Faire $U_{*}$ Blombäck M. Increased plasma levels of a rapid inhibitor of tissue plasminogen activator in young survivors of myocardial infarction. New Engl I Med 1985; 313: $1557-1563$.

65. Paramo JA. Colucci M. Collen D, Werf F van de. Plasminogen activator inhibitor in the blood of patients with coronary artery disease. Brit Med J $1985 ; 291: 573-574$. 


\section{CHAPTER 2}

\section{HABITUAL FISH CONSUMPTION, FATTY ACIDS OF SERUM PHOSPHOLIPIDS AND PLATELET FUNCTION}

\section{Summary}

To clarify whether the inverse relation between habitual fish consumption and cardiovascular mortality in the Dutch town of Zutphen could be explained by changes in platelet function or fibrinolysis, forty healthy elderly men were selected from the Zutphen study population on the basis of their fish consumption over the last 26 years. In the high-fish group $(\mathrm{n}=25)$ fish consumption was on average $33 \mathrm{~g}$; in the low-fish group $(n=15)$ it was on average $2 \mathrm{~g}$ per person per day. This difference was reflected by significant differences in the concentrations of timnodonic acid (20:5 $n-3)$ and cervonic acid (22:6 n-3) in the serum phospholipids of the participants, Between both groups no significant differences were observed in cutaneous bleeding time, platelet number, and collagen induced platelet aggregation and ATP-release in whole blood. The same holds for the actual as well as the potential $\mathrm{TxB}_{2}$-formation of activated platelets and for the activity of the plasminogen activator inhibitor. For most of the platelet-related variables a trend was found for a lower activity in the high-fish group. Therefore changes in platelet function might not explain, but may have slightly contributed to the inverse relationship between coronary heart disease and fish consumption, as observed in Zutphen.

Key words: habitual fish consumption, bleeding time, whole blood platelet aggregation, platelet ATP-release, $\mathrm{TxB}_{2}$, plasminogen activator inhibitor. 


\section{Introduction}

Retrospective epidemiological investigations suggest that consumption of fish or fish products lowers mortality caused by ischemic heart disease, although the results are equivocal (1). In many human intervention studies it has been demonstrated that diets enriched with fish or fish oils reduce the aggregability of blood platelets and prolong cutaneous bleeding times (1). These effects are likely to contribute to a reduced risk of cardiovascular disease, although full proof for this view has not yet been obtained in prospective intervention studies. Moreover, the changes observed in these short term studies may have been temporary and do not necessarily persist life-long.

Recently Kromhout et al have found an inverse relation between fish consumption and 20-year mortality from coronary heart disease in the Dutch town of Zutphen (2). Since this population was part of the Seven Countries Study $(3,4)$, information is available on their habitual food intake for over 25 years. Therefore, in a sample of the Zutphen study population, we investigated the association between habitual fish consumption (measured by the cross-check dietary history method as well as by the fatty acid composition of serum phospholipids) and a number of variables related to the cardiovascular risk profile: cutaneous bleeding time, platelet number, platelet aggregation and ATP release in whole blood, and the capability of activated blood platelets to produce Thromboxane $\mathrm{B}_{2}\left(\mathrm{TxB}_{2}\right)$. In addition, the activity of plasminogen activator inhibitor (PAI) was determined.

\section{Subjects, materials and methods}

Since 1960 , a longitudinal investigation on the relation of diet and other risk factors to chronic diseases has been carried out among middle-aged men from the town of Zutphen in The Netherlands. As a part of this study, information about the fish consumption of these men was collected in 1960,1965,1970 and 1985 by the crosscheck dietary history method (5). In 1985 a selection of volunteers from this study population was made on the basis of their habitual fish consumption. Persons suffering from clinically manifest heart and vessel disease were excluded, in order to prevent possible interference of medication with platelet function. Persons using drugs known to have an influence on platelet function were also left out. Men selected for the high fish group consumed on average $30.4 \pm 1.3$ (SEM) $g$ of fish per day (range 11-107 g) during the period between 1960 and 1985 . The average fish consumption of the low fish group was $3.6 \pm 0.4 \mathrm{~g}$ of fish per day (range $0-14 \mathrm{~g}$ ) during that period. In total 79 men (aged 66-81 in 1985) were selected for this study. Of these men, 15 did not participate: after the examination in 1985 two died, four suffered severe disease (eg. myocardial infarction, cancer, rheumatoid arthritis and mental illness), five used drugs not compatible with the present study and four refused to participate. 
In April-May 1986, the period in which the present study was conducted, the food consumption pattern of the volunteers was determined again by the cross-check dietary history method. From these data the energy and nutrient intake was calculated with the computerised version of the Uniform Food Encoding System developed in The Netherlands (6). Unfortunately, 22 men showed an inconsistent fish consumption pattern, which forced us to remove them from the initial selection. In addition, two volunteers were not eligible for other reasons and were also excluded from the study. This resulted in a high-fish group with 25 individuals and a low-fish group containing 15 persons.

The men were instructed not to use non-steroidal anti-inflammatory drugs three weeks before the investigation. As a replacement Glifanan (Glafenine, Roussel, Paris, France) was advised. Smoking was not allowed on the morning before blood sampling. Blood used to analyse the fatty acid composition of serum phospholipids and to determine platelet number was taken under fasting conditions and after a $24 \mathrm{~h}$ abstinence from alcohol. Blood was sampled between 8:00 and 9:30 AM at the homes of the volunteers, from an antecubital vein, with a 19 gauge needle, under minimum stasis. Two ml of blood were collected in a tube containing EDTA for analysis of platelet number using hospital routine methods (Nieuwe Spittaal Hospital, Zutphen). Subsequently $5 \mathrm{ml}$ of blood was taken for determination of fatty acid composition. After clotting, serum was separated and stored at $-20^{\circ} \mathrm{C}$ until analysis.

For the measurements of platelet functions and the plasminogen activator inhibitor (PAI) activity, the volunteers visited the laboratory. Again, they were asked to abstain from alcohol for $24 \mathrm{~h}$ and, on the day they visited the laboratory, not to smoke until the investigations were performed.

Bleeding times were determined with the Simplate II device as described in Chapter 4 (7). After completion of the bleeding time measurement, a blood sample was taken from an antecubital vein under minimum stasis, using a $19 \mathrm{G}$ butterfly veni system (no 4590, Abbott Ireland Ltd, Sligo, Republic of Ireland). Firstly, blood was taken into a $5 \mathrm{ml}$ Monovette (no 05114, Sarstedt, Numbrecht, FRG) for determination of the $\mathrm{TxB}_{2}$ content of serum (see below). Subsequently, $1.8 \mathrm{ml}$ of blood was taken into a warm syringe prefilled with $0.2 \mathrm{ml}$ of citrate $(109 \mathrm{mmol} / 1$ adjusted to $\mathrm{pH}$ $[18,0] .[15,0]$ with $10 \%(\mathrm{w} / \mathrm{v})$ citric acid solution). This blood sample was used immediately for the measurement of collagen induced platelet aggregation and ATP release using a whole blood lumi-aggregometer (Model 500, Chrono-log Cooperation, Havertown, PA, USA), as described in Chapter 7 . Finally $1.8 \mathrm{ml}$ of blood was taken into an ice-cold syringe pre-filled with $0.2 \mathrm{ml}$ of citrate $(109 \mathrm{mmol} / \mathrm{l})$. This anticoagulated blood was transferred into Eppendorf tubes and spun down for 2 min. The plasma was collected and stored at $-20^{\circ} \mathrm{C}$ until determination of PAI activity which was performed at the Gaubius Institute, Leiden, The Netherlands, according to Verheijen et al (8).

After completion of the aggregation measurements, the blood sample was trans- 
ferred into an Eppendorf cuvette and centrifuged for 2 min; plasma was collected into another Eppendorf tube for measuring the $\mathrm{TxB}_{2}$ content.

The blood taken for serum $\mathrm{TxB}_{2}$ measurements was allowed to clot at $37^{\circ} \mathrm{C}$ for 60 min after which the monovette was centrifuged $(15 \mathrm{~min}$ at $3000 \mathrm{xg})$. The serum was collected carefully and transferred into Eppendorf tubes. All plasma and serum samples for $\mathrm{TxB}_{2}$ measurements were frozen in liquid nitrogen immediately after centrifugation and stored at $-20^{\circ} \mathrm{C}$ until analysis, using a radio-immunoassay kit (NEK-007, New England Nuclear, Boston, MA, USA) according to the manufacturers" instructions. Immediately before the measurements the serum samples were diluted 500 -fold. To that end, $10 \mu \mathrm{l}$ of serum was added to $50 \mu \mathrm{l}$ ethanol (no 983 , Merck, Darmstad, FRG), mixed, and kept for $30 \mathrm{~min}$ at room temperature. Subsequently $940 \mu \mathrm{I}$ assay buffer was added to each sample. After centrifugation in an Eppendorf centrifuge for $10 \mathrm{~min}, 100 \mu \mathrm{l}$ of the mixture was added to another 400 $\mu \mathrm{l}$ assay buffer. This final dilution was used to perform the $\mathrm{TxB}_{2}$ measurements. The plasma samples were diluted 50 -fold. Twenty $\mu \mathrm{l}$ of plasma was mixed with 50 $\mu \mathrm{l}$ ethanol. Thirty min later $930 \mu \mathrm{l}$ assay buffer was added. After centrifugation for 10 min in an Eppendorf centrifuge, the supernatant was used for $\mathrm{TxB}_{2}$ analysis. For analysis of the fatty acid composition of serum phospholipids, the samples were transported on dry-ice to Maastricht. The lipids were extracted according to Bligh and Dyer (9). Total phospholipids (PL) were isolated from the rest of the extracts by thin layer chromatography (TLC) according to Peter and Reynolds (10). The PL spots on the TLC plates (Merck 13894) were visualized by spraying with Rodamine 6G (Merck 7600, 0.01\% w/v in methanol Merck no 6011), marked under UV-light $(366 \mathrm{~nm})$, scraped off, and collected in glass tubes. An amount of $1 \mathrm{ml}$ borontrifluoride $\left(\mathrm{BF}_{3}\right.$, no $\mathrm{B} 1252$, Sigma St. Louis, MO, USA, $14 \% \mathrm{w} / \mathrm{v}$ in methanol) was added to the gels and the tubes were screw-capped under a stream of nitrogen. PL's were hydrolyzed and fatty acids methylated as described by Morrison and Smith (11). After cooling, $1 \mathrm{ml} \mathrm{H} \mathrm{H}_{2} \mathrm{O}$ was added and the fatty acid methyl esters were extracted three times with $1 \mathrm{ml}$ pentane (Merck 7288). The extracts were combined, evaporated with $\mathrm{N}_{2}$ at $37^{\circ} \mathrm{C}$ and analysed by gas liquid chromatography (GLC) using a HP $5840 \mathrm{~A}$ gas chromatograph, fitted with two glass columns $(0.2 \times 180 \mathrm{~cm})$, packed with 5\% DEGS on Chromosorb WHP 100/120 mesh (Chrompack, Middelburg, The Netherlands), and two flame-ionisation detectors. The injection and detection temperatures were $250^{\circ} \mathrm{C}$. The chromatographic separation was performed using temperature programming which had been optimised with a reference mixture containing most of the fatty acid methyl esters of interest. This mixture was also used to identify the peaks. Starting temperature of the columns was $145^{\circ} \mathrm{C}$. After $1 \mathrm{~min}$, the temperature gradually increased up to $190^{\circ} \mathrm{C}$ with a rate of $4^{\circ} \mathrm{C} / \mathrm{min}$. Flowrate of the carrier gas $\left(\mathrm{N}_{2}\right)$ was $20 \mathrm{ml} / \mathrm{min}$. The samples to be analysed were taken up in $50 \mu$ iso-octane (no 8206, Baker Chemicals B.V., Deventer, The Netherlands). Using computer-assisted analysis, the fatty acid profiles were corrected for blank runs (1 for each series of 5 samples), originating from 'extraction' of saline, and were adjusted with respect to the internal standard: the methyl ester of 15:0. 
Table 1 . Farty acid composition (\%) of serum phospholipids (mean $\$$ SEM).

\begin{tabular}{lccc}
\hline fatty acida & $\begin{array}{l}\text { high fish group } \\
(\mathrm{n}=25)\end{array}$ & $\begin{array}{l}\text { low fish group } \\
(\mathrm{n}=14)\end{array}$ & $p$ \\
\hline $14: 0$ & $0.3 \pm 0.02$ & $0.3 \pm 0.03$ & - \\
$16: 0$ & $25.7 \pm 0.35$ & $25.2 \pm 0.29$ & - \\
$16: 1 \mathrm{n}-7$ & $1.5 \pm 0.07$ & $1.6 \pm 0.06$ & - \\
$17: 0$ & $0.7 \pm 0.03$ & $0.7 \pm 0.03$ & - \\
$2 \mathrm{c}$ & $0.5 \pm 0.03$ & $0.5 \pm 0.02$ & - \\
$18: 0$ & $12.0 \pm 0.19$ & $11.9 \pm 0.26$ & - \\
$18: 1 \mathrm{n}-9$ & $10.5 \pm 0.22$ & $10.5 \pm 0.34$ & - \\
$18: 2 \mathrm{n}-6$ & $21.1 \pm 0.56$ & $21.3 \pm 0.58$ & - \\
$18: 3 \mathrm{n}-6$ & traced & & - \\
$20: 0$ & $0.9 \pm 0.05$ & $0.9 \pm 0.13$ & - \\
$18: 3 \mathrm{n}-3$ & $0.2 \pm 0.06$ & $0.3 \pm 0.09$ & - \\
$20: 1 \mathrm{n}-9$ & $0.4 \pm 0.05$ & $0.4 \pm 0.09$ & - \\
$21: 0$ & $0.3 \pm 0.07$ & $0.3 \pm 0.09$ & - \\
$?$ & $0.5 \pm 0.08$ & $0.7 \pm 0.13$ & - \\
$20: 3 \mathrm{n}-9$ & $0.4 \pm 0.08$ & $0.3 \pm 0.10$ & - \\
$20: 3 \mathrm{n}-6$ & $2.5 \pm 0.17$ & $3.0 \pm 0.17$ & 0.03 \\
$22: 0$ & $1.1 \pm 0.06$ & $1.0 \pm 0.09$ & - \\
$20: 4 \mathrm{n}-6$ & $10.1 \pm 0.29$ & $10.7 \pm 0.44$ & - \\
$23: 0$ & $0.3 \pm 0.05$ & $0.4 \pm 0.06$ & - \\
$20: 5 \mathrm{n}-3$ & $1.7 \pm 0.22$ & $0.9 \pm 0.08$ & 0.004 \\
$24: 0$ & $0.8 \pm 0.07$ & $0.8 \pm 0.07$ & - \\
$24: 1 \mathrm{n}-9$ & $3.0 \pm 0.12$ & $2.8 \pm 0.24$ & - \\
$22: 5 \mathrm{n}-6$ & $\mathrm{trace}$ & $0.2 \pm 0.07$ & - \\
$22: 5 \mathrm{n}-3 \mathrm{f}$ & $1.1 \pm 0.06$ & $1.5 \pm 0.14$ & 0.03 \\
$22: 6 \mathrm{n}-3$ & $4.2 \pm 0.24$ & $3.2 \pm 0.22$ & 0.004 \\
\hline
\end{tabular}

a: In the momenclature used for fatty acids, the figure before the colon indicates the number of carbon atoms and that after the colon the number of double bonds. The final number refers to the position of the first double bond, counting from the methyl end of the carbon chain

b: not significant

e: not detectable

c: not identified

$\mathrm{d}:<0.1 \%$

f: $24: 2$ n-6 can be present as minor component

Results were expressed as $0 \%$ of total fatty acids. The anti-oxidant butylated hydroxytoluene $0.005 \%$ ( $w / v$, Sigma B.1378) was added to all organic solvents to prevent oxidation of the polyunsaturated fatty acids.

\section{Statistical analysis}

All results were checked as to their frequency distribution and, when necessary and possible, the distribution was normalized by transformation of the data. Subsequently, significant outliers, when present, were omitted (12). Student"s 2-sample 
Table 2. Infuerce of habitual fish conssumption on platelet number, bleeding time, $T x B_{2}$ formation, and PAI (mean $\pm S E M$ ).

\begin{tabular}{lll}
\hline Variable & $\begin{array}{l}\text { High-fish group } \\
\mathrm{n}=25\end{array}$ & $\begin{array}{l}\text { Low-fish group } \\
\mathrm{n}=15\end{array}$ \\
\hline Bleeding time $(\mathrm{min})$ & $8.1 \pm 0.5$ & $17.9 \pm 0.4$ \\
Platelet number $\left(.10^{9} / 1\right)$ & $250 \pm 9.4$ & $250 \pm 11.2$ \\
$\mathrm{TxB}_{2}$, serum $(\mathrm{ng} / \mathrm{ml})$ & $320 \pm 21.7$ & $320 \pm 19.9$ \\
TxB $_{2}$, plasma $(\mathrm{ng} / \mathrm{ml})^{\mathrm{at}}$ & $20.8 \pm 1.14$ & $22.2 \pm 1.84$ \\
PA.I (IU/ml) & $6.40 \pm 0.81$ & $5.09 \pm 0.92 \mathrm{c}$ \\
\hline
\end{tabular}
a: upon stimulation of whole blood with collagen
b: plasminogen activator inhibitor activity
c: $n=14$, one outlier excluded.

t-test was used to compare the differences between the high-fish group and the lowfish group. If normalization was impossible the non-parametric Mann-Whitney test was applied. Two-sided probabilities (p) were estimated for testing significance. Differences were considered statistically significant when $\mathrm{p}<0.05$.

\section{Results}

The average fish consumption in 1986 in the high-fish group was (mean \pm SEM) $31.5 \pm 2.7 \mathrm{~g} /$ day and varied from $15-61 \mathrm{~g} /$ day. In the low-fish group the average fish consumption was $2.3 \pm 1.0 \mathrm{~g} /$ day (range $0-10 \mathrm{~g} /$ day) which is significantly lower than that in the high-fish group. The two groups also differed significantly ( $p$ $<0.001$ ) with respect to the calculated intake of $n-3$ polyunsaturated fatty acids (high-fish group $245 \pm 82 \mathrm{mg} /$ day, low-fish group $49 \pm 24 \mathrm{mg} /$ day). The intake of linoleic acid (18:2 n-6) was not significantly different between the two groups (high-fish group $16.9 \pm 2.1$; low-fish group $12.7 \pm 1.7 \mathrm{~g} /$ day).

The men of the high-fish group were not different from those of the low-fish group concerning age, height, weight and cigarette smoking. Individuals in the high-fish group used twice as much alcohol as subjects in the low-fish group $(15.2 \pm 3.6$ vs $6.3 \pm 2.5 \mathrm{~g} /$ day, $\mathrm{p}<0.05$ ). Daily energy intake was also significantly higher in the high-fïsh group compared with the low-fish group $(9.5 \pm 0.35$, vs $8.5 \pm 0.28 \mathrm{MJ}$, $\mathrm{p}<0.05$ ).

The fatty acid composition of the serum phospholipids (PL) is given in Table 1. Due to a technical failure we lost one sample from the low-fish group. The difference in average fish consumption between the two groups was reflected in significantly higher concentrations of timnodonic acid (20:5 n-3) and cervonic acid (22:6n-3) in the high-fish group (both $p<0.004$ ). Lower amounts of dihomo-gamma-linolenic 


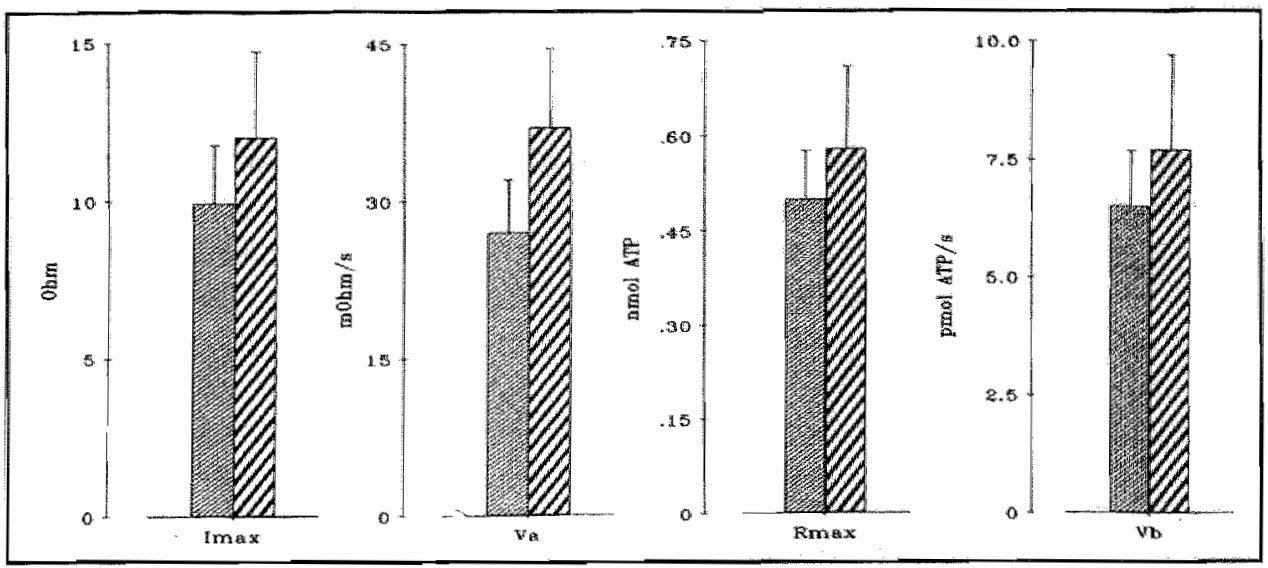

Fig 1. Platelet aggregation and ATP release in citrated whole blood.

High Fish group $(n=24)$

Imax $=$ maximum aggregation

Rmax $=$ maximum $A T P$ release

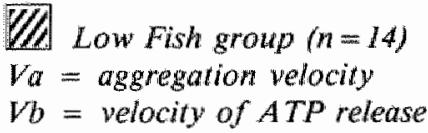

acid $(20: 3 n-6)$ and clupanodonic acid $(22: 5 n-3)$, both $p<0.03$, were observed in the serum PL of the high-fish group. For the other fatty acids no significant differences were found.

No difference between the high and low-fish groups was seen as to bleeding time and platelet number (Table 2). Moreover, platelet aggregation and ATP release in citrated whole blood were not significantlly different between the two groups (Fig 1). However, the results for both variables tended to be consistently somewhat lower in the high-fish group. $\mathrm{TXB}_{2}$ content of plasma obtained from collagen-stimulated whole blood was similar in both groups. The same held for the $T \times B_{2}$ content of serum (Table 2). Finally, no difference was observed between the groups in the activity of plasminogen activator inhibitor (PAI, Table 2 ).

\section{Discussion}

This study was performed to clarify whether the inverse relation between habitual fish consumption and mortality from cardiovascular disease, as found in the Dutch town of Zutphen (2), could be explained by an effect on platelet function and/or thromboxane formation or fibrinolysis.

For the present study, men were selected with a stable fish consumption over the last 26 years. Due to a considerable inconsistency in fish consumption pattern of the participants during the 26-year follow-up period, the sample size is rather small. The 
volunteers were divided in two groups on the basis of their habitual fish consumption measured via the cross-check dietary history method (5). The two groups differed significantly as to the calculated intake of $n-3$ polyunsaturated fatty acids timnodonic acid (20:5 n-3) and cervonic acid (22:6 n-3). The relative amounts of timnodonic acid and cervonic acid in the serum PL were also significantly higher in the high-fish group compared with the low-fish group. The amount of linoleic acid (18:2 n-6) was comparable for both groups; this applies for the calculated dietary intake as well as for the amount measured in the serum PL.

In the serum PL of the high-fish group the amount of dihomo-gamma-linolenic acid $(20: 3 \mathrm{n}-6)$ was significantly lower as compared with the group with the low fish consumption. The implications of this difference in terms of cardiovascular risk are not known. Dihomo-gamma-linolenic acid is the precursor fatty acid of the prostanoids of the 1 series. The amount of prostaglandins (PG) formed in vitro depends on the availability of their substrate fatty acid (13). Consequently, a change in dihomogamma-linolenic acid level can have an influence on the formation of $\mathrm{PGE}_{1}$, which is an active inhibitor of platelet aggregation (14). Unfortunately, fatty acid composition clata do not give information as to the fatty acid turnover in vivo. Consequently, the lower amount of dihomo-gamma-linolenic acid in the high-fish group does not necessarily indicate a lower $\mathrm{PGE}_{1}$ production in vivo; it may even reflect an enhanced $\mathrm{PGE}$, turnower.

The amounts of arachidonic acid (20:4 n-6) and 22:5 n-6 also tended to be lower in the high-fish group, which would be in agreement with the reported decrease in the relative content of plasma $n-6$ fatty acids in individuals with a high intake of n-3 fatty acid (15). In our study, however, the differences between the two groups did not reach statistical significance. In contrast to the other $n-3$ fatty acids in the serum PL, clupanodonic acid (22:5 n-3) was significantly lower in the high-fish group compared with the low fish group. The meaning of this finding is not clear as yet.

The functional variables studied were selected because they are known to be involved in arterial thrombus formation. The aggregatory potency of blood platelets might be contributory in the development and complications of atherosclerosis (16) and is thought to be regulated by the endogenous formation of thromboxane $A_{2}$ (17). In addition, the activity of plasminogen activator inhibitor (PAI) has been found to be increased in patients suffering from a wide spectrum of pathological conditions, cardiovascular and thrombo-embolic diseases included $(18,19,20)$. No significant difference in the functional variables studied was observed between the groups. This indicates that the inverse relationship between fish consumption and mortality from coronary heart disease, as observed in the Zutphen study (2), is difficult to explain by dietary fish-induced changes in platelet function. 
It should be mentioned, however, that the confidence limits, calculated on the differences between the high-and low-fish groups were very wide. As a result of which the observed type II errors were consistently larger than $70 \%$. This implies that the risk to overlook a difference as large as we observed between the two groups is at least $70 \%$. This is the more important since for various platelet-related parameters a tendency did occur for a lower platelet activity. Thus aggregation, ATP release and $\mathrm{TxB}_{2}$ formation of collagen-activated platelets tended to be lower in the high-fish group as compared to the low-fish group. Although the clinical implication of this finding is not clear, it cannot be excluded that the minor differences we observed between the groups and which may be expected to persist life-long may ultimately lead to a lower thrombotic risk and, after all, may have contributed to the negative relationship between fish consumption and cardiovascular mortality as observed in the Zutphen study.

Most intervention studies performed to investigate the effect of dietary fish(oil) on cardiovascular risk factors have employed much larger doses of timnodonic and cervonic acids than consumed by the participants of the high-fish group. Even under these more favourable experimental conditions the results were equivocal and, although often promising they do not yet warrant the conclusion that a marine diet is beneficial in the primary prevention of ischemic cardiovascular disease (1).

\section{Acknowledgements}

We are grateful to the Zutphen men who took part in this study.

The skillful technical assistance of Jos Stegen, Rob Kalafusz and Frederike Sieders is gratefully acknowledged. The activity of plasminogen activator inhibitor was analysed by Dr. Jef Emeis, Gaubius Institute, Health Research Division T.N.O. Leiden, The Netherlands. Platelet counts were performed at the Hematologic Laboratory, Nieuwe Spittaal Hospital, Zutphen, The Netherlands. We are indebted to Dr. A. Kester for stimulating discussions.

The study was supported by a grant from the Netherlands Heart Foundation.

\section{References}

1. Hornstra $G$. The significance of fish and fish-oil enriched food for the prevertion and therapy of ischemic cardiovascular disease. In: Crawford MA, Vergroesen AJ (eds). The role of fat in human nutrition II. London, UK: Academic Press (in press).

2. Kromhout D, Bosschieter EB, Lezenne Coulander $C$ de. Fish consumption and 20 year mortality from coronary heart disease. N Engl $\mathbb{N}$ Med $1985 ; 312 ; 1205-1209$. 
3. Keys Ar Arvanis C, Blackburn HW, et al. Epidemiological studies related to coronary heart disease: characteristics of men aged 40-59 in seven countries. Acta Med Scand 1967: suppl 460.

4. Keys A. Coronary heart disease in seven countries. Circulation 1970; 40: suppl1.

5. Den Hartog C, Van Schaik ThFSM, Dalderup LM, Drion EF, Mulder T. The diet of volunteers participating in a long term epidemiological field survey on coronary heart disease at Zutphen, The Netherlands. Voeding 1965; 26: 184-208.

6. Hautwast JGAJ. Development of a system for processing data obtained from nutrition questionnaires with the aid of a computer (in Dutch). Woeding $1975 ; 36: 356$-360.

7. Houwelingen AC v, Nordwy A, Beek E v d, Houtsmuller UMT, Metz MD, Hornstra G. Effect of a moderate fish intake on blood pressure, bleeding time, hematology and clinical chemistry in healthy males. Am J Clin Nutr 1987; 46:424-436. (Chapter 4).

8. Verheijen JH, Chang GITG, Kluft $\mathrm{C}$. Evidence for the occurrence of a fast-acting inhibitor for tissue-type plasminogen activator in human plasma. Thromb Haemostas. 1984; 151: 392-395.

9. Bligh EG, Dyer WJ. A rapid method for totall lipid extraction and purification. Can II Biochem Physiol 1959; 37: 911-917.

10. Petter F, Reynolds RG. Quantitative analysis of human serum cholesterol by thin-layer chromatographic spot test. J Chromatography 1977; 143: 153-160.

11. Morrison WR, Smith LM. Preparation of fatty acid methyl esters and dimethyl acetates from lipids with boron fluoridle-methanol. J Lipid Res 1964; 5: 600-608.

12. Dixom Wy. Ratios involving extreme values. Ann Math Stat 1951; 22: 68-78.

13. Hornstra G. Relation between dietary fat type, platelet fatty acid composition and eicosanoid formation by activated platelets. In: Dietary fats, prostanoids and arterial thrombosis. Martinus $\mathrm{Nij}$ hoff Publishers, The Hague 1982: 106-137.

14. Lagarde $\mathbf{M}$, Guichardant $\mathbf{M}$, Dechavanne $\mathbf{M}$. Human platelet $\mathbf{P G E}_{1}$ and arachidonic acid. Progr Lip Res $1981 ; 20: 439-443$.

15. Herolld PM, Kinsella JE, Fish oil consumption and decreased risk of cardiovascular disease: a comparison of findings from animal and human feeding trials. Am J. Clin Nutr 1986; 43: 566-598.

16. Ross R, Glomset JA. The pathogenesis of atherosclerosis. N Eng J Med 1976; 295: 369-377 and $420-425$.

17. Hamberg $\mathbf{M}$, Svensson $\mathbf{J}$, Samuelsson B. Thromboxanes: a new group of biologically active compounds derived from prostaglandin endoperoxides. Proc Natl Acad Sci, USA 1975; 72: 2994-2998.

18. Hamsiten A, De Faire UD, Walldius G, Dalalen G, Szamosi A, Landou C, Blombäck M, Wiman B. Plasminogen activator inhibitor in plasma: Risk factor for recurrent myocardial infaretion. Lancet 1987 ; ii: $3-9$.

19. Nilson IM, Ljungner $\mathbf{H}$, Tengborn $\mathbf{L}$. Two different mechanisms in patients with venous thrombosis and defective fibrinolysis: low concentration of plasminogen activator or increased concentration of plasminogen activator inhibitor. $\mathrm{Br}$ Med J 1985; 290: 1453.

20. Paramo dA, Colneci $M$, Collen $\mathbf{D}$, Werf $\mathbf{F}$ van de. Plaminogen aciivator inhibitor in the blood of pattients with cotonary artery disease. Brit Med. J 1985; 291: $573-574$. 


\section{COMPARISON BETWEEN THE HABITUAL INTAKE OF POLYUNSATURATED FATTY ACIDS FROM FISH AND THEIR CONCENTRATIONS IN SERUM LIPID FRACTIONS}

\section{Summary}

To evaluate the validity of the cross-check dietary history method for the assessment of the habitual intake of polyunsaturated fatty acids from fish, the relationship was investigated between the estimated intake of these fatty acids and their relative amounts in the various serum lipid fractions. Food intake data were obtained from a group of volunteers participating in a long-term epidemiologic study in the Dutch town of Zutphen. The fatty acid composition of total lipids, phospholipids, triglycerides and cholesterolesters was determined in fasting serum samples from these volunteers.

Although correlations between the calculated dietary intake of timnodonic acid (20:5 n-3, TA) and cervonic acid (22:6 n-3, CA), on the one hand, and the relative amounts of these fatty acids in the various serum lipid fractions, on the other, appeared to be statistically significant, no more than about $20 \%$ of the variance in the serum values could be explained on the basis of dietary intake. For linoleic acid $(18: 2 \mathrm{n}-6, \mathrm{LA})$ this was $55 \%$.

It is concluded that the cross-check dietary history method is an acceptable technique for estimating the habitual intake of linoleic acid of a given individual. For the fish-related fatty acids, however, this method is less reliable. This most probably results from the large differences in TA and CA content in similar foods. In addition, a negative association with the calculated LA intake on the proportional amount of TA for most of the serum lipid fractions was demonstrated. This indicates an interference of dietary LA with the metabolism of TA.

Key words: habitual fish consumption, fatty acid composition, serum, poly- unsaturated fatty acids, total lipids, triglycerides, phospholipids, cholesterolesters, dietary history. 


\section{Introduction}

Fish consumption affects serum lipid metabolism, which is involved in the onset of atherosclerosis (for a recent review: see 1). In a study of the effect of habitual fish consumption on platelet function (2) it was observed that the amounts of some of the fish-related fatty acids consumed, as well as the relative amounts of these fatty acids in serum phospholipids, differed significantly between the groups with a lowand high-fish consumption, respectively. The individual data within each of the groups, however, showed an almost complete overlap. This observation raised the question to what extent the ingested amounts of fish-related fatty acids, calculated from dietary history data, are reflected by the fatty acids composition of serum lipid fractions. Hence, this paper evaluates the association between the uptake of various polyunsaturated fatty acids, as calculated from data obtained with the cross-check dietary history method, and the relative amounts of these fatty acids in the various serum lipid fractions.

\section{Subjects, materials and methods}

In 1986, a group of elderly men (aged 67-82) was selected from the population of the town of Zutphen to participate in a study concerning the effect of habitual fish consumption on platelet function (3). These men belong to the Dutch cohort of the Seven Countries Study (4). Information about their food consumption pattern was collected and the fatty acid composition of various serum lipid fractions was analysed. Food consumption was assessed by the cross-check dietary history method (5), and the nutrient intake was calculated using the Uniform Food Encoding System (UFES), developed in The Netherlands (6), listing the energy values and nutrient composition of foods.

Subsequently, the intake of timnodonic acid (20:5 n-3, TA), cervonic acid (22:6n-3, CA) and linoleic acid (18:2 n-6, LA) was calculated on the basis of an extended version of this UFES-food table, developed by $\mathrm{D}$. Kromhout.

Blood, used to determine the fatty acid compositions of serum total lipids (TL), phospholipids (PL), triglycerides (TG), and cholesterolesters (CE), was taken under fasting conditions and after $24 \mathrm{~h}$ alcohol abstinence. Smoking was not allowed during the morning until after the venipuncture was performed. Blood was sampled between 8:00 and 9:30 AM at the homes of the volunteers. An antecubital vein was punctured with a $19 \mathrm{G}$ needle, under minimum stasis. After clotting, serum was collected and stored at $-20^{\circ} \mathrm{C}$ until analysis.

The samples were left to adjust to room temperature immediately before lipid extraction according to Bligh \& Dyer (7). PLs, TGs, and CEs were isolated from the extracts by thin layer chromatography (TLC) as described by v.d. Vusse et al (8). 
Table 1. Dietary data and age of the volunteers $(n=61)$.

$\begin{array}{lll}\text { Variable mean median } & \begin{array}{l}\text { Ist } \\ \text { quartile }\end{array} & \begin{array}{l}\text { 3rd quartile } \\ \text { qunge }\end{array}\end{array}$

fish consumption $\mathbb{1 9 8 6}$

$\mathrm{g} / \mathrm{day}$

15.5

10

0.0

27.0

$0-69$

timnodonic acid intake

$20: 5 \mathrm{n}-3, \mathrm{mg} /$ day

63.7

30

0.0

90.0

$0-830$

cervonic acid intake

$22: 6 \mathrm{n}-3, \mathrm{mg} /$ day

76.5

30

0.0

110.0

$0-1020$

linoleic acid intake

$18: 2 n-6, \mathrm{~g} /$ day

15.3

13

10.0

21.0

$2-45$

age, years

73.2

73

69

77

$67-82$

The lipid fractions were hydrolysed and their fatty acids methylated by using borontrifluoride $\left(\mathrm{BF}_{3}\right.$ Sigma, St. Louise, MO, USA, no. B1252, $14 \% \mathrm{w} / \mathrm{v}$ in methanol). The methyl esters originating from TL and CE were purified by an additional TLC step (9). All samples were analysed by gas liquid chromatography (GLC) as described by Rand et al (10).

\section{Statistical analysis}

The results were checked for their frequency distributions and, when necessary, the distribution was normalized by logarithmic transformation of the data. To avoid log zero, all values to be transformed were increased by a small figure. For the dietary fatty acids this figure was equal to half of the lowest amount observed. To the serum fatty acid values 0.05 was added, which is half the lowest detectable amount.

Association between variables was investigated by calculating the Pearson coefficient of correlation. Thereafter, the partial correlation was used to assess associations adjusted for the influence of a third variable.

\section{Results}

Blood samples could be obtained from 63 of the 64 men selected. Two volunteers reported the use of alcoholic drinks on the day before the blood was taken. They were excluded from the study. Table 1 presents the mean, range and quartiles of the age of the volunteers and of the dietary data obtained. 
Table 2. Fatty acid composition of serum lipids (0\% of total faty acids; mean $\pm S D ; n=61$ ).

\begin{tabular}{|c|c|c|c|c|}
\hline Fatty acid & $\mathbb{T L}$ & $\mathrm{PL}^{:}$ & $\mathrm{TG}_{\mathrm{i}}$ & $\mathrm{CE}$ \\
\hline $12: 0$ & tr & - & $0.1 \pm 0.17$ & $\mathrm{tr}$ \\
\hline $14: 0$ & $1.2 \pm 0.44$ & $0.3 \pm 0.11$ & $2.1 \pm 0.91$ & $0.9 \pm 0.27$ \\
\hline $16: 0$ & $23.9 \pm 1.43$ & $25.4 \pm 1.54$ & $25.0 \pm 2.81$ & $12.4 \pm 1.45$ \\
\hline $16: 1 n-7$ & $3.3 \pm 0.70$ & $1.5 \pm 0.31$ & $5.7 \pm 1.00$ & $4.2 \pm 1.09$ \\
\hline $17: 0+?$ & $0.5 \pm 0.50$ & $0.7 \pm 0.14$ & $1.0 \pm 0.47$ & $0.3 \pm 0.24$ \\
\hline $18: 0$ & $8.6 \pm 1.01$ & $12.0 \pm 1.02$ & $3.6 \pm 0.72$ & $0.9 \pm 0.36$ \\
\hline $18: 1 \mathrm{n}-9$ & $18.4 \pm 2.77$ & $10.7 \pm 1.31$ & $36.1 \pm 3.52$ & $18.4 \pm 2.96$ \\
\hline $18: 2 n-6$ & $26.5 \pm 3.84$ & $21.2 \pm 2.64$ & $17.5 \pm 5.18$ & $52.4 \pm 5.45$ \\
\hline $18: 3 n-6$ & $0.3 \pm 0.25$ & $\mathrm{tr}$ & $0.5 \pm 0.23$ & $0.8 \pm 0.26$ \\
\hline $20: 0$ & $0.2 \pm 0.12$ & $0.9 \pm 0.33$ & $\mathrm{tr}$ & - \\
\hline $18: 3 n-3$ & $0.5 \pm 0.27$ & $0.3 \pm 0.33$ & $1.5 \pm 0.38$ & $0.8 \pm 0.25$ \\
\hline $20: 1 n-9$ & $0.2 \pm 0.15$ & $0.4 \pm 0.28$ & $0.6 \pm 0.27$ & - \\
\hline $21: 0$ & - & $0.4 \pm 0.44$ & $0.3 \pm 0.2\rfloor$ & - \\
\hline $20: 3 \mathrm{n}-9$ & $\operatorname{tr}$ & $0.5 \pm 0.45$ & $0.2 \pm 0.16$ & tr \\
\hline $20: 3 n-6$ & $1.6 \pm 0.43$ & $2.8 \pm 0.83$ & $0.3 \pm 0.14$ & $0.6 \pm 0.18$ \\
\hline $22: 0$ & $0.3 \pm 0.18$ & $1.0 \pm 0.34$ & - & - \\
\hline $20: 4 n-6$ & $6.3 \pm 1.47$ & $10.2 \pm 1.47$ & $1.1 \pm 0.41$ & $5.6 \pm 1.43$ \\
\hline $22: 1$ n-9 & $0.4 \pm 0.46$ & - & - & - \\
\hline $23: 0$ & $0.1 \pm 0.08$ & $0.4 \pm 0.21$ & - & - \\
\hline $20: 5 n-3$ & $0.8 \pm 0.68$ & $1.3 \pm 0.84$ & $0.2 \pm 0.28$ & $0.8 \pm 0.57$ \\
\hline $24: 0$ & $0.3 \pm 0.14$ & $0.8 \pm 0.37$ & - & - \\
\hline $22: 4 n-6$ & $0.3 \pm 0.08$ & - & $0.2 \pm 0.11$ & - \\
\hline $24: 1 n-9$ & $0.6 \pm 0.22$ & $2.9 \pm 0.66$ & - & - \\
\hline $22: 5 n-6$ & $0.2 \pm 0.13$ & $0.1 \pm 0.20$ & $\operatorname{tr}$ & - \\
\hline $22: 5 n-3^{b}$ & $0.6 \pm 0.27$ & $1.3 \pm 0.41$ & $0.4 \pm 0.17$ & - \\
\hline $22: 6 n-3$ & $2.4 \pm 0.98$ & $3.7 \pm 1.17$ & $0.9 \pm 0.92$ & $0.5 \pm 0.22$ \\
\hline
\end{tabular}

TL: total lipids

PL: phospholipids

TG: triglycerides

CE: cholesterolesters

ur: $\operatorname{trace}(<0.1 \%)$
?: unidentified

- not detectable

a: $n=60$

b: $24: 2$ n-6 can be present as a minor fraction

The average fish consumption was $16 \mathrm{~g} /$ day, and the mean intakes of TA and CA were calculated to be 64 and $77 \mathrm{mg} /$ day, respectively. The average linoleic acid intake was estimated as $15 \mathrm{~g} / \mathrm{day}$. From the quartiles, it can be seen that the dietary intakes of fish, TA, and CA were highly skewed. For further calculations these variables were, therefore, log-transformed. The mean fatty acid compositions of the serum $T L$ and lipid fractions $P L, T G$ and $C E$ are given in Table 2. Logtransformation was required for $\mathrm{TA}$ and $\mathrm{CA}$, except for $\mathrm{CA}$ in the cholesterolesters. The correlations between the calculated intake of LA, TA and CA and the relative amounts of these fatty acids in the serum lipid fractions were statistically significant. However, this correlation was stronger for LA than for TA and CA (Table 3). The calculated intake of TA and CA showed the strongest relation with the relative 

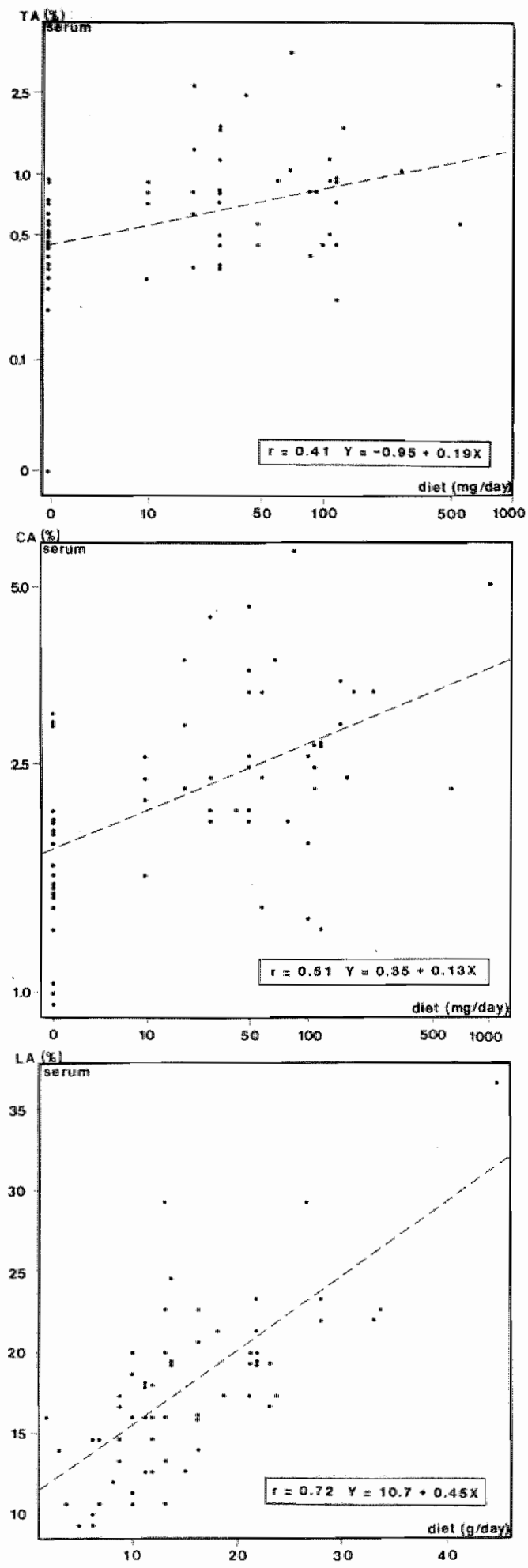

Fig 1. Scattergrams of the relationship between calculated intakes of timno donic acid (TA), cervonic acid (CA) and linoleic acid (LA, g/day) and the amounts of these fatty acids in serum (\% of total fatty acids).

Log transformarion was necessary for $T A$ and $C A$ values.

Horizontal axis: $\log (x+5), x=$ dietary TA (or CA) in $\mathrm{mg} / \mathrm{dlay}$.

Vertical axis: $\log (y+0.05), y=s e-$ rum $T A$ (or CA) in \%. 
Table 3. Correlation coefficients berween calculated intake per day and proportional content of linoleic acid (LA), timnodonic acid (TA) and cer. vonic acid (CA) in tolal lipids (TL), phospholipids (PL), triglycerides (TC), and cholesterolesters $(C E)(n=61 ; P L, n=60)$.

\begin{tabular}{llll}
\hline & $\mathbb{L A}$ & TA & CA \\
lipid fraction & $18: 2 \mathrm{n}-6$ & $20: 5 \mathrm{n}-3$ & $22: 6 \mathrm{n}-3$ \\
\hline TL & 0.59 & 0.41 & 0.51 \\
PL & 0.49 & 0.35 & 0.41 \\
TG & 0.72 & 0.33 & 0.49 \\
CE & 0.67 & 0.27 & 0.30 \\
\hline
\end{tabular}

$r$, required for $\mathrm{p}<0.05=0.25 ; \mathrm{p}<0.01=0.33 ; \mathrm{p}<0.001=0.41$

amounts of these fatty acids in the serum total lipids $(r=0.41$ and 0.51 respectively). For dietary LA the correlation with LA in the serum TG fraction was most pronounced $(r=0.72)$. Fig 1 shows the relations between dietary uptake and concentrations in serum for these fatty acids.

Since an influence of the amount of LA in the diet on the uptake and incorporation of TA has been reported $(11,12)$, partial correlation coefficients were calculated for serum TA (cq CA) and dietary intake of LA, adjusted for the dietary amount of TA (cq CA). The amount of TA in serum lipids was, after adjustment for dietary TA, negatively correlated with the amount of LA in the diet (not significant for TG, see Table 4). In addition, correlations of dietary TA and serum TA were somewhat stronger after adjustment for dietary LA (Table $5 \mathrm{cf}$ Table 3). An influence of dietary LA on serum CA could not be demonstrated.

\section{Discussion}

The volunteers who participated in this study belonged to the cohort of the Zutphen Study. Since this study started in 1960 with men aged $40-59$, the volunteers in our study were between 67 and 82 years of age (Table 1). They were selected on the basis of their habitual fish consumption in 1985 (3). In the present study, the validity of the cross-check dietary history method was investigated for the assessment of the habitual intake of fish-related polyunsaturated fatty acids by comparing the calculated intake of these fatty acids with their concentration in the various serum lipid fractions.

For TA and CA significant correlations were indeed observed, but, as can be seen from Fig 1, this was mainly due to the rather large number of cases in which the 
Table 4. Partial correlation coefficient (r) between the calculated dietary whake of linoleic acid and the amounts of TA and $C A$ in the serwm lipid fractions, corrected for the amounts of dietary $T A$ and $C A$ respectively $(n=61 ; P L n=60$ ).

\begin{tabular}{lccccc}
\hline & \multicolumn{2}{c}{ serum TA } & & \multicolumn{2}{l}{ serum CA } \\
\cline { 2 - 3 } \cline { 5 - 6 } lipid fraction & $\mathrm{r}$ & $\mathrm{p}$ & & $\mathrm{r}$ & $\mathrm{p}$ \\
\hline TL & -0.39 & $<0.001$ & & -0.21 & $<0.06$ \\
PL & -0.34 & $<0.005$ & & -0.04 & $\mathrm{NS}$ \\
TG & -0.18 & $\mathrm{NS}$ & & 0.07 & $\mathrm{NS}$ \\
$\mathrm{CE}$ & -0.35 & $<0.005$ & & -0.11 & $\mathrm{NS}$ \\
\hline
\end{tabular}

NS: $\mathrm{p}>0.10$

Table 5. Partial correlation coefficient (r) between calculated dietary uptake of $T A$ and $C A$ and the amounts of these fatty acids in the serum lipid fractions, corrected for the amount of dietary $L A .(n=61 ; P L n=60)$.

\begin{tabular}{llllll}
\hline & \multicolumn{2}{l}{ serum TA } & & \multicolumn{2}{l}{ serum CA } \\
\cline { 2 - 3 } \cline { 5 - 6 } lipid fraction & $\mathrm{r}$ & $\mathrm{p}$ & & $\mathrm{r}$ & $\mathrm{p}$ \\
\hline $\mathrm{TL}$ & 0.45 & $<0.001$ & & 0.50 & $<0.001$ \\
$\mathrm{PL}$ & 0.38 & $<0.005$ & & $0.4 \rrbracket$ & $<0.002$ \\
$\mathrm{TG}$ & 0.35 & $<0.01$ & & 0.49 & $<0.001$ \\
$\mathrm{CE}$ & 0.30 & $<0.01$ & & 0.30 & $<0.02$ \\
\hline
\end{tabular}

calculated fatty acid intake was zero. The low r-values imply that less than $20 \%$ of the variance in serum lipid values could be explained on the basis of dietary intake. For a vegetable polyunsaturated, LA, the results were better: the correlations were stronger than for TA and $\mathrm{CA}$, and about $50 \%$ of the variance in serum lipid values could be explained by the calculated dietary intake. It should be realised that $L A$ is present in the diet in much larger amounts than the n-3 fatty acids (Table 1). Moreover, there is less variation in the LA content than in the TA and/or CA content of similar foods. The latter variability can be appreciable, as is illustrated by results of the analysis of eight different lots of mackerel (Table 6): the amount of TA varied from 0.19 to 1.33 and of CA from 0.38 to $2.32 \mathrm{~g} / 100 \mathrm{~g}$ fish, which is a factor seven and six, respectively.

The relatively low correlations observed for TA and CA may also be due to errors inherent in the methods applied. The fatty acid composition of the various serum lipid fractions can be influenced by sudden changes (short term differences) in the fish consumption pattern (13). The coincidental consumption of two main courses of fish in the week preceding the blood analysis could have increased the amount 
Table 6. Amounts of timnodonic acid (TA) and cervonic acid (CA) in eight different lots of mackerel $(\mathrm{g} / 100 \mathrm{~g}$ fish).

\begin{tabular}{lllllllll}
\hline Fatty acid & 1 & 2 & 3 & 4 & 5 & 6 & 7 & 8 \\
\hline TA $(20.5 \mathrm{n}-3)$ & 0.19 & 0.50 & 0.54 & 0.66 & 0.70 & 0.76 & 1.12 & 1.33 \\
CA $(22: 6 \mathrm{n}-3)$ & 0.38 & 0.88 & 0.94 & 1.13 & 1.41 & 1.27 & 1.82 & 2.32 \\
\hline
\end{tabular}

of TA in serum compared to that of a volunteer who ate no fish at all during the last two weeks. This problem can possibly be prevented by determining the fatty acid composition of red blood cell membranes, because the rate at which fatty acid changes occur in red blood cells is slower than in plasma (14). However, in intervention studies the fatty acid composition of serum lipids and lipid fractions have repeatedly been shown to reflect the dietary fatty acid compositions in a reliable way (1). Therefore, more problems are to be expected in the assessment of dietary fatty acid intake. In this respect it should be recalled that, although dietary survey methods can supply information on the average composition of the diet of groups of subjects, they usually do not produce reliable information on an individual basis (15).

The dietary history method has been saild to provide information about the average food consumption pattern over the last 6-12 months $(16,17)$. Due to the complicated food consumption pattern nowadays, however, this period now seems to be limited to one month preceding the interviews (18).

Apart from the variations in food compositions, as mentioned above, the method of food preparation can be expected to influence greatly the dietary fatty acid composition. In this respect it may be recalled that food preparation may cause oxidation of the highly unsaturated fatty acids we are interested in. Since the cross-check dietary history method, like all methods of assessing food consumption, is very difficult to validate $(16,17)$, response errors, such as over-or under estimating food intake, poor memory ('old volunteers"), etc., can be sources of inaccuracy.

In addition, it has been shown that the differences between analysed and calculated intake data for a duplicate portion of a one-day test diet were about $7 \%$ for the major nutrients such as protein, fat and carbohydrates (16). This demonstrates that such calculations are not very accurate for dietary investigations in the case of major nutrients; for minor nutrients such as TA and $\mathrm{CA}$, even less reliable results may be expected.

In the volunteers reporting no fish consumption, the amounts of $n-3$ fatty acids in serum varied widely. The amount of TA in the serum TL, for instance, varied from 0.2 to $1.0 \%$, while the amount of CA varied from 0.9 to $3.0 \%$ (Fig 2). As can be seen, these data showed an almost complete overlap with the data of the volunteers 

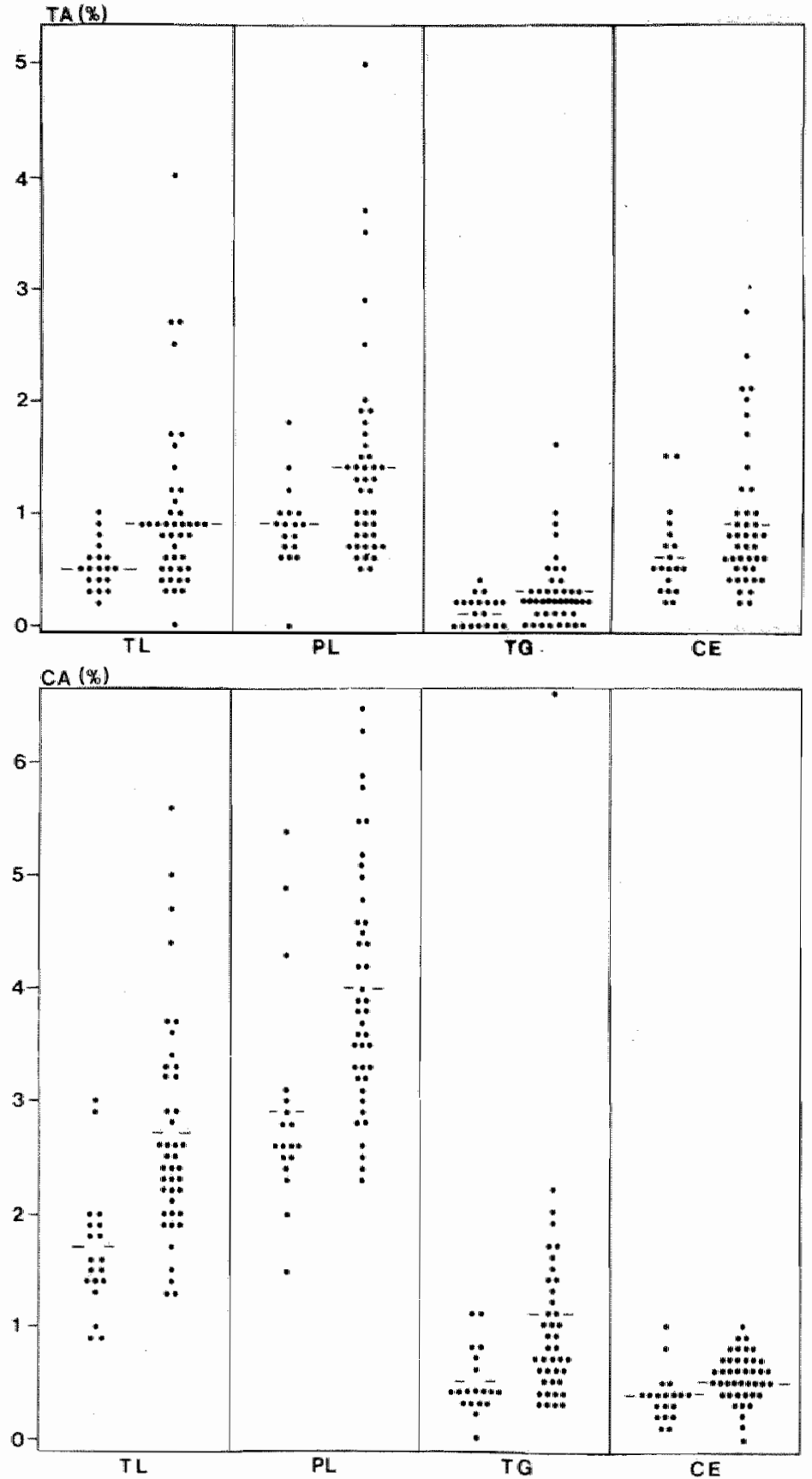

Fig 2. Amounts of timnodonic acid (TA) and cervonic acid (CA) in serum toral lipids and lipid fractions (\%o of total fatty acids) of volunteers who reported no fish consumption (left dots, $n=19$ ) and the volunteers who did report fish consumption (right dots, $n=42$ ). 
who did report fish consumption. This is most probably due to 'hidden' sources of n-3 fatty acids, such as chicken (which are often fed on fish meal, ref. 19) and organ meat, brain in particular. The contribution of allpha linolenic acid (18:3 n-3) is questionable. This fatty acid is not converted to 20 carbon fatty acids to any great extent, even when taken in high doses $(20,21,22,23,24)$.

To get an impression of the possible metabolic interaction between the various fatty acids as reported by Socini et al (11) and Sanders (12), the influence of dietary LA on the uptake and/or metabolism of TA and CA in serum was assessed taking into account the amounts of dietary TA and CA, respectively. A multiple correlation analysis showed that the amount of TA in the serum lipid fractions was negatively correlated with the amount of LA in the diet (not significant for TG, see Table 4). No significant relationship was observed for $\mathrm{CA}$. This observation cannot be due to a correlation between the amounts of these fatty acids in the diet, because the amounts of dietary LA did not correlate with either the amounts of dietary TA, or dietary CA.

These calculations also yielded partial correlation coefficients between the dietary uptake of TA and CA and the amounts of these fatty acids in the various serum lipid fractions, when corrected for the LA intake (Table 5). A slight improvement of this relationship was obtained for TA (Table $5 \mathrm{cf}$ Table 3 ) but not for CA. These results indicate that the amount of $\mathrm{LA}$ in the diet has a negative influence on the metabolism of TA. Accordingly, the amount of LA in the diet should be taken into account in assessing the incorporation of dietary TA.

From our present study it would appear that dietary LA intake is best reflected by the plasma triglycerides whereas the total lipid fraction would be preferable to reflect the habitual intake of TA and CA (Table 3 and 5). Analysis of TG requires the blood samples to be obtained in a fasting state, which is not necessary for CE. Although the CE fraction seem almost as sensitive as the TG fraction to reflect the LA intake, measurement of its fatty acid composition requires an aditional TLCstep for clean-up. Therefore, the TGs are the preferred lipid fraction to reflect the habitual LA intake.

The habitual intake of (n-3) fatty acids is best reflected by the plasma total lipids. This fraction also needs an additional TLC-step to remove certain cholesterol breakdown products, that co-elute from the column with $\mathrm{CA}$.

Based upon the results obtained by the dietary history method as well as through analysis of the fatty acid composition in serum, it is possible to distinguish between persons with a high- and a low-fish consumption on a group level. On an individual basis, however, this is not reliable for fish related fatty acids, in contrast to LA, which gives clearer results. 


\section{Acknowledgements}

We gratefully acknowledge the cooperation of the Zutphen men who took part in this study. The skillful technical assistance of Jos Stegen and Marianne Simonis was indispensable and is highly appreciated.

Our thanks are also extended to Dr. J.B. Luten, TNO-CIVO Technology Institute IJmuiden, The Netherlands, for analysing the fatty acid composition of the eight different lots of mackerel.

We thank Dr. F.J. Kok for critically reading the manuscript.

This study was supported by a grant from The Netherlands Heart Foundation.

\section{References}

1. Hornstra G. The significance of fish and fish-oil enriched food for prevention and therapy of ischeamic cardiovascular disease. In: The role of fats in human nutrition. Crawford MA, Vergroes. en AJ (eds). Academic Press, London 1988: (in press).

2. Houwelingen AC v, Hornstra G, Stegen J, Katan M, Kromhout D. Habitual fish consumption, serum lipids and platele functions. In: Lands WEM (ed). Proceedings of the AOCS Short Course on Polyunsaturated Fatty Acids and Eicosanoids. American Oil Chemists Society, Illinois 1987: 368-371.

3. Houwelingen AC $\mathbf{v}$, Hornstra G, Kromhout D, Lezenne Coulander D de. Habitual fish consumption, fatty acids of serum phospholipids and platelet function. Atherosclerosis 1988; in press (Chapter 2).

4. Keys A, Aravanis C, Blackburn HW et al. Epidemiological studies related to coronary heart disease: characteristics of men aged 40-59 in seven countries. Acta Med Scand 1967; suppl 460.

5. Kromhout D, Bosschieter $\mathbf{E B}_{\text {, }}$ Lezenme Coulander $\mathbf{C}$ de. Fish consumption and 20 year mortality from coronary heart disease. $N$ Engl J Med 1985; 312: 1205-1209.

6. Hautvast JGA. Development of a system for processing data obtained from nutrition questionaires with the aid of a computer (in Dutch). Voeding $1975 ; 36: 356-360$.

7. Bugh EG, Dyer WJ. A rapid method for total lipid extraction and purification. Can $\mathbf{J}$ Biochem Physiol 1959; 37: 911-917.

8. Vusse GJ wan der, Roemen ThHM, Prïnen FW, Coumans WA, Reneman RS. Uptake and tissue content of fatty acids in dog myocardium under normoxic and ischemic conditions. Circ Res 1982; 50: $538-546$.

9. Morrison WR, Smith LM. Preparation of fatty acid methyl esters and dimethyll acetates from lipids with boron fluoride-methanol. J Lipid Res 1964; 5: 600-608.

10. Rand ML, Hennissen AAHM, Hornstra G. Effects of dietary sunflower seed oil and marine oil on platelet membrane fluidity, arterial thrombosis and platelet responses in rats. Atherosclerosis $1986 ; 62: 267-276$. 
11. Socini A, Galli C, Colombo C, Tremoli E. Fish oil administration as a supplement to a corn oil containing diet effects arterial prostacyclin production more than platelet thromboxane formation in the rat. Prostaglandins 1983; 25: 699-710.

12. Sanders TAB. Influence of moderate intakes of fist ofl on blood lipids. In: Lands WEM (ed.). Proceedings of the AOCS Short Course on Polyunsaturated Fatty Acids and Eicosanoids. American Oil Chemists" Society, Illinois 1987: 70-86.

13. Schacky $C$ von, Weber PC. Metabolism and effects on platelet function of the purified eicosapentaenoic and docosahexaenoic acids in humans. J Clin Invest 1985; 76: 2446-2450.

14. Farquhar JW, Ahrens EH. Effects of dietary fats on human erythrocyte fatty acid patterns. J Clin lanvest $1963 ; 42: 675-685$.

15. Plakke $\mathbf{T}$, Herkel $\mathbf{J}_{\text {, }}$ Beynen AC, Hermus RJJ, Katan MB. Relationship between the fatty acid composition of the diet and that of the subcutaneous adipose tissue in individual human subjects. Human Nutrition; Applied Nutrition 1983; 37A: 365-372.

16. Staveren WA wan, Burema J. Food consumption surveys: frustrations and expectations. In: Staveren WA van. Food intake measurements; their validity and reproducibility. Thesis, Landbouwhogeschool, Wageningen 1985 .

17. Block G. A review of walidations of dietary assessment methods. Am J Epidemiol 1982; 115: $492-505$.

18. Kromhout D. Unpublished results.

19. Ackman RG. Some practical sources of EPA for diet modification. Proceedings of the n-3 fatty acid meeting, Reading, England 1984: 14-26.

20. Adam 0. Polyenoic fatty acids metabolism and effects of prostaglandin biosynthesis in adults and aged persons. In: Lands WEM (ed.) Proceedings of the AOCS Short Course on Polyunsaturated Fatty Acids and Eicosanoids. American Oil Chemists Society, Illinois 1987: 251-219.

21. Dyerberg J, Bang HO, Aagaard O. Alpha-linolenic acid and eícosapentaenoic acid (letter). Lancet 1980 ; i: 199.

22. Renaud S, Nordgy $\mathbf{A}$. 'Small is beautiful': alpha-linolenic acid and eicosapentaenoic acid in man (letter), Lancet 1983 ; i: II 169 .

23. Betiz J, Mest HJ, Forster W. Influence of linseed oil diet on the pattern of serum phospholipids in man. Acta Biol Med Ger; 40: k31-k35.

24. Sanders TAB, Younger KM. The effect of dietary supplements of omega-3 polyunsaturated fatty acids on the fatty acid composition of platelets and plasma choline phosphoglycericles. Br I Nutr $1981 ; 45: 613 \cdots 616$. 


\section{CHAPTER 4}

\section{EFFECT OF A MODERATE FISH INTAKE ON BLOOD PRESSURE, BLEEDING TIME, HEMATOLOGY AND CLINICAL CHEMISTRY IN HEALTHY MALES}

\section{Summary}

This paper describes the outline and first results of an international study to investigate the effect of a reasonable amount of dietary fish on some aspects of cardiovascular risk.

In Maastricht, Troms $\emptyset$, and Zeist healthy male volunteers were given a dietary supplement consisting of $100 \mathrm{~g}$ of mackerel or meat per day for a 6-week period. Conpliance was monitored on the basis of the urinary excretion of lithium, added to the supplements.

Average compliance was about $80 \%$, decreasing slightly over time. Systolic blood pressure decreased in both groups to a comparable degree; consequently no specific effect of the fish supplement was observed. The fish supplement significantly prolonged bleeding times. Hematology was hardly affected, but platelet counts decreased significantly. No indications were found for adverse effects of the fish supplement.

Key words: fish, diet, blood pressure, compliance, hematology, platelet count, bleeding time, serum, enzymes, kidney function. 


\section{Introduction}

Epidemiological studies indicate that a marine diet (containing fish, fish products or products from other marine animals) may be beneficial in the prevention of ischemic cardiovascular disease in man $(1,2,3)$. This protective effect has been suggested to be attributed to a favourable effect on the plasma lipid profile and on certain functions of blood platelets involved in arterial thrombogenesis.

Animal experiments have clearly shown that fish-oill feeding indeed lowers arterial thrombosis tendency, provided the oils have a low saturated fatty acid content (4, $5)$. Human studies, however, have given equivocal results $(6,7)$. In some studies diets enriched with fish or fish oils produced favourable effects on plasma lipid levels, lowered the aggregability of blood platelets in vitro and/or prolonged cutaneous bleeding times, but in other studies these effects were not observed. A careful screening of the available literature reveals that many of the beneficial effects of fish(oil) were obtained in studies that lacked a proper control group and/or were performed under extreme dietary conditions $(6,7)$. We therefore decided to conduct a well-controlled study to investigate the effect of a reasonable amount of fish in the diet on a series of variables associated with the risk of cardiovascular ischemia and, moreover, to obtain information on the physiological and biochemical effects of such a dietary treatment on blood platelets.

Because some information in the literature suggested possible adverse effects of fish(oil) rich diets (8-13), we also monitored hematological changes during the study, as well as some aspects of liver and kidney functions of the volunteers.

This paper describes the outline of the study, the way it was performed and the results with regard to compliance, blood pressure changes, bleeding time measurements and possible side effects.

\section{Subjects, materials and methods}

\section{Experimental design}

The study was designed as an open, well-controlled intervention trial, carried out almost simultaneously under comparable conditions in three different centers:

- Department of Medicine, University of Tromsø, Norway,

- TNO-CIVO Toxicology and Nutrition Institute, Zeist, The Netherlands,

- Departments of Human Biology and Biochemistry, University of Limburg, Maastricht, The Netherlands.

During the experimental period, which lasted 6 weeks, the volunteers were asked to consume the contents of one tin (ca. $135 \mathrm{~g}$ ) of mackerel paste (experimental group) or meat paste (control group) per day. The experimental period was preceded by a run-in period of 2 weeks, in order to diminish the differences in basal conditions between mackerel and control groups, to check logistics, and to get volunteers and 
Table 1 . Composition of the dietary supplements.

\begin{tabular}{|c|c|c|}
\hline Compound & Fish paste & Meat paste \\
\hline \multicolumn{3}{|c|}{ Composition (\% of dry weight) } \\
\hline protein & 35.0 & 39.3 \\
\hline fat & 51.5 & 49.4 \\
\hline carbohydrates & 13.5 & 11.3 \\
\hline water & 61.2 & 62.7 \\
\hline cholesterol $(\mathrm{mg} / 135 \mathrm{~g})^{\mathrm{a}}$ & 62.9 & 33.8 \\
\hline \multicolumn{3}{|l|}{ Ingredients $(0 \%, w / w)$ : } \\
\hline lean pork & - & 50 \\
\hline lean beef & - & 25 \\
\hline lard & - & 1,0 \\
\hline mackerel & 74 & - \\
\hline $\mathrm{H}_{2} \mathrm{O}$ & 19.8 & $8: 4$ \\
\hline starch & $5^{b}$ & $4^{c}$ \\
\hline $\mathrm{NaCl}$ & 1 & 1.88 \\
\hline $\mathrm{NaNO}_{3}$ & - & 0.12 \\
\hline phosphate & - & 0.3 \\
\hline miscellaneous substances ${ }^{c}$ & 0.2 & 0.3 \\
\hline lithium (mg/135g) & 2.7 & 1.4 \\
\hline
\end{tabular}

a: $135 \mathrm{~g}$ is the daily amount of the dietary supplements

b: potato starch

c: wheat starch

d: Latuw : cutterphosphate (polyphosphates)

e: $0.05 \%$ ascorbate (meat paste only) $0.05 \%$ glutamate (meat paste only) various flavorings: clove, curry, pepper, mustard, smoke and tomato

f: as lithium nitrate for the fish paste and as lithium chloride for the meat paste

laboratory staff accustomed to the experimental procedures. During this run-in perïod all volunteers were requested to consume one tin of meat paste per day. The dietary supplements were given as a replacement for fish, meat, cheese, and eggs consumed during the main meal. Compliance of the volunteers was checked by measuring the urinary excretion of lithium added to the supplements (14). Maximum care was taken to assure that the investigators remained unaware of the assignment of the volunteers to either the mackerel or the control group.

During the entire period of 8 weeks, the use of aspirin-like drugs was not allowed. As a replacement Glifanan ${ }^{\circledR}$ (glafenin, Roussel) or floctafanine (Roussel) was made available. Each volunteer was asked to keep a diary with special emphasis on physical condition, abnormal events, failure to meet the experimental requirements, etc. Blood was drawn and measurements were performed at the start of the experimental period (week 0 ) and 3 and 6 weeks later. Results obtained after 3 and 6 experimental weeks were related to those of the baseline measurements (week 0 ). The differences 
Table 2. Fatty acid composition (of of total fatty acids) of the dietary supplements.

\begin{tabular}{lcc}
\hline Fatty acid & Mackerel paste & Meat paste \\
\hline $14: 0$ & 6.8 & 1.7 \\
$16: 0$ & 13.3 & 24.2 \\
$16: 1 \mathrm{n}-7$ & 3.8 & 2.1 \\
$18: 0$ & 2.2 & 13.5 \\
$18: 1 \mathrm{n}-9$ & 11.5 & 47.6 \\
$18: 2 \mathrm{n}-6$ & 1.9 & 7.6 \\
$18: 3 \mathrm{n}-6$ & -5.7 & - \\
$18: 3 \mathrm{n}-3$ & 2.0 & - \\
$18: 4 \mathrm{n}-3$ & 5.3 & 0.8 \\
$20: 1 \mathrm{n}-9 / 11^{\mathrm{b}}$ & 9.5 & - \\
$20: 5 \mathrm{n}-3$ & 6.5 & - \\
$22: 1 \mathrm{n}-9 / 11^{\mathrm{b}}$ & 15.8 & - \\
$22: 6 \mathrm{n}-3$ & 11.6 & \\
\hline
\end{tabular}

a: In the nomenclature used for fatty acids, the figure before the colon indicates the numer of carbon atoms and that after the colon, the number of double bonds. The final number refers to the position of the first double bond, counting from the methyl end of the carbon chain

b: mainly $n-11$

occurring after 3 and/or 6 weeks (with respect to week 0 ) in both the mackerel and the control group were compared and evaluated statistically.

A large variety of parameters related to certain physiological and biochemical aspects of the cardiovascular risk profile were determined. For practical reasons the hematological determinations and physiological measurements were performed in each of the three experimental centers separately, using routine hospital techniques and standardized equipment and protocols, respectively. Samples for biochemical measurements were coded and transported to a number of specialized analytical centers" where the measurements were performed blindly. All data were sent to the Departments of Biochemistry and Human Biology, University of Limburg, Maastricht, The Netherlands for decoding, calculation, and statistical evaluation.

The study protocol was approved by the Medical Ethical Committee of the University of Limburg and of CIVO-TNO. Written informed consent was obtained from all volunteers.

\section{Composition of dietary supplements}

The dietary supplements (mackerel and meat paste) were prepared by the TNOCIVO Technology Institute in IJmuiden and Zeist, The Netherlands. 
Table 3. Contents of heavy metals, organochlorine compounds and PCBs of the fish paste.

\begin{tabular}{|c|c|c|c|}
\hline \multirow[t]{2}{*}{ Compound $^{a}$} & \multirow{2}{*}{$\begin{array}{l}\text { A.D.1. } \\
\mu \mathrm{g} / 75 \mathrm{~kg} / \mathrm{day}\end{array}$} & \multicolumn{2}{|c|}{ Consumption } \\
\hline & & $\mu \mathrm{g} / \mathrm{day}$ & $10 \%$ of A.D.I. \\
\hline Lead (Lb) & 338 & 2.70 & 0.5 \\
\hline Mercury (Hg) & 54 & 2.70 & 5.0 \\
\hline Cadmium (Cd) & 75 & 0.70 & 0.9 \\
\hline QCB & $-c$ & $<0.14$ & - \\
\hline $\mathrm{HCB}$ & 45 & 0.22 & 0.5 \\
\hline$\alpha \mathrm{HCH}$ & - & 2.30 & - \\
\hline$\gamma \mathrm{HCH}$ & - & 0.97 & - \\
\hline$\beta \mathrm{HCH}$ & - & $<0.27$ & - \\
\hline endrin & 15 & $<0.68$ & 4.5 \\
\hline hepo & 37.5 & $<0.41$ & $<1.1$ \\
\hline mirex & - & $<0.27$ & - \\
\hline aldrin & & $<0.14$ & \\
\hline dieldrim & 7.5 & 1.20 & $<18.0$ \\
\hline oxychloordane & & $<0.41$ & \\
\hline achloordane & -75 & $<0.41$ & $<1.6$ \\
\hline rchloordane & & $<0.41$ & \\
\hline $\mathrm{pp}^{\prime} \mathrm{DDE}$ & & 0.57 & \\
\hline op DDT & & $<0.68$ & \\
\hline $\mathrm{pp}^{\prime} \mathrm{DDT}$ & 375 & $<0.68$ & $<0.8$ \\
\hline $\mathrm{pp} \mathrm{p}^{\prime} \mathrm{TDE}$ & & 1.09 & \\
\hline PCB 28 & & $<0.14$ & \\
\hline $\mathrm{PCB} 52$ & & 0.22 & \\
\hline PCB 101 & & 0.35 & \\
\hline $\mathrm{PCB} 118$ & -75 & 0.24 & $<2.5$ \\
\hline PCB 138 & & 0.31 & \\
\hline PCB 153 & & 0.50 & \\
\hline PCB 180 & & 0.14 & \\
\hline
\end{tabular}

a: Abbreviations:

$$
\begin{aligned}
& \mathrm{PCB}=\text { polychlorinated-biphenyls } \\
& \mathrm{QCB}=\text { pentachlorobenzene } \\
& \mathrm{HCB}=\text { hexachlorobenzene } \\
& \mathrm{HCH}=1,2,3,4,5,6 \text {-hexachlorocyclohexane } \\
& \mathrm{DDE}=2,2 \text {-bis (p-chlorophenyl) - 1,1 dichloroethylene } \\
& \mathrm{DDT}=\text { dichlorodiphenyldichloroethane } \\
& \mathrm{TDE}=1,1 \text {-dichloro-2,2-di-(4-chlorophenyl)ethane } \\
& \text { pP }=\text { para para } \\
& \text { op }=\text { ortho para }
\end{aligned}
$$

b: ADI: acceptable daily intake calculated for mean body weight of volunteers

c: unknown 
Table 4. Characteristics of the volunteers (mackerel and control groups) at the starl of the experiment (mean \pm SEM).

\begin{tabular}{|c|c|c|c|c|}
\hline \multirow[b]{2}{*}{ Parameter $\mathrm{r}^{\mathrm{a}}$} & \multicolumn{2}{|l|}{ Maastricht } & \multicolumn{2}{|l|}{ Troms } \\
\hline & $M^{b}(19)$ & $C^{c}(20)$ & $M(11)$ & $C(12)$ \\
\hline Age (years) & $32.4 \pm 1.4$ & $32.6 \pm 1.2$ & $25.0 \pm 0.7$ & $25.1 \pm 0.7$ \\
\hline Body weight (kg) & $76.1 \pm 2.2$ & $74.0 \pm 2.1$ & $72.9 \pm 9.9$ & $73.0 \pm 8.0$ \\
\hline Quetelet index $\left(\mathrm{kg} / \mathrm{m}^{2}\right)$ & $23.4 \pm 0.5$ & $23.0 \pm 0.4$ & $22.4 \pm 0.7$ & $21.9 \pm 0.6$ \\
\hline \multicolumn{5}{|l|}{ Blood pressure*: } \\
\hline - systolic (mmHg) & $119 \pm 2.2$ & $123 \pm 1.9$ & $117 \pm 1.9$ & $118 \pm 2.6$ \\
\hline - diastolic $(\mathrm{K} 4, \mathrm{mmHg})$ & $76 \pm 1.9$ & $77 \pm 1.6$ & $76 \pm 1.6$ & $78 \pm 11$ \\
\hline Bleeding time (min)* & $9.41 \pm 0.79$ & $8.94 \pm 0.64$ & $7.60 \pm 0.89$ & $7.08 \pm 0.48$ \\
\hline \multicolumn{4}{|l|}{ Serum lipid content.: } & \\
\hline$(\mathrm{mmol} / \mathrm{l})$ & $4.8 \pm 0.2$ & $4.9 \pm 0.1$ & $4.8 \pm 0.2$ & $5.0 \pm 0.1$ \\
\hline - triglyceride (mmol/l) & $1.00 \pm 0.07$ & $0.98 \pm 0.08$ & $0.83 \pm 0.07$ & $0.84 \pm 0.08$ \\
\hline \multicolumn{5}{|l|}{ Alcohol consumption } \\
\hline (g/week) & $127 \pm 21.5$ & $114 \pm 22.2$ & $48 \pm 27.5$ & $70 \pm 17.4$ \\
\hline \multicolumn{4}{|l|}{ Meat consumption } & $14 \pm 1.9$ \\
\hline \multicolumn{5}{|l|}{ Fish consumption } \\
\hline (meals/month) & $4 \pm 0.7$ & $3 \pm 0.4$ & $9 \pm 1.1$ & $9 \pm 1.2$ \\
\hline Meat/Fish ratio & $11.9 \pm 2.1$ & $9.9 \pm 1.8$ & $1.6 \pm 0.3$ & $1.5 \pm 0.3$ \\
\hline
\end{tabular}

a: Results of screening ( 4 weeks before the run-in period)

For parameters with * the results of week o (initial walues) are given

b: $M=$ mackerel group. Number of volunteers between brackets

c: $\mathrm{C}=$ control group. Number of volunteers between brackets

The composition of supplements is shown in Table 1 . In Table 2 the fatty acid composition of the dietary supplements is given. The fish paste provided $1.7 \mathrm{~g}$ of timnodonic acid (20:5 n-3) and $3.0 \mathrm{~g}$ of cervonic acid (22:6n-3) per day. The contents of the major polychlorinatedbiphenyls (PCBs) and other organochlorine compounds was so low that the daily intake was far below the 'acceptable daily intake" as recommended by FAO/WHO (15). The same holds for lead, mercury and cadmium (Table $3)$.

\section{Screening, selection and assignation of volumteers}

Male volunteers were recruited from either the general population (Maastricht) or from students (Troms $\emptyset$ and Zeist) and screened for eligibility 4 weeks before the start of the run-in period. Only those volunteers were allowed to enter the study who met the following criteria: 
Table 4. Contimued.

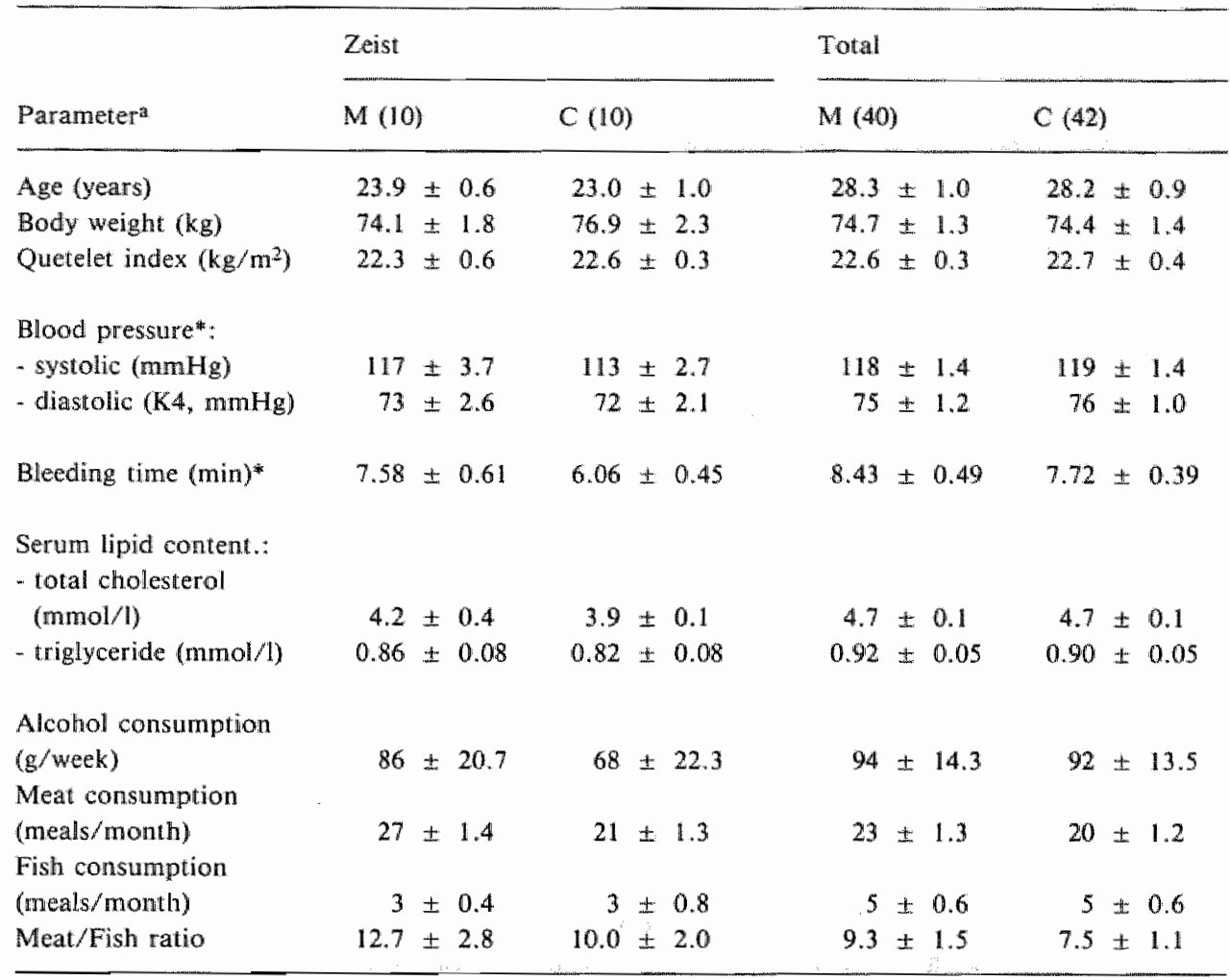

- between 20 and 45 years of age,

- non-obese (Quetelet index $<28$; weight $(\mathrm{kg}) /$ length $\left.(\mathrm{m})^{2}\right)$,

- clinically healthy (no medication, no glucose or protein in the urine),

- systolic blood pressure $100-140 \mathrm{mmHg}$, diastolic pressure (K5) $40-90 \mathrm{mmHg}$.

- total serum cholesterol content $<7 \mathrm{mmol} / 1$, triglyceride content $<2 \mathrm{mmol} / \mathrm{l}$,

- non smoking (fewer than 7 cigarettes per week),

- dietary habits not different from the general population. Decision as to this criterion was made on the basis of a dietary questionnaire filled out by the volunteers and evaluated by a professional dietician.

Eligible subjects were assigned to control- and mackerel groups by stratified randomization on the basis of serum triglyceride content as primary criterion and systollic blood pressure as secondary criterion. Care was taken that within each sampling day the numbers of 'experimental' and 'control' subjects were about equal. 
In total, 84 volunteers entered the study: $2 \times 20$ in Maastricht, $2 \times 12$ in Troms $\emptyset$ and $2 \times 10$ in Zeist. In Table 4 the characteristics of the mackerel and control groups are given.

\section{Clinical procedures}

All direct measurements and all blood samplings were performed between 08:00 and 12:00 AM, under fasting conditions (no calories after 22.00 PM the previous evening), and after a $24 \mathrm{~h}$ abstinence from alcohol. Upon entering the laboratory, the volunteers provided urine collected over $24 \mathrm{~h}$ the previous day. Subjects were weighted (Zeist volunteers excluded) without shoes and wearing minimum indoor clothing. The volunteers then started a 10 min rest in a recumbent position. During this period the diary was checked and explanatory questions could be asked and answered. After 10 min of rest the blood pressure was measured (see below). Subsequently, the volunteers moved to a comfortable chair for the measurements of their bleeding times (see below). Blood samples were taken with the volunteers in a recumbent position again (see below). Before leaving the laboratory, the volunteers were given the dietary supplements and a plastic bottle ( $2 \mathrm{l}$, without preservative) for the next collection of urine.

\section{Urine sampling and handling}

According to written instructions, $24 \mathrm{~h}$ specimens were collected from 8:00 AM until 8:00 AM the next day. The urine was mixed carefully and the volume was measured. Then $10 \mathrm{ml}$ of the mixed urine was transferred into a clean plastic tube, capped, and stored at $-20^{\circ} \mathrm{C}$ until transport to the Department of Clinical Chemistry, De Wever Hospital, Heerlen, The Netherlands, for the measurements of sodium, potassium, lithium and creatinine. For prostanoid measurements (Chapter 8) $100 \mathrm{ml}$ of the urine (in Maastricht $2 \times 100 \mathrm{ml}$ ) was stored at $-20^{\circ} \mathrm{C}$.

\section{Compliance measurements}

Compliance was calculated after 0 (compliance during the run-in period), 3 and 6 experimental weeks on the basis of consumption and urinary excretion of lithium added to the supplements.

For this calculation the following equation was used: $\mathrm{C}$ (ompliance) $=[\mathrm{a} /(\mathrm{b} \times \mathrm{v})]$ $\mathrm{x} 100 \%$, in which a is the daily lithium intake in $\mu \mathrm{mol}, \mathrm{b}$ is the urinary lithium concentration in $\mu \mathrm{mol} / \mathrm{h}$, and $\mathrm{V}$ is the amount of urine collected over $24 \mathrm{~h}$ in liters. To correct for possible inaccuracies in urine collection, compliance was also calculated on the basis of urinary creatinine content, according to the formula: Compliance $=\mathrm{x} / \mathrm{y}$; in which $\mathrm{x}$ is the excreted amount of lithium in the urine in $\mu \mathrm{mol} / 24 \mathrm{~h}$ and $y$ is the excreted amount of creatinine in the urine in mmol/24 h. Volunteers whose compliance was lower than the mean value minus 2 times the standard deviation for both methods of calculation were removed from the study. To minimize the influence of differences in body mass and sudden changes in exercise level, the compliance indices were multiplied by each other, resulting in a variable (the compliance 
index) which was used to investigate possible relationships between dietary adherence and the measured variables.

\section{Blood pressure measurements}

Blood pressures were measured at weeks $0,3,6$, by the same physician of the local experimenta] team, using the same sphygmomanometer and the same stethoscope. After $10 \mathrm{~min}$ of rest, blood pressures were measured (right arm) with the volunteers in the supine position. The manometer cuff was inflated to approximately $20 \mathrm{mmHg}$ above the expected systolic pressure and was deflated with a velocity of about 3 $\mathrm{mmHg}$ per second. When a tapping sound was heard for the first time (Korotkoff phase 1, ref. 16), the manometer pressure was recorded as the systolic pressure. The diastolic pressures were defined as the pressures at the start of Korotkoff phase 4, and at the disappearance of the Korotkoff sound (phase 5). On each occasion the blood pressure was measured twice and the lowest values were taken. When the difference between these readings was more than $10 \mathrm{mmHg}$, a third measurement was done and the outlying value was discarded.

Apart from the procedure mentioned above, the Zeist volunteers also measured their own blood pressures three times daily. These results will be reported elsewhere.

\section{Bleeding time measurements}

Bleeding time was measured after completion of blood pressure readings, while the volunteer was sitting in a comfortable chair. The measurements were performed on the right arm using the Simplate II device (General Diagnostic, Warner Lambert Ltd. New Jersey, USA). With this device two standard incisions ( $1 \mathrm{~mm}$ in depth and $5 \mathrm{~mm}$ in length) were made on the anterior surface of the forearm parallel to the fold of the elbow, while a constant pressure of $40 \mathrm{mmHg}$ was applied to the upper arm with a sphygmomanometer cuff. The site of the cuts had been properly desinfected beforehand. Shaving, however, was not allowed. Every $30 \mathrm{~s}$ blood oozing from both cuts was carefully taken up in a Whatman ${ }^{\circledR 1}$ filter paper disc, number 1, diameter $9 \mathrm{~cm}$ (Whatman Ltd. Moudstone, UK), without touching the edges of the wounds. The bleeding time was defined as the time between the incision and the moment the blood no longer stained the filter paper. Bleeding times were recorded for both cuts separately and averaged when the results were calculated. Skin closures (Steristrips ${ }^{\circledR}$ 3M, St. Paul, MN USA) were used to prevent scarring.

\section{Blood sampling procedure}

Blood was sampled after completion of bleeding time measurements. During blood sampling, the volunteer was again in a recumbent position. Under minimum stasis, a forearm vein was punctured using a $19 \mathrm{G}$ butterfly veni system (19G no. 4590 . Luer- or 8488 -Luer and Record-, Abbot Ireland Ltd., Sligo, Rep. of Ireland). Firstly, appropriate amounts of blood, as requested by hospital routine, were removed and transferred into a tube containing EDTA for hematological measurements. Subsequently, $4.5 \mathrm{ml}$ of blood, dripping freely from the cannula, were collected into 
a pre-cooled plastic tube containing $0.5 \mathrm{ml}$ of ice-cold sodium citrate solution (109 $\mathrm{mmol} / \mathrm{l}$ ), $\mathrm{pH}$ adjusted to $7.2-7.4$ with a $10 \%$ (wt/ $\mathrm{vol}$ ) citric acid solution. After careful mixing, the tube was placed back on ice until plasma preparation for determination of fibrinolysis parameters (Chapter 10). Next, a $20 \mathrm{ml}$ plastic syringe, prefilled with $2 \mathrm{ml}$ citrate solution, was connected to the catheter, and $18 \mathrm{ml}$ of blood were taken slowly for studies on blood platelets, erythrocytes and plasma. If a study center required blood for additional studies on platelets, this blood was taken next, after which another $20 \mathrm{ml}$ syringe, prefilled with $2 \mathrm{ml}$ of citrate solution, was filled with $18 \mathrm{ml}$ of blood for coagulation and platelet-lipid studies. Subsequently, blood was taken into a $5 \mathrm{ml}$ Monovette (Sarstedt no. 051104 Numbrecht, FRG) for the preparation of serum for prostanoid determinations. Detailed descriptions of the handling of these blood samples and of the procedures for preparing plasma, platelets and serum will be given in subsequent papers dealing with the respective studies.

Finally, $10 \mathrm{ml}$ blood were taken for serum preparation using a Monovette syringe (Sarstedt no. 021063). This blood was allowed to clot at room temperature for 60 min, after which the Monovette ${ }^{(i)}$ was centrifuged $(15 \mathrm{~min}$ at $3000 \mathrm{xg}$ ). The serum was collected carefully and 2 portions of $0.5 \mathrm{ml}$ each were transferred into 'Eppendorf tubes' (no. 616201, Greiner, Nurtingen, FRG) for Apoprotein determinations (Chapter 5). The rest of each serum sample was stored in a plastic tube at $-20^{\circ} \mathrm{C}$ until transport on dry ice to Unilever Research, Vlaardingen, The Netherlands, for the determination of enzymes, creatinine, urea, calcium, total protein and albumin and serum lipids.

The experimental centers were allowed to take additional blood samples after the sampling procedure, described above, had been completed.

\section{Analytical procedures}

The lithium determinations were performed with a Perkin-Elmer (PE) 3030 atomic absorption spectrophotometer (Bodenseewerk Perkin Elmer, Uberlingen, FRG), a PE HGA 500 graphite furnace atomizer (programmable) and a PE AS 40 autosampler, essentially according to manufacturers' instructions. Sodium, potassium and creatinine concentrations in urine were measured using hospital routine techniques. All these parameters were measured at the Department of Clinical Chemistry, de Wever Hospital, Heerlen, The Netherlands.

Hematological measurements were performed in each of the three experimental centers separately, using routine hospital techniques. Parameters measured were hematocrit $(\mathrm{HCT})$, hemoglobin $(\mathrm{Hb})$, red blood cell count $(\mathrm{RBC})$, mean cellular volume (MCV), mean cellular hemoglobin $(\mathrm{MCH})$, mean cellular hemoglobin concentration ( $\mathrm{MCHC}$ ), white blood cell count (WBC), and platelet count. Several enzyme activities and some biochemical parameters in serum were measured by Unilever Research, Department of Biosciences, Nutrition and Safety, Vlaardingen, The Netherlands, using a programmable Vitatron PA 800 automatic analyser (Meyvis, Bergen op Zoom, The Netherlands) and commercial test kits according to 
Table 5. Enzyme activities and some biochemical parameters, measured in serm.

\begin{tabular}{|c|c|c|c|}
\hline Parameter & & $\mathrm{EC} n r^{*}$ & Test kit \\
\hline Lactate dehydrogenase & $\mathbf{L D H}$ & 1.1 .1 .27 & $\mathrm{~b}$ \\
\hline Isocitrate dehydrogenase & $\mathrm{ICDH}$ & 1.1 .1 .42 & $b$ \\
\hline \multicolumn{4}{|l|}{ Alpha hydroxybutyrate } \\
\hline dehydrogenase & $\alpha H B D H$ & 1.1 .1 .61 & $\mathrm{~b}$ \\
\hline Glutamate dehydrogenase & GLDH & 1.4 .1 .3 & $\mathrm{~b}$ \\
\hline Gamma glutamyl transferase & $\eta \mathrm{GT}$ & 2.3 .2 .2 & $\mathrm{~b}$ \\
\hline Aspartate aminotransferase & ASAT & 2.6 .1 .1 & $\mathrm{~b}$ \\
\hline Alanine aminotransferase & ALAT & 2.6 .1 .2 & $\mathrm{~b}$ \\
\hline Creatinine (phospho) kinase & $\mathrm{CK}$ & 2.7 .3 .2 & $b$ \\
\hline Butyrylcholine esterase & $\mathrm{BCHE}$ & 3.1 .1 .8 & $\mathrm{~b}$ \\
\hline Alkaline phosphatase & $\mathrm{AF}$ & 3.1 .3 .1 & $b$ \\
\hline Urea & & & b \\
\hline Creatinine & & & $b$ \\
\hline Calcium & & & $\mathrm{c}$ \\
\hline Albumin & & & $\mathrm{c}$ \\
\hline Total protein & & & $\mathrm{d}$ \\
\hline
\end{tabular}

a: $\mathrm{EC}=$ Enzyme Commission (of the International Union of Biochemistry)

b: Boehringer Mannheim, FRG

c: Pierce Diagnostics, obtained from Hicol bv, Rotterdam, The Netherlands

d: Biuret method

manufacturers' prescription. The parameters analyzed and the kits used are listed in Table 5.

The renal creatinine clearance $(\mathrm{ml} / \mathrm{min})$ was calculated using the equation ( $U \mathrm{x}$ $\mathrm{V}) / \mathrm{S}$, in which $U$ is the creatinine concentration in urine $(\mathrm{mmol} / \mathrm{l}), \mathrm{S}$ is the creatinine concentration in serum ( $\mathrm{mmol} / \mathrm{l})$, and $\mathrm{V}$ is the urine production $(\mathrm{ml} / \mathrm{min})$, as deduced from $24 \mathrm{~h}$ urine volume.

\section{Statistical evaluation}

All data were checked as to their frequency distribution and, when necessary, transformation was used to normalize the distribution. Subsequentily, significant outliers were omitted.

The Student's 1-sample t-test for paired data was used to evaluate the changes within the mackerel and the control groups occurring after 3 and 6 weeks. All differences between the mackerel and the control groups were evaluated using Student"s 2-sample t-test. The three experimental centers were compared using the Bonferroni inequality test (17). Occasionally other statistical methods were used, which will be outlined when describing the results. All differences were considered significant when the two-sided $P$ value $(p)$ was equal to, or smaller than 0.05 . 
Table 6. Initial hematological walues, body weights, and their changes after 3 and 6 experimental weeks (mean \pm SEM).

\begin{tabular}{|c|c|c|}
\hline Parameter & Mackerel group & Control group \\
\hline \multicolumn{3}{|l|}{ n } \\
\hline I & 41 & 42 \\
\hline 3 & 39 & 42 \\
\hline 6 & 40 & 42 \\
\hline \multicolumn{3}{|l|}{$\operatorname{HCT}(0 \%)$} \\
\hline 1 & $42.5 \pm 0.41$ & $43.2 \pm 0.51$ \\
\hline$\Delta 3$ & $0.6 \pm 0.34$ & $0.7 \pm 0.39$ \\
\hline$\Delta 6$ & $0.1 \pm 0.45$ & $0.4 \pm 0.46$ \\
\hline \multicolumn{3}{|c|}{$\mathrm{HB}(\mathrm{mmol} / 1)$} \\
\hline 1 & $9.16 \pm 0.09$ & $9.26 \pm 0.09$ \\
\hline$\Delta 3$ & $-0.21 \pm 0.06^{b}$ & $-0.09 \pm 0.04^{a}$ \\
\hline$\Delta 6$ & $-0.13 \pm 0.06^{\mathrm{a}} \mathrm{e}$ & $0.06 \pm 0.06$ \\
\hline \multicolumn{3}{|c|}{$\operatorname{RBC}\left(10^{12} / 1\right)$} \\
\hline I & $4.86 \pm 0.06$ & $4.91 \pm 0.06$ \\
\hline$\Delta 3$ & $0.01 \pm 0.05$ & $0.11 \pm 0.04^{b}$ \\
\hline$\Delta 6$ & $-0.05 \pm 0.06$ & $0.03 \pm 0.05$ \\
\hline \multicolumn{3}{|l|}{ MCV (fi) } \\
\hline I & $87.9 \pm 0.72$ & $88.1 \pm 0.74$ \\
\hline$\Delta 3$ & $0.3 \pm 0.71$ & $-0.4 \pm 0.73$ \\
\hline$\Delta 6$ & $0.8 \pm 0.65$ & $-0.0 \pm 0.56$ \\
\hline \multicolumn{3}{|c|}{$\mathrm{MCH}$ (amol) } \\
\hline I & $1898 \pm 19.6$ & $1896 \pm 18.6$ \\
\hline$\Delta 3$ & $-56 \pm 14.8^{c}$ & $-64 \pm 14.2^{1}$ \\
\hline$\Delta 6$ & $-16 \pm 20.5$ & $-10 \pm 17.3$ \\
\hline \multicolumn{3}{|c|}{$\mathrm{MCHC}(\mathrm{mmol} / \mathrm{l})$} \\
\hline 1 & $21.6 \pm 0.21$ & $21.6 \pm 0.19$ \\
\hline$\Delta 3$ & $-0.8 \pm 0.16^{\|}$ & $-0.6 \pm 0.17^{\circ}$ \\
\hline$\Delta 6$ & $-0.3 \pm 0.22$ & $-0.2 \pm 0.23$ \\
\hline \multicolumn{3}{|c|}{ WBC $\left(10^{9} / 1\right)$} \\
\hline I & $4.73 \pm 0.17$ & $5.02 \pm 0.13$ \\
\hline$\Delta 3$ & $-0.13 \pm 0.14$ & $-0.09 \pm 0.12$ \\
\hline$\Delta 6$ & $0.02 \pm 0.15$ & $-0.04 \pm 0.14$ \\
\hline \multicolumn{3}{|c|}{ Platelets $\left(10^{9} / 1\right)$} \\
\hline 1 & $218 \pm 6.1$ & $231 \pm 7.1$ \\
\hline$\Delta 3$ & $-17 \pm 4.0^{418}$ & $1 \pm 4.4$ \\
\hline$\Delta 6$ & $-16 \pm 4.2^{\mathrm{c}, e}$ & $-1 \pm 4.4$ \\
\hline \multicolumn{3}{|c|}{ Body weight' } \\
\hline 1 & $75.5 \pm 1.66$ & $73.7 \pm 1.61$ \\
\hline$\Delta 3$ & $0.4 \pm 0.20$ & $0.2 \pm 0.13$ \\
\hline$\Delta 6$ & $0.5 \pm 0.23$ & $0.4 \pm 0.16$ \\
\hline
\end{tabular}

Values significantly diflerent from zero: $a: p<0.05, b: p<0.005, c_{*}^{*} p<0.001$, $\mathrm{d}: \mathrm{p}<0.0005$

Values significantly different from control group: e: $p<0.05, \mathrm{f}: \mathrm{p}<0.005$

$\begin{array}{llll}1 & =\text { Zeist excluded } & \mathrm{RBC} & =\text { red blood cell count } \\ \mathbb{I} & =\text { Initial values (week 0) } & \mathrm{MCV} & =\text { mean cellular volume } \\ \Delta 3 & =\text { week } 3 \text { - week } 0 & \mathrm{MCH} & =\text { mean cellular hemoglobin } \\ \Delta 6 & =\text { week } 6 \text { - week } 0 & \mathrm{MCHC} & =\text { mean cellular hemoglobin } \\ \mathrm{HCT} & =\text { hematocrit } & & \text { concentration } \\ \mathrm{Hb} & =\text { hemoglobin } & \mathrm{WBC} & =\text { white blood cell count }\end{array}$




\section{Results}

During the experiment no major problems were encountered. Although a small number of subjects experienced some difficulties in consuming the required amount of the dietary supplements, most volunteers accepted the supplements well. In Troms $\emptyset$ one person dropped out because he developed a strong aversion against the mackerel paste. All other volunteers completed the study successfully.

Logarithmic transformation of the data was required for three parameters only. Since this did not change the result of the statistical analysis and also for the sake of clarity, non-transformed values will be given only.

Habitual fish consumption was higher in Troms $\emptyset$ than in Zeist and Maastricht. This was also reflected by a higher content of timnodonic acid in the platelet phospholipids, measured at week 0 , that is after two weeks in which meat paste was administered (data not shown).

Habitual alcohol consumption was comparable for the mackerel and the control group. However, there were differences between the three centers (Table 4). Alcohol consumption in Maastricht was higher than in Troms $\varnothing$. Changes in alcohol consumption during the study were not evaluated.

In Maastricht and Troms $\varnothing$, the mean body weight of the volunteers increased slightly $(<1.0 \mathrm{~kg}$ ) during the experiment (Table 6). This weight gain was comparable for the mackerel and the control group and was significant in Maastricht only. In Zeist body weights were not recorded during the experiment.

\section{Compliance}

In Fig 1 the excretion of lithium in urine over $24 \mathrm{~h}$ after 0,3 and 6 weeks is given as a percentage of the required daily lithium intake. This lithium recovery reflects dietary adherence, and when the three centers were combined, compliance for the mackerel paste appeared slightly but not significantly less than for the meat paste. For each center separately, the difference between mackerel and meat paste consumption was significant only in Zeist ( $p=0.002$ after 3 weeks and $p=0.03$ after 6 weeks). In Maastricht, one volunteer had a compliance below $10 \%$. Since his values for lithium-percreatinine were also extremely low, he was removed from the study. Since approximately $90 \%$ of the ingested lithium is excreted in urine (16), the average compliance was about $85 \%$ for the control group and $78 \%$ for the mackerel group. In general, there was a tendency for the compliance to become lower, the longer the experimental time. This drop in compliance was significant at week $6(\mathrm{p}=0.002)$, mainly due to Maastricht. In general, compliance in Troms $\varnothing$ was lower than in the other centers. In the control group the difference with Zeist was significant $(\mathrm{p}<0.05)$; in the mackerel group the difference with Maastricht was significant $(\mathrm{p}<0.001)$. 


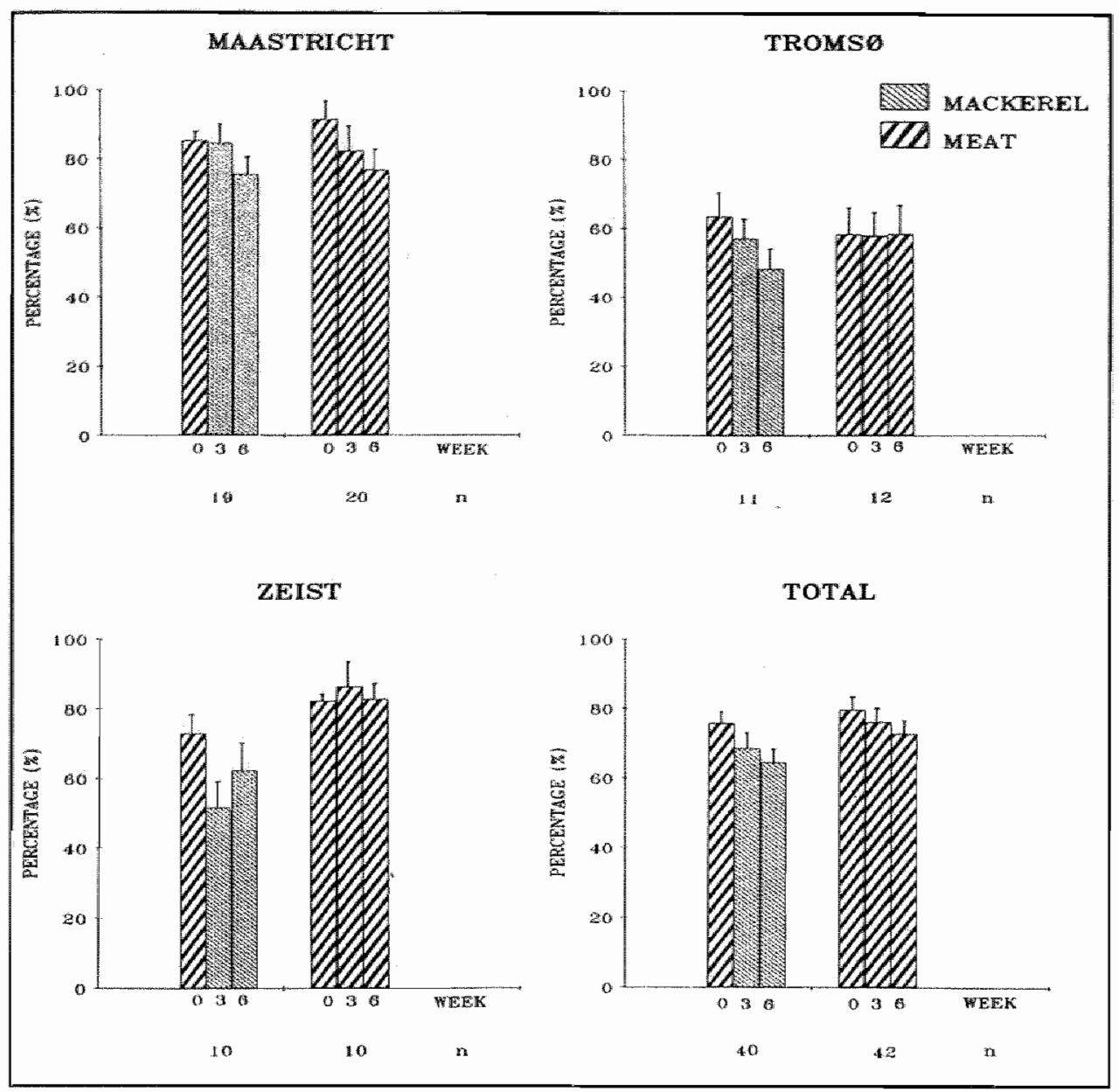

Fig 1. Lithium excretion in urine as percentage of the required daily lithium intake (mean and SEM). For differences between groups and centers: see text.

\section{Blood pressure}

Results of the blood pressure measurements are given in Table 4 (initial values) and Figs 2 and 3 ( $\Delta$ values).

With regard to the systolic blood pressure (Fig 2), a significant decrease was observed in the mackerel group after 3 and 6 weeks, in both Mastricht and Troms However, comparable blood pressure changes were also seen in the control group (significant after 6 weeks only).

Although systolic blood pressure did not change significantly in Zeist, either in the fish, or in the control group, the results after combining the three centers very clearly indicate a decrease in systolic blood pressure during the experimental period. Since at all measuring points this effect in the mackerel group is not significantly different from that in the control group, the fish supplements did not have a specific 


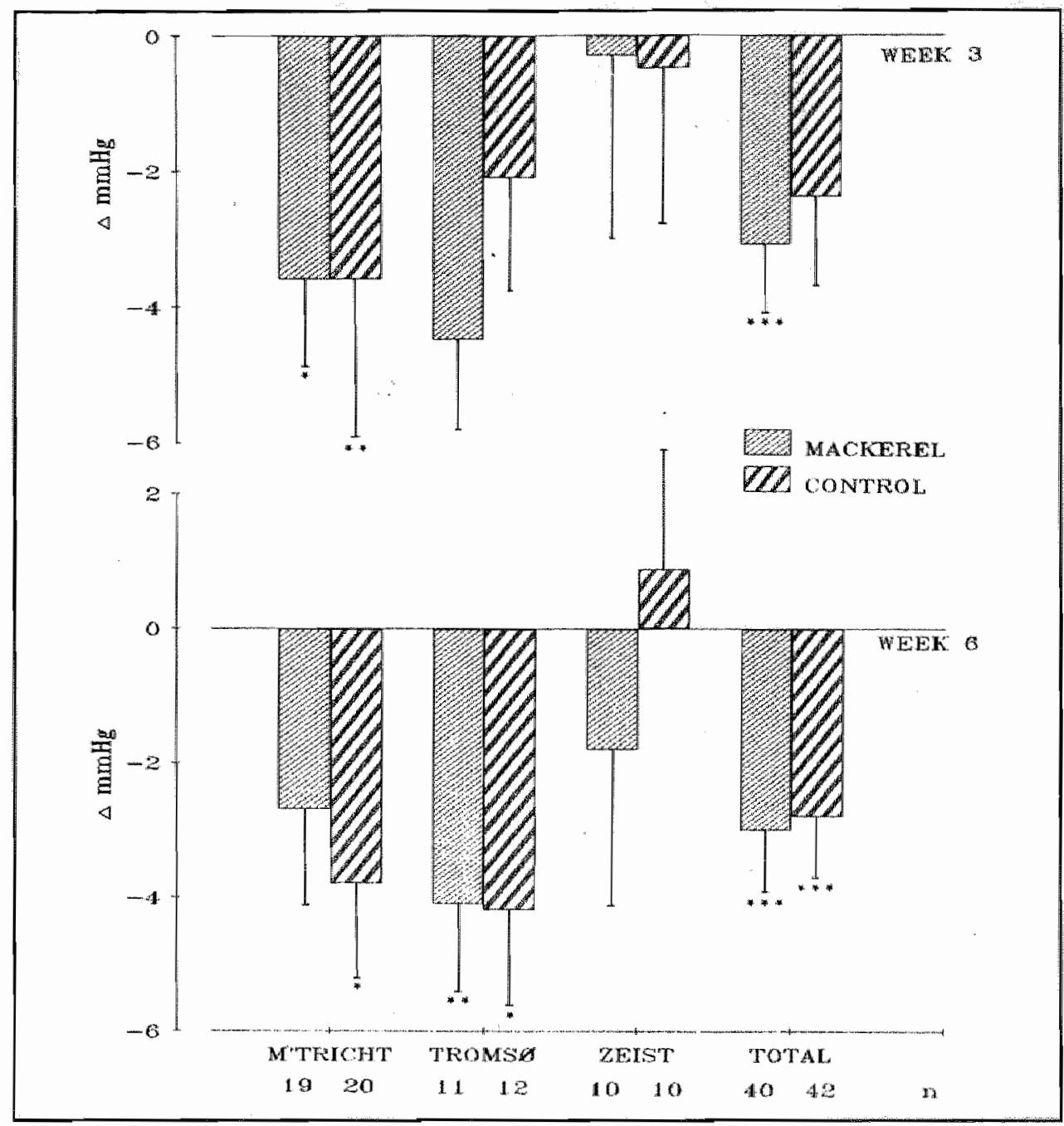

Fig 2. Effect of dietary supplements on the change in systolic blood pressure (KL, $\triangle \mathrm{mmHg})$ after 3 and 6 experimental weeks (mean and SEM). No significant differences between mackerel and control groups. Values significantly different from zero: $* p<0.05, * *<<0.01$, *** $p<0.005$. Initial values given in Table 4.

effect. In the mackerel groups the diastolic blood pressure (K4) decreased slightly more than in the control groups (Troms $\varnothing$ after 3 weeks excluded, Fig 3). When the results for the three mackerel groups were combined, this decrease in diastolic blood pressure was significantly different from zero after 6 weeks $(p<0.025)$. However, this pressure reaction was comparable to that in the control group. Therefore, a specific effect of the fish supplements on the K4-diastolic blood pressure could not be observed. 


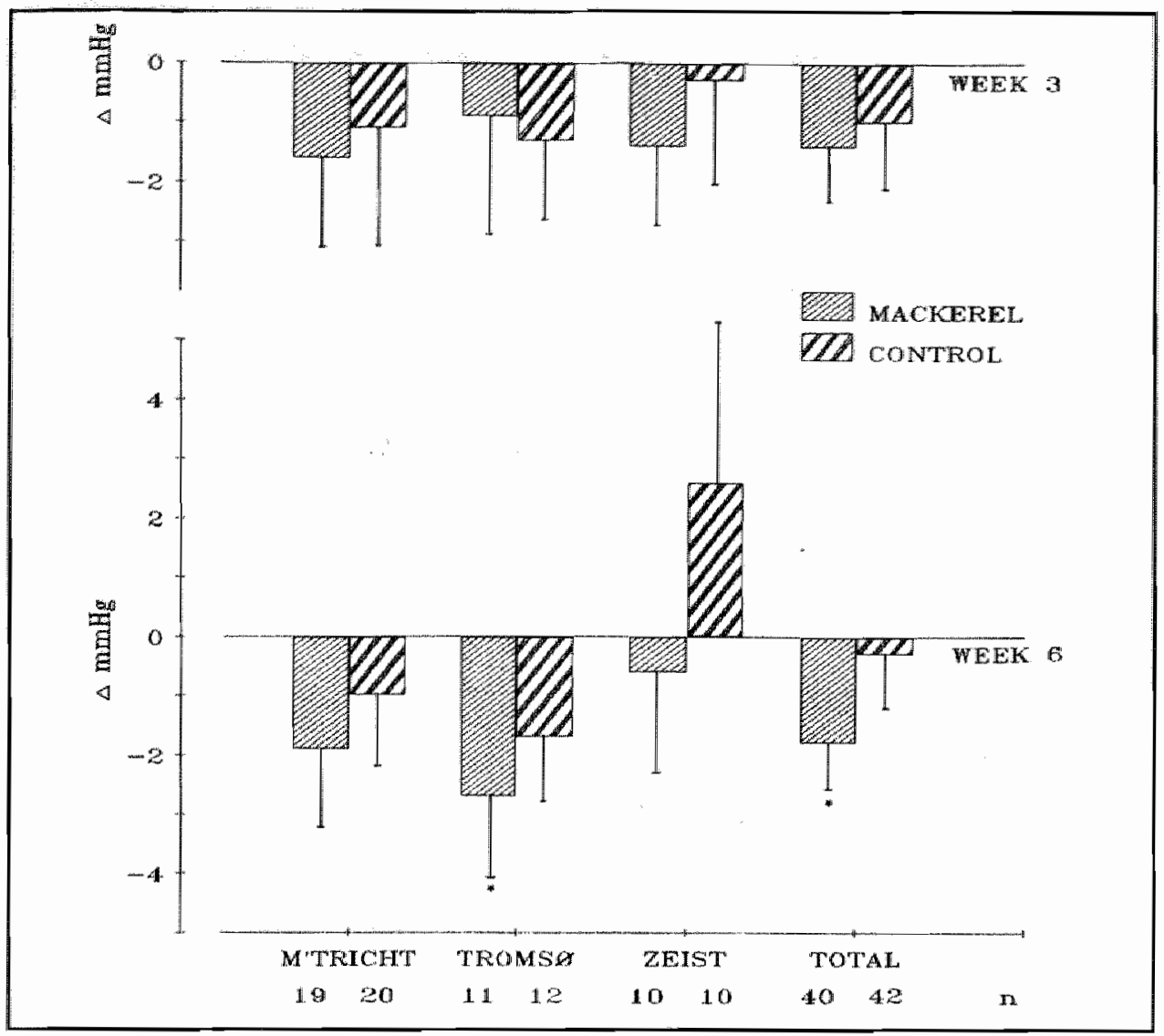

Fig 3. Effect of dietary supplements on the change in diastolic blood pressure $(\mathrm{KA}, \Delta \mathrm{mmHg})$ after 3 and 6 experimental weeks (mean and SEM). No significant differences between mackerel and control groups. Values significamity different from zero: ${ }^{*} p<0.05$. Initial values given in Table 4.

No significant pressure responses were seen for the K5-diastolic blood pressure (data not shown). Therefore an effect of the fish supplements on this parameter could not be observed.

\section{Bleeding time}

In Maastricht the initial bleeding times were significantly longer than in Troms $\emptyset$ and Zeist ( $p<0.001$ ); there was no significant difference between Troms and Zeist. In the control group the difference between Maastricht and the other experimental centers remained significant throughout the experiment. No significant differences were observed between the initial values of the mackerel and control groups (Table 4). After 3 and 6 weeks, however, the bleeding times in the mackerel groups were significantly longer than in the control groups (Maastricht after 3 weeks excluded; data not shown). 


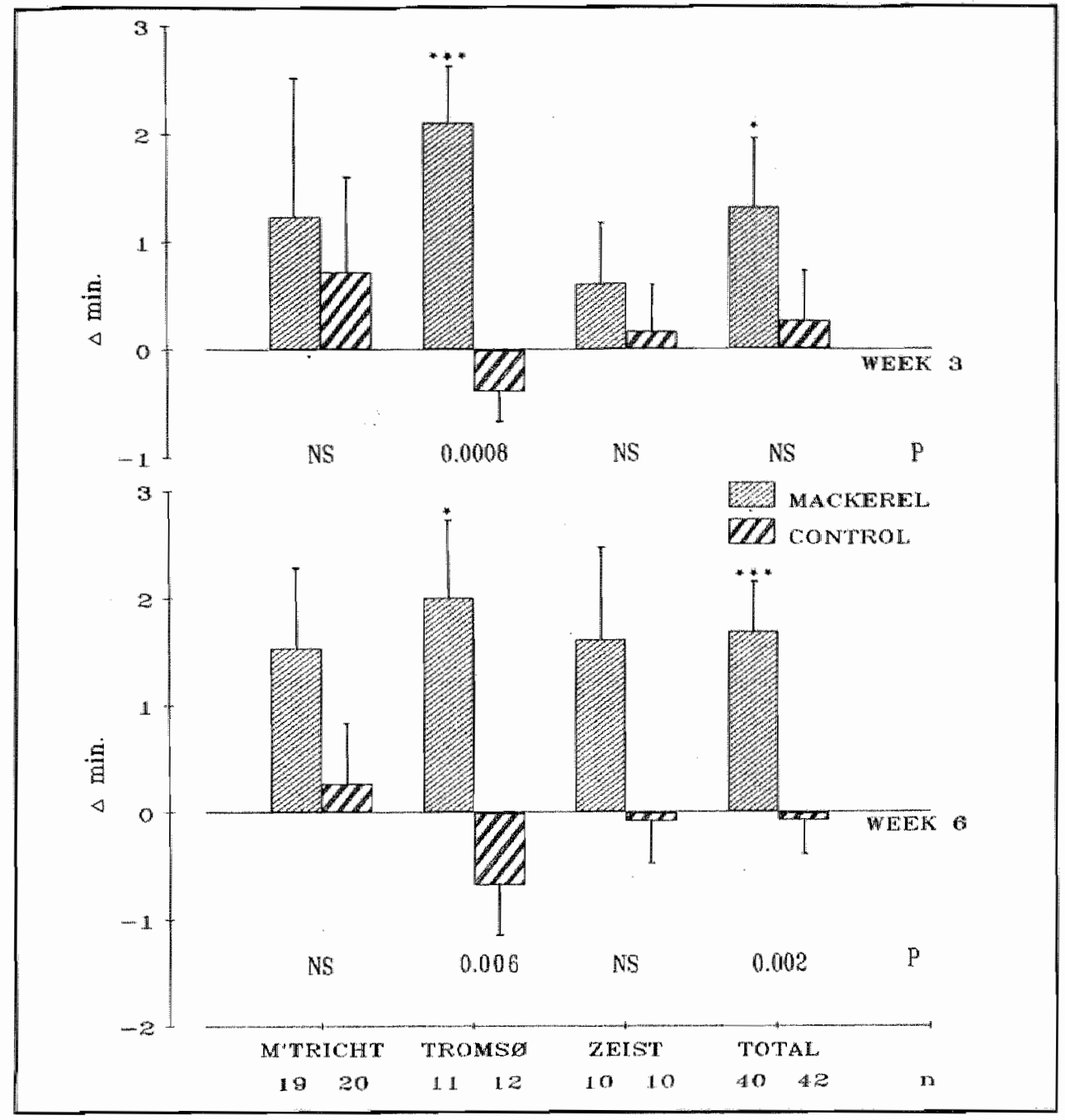

Fig 4. Effect of dietary supplements on the change in bleeding time $(\Delta \mathrm{min})$ after 3 and 6 experimental weeks (mean and SEM). p: significance of difference between mackerel and control groups. NS: not significant. Values significantly different from zero:* $p<0.05$, * $p$ $<0.0 .1, * * *<0.005$. Initial values given in Table 4.

Changes in bleeding times during the experiment are shown in Fig 4 . When the results for the three centers were combined, bleeding times in the mackerel group were more prolonged than in the control group. This difference is significant after 6 weeks only. For each experimental center separately, the same tendency was observed; however, results were significant for Tromsø only. 


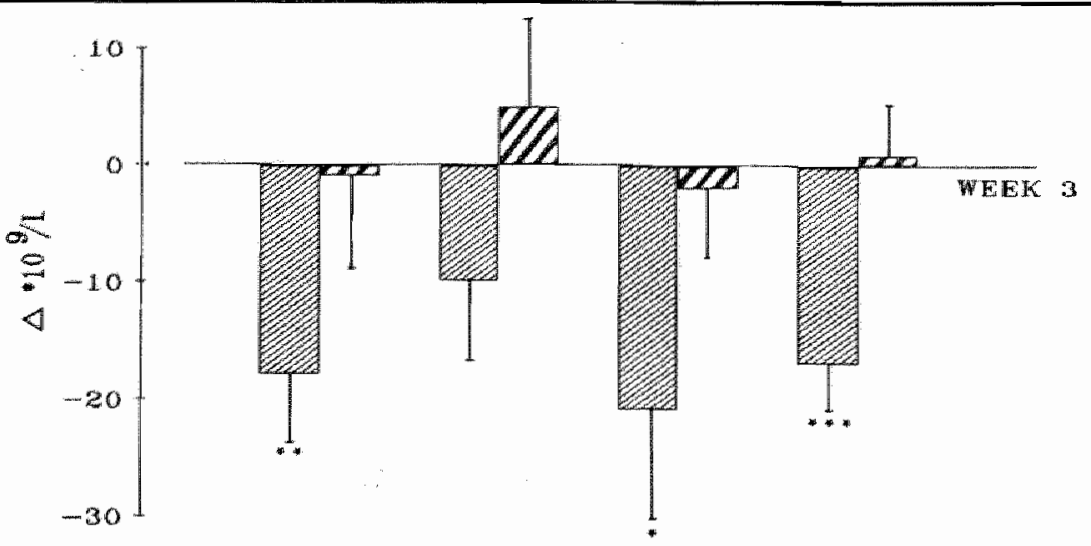

NS $\quad$ NS $\quad$ NS $\quad 0.005 \quad$ P

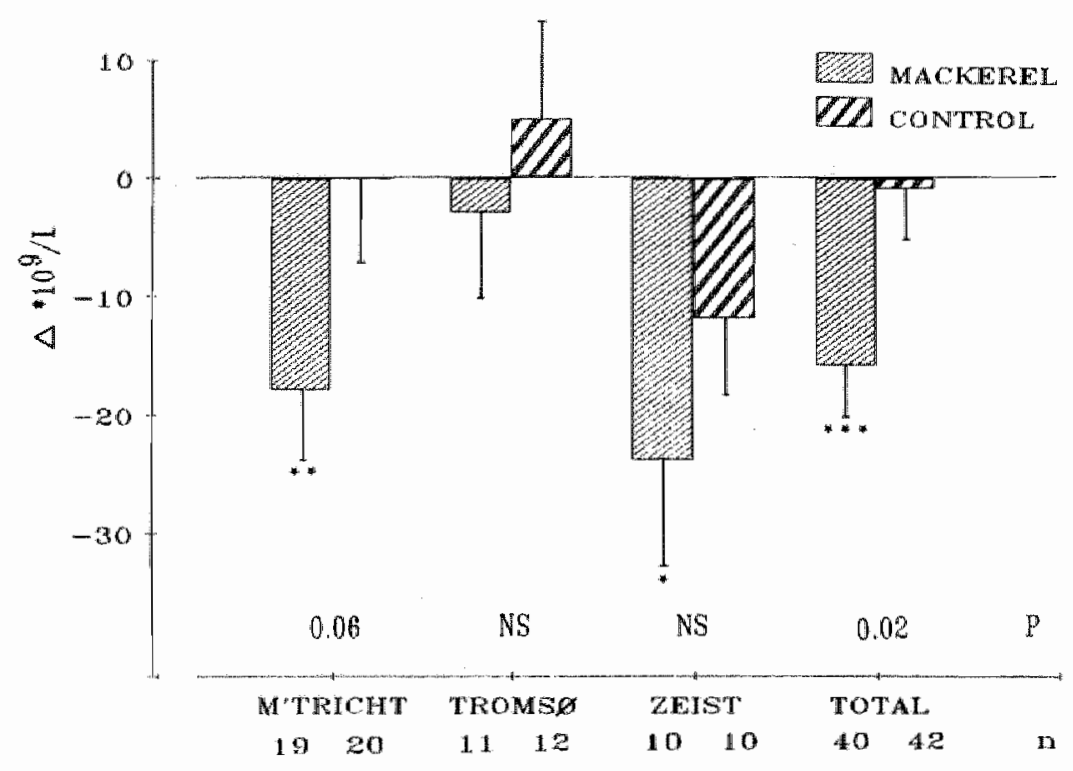

Fig 5. Effect of dietary supplements on the change in platelet count $\left(\Delta 10^{\circ} / 1\right)$ after 3 and 6 experimental weeks (mean and SEM). p: significances of differences between mackerel and control groups. NS: not significant. Values significantly different from zero: ${ }^{*} p<0.05$, ** $p<0.01$, *** $p<005$. Initial values given in Table 6 .

\section{Hematological parameters}

Initial values (week 0 ) and changes after week 3 and 6 are given in Table 6 . Because hardly any difference was observed between the three experimental centers, the combined results are given only. No significant effects of the dietary supplements were observed for HCT, RBC, MCV and WBC. Occasionaly, significant effects of the 
Table 7. Serum enzymes (mean $\pm S E M$ ).

\begin{tabular}{|c|c|c|c|}
\hline $\begin{array}{l}\text { Parameter } \\
(\mu \text { katal/l) }\end{array}$ & & $\begin{array}{l}\text { Mackerel group } \\
(\mathrm{n}=36-41)\end{array}$ & $\begin{array}{l}\text { Control group } \\
(n=41-42)\end{array}$ \\
\hline $\mathrm{LDH}^{\mathrm{I}}$ & $\begin{array}{r}1 \\
\Delta 3 \\
\Delta 6\end{array}$ & $\begin{array}{l}4.73 \pm 0.151 \\
0.15 \pm 0.097 \\
0.37 \pm 0.098^{1}\end{array}$ & $\begin{array}{l}4.89 \pm 0.110 \\
0.10 \pm 0.086 \\
0.30 \pm 0.124^{\mathrm{a}}\end{array}$ \\
\hline $\mathrm{ICDH}$ & $\begin{array}{r}1 \\
\Delta 3 \\
\Delta 6\end{array}$ & $\begin{array}{l}0.015 \pm 0.001 \\
0.003 \pm 0.003 \\
0.005 \pm 0.002^{\mathrm{a}}\end{array}$ & $\begin{array}{r}0.017 \pm 0.002 \\
-0.001 \pm 0.003 \\
0.004 \pm 0.003\end{array}$ \\
\hline$\alpha \mathrm{HBDH}$ & $\begin{array}{r}1 \\
\Delta 3 \\
\Delta 6\end{array}$ & $\begin{array}{l}1.20 \pm 0.049 \\
0.03 \pm 0.026 \\
0.18 \pm 0.073^{\mathrm{a}}\end{array}$ & $\begin{array}{l}1.24 \pm 0.033 \\
0.05 \pm 0.022^{a} \\
0.04 \pm 0.025\end{array}$ \\
\hline GLDH & $\begin{array}{r}1 \\
\Delta 3 \\
\Delta 6\end{array}$ & $\begin{array}{r}0.119 \pm 0.017 \\
-0.024 \pm 0.018 \\
-0.074 \pm 0.019^{4}\end{array}$ & $\begin{array}{r}0.103 \pm 0.009 \\
-0.002 \pm 0.007 \\
-0.062 \pm 0.010^{d}\end{array}$ \\
\hline$\gamma \mathrm{GT}$ & $\begin{array}{c}1 \\
\Delta 3 \\
\Delta 6^{2}\end{array}$ & $\begin{array}{l}0.145 \pm 0.009 \\
0.023 \pm 0.007^{\mathrm{b}, \mathrm{e}} \\
0.012 \pm 0.006\end{array}$ & $\begin{array}{l}0.153 \pm 0.013 \\
0.003 \pm 0.004 \\
0.028 \pm 0.016\end{array}$ \\
\hline ASAT & $\begin{array}{r}I \\
\Delta 3 \\
\Delta 6\end{array}$ & $\begin{array}{l}0.35 \pm 0.022 \\
0.03 \pm 0.029 \\
0.00 \pm 0.021\end{array}$ & $\begin{array}{l}0.33 \pm 0.0115 \\
0.00 \pm 0.010 \\
0.01 \pm 0.011\end{array}$ \\
\hline ALAT & $\begin{array}{r}\text { I } \\
\Delta 3 \\
\Delta 6\end{array}$ & $\begin{array}{l}0.14 \pm 0.015 \\
0.06 \pm 0.029^{\mathrm{a} e} \\
0.07 \pm 0.014^{\mathrm{d}}\end{array}$ & $\begin{array}{r}0.15 \pm 0.022 \\
-0.00 \pm 0.011 \\
0.04 \pm 0.013^{b}\end{array}$ \\
\hline CK & $\begin{array}{r}1 \\
\Delta 3 \\
\Delta 6\end{array}$ & $\begin{array}{r}0.98 \pm 0.219 \\
0.02 \pm 0.215 \\
-0.18 \pm 0.214\end{array}$ & $\begin{array}{r}0.85 \pm 0.087 \\
-0.12 \pm 0.108 \\
-0.05 \pm 0.101\end{array}$ \\
\hline $\mathrm{BCHE}$ & $\begin{array}{r}1 \\
\Delta 3 \\
\Delta 6\end{array}$ & $\begin{array}{l}94.1 \pm 3.71 \\
-3.6 \pm 1.59^{\mathrm{a} . \mathrm{f}} \\
-3.4 \pm 1.71^{\mathrm{g}}\end{array}$ & $\begin{array}{r}97.7 \pm 3.23 \\
3.1 \pm 1.26^{\mathrm{a}} \\
7.0 \pm 1.61^{\mathrm{d}}\end{array}$ \\
\hline $\mathrm{AP}$ & $\begin{array}{l}\text { I } \\
\Delta 3 \\
\Delta 6\end{array}$ & $\begin{array}{r}1.69 \pm 0.055 \\
-0.00 \pm 0.053 \\
0.08 \pm 0.064\end{array}$ & $\begin{array}{l}1.66 \pm 0.050 \\
0.01 \pm 0.030 \\
0.05 \pm 0.035\end{array}$ \\
\hline
\end{tabular}

Values significantly different from zero: a: $p<0.05$; $\mathrm{b}$ p $<0.005 ; \mathrm{c}: \mathrm{p}<0.001$; d: $p<0.0005$

Values significantly different from control group: e: $p<0.05: \mathrm{f}: \mathrm{p}<0.005$; $\mathrm{g}$ : p $<0.0001$

1 Abbreviations: see Table 5

$\mathbb{l}=$ Initial values (week 0 )

$\Delta \mathbf{3}=$ week 3 - week 0

$\Delta 6=$ week 6 - week 0

2 Troms $\emptyset$ only; $\mathrm{n}=11$ mackerel and 12 control 

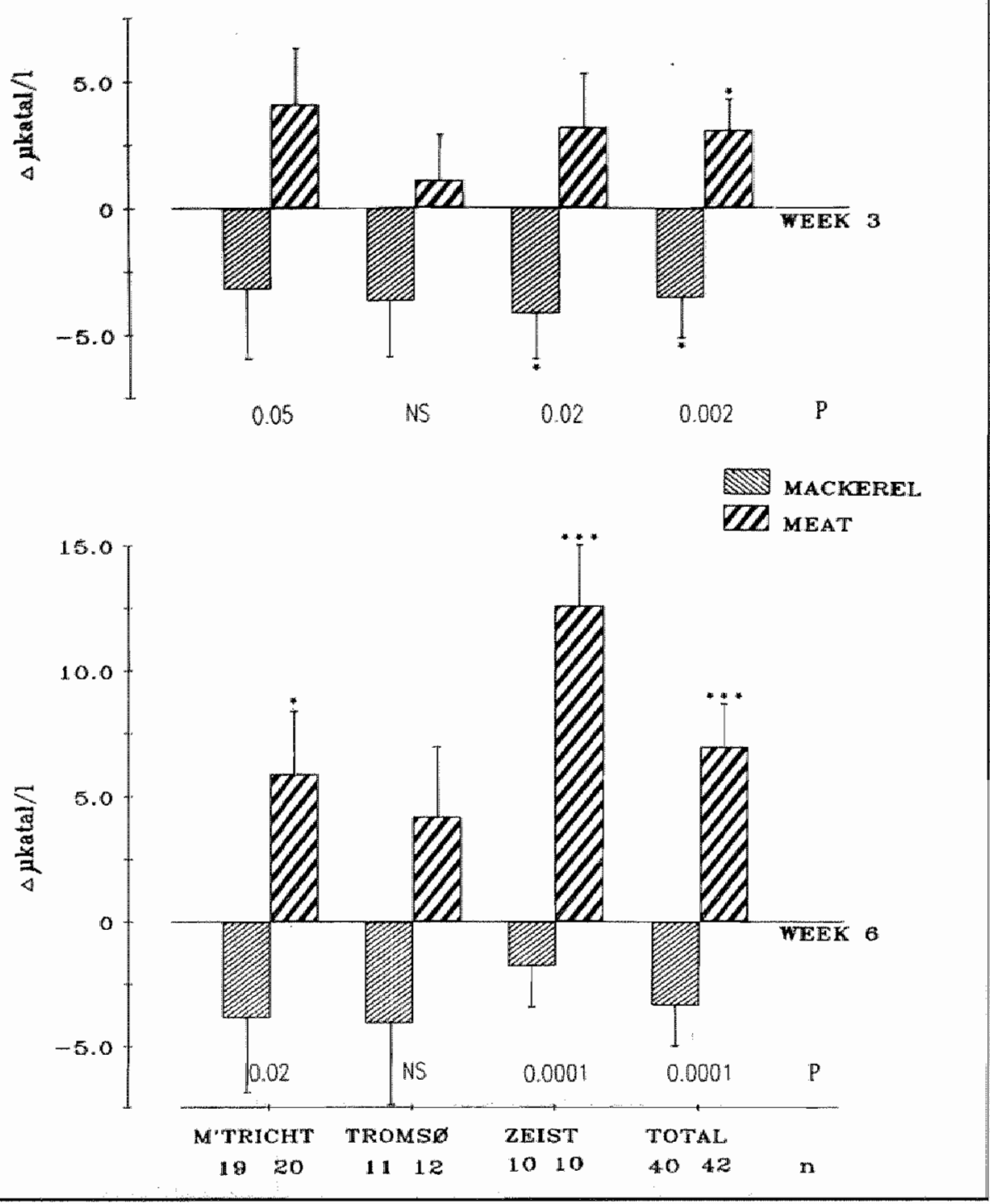

Fig. 6. Effect of dietary supplements on the change in BCHE ( $\triangle \mu$ kalal/l) after 3 and 6 experimental weeks (mean and SEM). p. significances of difference beiween mackerel and control groups. NS: not significant. Walues significantly different from zero: ${ }^{*} p<0.05$, ** $p<0.01$.*** $p<0.005$. Initial values given in Table 7 .

dietary supplements were found for $\mathrm{MCH}$ and $\mathrm{MCHC}$. However, no significant differences were observed between the mackerel and the control groups. The $\mathrm{Hb}$ values decreased slightly more in the mackerel group than in the control group. This resulted in a significant difference between both groups after 6 weeks. The platelet 
Table 8. Other biochemical parameters in serum (mean $\pm S E M$ ).

\begin{tabular}{|c|c|c|c|}
\hline \multicolumn{2}{|l|}{ Parameter } & $\begin{array}{l}\text { Mackerel group } \\
(\mathrm{n}=35-41) \\
4.46 \pm 0.174\end{array}$ & $\begin{array}{l}\begin{array}{l}\text { Control group } \\
(\mathrm{n}=41-42)\end{array} \\
4.69 \pm 0.214\end{array}$ \\
\hline $\begin{array}{l}\text { Urea } \\
(\mathrm{mmol} / \mathrm{l})\end{array}$ & $\begin{array}{r}1 \\
\Delta 3 \\
\Delta 6\end{array}$ & $\begin{array}{l}4.46 \pm 0.174 \\
0.20 \pm 0.217 \\
0.17 \pm 0.175\end{array}$ & $\begin{array}{r}4.69 \pm 0.214 \\
0.06 \pm 0.208 \\
-0.29 \pm 0.151\end{array}$ \\
\hline $\begin{array}{l}\text { Creatinine } \\
(\mu \mathrm{mol} / \mathrm{l})\end{array}$ & $\begin{array}{r}\text { I } \\
\Delta 3 \\
\Delta 6\end{array}$ & $\begin{aligned} 77 & \pm 1.1 \\
0 & \pm 1.0 \\
1 & \pm 0.8\end{aligned}$ & $\begin{array}{r}76 \pm 1.3 \\
-0 \pm 0.9 \\
-1 \pm 1.2\end{array}$ \\
\hline $\begin{array}{l}\text { Calcium } \\
(\mathrm{mmol} / \mathrm{l})\end{array}$ & $\begin{array}{c}1 \\
\Delta 3^{1} \\
\Delta 6\end{array}$ & $\begin{array}{l}2.05 \pm 0.034 \\
0.17 \pm 0.066^{\mathrm{a}} \\
0.19 \pm 0.040^{\mathrm{c}}\end{array}$ & $\begin{array}{l}2.04 \pm 0.032 \\
0.15 \pm 0.052^{6} \\
0.18 \pm 0.043^{\mathrm{c}}\end{array}$ \\
\hline $\begin{array}{l}\text { Albumin } \\
(\mathrm{g} / \mathrm{l})\end{array}$ & $\begin{array}{r}1 \\
\Delta 3 \\
\Delta 6\end{array}$ & $\begin{array}{r}45.8 \pm 0.38 \\
0.5 \pm 0.44 \\
-0.4 \pm 0.37\end{array}$ & $\begin{aligned} 45.4 & \pm 0.37 \\
0.6 & \pm 0.27^{8} \\
-0.7 & \pm 0.63\end{aligned}$ \\
\hline $\begin{array}{l}\text { Total protein } \\
(\mathrm{g} / \mathrm{l})\end{array}$ & $\begin{array}{c}1 \\
\Delta 3^{1} \\
\Delta 6\end{array}$ & $\begin{array}{r}69.8 \pm 0.68 \\
-1.2 \pm 1.35 \\
-1.0 \pm 0.57\end{array}$ & $\begin{array}{r}69.8 \pm 0.73 \\
-0.7 \pm 0.65 \\
-0.6 \pm 0.99\end{array}$ \\
\hline
\end{tabular}

Values significantly different from zero: a: $p<0.05 ; \mathrm{b}: \mathrm{p}<0.01 ; \mathrm{c}: \mathrm{p}<0.001$ No significant differences between mackerel and control groups

$I=$ Initial values (week 0 )

$\Delta 3=$ week 3 - week 0

$\Delta 6=$ week 6 - week 0

1. Maastricht values not available; $\mathrm{n}=18$ mackerel and 21 control

concentration in blood decreased significantly in the mackerel group. This is illustrated in more detail in Fig 5. Within each center the platelet counts in the fish group invariably decreased. This effect is significantly different from zero in Maastricht and Zeist. Small changes occurred in the control groups also; however, these changes were not significant. Although within each center the decrease of the platelet count in the mackerel group was not significantly different from that in the control group, the tendency in each center was the same. This resulted in a significant effect when data from the three centers were combined. This lowering effect of the fish supplement on the platelet count was already maximal after three weeks.

Taking all these data together, we conclude that the fish supplement does not have a specific effect on the hematological parameters, with the exclusion of platelet concentration and $\mathrm{Hb}$. 
Table 9. Urine analysis and creatimine clearance (mean \pm SEM).

\begin{tabular}{|c|c|c|c|}
\hline Parameter & & $\begin{array}{l}\text { Mackerel group } \\
(\mathrm{n}=35-39)\end{array}$ & $\begin{array}{l}\text { Control group } \\
(n=40-41)\end{array}$ \\
\hline $\begin{array}{l}\text { Potasium } \\
\text { (mnol/24h) }\end{array}$ & $\begin{array}{r}1 \\
\Delta 3 \\
\Delta 6\end{array}$ & $\begin{array}{r}73 \pm 3.1^{9} \\
3 \pm 3.9 \\
7 \pm 4.7\end{array}$ & $\begin{array}{r}85 \pm 4.2 \\
-2 \pm 4.5 \\
1 \pm 4.0\end{array}$ \\
\hline $\begin{array}{l}\text { Sodium } \\
(\mathrm{mmol} / 24 \mathrm{~h})\end{array}$ & $\begin{array}{r}I \\
\Delta 3 \\
\Delta 6\end{array}$ & $\begin{array}{l}171 \pm 9.3 \\
-5 \pm 9.6 \\
-7 \pm 11.0\end{array}$ & $\begin{array}{l}193 \pm 9.8 \\
-8 \pm 10.8 \\
-5 \pm 10.7\end{array}$ \\
\hline $\begin{array}{l}\text { Creatinine } \\
(\text { mmol } / 24 h)\end{array}$ & $\begin{array}{r}\text { I } \\
\Delta 3 \\
\Delta 6\end{array}$ & $\begin{array}{r}15.5 \pm 0.58 \\
-0.0 \pm 0.71 \\
-0.6 \pm 0.68\end{array}$ & $\begin{array}{r}15.8 \pm 0.50 \\
-0.2 \pm 0.69 \\
-0.4 \pm 0.56\end{array}$ \\
\hline $\begin{array}{l}\text { Creatinine } \\
\text { clearance } \\
(\mathrm{ml} / \mathrm{min})\end{array}$ & $\begin{array}{r}I \\
\Delta 3 \\
\Delta 6\end{array}$ & $\begin{array}{r}140 \pm 5.0 \\
1 \pm 7.5 \\
-6 \pm 6.4\end{array}$ & $\begin{array}{r}145 \pm 4.9 \\
2 \pm 6.9 \\
-2 \pm 5.9\end{array}$ \\
\hline
\end{tabular}

Values significantly different from control group: $a: p=0.035$

1 = Initial values (week 0 )

$\Delta 3=$ week 3 - week 0

$\Delta 6=$ week 6 - week 0

\section{Serum enzymes}

The results of the serum enzyme analyses are summarized in Table 7 . For AP, ICDH, LDH, ASAT and CK no significant differences in the changes after 3 and 6 weeks were observed between the mackerel and control groups. Occasionally significant differences did occur for ALAT, GLDH, $\gamma \mathrm{GT}$ and $\alpha \mathrm{HBDH}$ but since these changes were seen in Maastricht only, were not consistent at all, and only occasionally caused values outside the reference range (see below), the importance of these changes is questionable. The only enzyme that was clearly affected by the dietary supplements was BCHE (see Fig 6). The meat supplement significantly increased the level of this enzyme in the serum, whereas the fish supplement tended to decrease it. This latter effect was significant after three weeks only.

Occasionally enzyme values outside the reference range were observed and in some instances even pathologically high values were found.

Although these abnormal values did occur more frequently in the mackerel group $(p=0.04$, Fishers exact test, ref. 18), the inconsistency of these values with regard to volunteers and points in time indicate that the fish supplement did not have a systematic adverse effect on the integrity of liver and heart- and skeletal muscle. 


\section{Other biochemical parameters in serum}

With regard to total protein, albumin, urea, creatinine, and calcium content of serum, some significant changes occurred during the experimental period. However, these changes were not consistent for the various centers and, moreover, no significant differences were observed between the mackerel and the control group, except for creatinine after 6 weeks in Maastricht and for urea after 6 weeks in Tromsø (Table 8). Therefore it can be concluded that, in general, the fish supplement did not affect these biochemical serum parameters in any specific way.

\section{Urine analysis}

At the start of the experiment a significant difference existed between the mackerel and control groups as to the amount of potassium excreted in urine (Table 9). During the experiment, some significant changes occurred within the experimental centers as to the urinary excretion of potassium, sodium or creatinine. However, these changes were always comparable for the mackerel and the control groups. As to creatinine clearance no significant changes were observed during the experimental period either within or between the groups. These findings clearly indicate that an influence of the fish supplement on kidney function was unlikely.

\section{Discussion}

Many studies have been published with respect to the effects of fish or fish oil on the possible prevention of ischemic cardiovascular disease in man. Most of those investigations, however, lacked a proper control group and/or were performed under extreme dietary conditions. In several trials fish products were given as a drug, not as a constituent of the normal diet.

This study investigated the effect of a reasonable amount of fish in the diet on some aspects of the cardiovascular risk profile in healthy males. The main purpose of this investigation was to perform a well controlled study without the drawbacks of earlier ones, which lacked a proper control group and/or were performed under extreme dietary conditions. Therefore a detailed description of this experimental design is given.

To provide each volunteer with exactly the same daily amount of fish (or meat in the control group), standardized canned products were given as a supplement to the normal diet. The use of canned products also gave the opportunity to add lithium, which was used as a dietary marker to check compliance. The maximum lithium intake per day was about 100 times the naturally (dietary) available lithium and yet represented only a minute $\left(10^{-2}\right)$ proportion of the therapeutic dose (14).

In both groups compliance decreased over time. In the fish group this decrease was somewhat more pronounced than in the control group. This finding demonstrates that the obligatory consumption of rather small amounts of fish and meat, prepared 
as in this study, is difficult to maintain.

In general, correction for compliance did not improve the level of significance of the differences between mackerel and control groups.

From eight available lots of mackerel we choose the one which assured the highest daily intake of timnodonic acid $(1.7 \mathrm{~g})$ and cervonic acid $(3.0 \mathrm{~g})$. The intake of docosenoic acids $(4.1 \mathrm{~g} /$ day) was rather high compared with international recommendations $(19,20)$. However, as has been pointed out by Ackman et al (21), current concern as to the impact of dietary docasaenoic acids on the human myocardium is based largely on animal feeding studies, the results of which are equivocal. Absolute proof that dietary long chain monoenes are without adverse effects in man requires histopathological studies in humans. As long as such data are not available, the consequences of a higher intake of eicosenoic and docosenoic acids accompanying an increased fish consumption should receive proper attention.

Although the blood pressure of traditionally living Greenland Eskimos is not different from that of mainland Danes ( $J$. Dyerberg, personal communication), some Japanese epidemiological data suggest a weak association between a high fish consumption and a lower blood pressure (1). In another Japanese study, however, such an association was not observed (22). Of the human studies which reported a decrease in systolic blood pressure upon fish(oil) consumption, all except two (23, 24) have been performed without adequate controls (25-28). Therefore it cannot be excluded that other factors than the fish(oil) were involved in the changes in blood pressure observed in these studies.

In our trial, blood pressure decreased in the experimental group but also in the control group (Figs 2 and 3). This decrease might have been caused by the fact that the volunteers got used to the experimental circumstances. Without a control group, we would have concluded that the decrease in systolic blood pressure was caused by the fish supplement. However, there was no difference in the blood pressure response between the experimental and control groups and, therefore, no evidence has been obtained for a decrease in blood pressure induced by the fish paste. This demonstrates the great importance of a proper control group in dietary trials.

The prolongation of bleeding times (Fig 4) indicates that dietary factors are able to modulate the interaction of platelets with the vessel wall. Our findings parallel epidemiological observations in Greenland Eskimos (2) and in a Japanese fisheating population (22). Our results are also in agreement with those of three other well-controlled feeding trials $(23,29,30)$. In another two, however, no significant effect on cutaneous bleeding time was observed $(31,32)$. In most of the non- or poorly controlled studies, the bleeding times were shown to be prolonged upon the administration of fish, fish oil, or fish oil concentrates (6).

Initial bleeding times in Maastricht were longer than in Troms $\varnothing$ and Zeist. This is 
probably due to slight inter-individual differences in the way the bleeding time measurements were performed.

Prolongation of the bleeding times in association with fish supplementation was strongest in Troms $\varnothing$. This is difficult to understand because of the higher habitual fish consumption and the lower compliance. However, it should be noted that the habitual fish consumption in Tromsø concerns mainly lean fish.

In most of the human studies reported earlier, no effect of marine food or fish oil on $\mathrm{Hb}$ values has been observed $(9,22,23,31,33-36)$. One case of anemia has been reported but this occurred under extreme dietary conditions (13). Although we noticed a significant decrease in $\mathrm{Hb}$ (Table 5), the lower values are still well within the reference range. Therefore this finding is hardly of physiological relevance.

No significant differences were observed in RBC and other erythrocyterelated parameters, which is in line with studies reported by others $(9,22,25,26$, $31,33,34,37)$. Therefore, a systematic effect, of the fish supplement on red-cell physiology is unlikely.

The WBC was not altered in our study, which is in agreement with two earlier reports $(23,26)$. In patients suffering from ischemic heart disease, fish-oil administration has been reported to lower WBC (9). However, the study in question lacked a control group, and moreover, the lower values remained within the reference range. Therefore, fish(oil) consumption is unlikely to affect WBC.

In het mackerel groups the platelet counts invariably decreased (Fig 5). A comparable effect of fish(oil) had been observed in several other studies $(9,13,25,29,38$, $39,40)$. However, the platelet counts remained well within the reference range. It is unlikely that the lower platelet counts at week 6 caused the prolongation of the bleeding time in the mackerel group, since we did not find a relationship between the decrease in platelet count and the prolongation of the bleeding time during the experiment. Moreover, no correction existed between the initial platelet counts (range $135-327.10^{9} / 1$ ) and the initial bleeding times.

Apart from $\mathrm{BCHE}$, no differences were observed between the mackerel and the control group as to the level of a number of serum enzymes (Table 7). The meat paste clearly increased $\mathrm{BCHE}$ activity whereas the fish paste tended to decrease it. The meaning of this observation is not clear and requires further investigation. It should be noted that the meat paste was given during the run-in period also. Therefore, the initial BCHE value (at week 0 ) was likely to be elevated already. Consequently, the fish effect on BCHE-activity can be considered a return to pre-experimental values and not an actual decrease.

On the basis of the results obtained for the other enzymes we conclude that the dietary supplement did not induce cellular damage to liver or to heart- and skeletal 
muscle. Moreover, we found no evidence (Tables 8 and 9) for an effect of the fish supplement on kidney function.

\section{Acknowledgements}

Statistical analyses were performed by Dr. A. Kester, Department of Medical Information and Statistics, Limburg University, Maastricht, The Netherlands. We gratefully acknowledge the skillful technical assistance of $\mathbf{A}$. Hennissen and J. Stegen (Maastricht), B. Svensson, A. Vartun, V. Lyngmo and B. Sundsfjord (Troms $\emptyset$ ), H. v.d. Weerd, J.A. Wesstra, and Dr. W. v. Dokkum (Zeist).

Financial support was obtained from The Netherlands Heart Foundation, the Norwegian Research Council for Fisheries and the Norwegian Cardiovascular Research Coumcil.

The International Society of Fish Meal Manufactures (Potters Bar, Herts, England) provided the mackerel used in this study.

\section{References}

1. Kagawa $Y$, Nishizawa M, Suzuki M, Miyatake T, Hamamoto T, Goto K, Motonaga E, Izumikawa $\mathbf{H}_{4}$. Hirata $\mathbf{H}$, Ebihara $\mathbf{A}$. Eicosapolyenoic acid of serum lipids of Japanese islanders with low incidence of cardiovasculai diseases. J Nutr Sci Vitamol 1982; $28: 441-453$.

2. Kromann N, Green A. Epidemiological studies in the Upernavik district, Greenland. Incidence of some chronic diseases. 1950-1974. Acta Med Scand 1980; 208: $401-406$.

3. Kromhout D, Bosschieter EB, Lezenne Coulander $\mathbf{C}$ de. The inverse relation between fish com sumption and 20-year mortality from coronary heart disease. N Engl J Med 1985; 312: 1205-1209.

4. Hornstra G. Dietary fats, prostanoids and arterial thrombosis. Chapter 7: Effect of fish oill feeding on arterial thrombosis, platelet function and blood coagulation. Martinus Nijhoff Publ. The Hague 1982: $106-137$.

5. Mornstra G. Dietary lipids, platelet function and arterial thrombosis in animals and man. Proc Nuti Soc $1985 ; 44: 371-378$.

6. Hornstra $G$. The significance of fish and fish-oil enriched food for prevention and therapy of ischaemic cardiovascular disetse. In: Crawford MA, Vergroesen AJ (eds). The role of fats in hu. man nutrition III. Academic Press, London (in press).

7. Herold PM, Kinselta JE. Fish oil consumption and decreased risk of cardiovascular disease: a comparisom of findings from animal and human feeding trials. Am J Clin Nutr 1986; 43: 566-598.

8. Gudbjamason $\mathrm{S}$, Hallgrimson $\mathbf{J}$. The role of myocardial membrame lipids in the development of cardiac necrosis. Acta Med Scand (Suppl 587) 1976: 17.27. 
9. Hay CRM, Durber AP, Saynor R. Effect of fish oil on platelet kinetics in patients with ischaemic heart disease. Lancet 1982; i: 1269-1272.

10. Hornstra G, Hadleman E, Kloeze J, Verschuren PM. Dietary-fat-induced changes in the formation of prostanoids of the 2 and 3 series in relation to arterial thrombosis (rat) and atherosclerosis (rabbit). Adv Prost Thrombox Leukotr Res 1983; 12: 193-202.

11. Lee TH, Hoover RL, Williams JD, Sperling RI, Ravalese J, Spur B, Robinson DR, Corey E., Lewis RA, Austen KF. Effect of dietary enrichment with eicosapentaenoic and decosahexaenoic acids on in vitro neutrophil and monocyte leukotriene generation and neutrophil function. N Engl J Med 1985; 312: $1217-1224$.

12. Ruiter A, Jongbloed AW, Van Gent CM, Danse LHJX, Metz SHM. The influence of dietary mackerel oil on the condition of organs and on blood lipid composition in the young growing pig. Am J Clin Nutr 1978; $31: 2159-2166$.

13. Sinclair HM. Advantages and disadwantages of an Eskimo diet. In: Fumigalli $R$, Kritchevski $D$, Paoletti R, eds. Drugs affecting lipid metabolism. Elsewier/North Holland Biomedical Press, A.msterdam $\llbracket 980: 363-370$.

14. Sanchex-Castill CP, James WPT. The use of lithium as a marker of sodium intake. Proc Nutr Soc 1983; 42: 168 (abstract).

15. FAO/WHO. Guide to codex maximum limits for pesticide residues. Ist Issue. CAC/PR Rronie $1978 ; 1: 63 \cdot 166$.

16. McCutcheon EP, Baker DW, Wiederhielm CA. Frequency spectrum changes of Korotkoff sounds with muffling. Med Res Eng 1969, 8: 30-33.

17. Miller RG. Sinultaneous statistical inference. 2nd ed.; Springer Verlag, New York 1981.

18. Fleiss JL. Statistical methods for rates and proportions. 2nd ed.; Wiley, New York 1981: 25 .

19. Anonymous. Consolidated Regulations of Canada. 1978; 7 C 870, B.09.022.

20. Anonymous. Official Journal of the European Communities L 202, 1976; 35-37.

21. Ackman RG, Eaton CA, Dyerberg J. Marine docosenoic acid isomer distribution in the plasma of Greenland Eskimos. Am IClin Nutr 1980; 33: 1814-1817.

22. Hirai A, Terano T, Saito H, Tamura $\mathbf{Y}$, Yoshida S. Eicosapentaenoic acid and platelet function in Japanese. In: Lovenberg W, Yamori $Y(e d s)$. Nutritional prewention of cardiovasculair disease. Academic Press, London 1984: 231-239.

23. Mortensen JZ, Schmidt EB, Nielsen AH, Dyerberg J. The effeci of ( $n-6)$ and (n-3) polyunsaturated fatty acids on hemostasis, blood lipids and blood pressure. Thromb Haemostas 1983; 50: 543-546.

24. Singer $\mathbf{P}$, Berger I, Luck $\mathbf{K}$, Taube $\mathbf{C h}$, Naumann $\mathbf{E}$, Godicke $\mathbf{W}$. Long-term effect of mackerel diet on blood pressure, serum lipids and tromboxane formation in patients with mild essential hypertension. Atherosclerosis 1986; 62: 259-265.

25. Lorentz $\mathbf{R}$, Spengler $\mathbf{U}$, Fischer $\mathbf{S}$, Duhm $\mathbf{J}$, Weber $\mathbf{P}$. Platelet function, thromboxane formation and blood pressure control during supplemention of the western diet with cod-liver oil. Circulation 1983; 67: $504-511$. 
26. Sanders TAB, Vickers M, Haines AP. Effect on blood lipids and haemostasis of a supplement of cod-liwer oll, rich in eicosapentaenoic and docosabexaenoic acids, in healthy young men. Clin SCi $1981: 61: 317-324$.

27. Singer $P$, Jaeger $W$, Wirth M, Voight S, Naumann, Zimontkow si S, Hadju I, Goedicke W. Lipid and blood pressure-lowering effect of mackerel diet in man. Atherosclerosis 1983; 49: 99-108.

28. Singer P, Wirth M, Voigt S, Zimontkowski G, Godicke W, Heine H. Clinical studies on lipid and blood pressure lowering effect of eicosapentaenoic acid-rich diet. Biomed Biochim Acta 1984; 43: S421-425.

29. Goodnight SH Jr, Harris WS, Connor WE. The effect of dietary n-3 fatty acids on platelet composition and function in man: a prospective, controlled study. Blood 1981; $58: 880-885$.

30. Kremer JM, Bigaouette J, Michalck AV, Timchalk MA, Lininger $\mathbb{L}$, Rynes RI, Huyck C, Zieminski J, Bartholomew LE. Effects of manipulation of dietary fatty acids on clinical manifestations of rheumatoid arthritis. Lancet 1985; ii: 184-187.

31. Brox JH, Killie JE, Gunnes S, Nordgy A. The effect of cod-liver oil and corn oil on platelets and vessel wall in man. Thromb Haemostas 1981; 46: 604-611.

32. Simons LA, Hickie JB, Balasubramaniam S. On the effects of dietary (n-3) fatty acids (Maxepa) on plasma lipids and lipoproteins in patients with hyperlipidaemid. Atherosclerosis $1985 ; 54: 75-88$.

33. Bronsgeest-Schoute HC, Van Gent CM, Luten JB, Ruiter A. The effect of various intakes of n-3 fatty acids on the blood lipid composition in healthy human subjects. Am $\mathbb{I}$ Clin Nutr 1981; 34: $1752-1757$.

34. Terano T, Hirai A, Hamazaki T, Kobayashi S, Fujita T, Tamura Y, Kamagai A. Effect of oral administration of highly purified eicosapentaenoic acid on platelet function, blood viscosity ${ }_{n}$ and red cell deformability in healthy human subjects. Atherosclerosis 1983; 46: 321-331.

35. Harris WS, Connor WE. The effects of salmon oil upon plasma lipids, lipoproteins and triglyceride clearance. Trans Assoc Am Physicianss 1980; 43: 148-155.

36. Woodcock BE, Smit E, Lambert WH, Morris Jones W, Galloway JH, Greaves M, Preston FE. Beneficial effects of fish oil on blood viscosity in peripheral vascular disease. Br Med J 1984; 288: $592-594$.

37. Sanders TAB, Naismith DJ, Haines AP, Vickers M. Cod liver oil, platelet fatty acids, and bleeding times. Lancet 1980; ii: 1189-1195.

38. Harris WS, Connor WE, Goodnight SJ Jr. Dietary fish oils, plasma lipids and platelets in man. Progr Lip Res 1981; 20; 75-79.

39. Saymor R, Verel D. Effect of a marine oil high in eicosapentaenoic acid on blood lipids and coagulation. IRCS Med Sei 1980; 8: 378-379.

40. Saynor $\mathbf{R}$, Verel $\mathbf{D}$, Gillot $T$. The long term effect of dietary supplementation with fish lipid concentrate on serum lipids, bleeding time, platelets and angina. Ahterosclerosis 1984; 50: 3-10. 


\section{Addendum}

This is the first publication of the International Working Party 'Fisl against thrombosis?' coordinated by Dr. G. Hornstra, Limburg University, Department of Biochemistry, P.O. Box 616, $6200 \mathrm{MD}$ Maastricht, The Netherlands.

The aim of this working party is to investigate the effect of reasonable amount of fish in the diet of healthy wolunteers on platelet function and biochemistry and on parameters related to blood pressure and serum lipids.

The 'experimental centers' participating in the working party were completely autonomous. They organized the intervention trial in their own way and according their own local standards, but following a detailed technical protocol that had been agreed upon by the members of the working party.

Moreover, the working party organized the central measurements of most of the parameters in various specialized 'analytical centers', thereby optimizing the comparability of the three different studies and minimizing the analytical variance which is inevitable between warious institutes. Where possible, the working party provided the opportunity for 'satellite centers" to take part in the study, either by offering access to the volunteers during the study, or by making available samples for special analyses.

In this working party the following institutes cooperate:

\section{Experimental centers}

- Department of Medicine, University Hospital, Uniwersity of Troms $\varnothing$, P.O. Box 977,9012 Troms $\varnothing$, Norway.

Prof.Dr. A. Nord $\varnothing y$ MD, T. Simonsen MD.

- TNO-CIVO Toxicology and Nutrition Institute, P.O. Box 360, 3700 AJ Zeist, The Netherlands.

Prof.Dr.Ir. R.J.J. Hermus, E.J. v.d. Beek MD.

- Departments of Biochemistry and Human Biology, Limburg University, P.O. Box 616, 6200 MD Maastricht, The Netherlands.

Dr. G. Hornstra, A.C. v. Houwelingen MD.

\section{Analytical centers}

- Unilever Research, Department of Biosciences, Nutrition and Safety, P.O. Box 114, 3130 AC Vlaardingen, The Netherlands.

Dr. U.M.T. Houtsmuller, Dr. J.L. Zevenbergen, Dr. D.H. Nugteren.

- Departments of Biochemistry, Human Biology and Medical Statistics, Limburg University, P.O. Box 616, 6200 MD Maastricht, The Netherlands.

Dr. G. Hornstra, A.C. v. Houwelingen MD, Dr. A. Kester, A.D. Muller.

- Department of Clinical Chemistry, De Wever Hospital, P.O. Box 4446, 6401 CX Heerlen, The Netherlands.

Dr. M. de Metz.

- Gaubitis Institute TNO, Herenstraat 5d, 2313 AD Leiden, The Netherlands. Dr. J. Emeis.

- Medizinische Klinik Innenstadt der Universität München, Ziemussenstrasse 1, 8000 München 2,F.R.G.

Dr. S. Fischer. 


\section{Satellite centers}

- Department of Biochemistry 1, Erasmus University, P.O. Box 1738, 3000 DR Rotterdam, The Netherlands.

Dr. P.H.E. Groot.

- Department of Pathology, 3N 26G, McMaster University, Hamilton, Ontario Canada, L8N 325 .

Dr. M.L. Rand.

- Department of Haematology, Academic Hospital Utrecht, P.O. Box $16250,3500 \mathrm{CG}$ Utrecht, The Netherlands.

Prof. Dr, J.J. Sixma MD.

- Department of Pharmacology, Kings College, London Strand, London WC2R 2LS England.

Prof.Dr. G.V.R. Born.

- Malmöhus Läns Landsting Lunds Sjukvărdsdistrik Getingevägen 4, 22185 Lund, Sweden.

Dr. M. Thorngren. 


\section{A CONTROLLED STUDY ON THE EFFECTS OF A FISH-ENRICHED DIET ON SERUM LIPIDS AND APOPROTEINS}

\section{Summary}

In Maastricht and Zeist, The Netherlands, and Tromsø, Norway, a well controlled study was performed on the effect of a fish enriched diet on serum lipids, apoproteins A-1 and B, and the fatty acid compositions of serum triglycerides and cholesterolesters. For a 6 week period, 2 groups of 42 healthy male volunteers were given a daily dietary supplement consisting of $135 \mathrm{~g}$ of mackerel paste (experimental group) or meat paste (control group). Dietary adherence was calculated on the basis of urinary excretion of a standard amount of lithium, added to the supplements. Average compliance was ca. $80 \%$, which resulted in a daily intake of $1.4 \mathrm{~g}$ timnodonic acid (20:5 n-3) and $2.4 \mathrm{~g}$ cervonic acid (22:6 n-3) in the mackerel group.

LDL- and total serum cholesterol concentrations were unaffected. HDL cholesterol increased to a comparable degree in both the mackerel and the control group; thus no specific fish effect was observed. Triglyceride content of serum decreased in the fish group as compared with the control group.

Apolipoproteins A-1 and B (Maastricht only) were only slightly affected. In the mackerel group the $\mathrm{n}-3$ fatty acids increased significantly in the serum cholesterolesters and triglycerides; the n-6 fatty acids decreased in the cholesterolesters only.

Key words: dietary fish, cholesterol, triglycerides, cholesterolesters, apoproteins, fatty acid composition, serum. 


\section{Introduction}

Serum lipids are considered to be related to the incidence of coronary heart disease (1). Epidemiological data have revealed an association between the incidence of ischemic heart and vessel disease and the concentration of serum lipids (2).

Not only the amount but also the composition of the serum lipid fractions may give some information about the cardiovascular risk (3). Thus the atherogenicity of circulating cholesterol depends on the distribution of cholesterol over each class of lipoproteins (4).

In addition, serum levels of apoproteins A-1 and B may be even more strongly related to cardiovascular risk than their respective lipoprotein-cholesterol fractions, as clinical studies have suggested (5).

The type of dietary fat is an important determinant of serum lipid concentration in man. Marine diets rich in n-3 polyunsaturated fatty acids claimed to be associated with a lower incidence of cardiovascular disease (6), are thought to lower serum lipids. This has been observed in epidemiological as well as in intervention studies. This latter evidence, however, is equivocal except for triglycerides. We therefore investigated the influence of a fish-enriched diet on serum lipids, apoproteins A-1 and $B$ and the fatty acid composition of serum triglycerides (TG) and cholesterolesters (CE).

\section{Materials and methods}

The study was carried out within the framework of the International Working Party 'Fish against thrombosis?'. The design of the study has been described in detail before (7) and is briefly recapitulated below.

Eighty-four healthy male volunteers between 20 and 45 years of age entered the study, which was performed in three different centers, viz. Maastricht $(2 \times 20)$ and Zeist $(2 \times 10)$, both in The Netherlands, and Troms $\varnothing(2 \times 12)$ in Norway. The volunteers were randomised in an experimental and a control group on the basis of screening values for serum triglyceride content as the primary criterion and systolic blood pressure as the secondary criterion.

The study lasted for eight weeks; a run-in period of two weeks during which each volunteer consumed one tin of meat paste $(135 \mathrm{~g})$ per day and an experimental period of 6 weeks, during which the experimental group consumed one tin of mackerel paste $(135 \mathrm{~g})$ per day, whereas the control group continued the meat consumption. The fatty acid composition of the dietary supplements is given in Table 1. The mackerel paste provided $1.7 \mathrm{~g}$ timnodonic acid $(20: 5 \mathrm{n}-3)$ and $3.0 \mathrm{~g}$ cervonic acid (22:6 n-3) per day. The cholesterol content of the mackerel paste was $62.9 \mathrm{mg} / \mathrm{tin}$ and that of the meat supplements $33.8 \mathrm{mg} / \mathrm{tin}$.

Compliance was calculated on the basis of the daily urinary excretion (\%) of a standard amount of lithium, added to the supplements. The maximum lithium intake 
Table 1. Fatty acid composition (\% of total farty acids) of the dietary supplements. Mean and SEM of 4 independent measurements.

\begin{tabular}{lrr}
\hline Fatty acid & Mackerel paste & Meat paste \\
\hline $12: 0$ & & $0.1 \pm 0.01$ \\
$14: 0$ & $7.5 \pm 0.16$ & $2.3 \pm 0.04$ \\
$16: 0 \mathrm{dma}^{\text {b }}$ & $15.2 \pm 0.18$ & $0.4 \pm 0.06$ \\
$16: 0$ & $0.8 \pm 0.10$ & $24.3 \pm 0.16$ \\
$16: 1 \mathrm{n}-\mathrm{b}$ & $3.8 \pm 0.10$ & $3.6 \pm 0.04$ \\
$16: 1 \mathrm{n}-7$ & & $0.6 \pm 0.03$ \\
$17: 0$ & $2.4 \pm 0.04$ & $13.5 \pm 0.22$ \\
$18: 0$ & $0.4 \pm 0.17$ & $0.5 \pm 0.02$ \\
$18: 1 \mathrm{dma}$ & $9.4 \pm 0.35$ & $41.7 \pm 0.39$ \\
$18: 1 \mathrm{n}-9$ & $2.2 \pm 0.16$ & $9.6 \pm 0.26$ \\
$18: 1 \mathrm{n}-7$ & $2.2 \pm 0.03$ & $1.0 \pm 0.02$ \\
$18: 2 \mathrm{n}-6$ & $0.1 \pm 0.06$ & $0.1 \pm 0.01$ \\
$18: 3 \mathrm{n}-3$ & $5.3 \pm 0.12$ & $0.1 \pm 0.00$ \\
$18: 4 \mathrm{n}-3^{b}$ & & \\
$20: 0$ & $3.0 \pm 0.11$ & $0.7 \pm 0.02$ \\
$20: 1 \mathrm{n}-11$ & $8.8 \pm 0.26$ & $0.5 \pm 0.03$ \\
$20: 1 \mathrm{n}-9$ & $1.2 \pm 0.03$ & \\
$20: 4 \mathrm{n}-6$ & $7.1 \pm 0.22$ & \\
$20: 5 \mathrm{n}-3$ & $15.5 \pm 0.27$ & $0.7 \pm 0.03$ \\
$22: 1 \mathrm{n}-11$ & $0.9 \pm 0.02$ & $0.2 \pm 0.02$ \\
$22: 1 \mathrm{n}-9$ & $0.6 \pm 0.20$ & \\
$22: 4 \mathrm{n}-6$ & $0.7 \pm 0.24$ & \\
$22: 5 \mathrm{n}-3$ & $10.6 \pm 0.34$ & \\
$22: 6 \mathrm{n}-3$ & $2.3 \pm 0.12$ & \\
Unidenified & & \\
\hline & & \\
& &
\end{tabular}

a: In the nomenclature used for fatty acids, the figure before the colon indicates the numer of carbon atoms and that after the colon ${ }_{n}$ the number of double bonds. The final number refers to the position of the first double bond, counting from the methyl end of the carbon chair

b: Tentative identification

c: dma = dimethylacetal

per day was about 100 times the amount naturally available in the diet and yet represented only one percent of the therapeutic dose (8). Lithium recovery was also calculated in relation to urinary creatinine excretion. To correct for a possible influence of inaccuracies during urine collection and to minimize the influence of differences in body mass and sudden changes in exercise level, both compliance indices were multiplied, resulting in a variable (the compliance index) which was used to investigate possible relationships between dietary adherence and diet induced changes in serum lipids, apoproteins and fatty acid composition of serum triglycerides and cholesterolesters. 
At week zero (the end of the run-in period), week 3 and week 6 , blood was drawn under fasting conditions, after the volunteers had been resting for $20 \mathrm{~min}$ in a supine position. Under minimum stasis a forearm vein was punctured, using a $19 \mathrm{~g}$ butterfly-venisystem, and a series of blood samples were taken for various measurements (7). Ten $\mathrm{ml}$ of blood were taken in a monovette syringe (Sarstedt, Numbrecht, FRG, no. 021063) for serum preparation. The blood was allowed to clot at room temperature for $60 \mathrm{~min}$, after which the Monovette was centrifuged (15 min 3000 $\mathrm{x} \mathrm{g}$ ). The serum was collected carefully and 2 portions of $0.5 \mathrm{ml}$ each were transferred into Eppendorf tubes (Greiner, Nurtingen, FRG, no. 616201), and transported on dryice to Rotterdam (Erasmus University, Department of Biochemistry) for apoprotein determinations. The remainder of each serum sample was stored in a properly sized plastic tube at $-20^{\circ} \mathrm{C}$ until transported on dry ice to Unilever Research, Vlaardingen, The Netherlands, for analysis of serum lipids and the fatty acid compositions of serum TO and CE.

After the samples had adjusted to room temperature, serum lipids were analysed using a programmable Vitatron PA 800 automatic analyser (Meyvis, Bergen op Zoom, The Netherlands) and commercial test kits according to the manufacturer's instructions (triglyceride: Boehringer Mannheim, FRG, no 124133; total cholesterol: Boehringer Mannhein, no 237574; HDL cholesterol: Bio Merieux, Wilnis, The Netherlands, no 6531). LDL cholesterol was calculated by applying the Friedewald equation (9).

Apolipoprotein A-1 (Apo A-1) was measured by radial immunodiffusion (10) and apolipoprotein B (Apo B) was determined by rocket immunoelectrophoresis (11). Monospecific antisera against human apoprotein $A-11$ and apoprotein $B$ were raised in goats using pure Apo A-1 and pure Apo B in LDL as antigens. The gel plates for Apo A-1 assay contained 1\% agarose, $0.01 \% \mathrm{NaN}_{3}, 30 \mathrm{mM}$ sodium barbital buffer ( $\mathrm{pH} 8.6)$ and $1.16 \%$ antiserum. Serum samples to be measured were delipidated with tetramethylurea and diluted with urea solutions as described by Groot et al (10). The applied samples were allowed to diffuse into the antiserum-containing gel during a 44 to $64 \mathrm{~h}$ period at $37^{\circ} \mathrm{C}$ in a humid chamber. The ring-shaped immunoprecipitates were stained and quantified, using a measuring projector designed for this purpose (10). The Apo B electrophoresis was performed at $\mathrm{pH} 8.6$ using $0.8 \%$ agarose in $50 \mathrm{mM}$ diethylbarbiturate buffer as supporting medium for the antiserum. Undelipidated serum samples were analysed in three dilutions (11).

Standards for both immunoassays consisted of dilutions of freshly thawn batches of a pool of human sera $(10,11)$. The absolute concentration of Apo B in the standard was determined as described earlier (11). Concentrations of Apo A-1 are expressed in relative terms only.

For fatty acid analysis, lipids were extracted according to Bligh and Dyer (12). Triglycerides and cholesterolesters were isolated from the extracts by means of thin layer chromatography (TLC), essentially according to Christie (13). Fatty acids were 


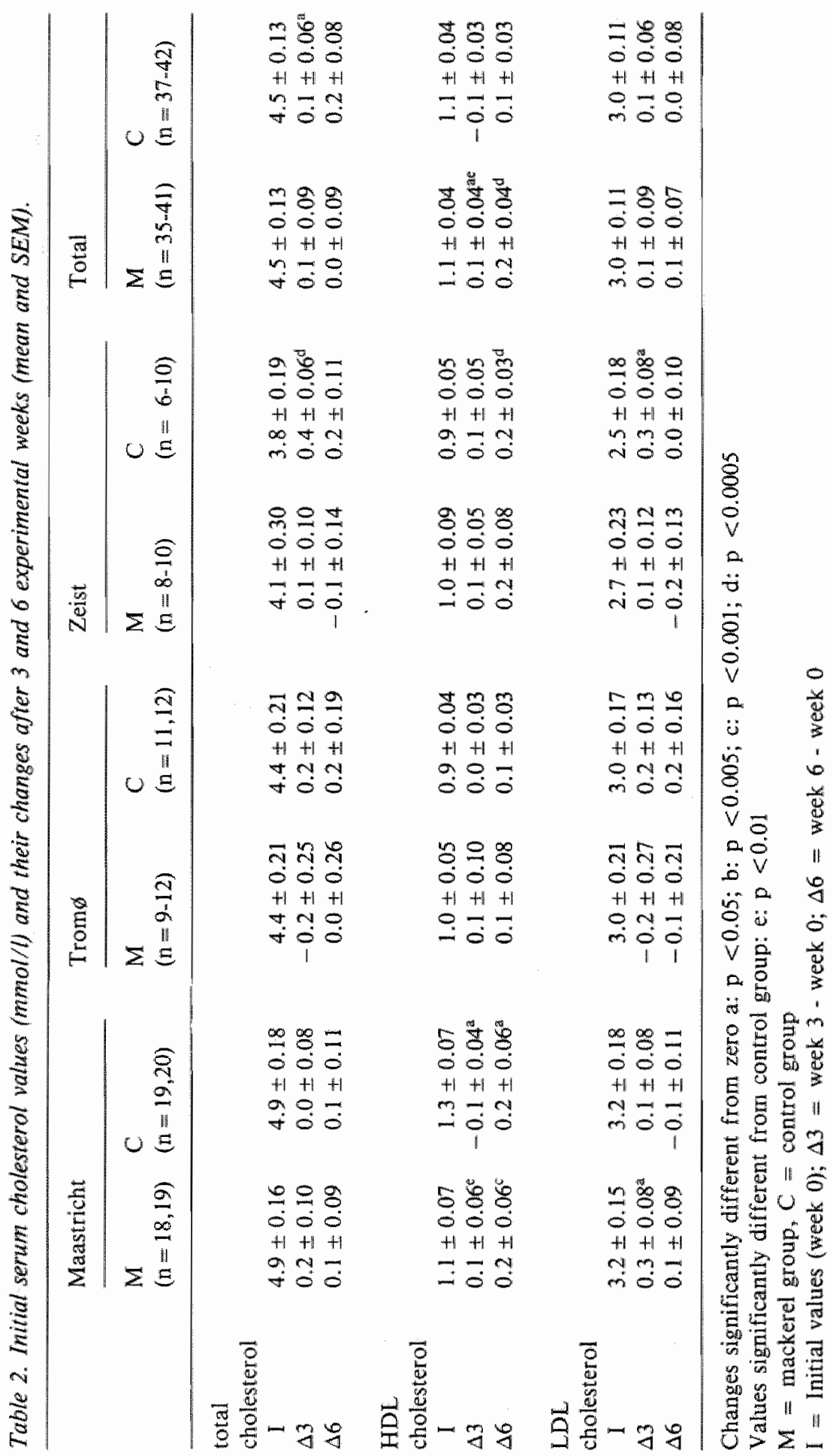


Table 3. Screening values and Initial values of serum triglyceride (mmol/t; mean and SEM).

\begin{tabular}{llllr}
\hline Center & Group (n) & \multicolumn{1}{l}{$\mathrm{S}$} & \multicolumn{1}{l}{$\mathrm{D}$} \\
\hline Masastricht & $\mathrm{M}(19)$ & $1.01 \pm 0.08$ & $1.39 \pm 0.14$ & $0.39 \pm 0.10^{\mathrm{a}}$ \\
& $\mathrm{C}(20)$ & $0.98 \pm 0.08$ & $1.09 \pm 0.13$ & $0.11 \pm 0.10$ \\
Troms & $\mathrm{M}(12)$ & $0.83 \pm 0.07$ & $0.77 \pm 0.06$ & $-0.06 \pm 0.10$ \\
& $\mathrm{C}(12)$ & $0.84 \pm 0.08$ & $0.99 \pm 0.10$ & $0.14 \pm 0.11$ \\
Zeist & $\mathrm{M}(10)$ & $0.86 \pm 0.08$ & $0.94 \pm 0.08$ & $0.07 \pm 0.10$ \\
& $\mathrm{C}(10)$ & $0.82 \pm 0.07$ & $0.82 \pm 0.06$ & $0.00 \pm 0.07$ \\
Total & $\mathrm{M}(41)$ & $0.91 \pm 0.05$ & $1.10 \pm 0.08$ & $0.18 \pm 0.06^{2}$ \\
& $\mathrm{C}(42)$ & $0.90 \pm 0.05$ & $1.00 \pm 0.07$ & $0.10 \pm 0.06$ \\
\hline
\end{tabular}

$M=$ mackerel group

$\mathrm{C}=$ control group

$\mathrm{S}=$ Screening values

$I=$ Initial values

$\mathrm{D}=\mathrm{I}-\mathrm{S}$

a: Value significantly different from zero: $p<0.005$

No significant differences between mackerel and control groups

methylated and purified by another TLC step (13). Subsequently the fatty acid pattern was determined on a Perkin Elmer $8320 \mathrm{~B}$ gas chromatograph and FID detection using a $50 \mathrm{~m}$ CBSill 88 capillary column.

\section{Statistical evaluation}

The data were checked for their frequency distribution and, when necessary, transformation was used to normalize the distribution. Subsequently, significant outliers were omitted.

Student's 1-sample t-test for paired data was used to evaluate the changes occurring. after 3 and 6 weeks within the mackerel and control groups. Differences between the mackerel and control groups were evaluated using Student's 2-sample t-test. Differences were considered significant when the two sided probability (p) was 0.05 or less.

\section{Results}

During the study no side effects of the dietary supplements were observed, however, a few subjects experienced some difficulties in consuming the required amount of the dietary supplements. In Troms $\emptyset$ one person dropped out because he developed a strong aversion to the mackerel paste. The average dietary compliance was $78 \%$ for the mackerel group and $85 \%$ for the control group. Results from one volunteer had to be discarded because of very poor compliance. 


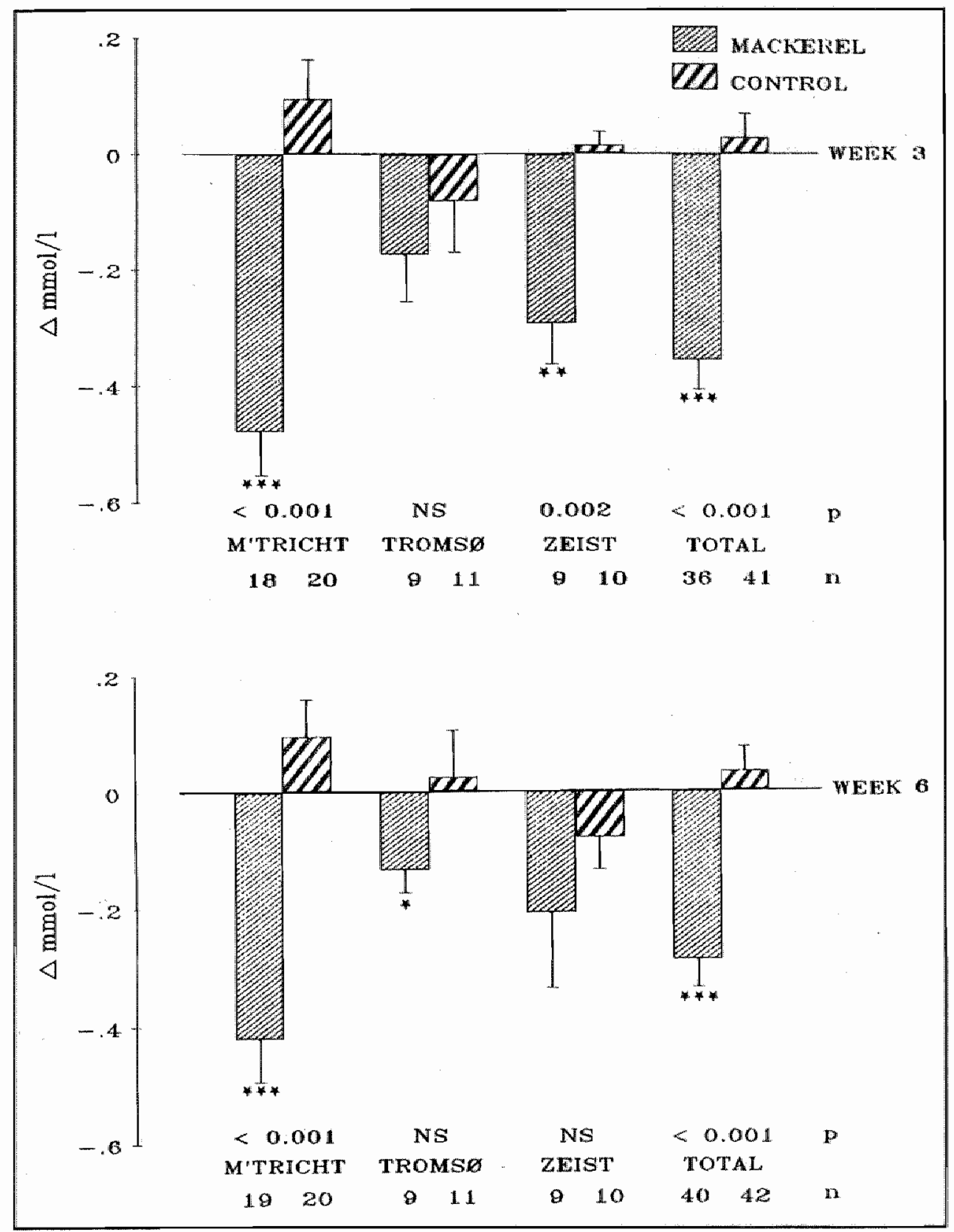

Fig 1 . Change in serum triglyceride content ( $\Delta$ mmolll) after 3 and 6 experimental weeks (mean and SEM). p: significance of difference between mackerel and control groups. NS: not significant. Values significantly different from zero: ${ }^{*} p<0.01 ; * *<0.005 ; * * *<0.0001$. 


\section{Cholesterol}

Table 2 shows the initial total-, HDL-, and LDL cholesterol values and their changes after 3 and 6 experimental weeks. When all control subjects were taken together, a significant increase in total cholesterol was seen after 3 experimental weeks. After 6 weeks this increase was no longer significant. The same was observed for the control volunteers in Zeist. Notwithstanding these intra-group effects no significant differences were observed between the mackerel and the control group as to the total cholesterol content of the serum. HDL cholesterol increased significantly in the mackerel group compared with the control group at week 3 for Maastricht and for the total group of participants. Furthermore a significant decrease in HDL cholesterol was obserwed in Maastricht at week 3 in the control group.

At week 6, HDL cholesterol was found to be increased both in the mackerel and the control group in Maastricht and in the total group. In Zeist a significant increase was seen in the control group. Despite these effects no significant differences were observed between the control and mackerel groups.

In two instances (Maastricht-mackerel and Zeist-control) the calculated amount of LDL cholesterol showed a significant increase at week 3 , but no significant differences were found between the mackerel and control groups.

The same was true for the ratio LDL/HDL cholesterol (data not shown).

No significant correlations could be found between the changes in serum total-, HDL- and LDL cholesterol and the compliance index.

\section{Triglyceride}

Table 3 shows the screening values and the initial (week 0 ) values of serum total triglycerides, and in Fig 1 the changes after 3 and 6 experimentall weeks are shown. A decrease in serum triglycerides content was observed in the mackerel groups which was significant at week 3 for Maastricht, Zeist and the total group, and at week 6 for Maastricht, Tromsø and the total group. Significant differences between the mackerel and control groups were seen in Maastricht and for the three centers combined both at week 3 and 6 and in Zeist at week 3 only.

Initial values of the mackerel group in Maastricht were slightly higher as compared to the screening values. This was unanticipated, since the screening values were used to randomise placement of the volunteers in an experimental and a control group. Multiple regression analysis, in which the screening values were taken into account, showed that the decrease in TG in the Maastricht fish group was not due to the difference between the screening and week 0 .

The compliance index was not significantly correlated with the decrease in TG.

\section{Apolipoproteins}

The amounts of Apo A-1 and Apo B were measured in the serum samples of the Maastricht volunteers only. The initial values and their changes after 3 and 6 experimental weeks are shown in Table 4. For Apo A-1 no significant differences were 
Table 4. Initial concentrations of Apoprotein $A-1$ and $B$ in plasma and their changes $(\Delta)$ after 3 and 6 experimental weeks. Mean and SEM.

\begin{tabular}{llllll}
\hline Sample & Group & $\mathrm{n}$ & $\begin{array}{l}\text { Apolipropotein } \\
\text { A-1 } \\
(\% 0 \text { of serum pool) }\end{array}$ & $\mathrm{n}$ & $\begin{array}{l}\text { Apolipoprotein } \\
\text { B } \\
(\mathrm{mg} / 100 \mathrm{mI})\end{array}$ \\
\hline Initial & mackerel & 19 & $97.2 \pm 4.00$ & 19 & $86.7 \pm 4.58$ \\
& control & 20 & $93.7 \pm 2.48$ & 19 & $93.9 \pm 4.87$ \\
$\Delta 3$ & mackerel & 19 & $-1.9 \pm 2.07$ & 19 & $-0.7 \pm 1.92$ \\
& control & 20 & $-0.6 \pm 3.44$ & 19 & $2.5 \pm 2.29$ \\
$\Delta 6$ & mackerel & 19 & $-0.6 \pm 1.92$ & 19 & $1.3 \pm 1.75$ \\
& control & 19 & $-2.6 \pm 2.88$ & 18 & $-5.9 \pm 2.39 \mathrm{at}$ \\
\hline
\end{tabular}

a: change significantly different from zero $(\mathrm{p}<0.005)$

$\mathrm{b}$ : value significantly different from control group $(\mathrm{p}<0.02)$

observed. A significant difference between the mackerel and control groups was measured in the change of Apo B at week $6(\mathrm{p}<0.02)$ However, this was mainly due to a decrease of Apo B in the control group.

The compliance index was not related to changes in Apo A- $[12,0]$ or Apo B. At week zero a significant correlation was found between the Apo A-1 and the HDL cholesterol values $(r=0.38 ; n=39 ; p=0.02)$. For Apo $B$ a strong relation was observed with the total serum cholesterol and the LDL cholesterol values obtained at weeks 0,3 and $6(\mathrm{p}<0.001)$.

\section{Fatty acid patterns}

Fatty acid compositions of serum cholesterolesters and triglycerides are shown in Table 5A and 5B, respectively. Due to technical failures, the results of 50 samples were availlable only. The fatty acid compositions were determined at week 0 and week 6 . The fish-related fatty acids timnodonic acid (20:5 n-3) and cervonic acid (22:6 n-3) increased significantly in the mackerel group in both lipid fractions $(\mathrm{p}<0.001)$. In the serum TG the other $\mathrm{n}-3$ fatty acids also increased significantly in the fish group, compared with the control group. In the $\mathrm{CE}$ fraction the $\mathrm{n}-3$ fatty acids replaced linoleic acid. In the TG fraction oleic acid (18:1 n-9) was replaced by the $n-3$ fatty acids. The ratio timnodonic/cervonic acid of the dietary supplements $(0.67)$ is better reflected by the ratio of these fatty acids in the TG fraction $(0.50)$ than in the CE fraction (5.0).

During the experimental period no significant changes were observed in the control group (except for 20:3 n-6 in the CE, which increased, but this may be coincidental). As can be seen from Table 5 a significant difference between the mackerel and control groups existed at week 0 for several minor fatty acids. In most cases these differences persisted throughout during the experimental period. 
Table 5. Fatty acid composition of serum cholesterolesters (\% of total) faty acids) at the start of the study (week 0 ) and the change $(\Delta 6)$ dwring the 6 week experimental period.

\begin{tabular}{|c|c|c|c|c|}
\hline \multirow{2}{*}{ Fatty acid } & \multicolumn{2}{|c|}{ Mackerel $(n=23)$} & \multicolumn{2}{|c|}{ Control $(n=27)$} \\
\hline & week 0 & change $(\Delta 6)$ & week 0 & change $(\Delta 6)$ \\
\hline $12: 0$ & $0.2 \pm 0.04$ & $-0.05 \pm 0.04$ & $0.1 \pm 0.02$ & $-0.00 \pm 0.03$ \\
\hline $14: 0$ & $0.9 \pm 0.06$ & $0.15 \pm 0.05^{\text {te }}$ & $0.8 \pm 0.04$ & $-0.01 \pm 0.04$ \\
\hline $16: 0$ & $12.0 \pm 0.22$ & $1.67 \pm 0.20^{d h}$ & $11.8 \pm 0.18$ & $-0.11 \pm 0.19$ \\
\hline 16:1 trans & $0.2 \pm 0.03$ & $0.13 \pm 0.02^{\mathrm{dn}}$ & $0.3 \pm 0.04$ & $-0.03 \pm 0.02$ \\
\hline $16: 1 \mathrm{n}-9 \mathrm{cis}$ & $0.7 \pm 0.03$ & $-0.06 \pm 0.02$ & $0.7 \pm 0.03$ & $-0.04 \pm 0.02$ \\
\hline $16: 1 \mathrm{n}-7 \mathrm{cis}$ & $2.4 \pm 0.21$ & $-0.50 \pm 0.11^{\mathrm{d} d}$ & $2.2 \pm 0.16$ & $0.10 \pm 0.11$ \\
\hline $16: 1$ cis rest & $0.1 \pm 0.02$ & $0.03 \pm 0.02^{\mathrm{a}}$ & $0.2 \pm 0.03$ & $-0.00 \pm 0.02$ \\
\hline $16: 2$ & $0.2 \pm 0.02^{\mathfrak{c}}$ & $-0.03 \pm 0.03$ & $0.3 \pm 0.03$ & $-0.02 \pm 0.03$ \\
\hline $18: 0$ & $2.1 \pm 0.14$ & $-0.23 \pm 0.12$ & $1.9 \pm 0.13$ & $-0.08 \pm 0.13$ \\
\hline $18: 1$ trans & $\mathrm{nd}^{\mathrm{h}}$ & & $0.1 \pm 0.02$ & $-0.02 \pm 0.02$ \\
\hline $18: 1 \mathrm{n}-9 \mathrm{cis}$ & $118.3 \pm 0.47$ & $-1.80 \pm 0.31^{\mathrm{dh}}$ & $17.6 \pm 0.40$ & $0.45 \pm 0.36$ \\
\hline $18: 1 n-7$ cis & $1.2 \pm 0.03$ & $0.06 \pm 0.05$ & $1.1 \pm 0.04$ & $0.00 \pm 0.02$ \\
\hline $18: 2 n-6$ & $53.8 \pm 0.85$ & $-5.22 \pm 0.65^{\mathrm{d} h}$ & $54.2 \pm 0.75$ & $-0.57 \pm 0.73$ \\
\hline $18: 3 n n-6$ & $0.5 \pm 0.04$ & $-0.21 \pm 0.03^{d h}$ & $0.5 \pm 0.03$ & $0.06 \pm 0.03$ \\
\hline $18: 3 n-3$ & $0.5 \pm 0.02^{n}$ & $0.01 \pm 0.03$ & $0.5 \pm 0.05$ & $-0.01 \pm 0.03$ \\
\hline $20: 3 n-6$ & $0.5 \pm 0.02$ & $-0.19 \pm 0.02^{\mathrm{dh}}$ & $0.5 \pm 0.03$ & $0.07 \pm 0.03^{a}$ \\
\hline $20: 4 n-6$ & $3.8 \pm 0.19$ & $0.19 \pm 0.19$ & $3.5 \pm 0.16$ & $0.31 \pm 0.15$ \\
\hline $20: 5 n-3$ & $0.5 \pm 0.07$ & $4.39 \pm 0.28^{\mathrm{dh}}$ & $0.4 \pm 0.05$ & $-0.02 \pm 0.04$ \\
\hline $22: 5 n-3$ & $0.3 \pm 0.16$ & $0.21 \pm 0.15$ & $0.6 \pm 0.20$ & $0.16 \pm 0.11$ \\
\hline $22: 6 n-3$ & $0.3 \pm 0.05$ & $0.80 \pm 0.06^{\mathrm{dhh}}$ & $0.2 \pm 0.03$ & $-0.01 \pm 0.03$ \\
\hline sum n-6 & $58.6 \pm 0.88$ & $-5.43 \pm 0.66^{\mathrm{dh}}$ & $58.7 \pm 0.81$ & $-0.10 \pm 0.86$ \\
\hline sum $n-3$ & $1.6 \pm 0.19$ & $5.42 \pm 0.37^{\mathrm{dh}}$ & $1.5 \pm 0.25$ & $0.11 \pm 0.13$ \\
\hline
\end{tabular}

tr: trace $(=<0.1 \%)$ nd: not detectable. Values significantly different from zero: a: $p<0.05$; b: $p<0.01 ; c: p<0.005$; $\mathrm{d}$ : $p<0.001$. Values significantly different from control group: e: $p<0.05$; $: p<0.01$; : $p<0.005$; h: $p<0.001$

\section{Discussion}

Epidemiological investigations and human intervention studies indicate that blood lipid levels are related to the risk of cardiovascular disease (1). Populations with a high fish consumption pattern show lower serum lipid concentrations than comparable populations with a low fish consumption. This is more pronounced for triglyceride than for cholesterol values $(14,15,16)$. In addition, epidemiological investigations demonstrate that the consumption of fish products is associated with a reduced mortality from ischemic heart disease (17). Consequently, it has been suggested that fish consumption is related to coronary heart disease through an effect on serum lipids (2). 
Table SB. Fatty acid composition of serwm triglycerides (\% of total fatty acids) at the start of the siudy (week 0 ) and the change $(\Delta 6)$ during the 6 week experimental period.

\begin{tabular}{|c|c|c|c|c|}
\hline \multirow{2}{*}{ Fatty acid } & \multicolumn{2}{|c|}{ Mackerel $(n=22)$} & \multicolumn{2}{|c|}{ Control $(n=27)$} \\
\hline & week 0 & change $(\Delta 6)$ & week 0 & change $(\Delta 6)$ \\
\hline $12: 0$ & $0.4 \pm 0.10$ & $-0.00 \pm 0.09$ & $0.5 \pm 0.07$ & $-0.14 \pm 0.07$ \\
\hline $14: 0$ & $2.2 \pm 0.25$ & $0.03 \pm 0.18$ & $2.3 \pm 0.20$ & $-0.16 \pm 0.13$ \\
\hline $16: 0$ & $28.2 \pm 0.58$ & $-1.12 \pm 0.62$ & $26.5 \pm 0.93$ & $-0.60 \pm 0.84$ \\
\hline $16: 1$ trans & $0.7 \pm 0.07$ & $0.23 \pm 0.06^{\mathrm{dhh}}$ & $0.6 \pm 0.06$ & $-0.03 \pm 0.04$ \\
\hline $16: 1 \mathrm{n}-9 \mathrm{cis}$ & $1.1 \pm 0.05$ & $0.00 \pm 0.04$ & $1.1 \pm 0.06$ & $-0.05 \pm 0.06$ \\
\hline $16: 1 \mathrm{n}-7 \mathrm{cis}$ & $3.0 \pm 0.14$ & $-0.34 \pm 0.13^{b}$ & $3.1 \pm 0.16$ & $-0.01 \pm 0.16$ \\
\hline $16: 1$ cis rest & $0.2 \pm 0.02^{\mathrm{g}}$ & $-0.05 \pm 0.03$ & $0.3 \pm 0.04$ & $0.01 \pm 0.06$ \\
\hline $16: 2$ & $0.4 \pm 0.05$ & $-0.01 \pm 0.06$ & $0.5 \pm 0.07$ & $0.05 \pm 0.12$ \\
\hline 18:0 & $5.7 \pm 0.39$ & $1.45 \pm 0.40^{\mathrm{r}}$ & $6.4 \pm 0.74$ & $-0.47 \pm 0.74$ \\
\hline $18: 1 \mathrm{n}-9$ trans & $0.3 \pm 0.12$ & $-0.15 \pm 0.12$ & $0.3 \pm 0.11$ & $0.05 \pm 0.12$ \\
\hline $18: 1$ trans rest & $1.7 \pm 0.41$ & $-0.45 \pm 0.42$ & $1.4 \pm 0.24$ & $0.13 \pm 0.13$ \\
\hline $18: 1 \mathrm{~m}-9$ cis & $34.1 \pm 0.67$ & $-5,65 \pm 0.65^{d h}$ & $33.3 \pm 0.96$ & $1.56 \pm 0.85$ \\
\hline $18: 1 \mathrm{n}-7 \mathrm{cis}$ & $2.1 \pm 0.13$ & $-0.31 \pm 0.12^{\mathrm{agg}}$ & $2.1 \pm 0.13$ & $0.17 \pm 0.09$ \\
\hline $18: 2 n-6$ & $15.7 \pm 0.77$ & $0.55 \pm 0.49$ & $15.6 \pm 0.70$ & $0.29 \pm 0.80$ \\
\hline $18: 3 n-3$ & $0.9 \pm 0.07^{\mathrm{e}}$ & $0.21 \pm 0.09^{\mathrm{aff}}$ & $0.7 \pm 0.08$ & $-0.110 \pm 0.08$ \\
\hline $18: 3 n-6$ & $\operatorname{tr}^{h}$ & $-0.01 \pm 0.01$ & $0.5 \pm 0.10$ & $-0.02 \pm 0.05$ \\
\hline $20: 1$ & $\mathrm{tr}^{\mathrm{h}}$ & $0.02 \pm 0.03$ & $0.1 \pm 0.03$ & $0.08 \pm 0.07$ \\
\hline $20: 1 \mathrm{n}-9$ & $0.2 \pm 0.03^{\mathrm{e}}$ & $0.15 \pm 0.05^{\mathrm{be}}$ & $0.1 \pm 0.03$ & $0.01 \pm 0.03$ \\
\hline $20: 3 n-6$ & $\mathrm{tr}$ & $-0.02 \pm 0.01$ & $\operatorname{tr}$ & $0.00 \pm 0.02$ \\
\hline $20: 3 n-9$ & $\mathrm{tr}^{\mathrm{e}}$ & $-0.05 \pm 0.02^{\mathrm{a}}$ & $0.2 \pm 0.03$ & $-0.03 \pm 0.02$ \\
\hline $20: 4 n-6$ & $0.7 \pm 0.05$ & $0.20 \pm 0.07^{a}$ & $0.7 \pm 0.04$ & $0.03 \pm 0.06$ \\
\hline $20: 5 \mathrm{n}-3$ & $0.1 \pm 0.02$ & $1.50 \pm 0.18^{\mathrm{dth}}$ & $0.2 \pm 0.04$ & $-0.07 \pm 0.04$ \\
\hline $22: 5 n-3$ & $0.2 \pm 0.03$ & $0.56 \pm 0.07^{\mathrm{dh}}$ & $0.2 \pm 0.04$ & $-0.03 \pm 0.03$ \\
\hline $22: 5 \mathrm{n}-6$ & $\operatorname{tr}$ & $0.08 \pm 0.02^{b h h}$ & $0.1 \pm 0.02$ & $-0.02 \pm 0.01$ \\
\hline $22: 6 n-3$ & $0.3 \pm 0.07$ & $2.97 \pm 0.34^{\mathrm{dh}}$ & $0.3 \pm 0.04$ & $-0.03 \pm 0.05$ \\
\hline sumin $n-6$ & $16.5 \pm 0.80$ & $0.80 \pm 0.50$ & $16.9 \pm 0.76$ & $0.29=0.83$ \\
\hline sum $n-3$ & $1.5 \pm 0.14$ & $5.25 \pm 0.61^{\mathrm{th}}$ & $1.4 \pm 0.12$ & $-0.23 \pm 0.14$ \\
\hline
\end{tabular}

Explanation see Table SA

\section{Cholesterol}

The results of intervention studies concerning the effect of fish (oil) enriched diets on the plasma cholesterol content are inconsistent. Although many studies (18-37) have shown a moderate lowering effect on serum cholesterol, an even greater number of trials $(36,38-65)$ showed no effect. There have been, indeed, seven reports of an increase in plasma cholesterol (66-72).

In the present study no significant influence of the fish supplements could be observed for total cholesterol or for the calculated amount of LDL cholesterol. HDL cholesterol increased in the mackerel group as well as in the control group. This lat- 
Without a control group we might have concluded that the increase in HDL cholesterol was caused by the fish supplement. However, no difference was observed between the mackerel and control groups in this respect.

It should be mentioned that the amount of cholesterol in the mackerel paste was slightly $(29.1 \mathrm{mg} / \mathrm{tin})$ higher than that in the meat paste. According to the Key's equation $(73,74)$, the influence of this difference in cholesterol intake on the serum cholesterol level is less than $0.02 \mathrm{mmol} / 1$. The expected change in serum cholesterol based on the differences in $\mathrm{P} / \mathrm{S}$ ratio of the dietary supplements and cholesterol intake was calculated to be $0.1 \mathrm{mmol} / \mathrm{l}$. As can be seen from Table 2, the change in total serum cholesterol at the end of the experimental period was indeed a reduction by $0.1 \mathrm{mmol} / \mathrm{l}$ in the mackerel group as compared with the control group.

\section{Triglyceride}

A triglyceride-lowering effect of diets enriched with fish or fish product has been reported in many intervention studies (for reviews see refs. 75 and 76), although the effects have not always been significant. The decrease in triglyceride found in the present study is in agreement with these observations. It is, however, questionable whether this reduction contributes to the putative lower cardiovascular risk brought about by fish consumption. Hulley et al (77) concluded from 27 epidemiological studies that hypertriglyceridemia is not a proven risk factor for coronary heart disease.

\section{Apolipoproteins}

Unlike the influence of fish (products) on serum lipids, the influence on apoproteins has not received a great deal of attention from investigators. The results of studies in this field are equivocal. In five studies a decrease in plasma Apo A-1 as well as plasma Apo B was observed $(26,30,31,78,79)$, but in another study no effect was found (65) and an increase has also been reported (55).

In the present study we did not observe an influence of the fish supplement on the amount of Apo A-1, the main protein found in HDL cholesterol. The significantly different change of Apo B in the mackerel and control groups, respectively, during the experimental period is mainly due to the rather high initial (week 0 ) Apo B values in the control group. Moreover, the Apo B values at week 6 did not differ significantly between the mackerel and control groups. Apo B is the most prominent apoprotein of LDL cholesterol. A strong correlation between Apo B and LDL cholesterol was observed at week $0(n=38, r=0.82, p<0.001)$. Therefore, the decrease in Apo B in the control group is unlikely to be due to determination errors, and must have been coincidental.

\section{Fatty acid patterns}

The fatty acid compositions of serum TG and CE in the control group showed little change during the study. In the mackerel group, however, the changes in fatty acid 
Table 6 . Correlation coefficients of the linear regressions between wolwes obtamed at week 0 and week 6 .

\begin{tabular}{lccc}
\hline Variable & $\begin{array}{c}\text { Total } \\
(\mathrm{n}=49-50)\end{array}$ & $\begin{array}{c}\text { Mackerel } \\
(\mathrm{n}=22 \times 23)\end{array}$ & $\begin{array}{l}\text { Control } \\
(\mathrm{n}=27)\end{array}$ \\
\hline TG - TA & -0.13 & 0.14 & $0.45^{\mathrm{n}}$ \\
TG - CA & -0.09 & -0.33 & 0.25 \\
CE - TA & 0.22 & 0.10 & $0.56^{\mathrm{b}}$ \\
CE - CA & 0.23 & 0.25 & $0.60^{\circ}$ \\
Compliance Index & $0.64^{\mathrm{c}}(47)$ & $0.59^{\mathrm{b}}$ & $0.67^{\circ}(25)$ \\
\hline
\end{tabular}

$\mathrm{TG}=$ triglyceride; $\mathrm{CE}=$ cholesterolester; TA = timnodlonic acid $(20.5 \mathrm{n}-3)$

$\mathrm{CA}=$ cerwonic acid $(22: 6 \mathrm{n}-3)$

a: $\mathrm{p}<0.05 ; \mathrm{b}: \mathrm{p}<0.01$; $\mathrm{c}: \mathrm{p}<0.001$

composition clearly reflected the different fatty acid patterns of the dietary supplements (Table 1). The ratio between the two major fish related fatty acids of the mackerel paste was better reflected in the TG fraction (Table 5) than in the CE fraction. The appreciable amount of cetoleic acid (22:1 n-11), present in the fish supplement did not result in a detectable increase of this fatty acid in the serum lipid fractions analysed.

Dietary adherence measured by the compliance index provided an unique opportunity to check the validity of changes in serum n-3 fatty acids which are often used as a measure for dietary adherence. The increase in TA and CA in serum TG and $\mathrm{CE}$, however, did not correlate significantly with the compliance inclex. Exclusion of one value resulted in significant correlations with the compliance index for TA and $\mathrm{CA}$ in TG as well as in CE. Because this value had an extreme influence, the relation between the compliance index and the fish-related fatty acids was also tested nonparametrically (Spearman correlation). This resulted in a significant association between TA and CA in both $\mathrm{CE}$ and $\mathrm{TG}$ and the compliance index $(\mathrm{p}<0.05)$. In the CE fraction the correlation coefficients were 0.46 and 0.50 for TA and CA respectively. In the TG fraction the $r$ value was 0.43 for both $T A$ and $C A$.

The rather poor correlation between the compliance index and the change in serum fatty acid concentration might be due to inaccuracy in determining both variables. Within the control groups the values obtained for weeks 0 and 6 should correlate to a significant degree because no major changes were to be expected. However, this was not always the case (Table 6).

It should be mentioned, however, that the incorporation of the n-3 fatty acids into serum lipids might be influenced by the amount of linoleic acid in the diet. Such an influence has been found in rats $(80,81)$. In addition we found a significant correlation between the amount of dietary linoleic acid and the amount of serum timnodonic acid in various serum lipid fractions (adjusted for the amount of dietary tim- 
nodonic acid, see Chapter 2). In the present intervention study, however, no significant correlations were observed between dietary linoleic acid intake (as reflected by serum linoleic acid content) and the amount (\%) of serum timnodonic acid, taking into account the intake of timnodonic acid, as calculated on the basis of the compliance index. Adjustment for serum linoleic acid did not improve the degree of significance of the relationship between $\mathrm{n}-3$ fatty acids and the compliance index.

The amount of LA in the CE serum fraction is sometimes used to get an impression of the consumption of dietary $\mathbb{L}$ A. By extrapolation of the data obtained before (Chapter 3), the present decrease of LA in CE (ca. 5\%) would correspond with a decrease in LA consumption of about $11 \mathrm{~g}$ per day. However, there is no reason to believe that the volunteers did change their LA intake. Therefore, the decrease of LA in the CE fraction was most probably due to the enhanced n- 3 fatty acid consumption. Consequently, we might conclude that the amount of LA in the CE fraction is not the most suitable variable to reflect the uptake and incorporation of dietary LA. In contrast, the amount of dietary n-3 fatty acids does not influence the LA concentration in the serum TG. Therefore this TG fraction might give a better reflection of $\mathrm{LA}$ consumption than the $\mathrm{CE}$ fraction.

An increased level of $n-3$ fatty acids in plasma, as observed in the present study, might be beneficial, since recent findings indicate that a poor $n-3$ polyunsaturated fatty acid status is associated with an increased cardiovascular risk $(6,82)$. On the other hand we might conclude that the fish supplement used in our study did not lower cardiovascular risk by means of a favourable change in serum choles terol content. The triglyceride content did decrease but in terms of benefit to cardiovascular risk the importance of this change is questionable.

\section{Aknowledgements}

We gratefully acknowledge the skillful statistical assistance of $M$. Theunissen of the Department of Medical Information and Statistics, Limburg University, Maastricht, The Netherlands.

\section{References}

1. Assmann G. Lipid metabolism and atherosclerosis. Schattauer Verlag GmbH, Stuttgart 1982: 1-14.

2. Inkeles S., Eisenberg D. Hyperlipidemia and coronary atherosclerosis: a rewiew. Medicine, Baltimore 1981; 60: 110-123. 
3. Lewis B. The lipoproteins: predictors, protectors and pathogens. Br Med J 1983; 287: 1161-1164

4. Kannel, BW, Castelli WP, Gordon T. Cholesterol in the prediction of atherosclerotic disease. New perspectives based on the Framingliam study. Ann Intern Med 1979; 90: 85-91.

5. Thompson $\mathbf{G}$. Apoproteins: determinants of lipoprotein metabolism and indices of coronary risk. Br Heart I 1984; 51 : 585-588.

6. Aursnes I, Doørum HP, Smith $\mathbf{P}$, Arnesen $\mathbf{H}$, Christiansen $\mathbf{E N}$, Nortum $\mathbf{K R}_{\text {, }}$ Fisher $\mathbf{S}_{4}$ Weber $\mathbf{P C}$. Low and high risk coronary patients discriminated by blood platelet fatty acid composition. Scan J Clin Lab Invest $1986 ; 46: 115-120$.

7. Houwelingen AC v, Norday A, Beek E v d, Houtsmuller UMT, Metz M d, Hornstra G. Effect of - a moderate fish intake on blood pressure, bleeding time, hematology, and clinical chemistry in healthy males. Am $\sqrt{ }$ Clin Nutr 1987; 46: 871-875 (Chapter 4)

8. Sanchez-Castill CP, James WPT. The use of lithium as a marker of sodium intake (abstract). Prod Nutr Soc 1983; 42: 168.

9. Friedewald WT, Levi RI, Frederickson DS. Estimation of plasma LDL-cholesterol concentration without use of the preparative ultra centrafuge. Clin Chemistry 1972; 18: 499-502.

10. Groot PHE, Scheek LM, Havekes L, Noort WL van, 't Hooft FM van. A one step separation of human serum HDL 2 and 3 by rate-zonal density gradient ultracentrifugation in a swinging bucket rotor. J Lipid Res 1982; 23: 1342-1353.

11. Brussaard JH, Dallinga-Thie G, Groot PHE, Katan MB. Effect of amount and type of dietary fat on serum lipids, lipoproteins and apolipoproteins in man. Atherosclerosis 1980; 36: 515-527.

12. Bligh EG, Dyer WJ. A rapid method for total lipid extraction and purification. Can J Biochen Physiol 1959; 37: 911-917.

13. Christie WW. Lipid Analysis. Pergamon Press Oxford, 1982: 52-53 and 93-94.

14. Bang HO, Dyerberg J, Brondum Nielsen A. Plasma lipid and lipoprotein pattern in Greenlandic West-coast Eskimos. Lancet 1971; i: 1143-1146.

15. Hirai A, Terano T, Saito H, Tamura Y, Yoshida S. Eicosapentaenoic acid and platelet function in Sapanese. In: Lovenberg $W$, Yamori $Y$ (eds). Nutritional prevention of cardiovascular disease. Academic Press, Londion 1984; 231 -239.

16. Robinson D, Day J. Low plasma triglyceride levels in lake dwelling East African tribesmen - A fishy story? Int J Epidem 1986; 15; 183-187.

17. Kromhout D, Bosschieter $\mathbf{E B}$, Lezenne Coulander $\mathbf{C}$ de. The inverse relation between fish consumption and 20-year mortality from coronary heart disease. New Eng J med 1985; 312: 1205-1209.

18. Ahrens EH Jr, Insull W Jr, Hirsch J, Stoffel W, Peterson J, Farquahar JM, Miller T, Thomasson HJ. Effect on human serum lipids of a dietary fat, highly unsaturated but poor in saturated fatly acids. Lancet $1959 ; \mathrm{i}: 115-119$.

19. Bradlow BA, Chetty N, Westhuyzen J van der, Mendelsohn D, Gibson JE. The effects of a mixed fish diet on platelet function, fatty acids and serum lipids. Thromb Res 1983; 29: 561-568.

20. Davidson MH, Liebson PR, Bagdade JD, Messer JV, Schoenberger JA. Marine lipid concentrate reduces coronary risk factors: double blind comparison with olive oil. J Am Coll Cardiol 1986; 7 : $247 \mathrm{~A}$. 


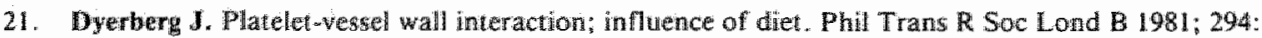
$373-381$

22. Mamazaki $T_{\text {, Nakzawa }} R_{\text {, }}$ Taleno $S$, Shihido $H$, Isoda $K_{\text {, Hattori }} Y_{\text {, Yosh da }} T$, Fujita $T$, Yano S, Kumagal A. Effects of fish oil rich in eicosapentaenoic acid on serum lipid in hyperlipidemic hemodialysis patients. Kidney International 1984; $26: 81-84$.

23. Harris WS, Connor WE, Coodnight SHJ. Dietary fish oils, plasma lipids and platelets in man. Prog Lip Res 1981; 20:75-79.

24. Harris WS, Connor WE, McMurry MP. The comparative reductions of the plasma lipids and lipoproteins by dietary polyunsaturated rats: salmon oil wersus vegetable oils. Metabolism 1983; 32: 179.184.

25. Hock CE, Holohan MA, Reibel DK. Effect of dietary fish oil on myocardial phospholipids and myocardial ischemic damage. Am J Physiol 1987; 252: H554-560.

26. Illingworth DR, Harris WS, Connor WE. Inhibition of low-density lipoprotein synthesis by dietary omega-3 fatty acids in thumans. Arteriosclerosis $1984 ; 4: 270-275$.

27. Lossonexy TO von, Ruiter A, Bronsgeesi-Schoute HC, Gen CM van, Hermus RJy. The effect of a fish diet on serum lipids in healthy human subjects. Am J Clin Nutr 1978; 31: 1340-1346.

28. Nagakawa $\mathbf{Y}$, Orimo H, Harazawa M, Morita I. Yashiro K, Murota S. Effect of eicosapentaenoic acid on the platelet aggregation and composition of fatty acid in man. Atherosclerosis 1983; 47; $71-75$.

29. Nelson AM. Diet therapy in coronary disease. Effect on mortality of high-protein, high-seafood, fat-controlled diet. Geriatrics 1972: 103-116.

30. Nestel, PJ, Comnor WE, Reardon MF, Connor S, Wong S, Boston R. Suppression by diets rich in fish oil of wery low density lipoprotein production in man. J Clin Invest 1984; 74: 82-89.

31. Phillipson BE, Rothrock DW, Conmor WE, Harris WS, Illingworih DR. Reduction of plasma lipids, lipoproteins and apoproteins by dietary fish oils in patients with hypertriglyceridaemia. New Engl J Med 1985; 312: 1210-1216.

32. Sanders $\mathbf{T}$, Roshanai $\mathbf{F}$. The influence of different types of omega-3 polyunsaturated fatty acids on blood lipids and platelet function in healthy volunteers. Clin Sci 1983; 64: 91-99.

33. Saynor R. Effects of omega-3 fatty acids on serum lipids. Lancet 1984; ii: 696-697.

34. Saynor $\mathbf{R}$, Verel $\mathbf{D}$, Gillot T. The long-term effect of dietary supplementation with fish lipid concentrate on serum lipids, bleeding time, platelets and angina. Atherosclerosis 1984; 50:3-10.

35. Singer P, Gerhard U, Moriz $V$, Förster $\mathbf{D}$, Berger $I_{\text {, Heines }} H_{\text {. Different changes of } n-6 \text { and } n-3}$ fatty acids in adipose tissue from spontaneously hypertensive (SHR) and normotensive rats after diets supplemented with linolenic or eicosapentaenoic acids. Prost Leukotr Med 1986; 24: 163-172.

36. Singer P, Jatger W, Wirth M, Voigt S, Naumann E, Zimontkowski S, Hajdu I, Goedicke W. Lipid and bloodpressure-lowering effect of mackerel diet in man. Atherosclerosis 1983; 49: 99-108.

37. Wissler RW, Frazier LE, Highes RH, Rasmussen RA. The development of atheromatous disease in cebus monkeys using saturated and unsaturated fats (abstract). Fed Proc 1960; 19: 17. 


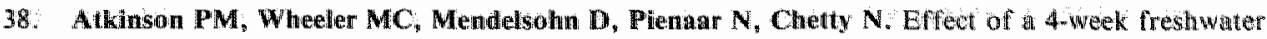
fish (trout) diet on platelet aggregation, platelet faty seids, serum lipids, and coagulation factors. Am J Hematol $1987 ; 24: 143-149$.

39. Barcelli U, Glas-Greenwalt $\mathbf{P}$, Pollak VE. Bnhancing effect of dietary suppleinentation winth omega-3 falty acids on plasma fibrinolysis in normal subjects. Thromb Res 1985; 39: $307-312$.

40. Bronsgeest-Schoute HC, Gent CM van, Laten $\mathbf{J B}_{*}$ Ruiter A. The effect of various intakes of omega-3 fatty acids on the blood lipid composition in healthy humarn subjects. Am 1 Clin Nuir $1981 ; 34: 1752-1757$.

41. Brox $\mathbf{J H}$, Killie JE, Gumes $\mathbf{S}_{4}$ Nordgy $\mathbf{A}$. The effect of cod-liver ail and corn oil on platelets and vessel wall in man. Thromb Haemostas $1981 ; 46: 604411$.

42. Brox JH, Killie JE, Osterud B, Holme: $\mathbf{S}$, Nondøy A. Effects of cod-liver oil on platelets and coagulation in familial hypercholesterolemia (Type 1la). Acta Med Scand 1983; 213: 137-144.

43. Fehily AM, Burr, ML, Phillips KM, Deadman NM. The effect of fatty fish on plasma lipid and lipoprotein concentrations. Am J Clin Nutr 1983; 38: 349.351.

44. Green D, Barreres L, Borensztain J, Kaplan P, Reddy N, Rovner R, Simon H. A double-blind, placebo-controlled trial of fish oil concentrate (MaxEPA) in stroke patients. Stroke 1985; 16: 706-709.

45. Hay CRM, Durber AP, Saynor R. Effect of fish oul on platelet kinetics in patients with isehaemic theart disease. Lancet 1982 ; i: $1269-1272$.

46. Holub B.T, Bakker DJ, Skeaff CM. Alterations in molecular species of cholesterol esters rormed via plasma lecithinmcholesterol acyl-transferase in human subjects consuming fish oil. Atherosclero. sis $1987 ; 66: 11-18$.

47. Kamada T, Yamashita T, Baba Y, Kai M, Setoyama S, Chuman Y, Otsuji S. Dietary sardine oil imcreases erythrocyte membrane fluidity in diabetic patients. Diabetes $1986: 35: 604-611$.

48. Kremer JM, Bigauoette J, Michalek AV, Timchaik MA, Linänger L, Rynes RI, Huyck C, Zieminski J, Bartholomew LE. Effects of manpulation of dietary fatty acids on clinical manifestations of wheumatoid arthritis. Lancet 1985; i: $184-187$.

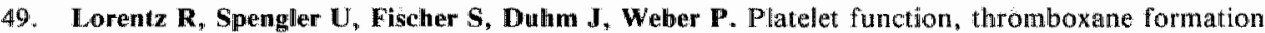
and blood pressure control during supplementation of the western diet whth cod-liver oll. Circula. tion $1983 ; 67: 504-511$.

50. Mehta IL, Lopez LM, Lawson D, Wargowich TI, Williams LI Dietary supplementaition with omega-3 polyunsaturated fatty acids in patients with stable coronary heart disease. Am J Med 1988 84: $45-52$.

51. Miller ME; Anagnostou A, Ley B, Marshall P, Steiner M. Effect of fislo oil concentrate on hemorheological and hemostatic aspects of diabetis mellitus: a preliminary study. Thromb Res $1987 ; 47: 201.214$.

52. O'Briem HC, Reiser R. Human plasma lipid responses to red meat, poultry, figh and eggs. Am I Clin Nutr 1980; 33: 2573-2580.

53. Rogers S, James. KS, Butland BK, Etherington MD, O'Brien JR, Jones JG. Effects of a fish oil supplement on serum lipids, blood pressure, bleeding time, haemostatic and rheological variables. A double blind randomised controlled trial in heallhy volunteers. Atherosclerosis 1987; 63 ; $137 \times 143$. 
54. Sander TAB, Hochland MC. A comparison of the influence on plasma lipids and platelet function of supplements of omega-3 and onega-6 polyunsaturated fatty acids. Brit $J$ Nutr 1983; 50: $521-529$.

55. Sanders TAB, Lowat L, Mistry M, Upton $K$. Influence of a mackerel diet on plasma lipoproteins aind platelet function. Proc Nutr Soc 1986; $45: 5$.

56. Sanders TAB, Vickers M, Haines AP. Effect on blood lipids and haemostasis of a supplement of cod-liver oil, rich in eicosapentaenoic and docosahexaenoic acids, in healthy young men. Clin Sci $1981 ; 61: 317-324$.

57. Saynor $\mathbf{R}$, Verel $D$. Effect of a marine oil high in eicosapentaenoic acid on blood lipids and coagulation. IRCS Med Sci 1980; 8: 379-379.

58. Schimke E, Hildebrandt R, Beitz J, Schimke I, Semmler S, Honigmann G, Mest HJ, Schliack V. Influence of a cod-liwer oil diet in diabetics type 1 on fatty acid patterns and platelet aggregation. Biomed Biochem Acta 1984; 43: S351-S353.

59. Simons LA, Hickie $\mathbf{J B}_{*}$ Balasubramaniam S. On the effects of dietary (n-3) fatty acids (Maxepa) on plasma lipids and lipoproteins in patients with hyperlipidaemia. Atherosclerosis 1985; 54: 75-88.

60. Simons LA, Ruys J, Chong S, Balasubramaniam S. Maintenance of plasma triglyceride-lowering through use of low-close fish-oils in the diet. Artery 1987; 14: 127-136.

64. Sinclair HM. Advantlages and disadvantages of an Eskimo diet. In: Fumigalli R, Kritchevski D, Paoletti R (eds). Drug affecting lipid metabolism. Elsevier, North Holland, Biomedical Press, Amsterdam 1980: 363-370.

62. Terano T, Hirai A, Hamazaki T, Kobayashi S, Fujita T, Tamura Y, Kumagai A. Effect of oral administration of highly purified eicosapentaenoic acid on platelet function, blood viscosity and red cell deformability in healthy human subjects. Atherosclerosis 1983; 46: 321-331.

63. Thorngren $\mathbf{M}$, Nilsson $\mathbf{E}_{\mathrm{w}}$ Gustafson $\mathbf{A}$. Plasma lipoproteins and fatty acid composition during a moderate eicosapentaenoic diet. Acta Med Scan 1986; 219: 23-28.

64. Woodcock BE, Smith E, Lambert, WH, Morris Jones W, Galloway JH, Greaves M, Preston FE. Beneficial effect of fish oil on blood viscosity in peripheral vascular disease. Brit Med J 1984; 288: $592-594$.

65. Yoshimura T, Matsui K, Yunohara T, Kawasaki N, Nakamura T, Olamura H. Effects of highly purifled eicosapentaenoic acid on plasma beta thromboglobulin level and vascular reactivity to angiotension II. Artery 1987; 14: 295-303.

66. Bruckner G, Webb P, Greenwell L, Chow C, Richardson D. Fish oil in creases peripheral capillary blood hlow velocity in humans. Atherosclerosis 1987; 66: 237.245.

67. Haimes AP, Sanders TAB, Imeson JD, Mahler RF, Marin, J, Mistry M, Vickers M, Wallace PG. Effects of a fish oil supplement on platelet function, hemostatic wariables and albuminuria in insulin-dependent diabetics. Thromb Res 1986; 43: 643-655.

68. Harris WS, Dujovne CA, Zucker ML, Johnson BE. Fish oil supplements raise low density Uipoprotein cholesterol levels in hypertriglyceridemic patients. Circulation (Suppl IV) 1987: 76: 168.

69. Kahl PE, Schimke E, Hildebrandl R, Beitz J, Schimke I, Beitz H, Mrochen H, Mest HJ. The influence of cod-liver ofl diet on various lipid metabolism parameters, the thromboxane formation capacity "platelet function and the serum MDA level in patients suffering from myocardial infarc. tion. Cor Vasa 1987; 29: 199-208. 


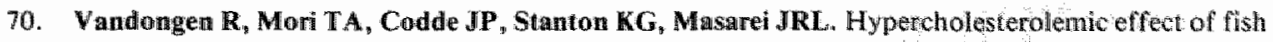
oil in insulin-dependent duabetic patients. Med J Australia 1988; 148: 141-143.

71. Lempert KD, Rogers JS, Albritk MJ. Effects of dietary fish oul on serum lipids and blood coagulacion in peritoneal dialysis patients. Am J Kidney Dis 1988; 11* 170-175.

72. Demke DM, Peters GR, Linet OI, Metaler CM, Kott KA. Effects of a fish oil concentrate in pam tients with hypercholesterolemia. Atherosclerosis 1988; 70: 73-80.

73. Keys A, Anderson JT, Grande F. Prediction of serum cholester ol responses of man to changes in fats in the diets. Lancet 1957 ; if 959966 .

74. Keys A. Serum cholesterol response to dietary cholesterol. An J Clin Nutr 1984: 40:351-359.

75. Hornstra G. The significance of fish and tish-oil enriched food for prevention and therapy of ischemic cardiovascular disease. In: Crawford MA, Vergroesen AJ (eds). The role of fat in human nutrition II. London, UK: Academic Press, London (in Press).

76. Herold PM, Kinsella JE. Fish oil consumption and decreased risk of cardiovascular disease: comparison of findings from amimal and human feeding trials. Am J Clin Nutr 1986; 43; 566-598.

77. Hulley SB, Rosenman RH, Bawol RD, Brand RJ. Epidemiology as a guide to clinical dicisions. The association between triglyceride and coronary heart disease. New Engl J Med 1980; 302: $1381-1389$.

78. Harris WS, Connor WE, Inkeless SB, Illingworth DR. Dietary omega-3 fatty acids prevent carbohydrate-induced hypertriglyceridemia. Meta bolism 1984; 33: 1016-1019.

79. Nestell PJ. Fish oil attenuates the cholesterol induced rise in lipoprotein cholesteral. Am J Clin Nutr 1986; 43: 752 757 .

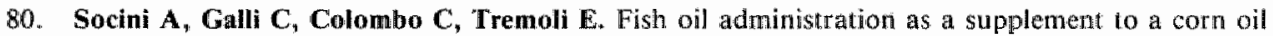
containing diet affects arterial prostacyclin production more that platlet tromboxane formation in the rat. Prostaglandin $1983 ; 25: 693-710$.

81. Sanders TAB. Influence of moderate intakes of fish oil on blood lipids. In: Lands WEM (ed). Proceedings of the AOCS short cours on polyunsaturated fatty acids and eicosanoids. American Oil Chemists" Society, Illinois 1987: 70-86.

82. Prisco ED, Rogasi PG, Matacei M, Ablute R, Gensini GF, Neni Serneri GG. Increated thronbox. ane $A_{2}$ generation and altered merabrane fatty acid compostion in platelets from patienss with aclive angina pectoris. Thromb Res 1986; 44: 101-112. 


\section{CHAPTER 6}

\section{EFFECT OF MODERATE FISH INTAKE ON PLATELET AGGREGATION IN HUMAN PLATELET RICH PLASMA}

\section{Summary}

This paper describes the results of an international study to investigate the effect of a reasonable amount of dietary fish on platelet aggregation in platelet rich plasma (PRP), induced by collagen and thrombin.

In Maastricht, Tromsø, and Zeist two groups of healthy male volunteers were given a daily dietary supplement consisting of $135 \mathrm{~g}$ of canned mackerel paste (experimental group, $n=40$ ) or meat paste (control group, $n=42$ ) for a 6 -week period. Compliance, calculated on the basis of the urinary excretion of lithium added to the supplements, was about $80 \%$.

Platelet number in PRP decreased significantly in the fish group.

Collagen-induced platelet aggregation in PRP differed widely between the three centers despite the attempt to use exactly the same conditions. Nonetheless, aggregation decreased significantly in the fish group. The mackerel effect on thrombininduced aggregation was inconsistent.

Key words: fish, diet, compliance, platelet aggregation, platelet number, PRP, collagen, thrombin. 


\section{Introduction}

Blood platelets play a major role in the development of ischemic cardiovascular disease because of their ability to adhere to damaged vascular tissue and to aggregate with each other. It has been suggested that the consumption of polyunsaturated fatty acids (PUFAs) of the n-3 family, present in fish and fish products, diminishes the interaction between platelets and vessel wall by causing a shift in the balance between pro- and anti-aggregatory prostanoids formed by the platelets and the vessel wall, respectively (1). However, previous studies on the effects of additional dietary n-3 PUFAs on platelet aggregation generated conflicting results. Although a large number of human studies have been performed, only eight included a proper control group (2), and methods used to monitor compliance with the treatment were often absent. Moreover, there was a large variability in quantities and types of dietary supplementation which, frequently, were not realistic at all.

We therefore conducted a well-controlled study to investigate the effect of a reasonable amount of fish in the diet on collagen- and thrombin-induced platelet aggregation in platelet rich plasma (PRP). Thrombin was chosen to activate the platelets because it is increasingly recognized as an important physiological platelet activator $(3,4)$. Collagen was used, not only because it is another physiological platelet activator $(5,6)$, but also because it has been widely used in previous fish(oil) studies (7-32).

\section{Materials and methods}

The study was part of a trial conducted by the International Working Party 'Fish against thrombosis?'. The design of the study was published in detail before (33) and is briefly reiterated below. Experimental details will be given only insofar as they are related to the results presented in this paper.

In Troms $\emptyset$ (Norway) and in Maastricht and Zeist (The Netherlands) 84 healthy male volunteers (20-45 years of age, see Table 1) participated in the study. The experiment lasted 6 weeks, and was preceded by a run-in period of 2 weeks. During this run-in period all volunteers were requested to consume one tin of meat paste $(135 \mathrm{~g})$ per day. Subsequently, they were randomized into a mackerel and a meat (control) group. During the 6 experimental weeks the volunteers of the mackerel group consumed one tin of mackerel paste $(135 \mathrm{~g})$ and the controls continued the consumption of meat paste. The dietary supplements were given as a replacement for the fish, meat, cheese and eggs normally consumed during the main meal. The mackerel paste provided $1.7 \mathrm{~g}$ timnodonic acid (EPA, 20:5 n-3) and $3.0 \mathrm{~g}$ cervonic acid (DHA, 22:6 n-3) per day.

Compliance was calculated on the basis of the urinary excretion ( $\%$ ) of a standard amount of lithium added to the supplements. The maximum lithium intake per day was about 100 times the amount naturally available in the diet and yet represented 
Table 1 . Age (years) of volunteers and initial values for platelet counts in PRP $\left(10^{\circ} / 1\right)$.

\begin{tabular}{|c|c|c|c|c|c|c|c|}
\hline \multirow[b]{2}{*}{ Center } & \multirow[b]{2}{*}{ group } & \multicolumn{3}{|c|}{ age } & \multicolumn{3}{|c|}{ platelet count in PRP } \\
\hline & & $\mathrm{n}$ & mean & (range) & $\mathrm{n}$ & mean & $\pm \mathrm{SEM}$ \\
\hline \multirow[t]{2}{*}{ Maastricht } & mackerel & 19 & $32.4^{a}$ & $(21-45)$ & 19 & 314 & \pm 14.6 \\
\hline & control & 20 & $32.6^{\mathrm{a}}$ & $(22-44)$ & 20 & 316 & \pm 12.3 \\
\hline \multirow[t]{2}{*}{ Troms $\varnothing$} & mackerel & 11 & 25.0 & $(22-30)$ & 9 & 370 & \pm 34.8 \\
\hline & control & 12 & 25.1 & $(20-29)$ & 10 & $424^{6}$ & \pm 27.6 \\
\hline \multirow[t]{2}{*}{ Zeist } & mackerel & 10 & 23.9 & $(21-27)$ & 10 & 365 & \pm 19.6 \\
\hline & control & 10 & 23.0 & $(21-26)$ & 10 & 382 & \pm 28.4 \\
\hline \multirow[t]{2}{*}{ Total } & mackerel & 40 & 28.3 & $(21-45)$ & 38 & 341 & \pm 12.8 \\
\hline & control & 42 & 28.2 & $(20-44)$ & 40 & 359 & \pm 13.5 \\
\hline
\end{tabular}

a: Maastricht differed significantly from Tromsø and Zeist ( $p<0.0001$, Bonferroni inequality test)

b: Significantly different from Maastricht controls ( $p<0.01$, Bonferroni inequality test)

only one percent of the therapeutic dose (34). Compliance was also calculated on the basis of urinary lithium per urinary creatinine $(\mu \mathrm{mol} / \mathrm{mmol})$. To correct for a possible influence of inaccuracies during urine collection and to minimize the influence of differences in body mass and sudden changes in exercise level, both compliance indices were multiplied, resulting in a variable (the compliance index) which was used to investigate possible relationships between dietary adherence and dietinduced changes in platelet aggregation.

At week 0 (the end of the run-in period) and week 6 , blood was drawn under fasting conditions after the volunteers had been resting for $20 \mathrm{~min}$ in a supine position. Under minimum stasis a forearm vein was punctured using a $19 \mathrm{G}$ butterfly-venisystem (no. 4590, Luer, or no. 8488, Luer and Record; Abbott Ireland Ltd., Sligo, Republic of lreland).

For platelet aggregation in PRP, $18 \mathrm{ml}$ of blood were taken slowly into $20 \mathrm{ml}$ syringe, prefilled with $2 \mathrm{ml}$ citrate solution (109 mmol/1, pH 7.2-7.4). The anticoagulated blood was mixed gently and PRP was prepared by centrifugation for 10 min at $120-160 \times \mathrm{g}$. After removing the PRP, the residue was centrifuged again

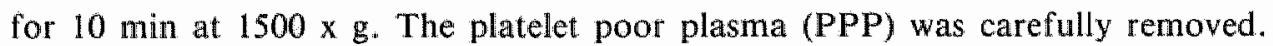
Platellet concentrations in PRP were measured with a Thrombocounter (Coulter Electronics, Luton, Beds. England). PRP was normalized to contain $220 \times 10^{9}$ platelets per liter by adding autologus PPP. Aggregation was measured with a Chrono-log aggregometer (model 430, Chrono-log Corporation, Havertown, PA, USA). For each aggregation measurement $450 \mu \mathrm{l}$ PRP was brought into a prewarmed $\left(37.5^{\circ} \mathrm{C}\right.$ ), siliconized (Prosil, no. 11975-0, Ventron, Alfa Produkte, 

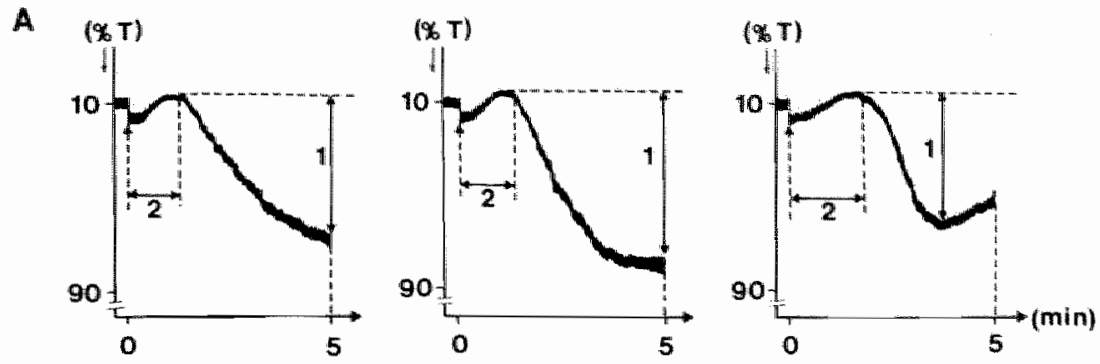

B
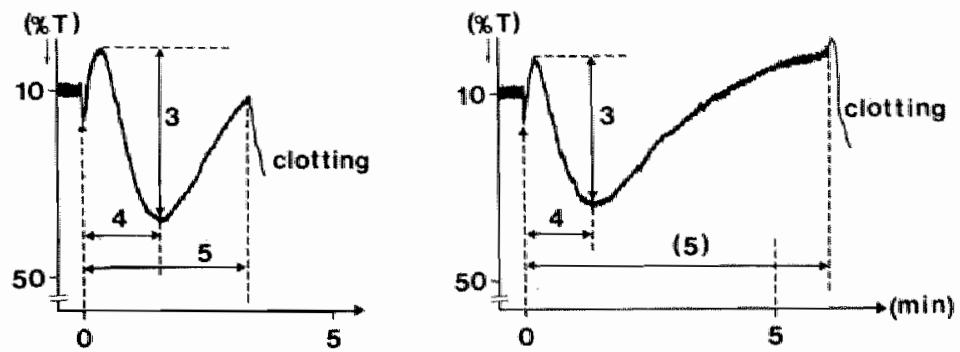

Fig I. Schematic representation of aggregation curves in PRP induced by collagen $(A)$, and thrombin (B).

1: Maximum aggregation at, or within 5 min after collagen addition (change in percentage of light transmission: $\%$ T).

2: Aggregation induction time (tai, s).

3: Maximum aggregation (\% T) occurring within 5 min after thrombin administration.

4. Time to maximum aggregation ( $m$ max, s).

5: Clotting time (tc, s). If clotting did not occur within $300 \mathrm{~s}$ after thrombin addition, this parameter was set to 301 .

Karlsruhe, FRG) glass cuvette (no. 312, AHS, Maarssenbroek, The Netherlands) and stirred at $1000 \mathrm{rpm}$. Exactly 3 min later $50 \mu \mathrm{l}$ of the activator (collagen or thrombin) was added and the change in percentage of transmitted $\|$ ight $(\% \mathrm{~T}$, see Fig 1) was monitored continuously for 5 min or until clot formation occurred (thrombin only). In each case collagen (Collagen Horm ${ }^{\circledR}$, Hormon Chemie, Munich, FRG) was used as the first agonist. At week 0 a range of collagen concentrations was tested, two of which were selected, giving a difference in $\% \% \mathrm{~T}$ within 5 min of about $30 \%$ (low dose) or 60\% (high dose), respectively. Because of large inter-individual differences in aggregation responses to collagen, the appropriate dose had to be determined for each volunteer separately. Each day a stock solution was prepared by diluting $80 \mu \mathrm{l}$ collagen $1(\mathrm{mg} / \mathrm{ml})$ in $420 \mu \mathrm{l}$ buffer Horm (concentration $160 \mu \mathrm{g} / \mathrm{ml}$ ). 
Table 2. Working solutions of collagen.

\begin{tabular}{llll}
\hline $\begin{array}{l}\text { Concentration } \\
\mu \mathrm{g} / \mathrm{ml}\end{array}$ & $\begin{array}{l}\text { Stock solution } \\
160 \mu \mathrm{g} / \mathrm{ml} \\
(\mu \mathrm{l})\end{array}$ & $\begin{array}{l}\text { Hormbuffer } \\
(\mu \mathrm{l})\end{array}$ & $\begin{array}{l}\text { Final concentration } \\
\text { in aggregation cuvette } \\
(\mu \mathrm{L} / \mathrm{ml})\end{array}$ \\
\hline 8.0 & 30 & 570 & $0.8^{\mathrm{a}}$ \\
7.0 & 25 & 546 & 0.7 \\
6.0 & 25 & 508 & 0.6 \\
5.0 & 20 & 620 & 0.5 \\
4.0 & 15 & 585 & 0.4 \\
3.0 & 10 & 520 & 0.3 \\
\hline
\end{tabular}

a: This collagen dilution was also used to activte the platelets for hydroxy fatty acid measurements

In Maastricht, the working solutions were prepared from this stock solution as shown in Table 2. For each volunteer the first aggregation was performed at 0.5 $\mu \mathrm{g} / \mathrm{ml}$ (f.c.). If the response was $<30 \%$ the next measurement was performed at a f.c. of $0.6 \mu \mathrm{g} / \mathrm{ml}$ and if the results were still $<30 \%, 0.7 \mu \mathrm{g} / \mathrm{ml}$ f.c. was used etc. If the response of the first measurement was $>30 \%$ the next measurement was done at a f.c. of $0.4 \mu \mathrm{g} / \mathrm{ml}$ etc. After the appropriate doses had been selected, duplicate measurements were performed. At week 6 these doses were used again in exactly the same order as at week 0 . A similar dose-finding procedure was followed for thrombin. Thrombin (T 9010, lyophilized, Sigma, St. Louis, Missouri, USA) was dissolved in complete Tyrode (Table 3) solution to a stock solution containing $10 \mathrm{U} / \mathrm{ml}$ (NIH units). This stock solution was stored in $0.15 \mathrm{ml}$ portions in plastic tubes at $-15^{\circ} \mathrm{C}$ for a maximum period of 2 weeks. The working solutions were prepared fresh daily, using Tyrode solution as a diluent (Table 4). At week 0 , doses were used which gave a maximum aggregation response (\% $\%$ ) within $5 \mathrm{~min}$ of about $10 \%$ (low dose) or $30 \%$ (high dose) respectively. Although the inter-individual variation appeared to be far less for thrombin than for collagen, the same procedure was used for find-

Table 3. Tyrode solutions.

\begin{tabular}{|c|c|c|c|}
\hline \multicolumn{2}{|c|}{ Basic Tyrode: } & \multicolumn{2}{|c|}{ Complete Tyrode: } \\
\hline $\mathrm{NaCl}$ & $8.7 \mathrm{~g}$ & $\mathrm{CaCl}(5 \%)$ & $0.4 \mathrm{ml}$ \\
\hline $\mathrm{KCl}$ & $0.2 \mathrm{~g}$ & $\mathrm{MgCl}_{2}$ l moll/ & $0.12 \mathrm{ml}$ \\
\hline $\mathrm{NaHCO}_{3}$ & $0.8 \mathrm{~g}$ & Basic Tyrode & $100 \mathrm{ml}$ \\
\hline $\mathrm{NaH}_{2} \mathrm{PO}_{4}^{3}$ & $0.07 \mathrm{~g}$ & $\mathrm{pH} 7.4$ (adjusted & \\
\hline Dextrose & $1.0 \mathrm{~g}$ & & \\
\hline $\mathrm{H}_{2} \mathrm{O}$ bidest & $1000 \mathrm{ml}$ & & \\
\hline
\end{tabular}

a: (Merck no 14030 ) 
Table 4. Working solution of thrombir.

\begin{tabular}{llll}
\hline $\begin{array}{l}\text { Concentration } \\
(\mathrm{U} / \mathrm{ml})\end{array}$ & $\begin{array}{l}\text { Basic solution } \\
(\mu \mathrm{l})\end{array}$ & $\begin{array}{l}\text { Complete Tyrode } \\
(\mu \mathrm{l})\end{array}$ & $\begin{array}{l}\text { f.c. in aggregometer } \\
\text { cuvette }(\mathrm{U} / \mathrm{ml})\end{array}$ \\
\hline 1.8 & 108 & 492 & 0.18 \\
1.5 & 90 & 510 & 0.15 \\
1.2 & 36 & 264 & 0.12 \\
\hline
\end{tabular}

f.c. = finall concentration

ing the dose range to obtain the required difference in $\%$ T of $10 \%$ and $30 \%$, starting with a f.c. of thrombin of $0.15 \mathrm{U} / \mathrm{ml}$. At week 6 these doses were used in exactly the same order.

For collagen-induced aggregation measurements 5 teflon coated stirbars were selected which before had been demonstrated to give comparable results at $1000 \mathrm{rpm}$. For the measurements of thrombin induced aggregation a number of stirbars were available which were used once, whereafter they were carefully cleaned, with $\mathrm{NaOH}(1 \mathrm{~N})$ and $\mathrm{HCL}(1 \mathrm{~N})$, overnight to remove all traces of thrombin and fibrin.

Aggregation was quantified as shown by the diagrams in Fig 1. Transmitted light was adjusted at $90 \%$ for PPP and $10 \%$ for PRP. When thrombin is used to activate the platelets, aggregation is followed by clotting. To prevent interference of this latter process with the aggregation recordings, only those aggregation results were accepted which showed a time lapse of at least $30 \mathrm{~s}$ between the moment of maximum aggregation and the occurrence of clotting. This interval was chosen on the basis of a series of measurements in PPP which revealed that the time between fibrin formation (decrease in light transmission) and clotting (increase in light transmission) was never more than $10 \mathrm{~s}$.

All measurements were done in duplicate between 60 and $120 \mathrm{~min}$ after blood collection. All working solutions were stored in melting ice, and all platelet handling was carried out in plastic material and at room temperature.

\section{Statistical evaluation}

Frequency distributions of all data were checked and when necessary, data were transformed to normalize the distribution. Subsequentiy significant outliers were omitted (35).

Student's t-test for paired data was used to evaluate the changes within the mackerel and the control groups after 6 weeks.

Differences between the mackerel and control groups were evaluated using Student's 2-sample t-test. To compare these differences for the three experimental centers, combined analysis of variance (anova) was used.

Occasionally, other statistical methods were used which will be outlined when describing the results.

Differences were considered significant when the two-sided $\mathrm{P}$ value (p) was equal to or smaller than 0.050 . 


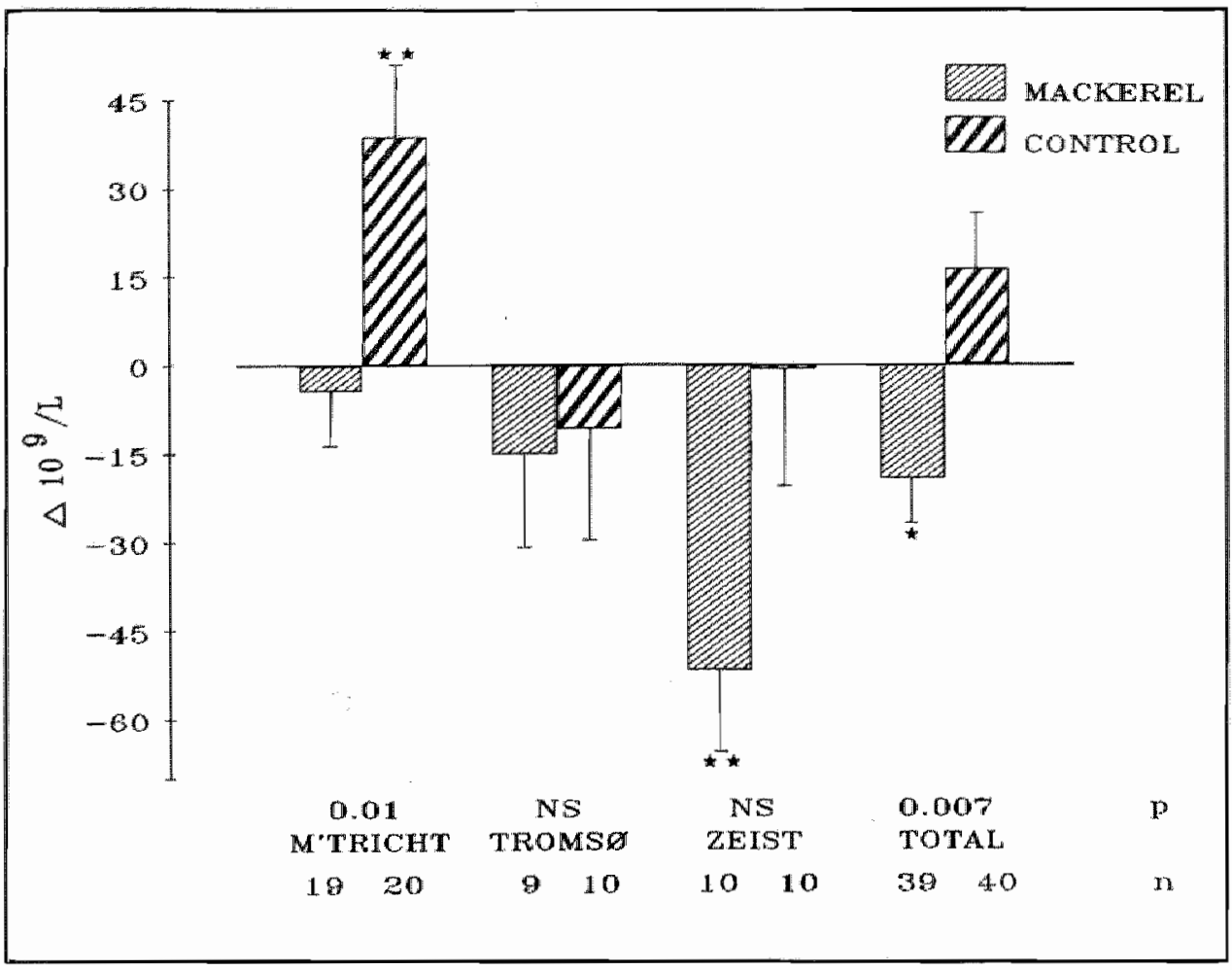

Fig 2. Effect of dierary supplements on the change in platelet count in PRP $\left(\Delta .10^{9} / 1\right)$ afier 6 experimental weeks (mean and SEM). For initial values: see Table 1.

p." significance of differences between mackerel and control groups. NS: not significant.

Values significantly different from zero: * $p<0.05$, ** $p<0.01$.

\section{Results}

As described before (33) average dietary adherence was $85 \%$ for the control group and $78 \%$ for the mackerel group. Data from one volunteer had to be omitted because of a very poor compliance. No side effects of the dietary supplements were observed during the study (33).

Transformation of the data was required for time-related parameters only. For the sake of clarity, non-transformed values will be given only.

\section{Platelet concentration in PRP}

Initial values for the platelet counts in PRP are given in Table 1. No significant differences were observed between the mackerel and control groups (anova). Moreover, there were no significant differences between the three centers, except for the control group in Troms $\phi$, which showed a significantly higher platelet count than the control group in Maastricht ( $\mathrm{p}<0.05$, Bonferroni inequality test; ref. 36 ). 
Table 5. Platelet aggregation in PRP (\% T) in response to the same dose of collagen $(0.8 \mu \mathrm{g} / \mathrm{ml}, \mathrm{f} . \mathrm{c}$.) in the three different centers.

\begin{tabular}{lccc}
\hline Center & n & mean & SEM \\
\hline Maastricht & 36 & $62.7^{\mathrm{a}}$ & 2.07 \\
Troms & 23 & 13.1 & 4.29 \\
Zeist & 20 & 23.4 & 4.94 \\
\hline
\end{tabular}

a: Significantly different from other centers $(p<0.01$, Bonferroni inequality test)

In each center, the number of platelets in PRP tended to decrease in the mackerel group (Fig 2). This decrease was significant for Zeist $(\mathrm{p}<0.01)$ as well as for all centers combined $(\mathrm{p}<0.05$ ). In the control groups the changes in platelet count were very inconsistent, showing a significant increase in Maastricht $(\mathrm{p}<0.01)$ and no significant changes in the other experimental centers. All data taken together, it appeared that, as compared to the control group, platelet concentration in PRP decreased significantly in the mackerel group ( $p<0.01$ ). Analysis of covariance demonstrated that this fish effect was not influenced by the initial difference in the platelet count of the Troms $\phi$-control group. As was also observed for whole blood (37), this lowering effect of the fish supplement on platelet number was already maximal after three weeks (data not shown). The fish-induced decrease in platelet number did not correlate significantly with the dietary adherence as reflected by the compliance index.

Table 6. Initial values for maximum aggregation in PRP induced by collagen (\%T \pm SEM).

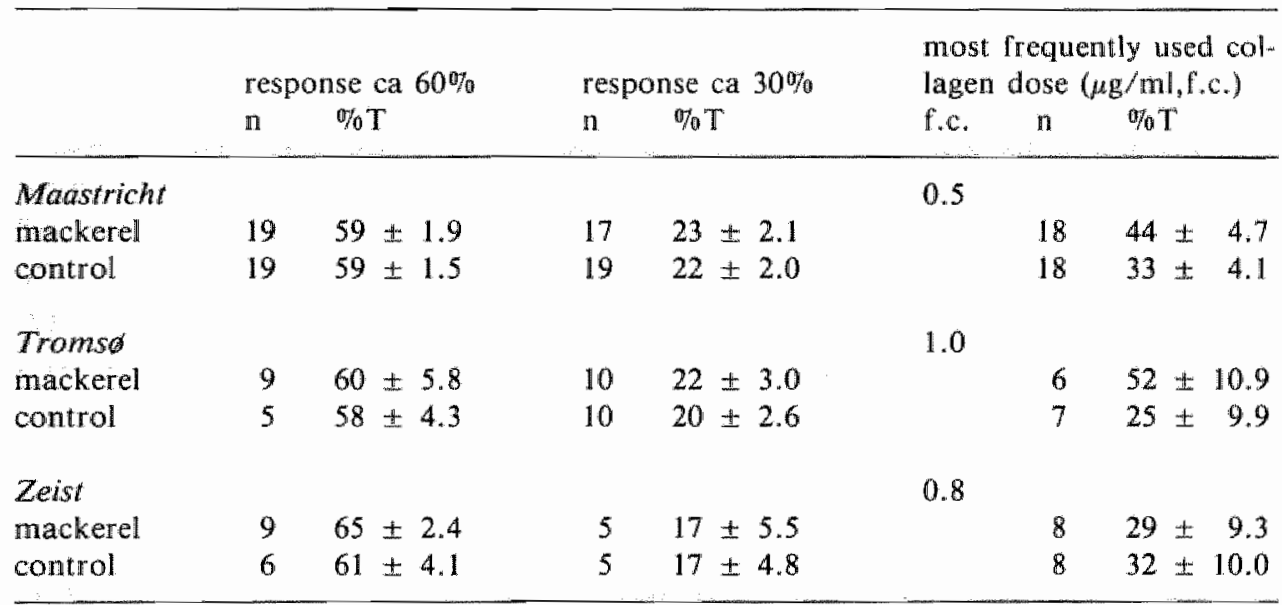

f.c.: final concentration 


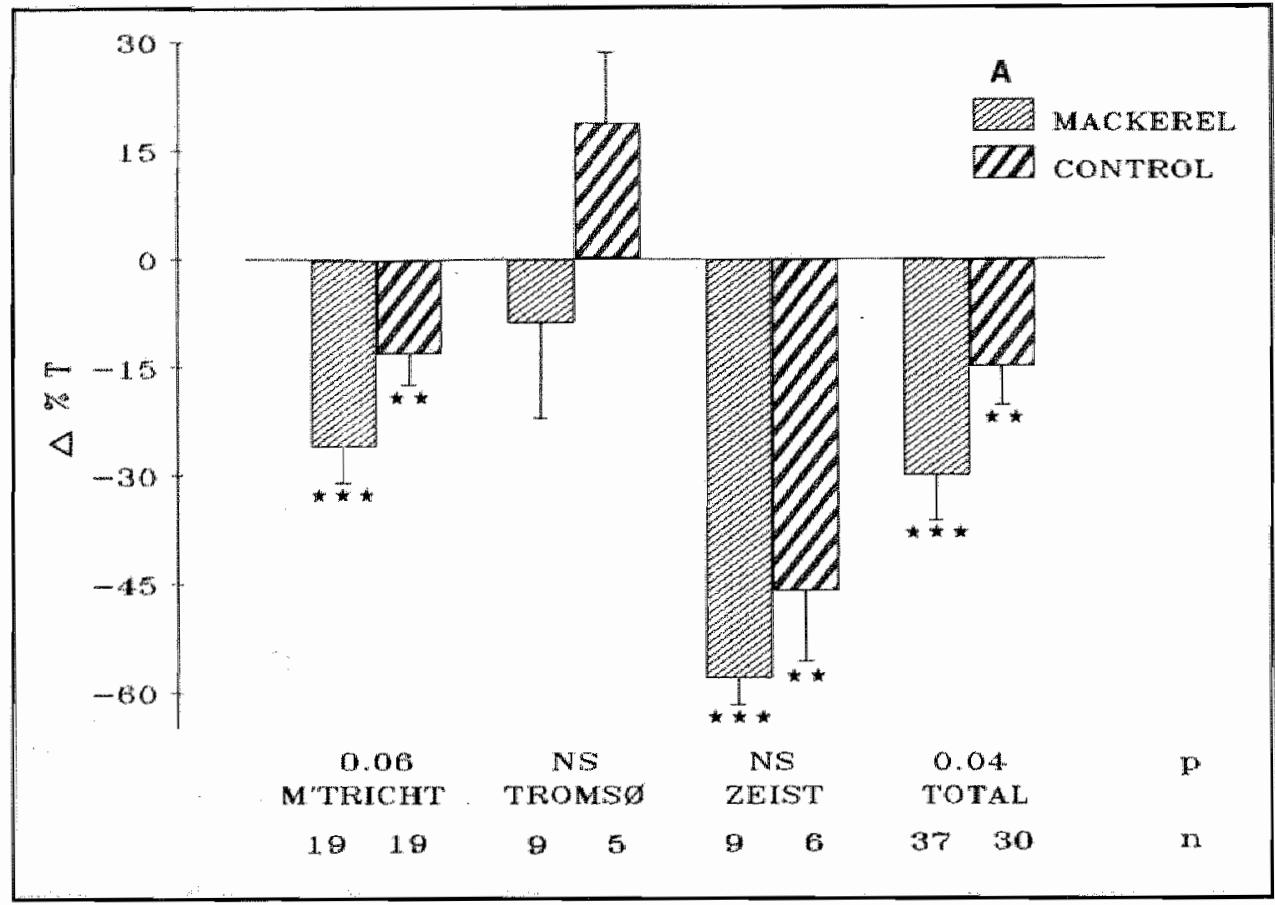

Fig 3.A. Effect of dietary supplements on the change in collagen-induced aggregation in PRP ( $\triangle \% T$ and SEM) of the measurements which gave a maximum aggregation response of about $60 \%$ (but always $>35 \%$ ). See Table 3 for initial walues. $p$ : significance of differences between mackerel and control groups. NS: not significant. Values significantly different from zero: ${ }^{*} p<0.05, * 0<0.01$ and **** $p<0.005$. Using analysis of variance the overall fish effect was significant $(p=0.02)$ for the high as well as the low dose of collagen.

\section{Collagen-induced aggregation in PRP}

In the three different centers the aggregation response to the same amount of collagen varied widely. In Table 5 the aggregation response to the dose of $0.8 \mu \mathrm{g}$ collagen $/ \mathrm{ml}$ final concentration (f.c.) is shown. This collagen dose was used simultaneously but independently from the present aggregation study and was meant to investigate the effect of the dietary supplements on the formation of cyclo-oxygenase and lipoxygenase products by collagen-activated platelets, (Chapter 8). In Maastricht the aggregation response was much higher than in Troms and Zeist $(p<0.01$, Bonferroni inequality test). In all three centers collagen of the same batch was used as well as identical aggregometers.

In Figs $3 \mathrm{~A}$ and $3 \mathrm{~B}$ the changes in maximum aggregation after 6 experimental weeks are shown for the measurements giving an initial response ( $\max \% \mathrm{~T}$ ) of approximately $60 \%$ and $30 \%$, respectively. Values obtained at week 0 are given in Table 6. For the high doses (initial aggregation response about 60\%), the changes in aggregation during the study were significantly different from zero for the mackerel as 


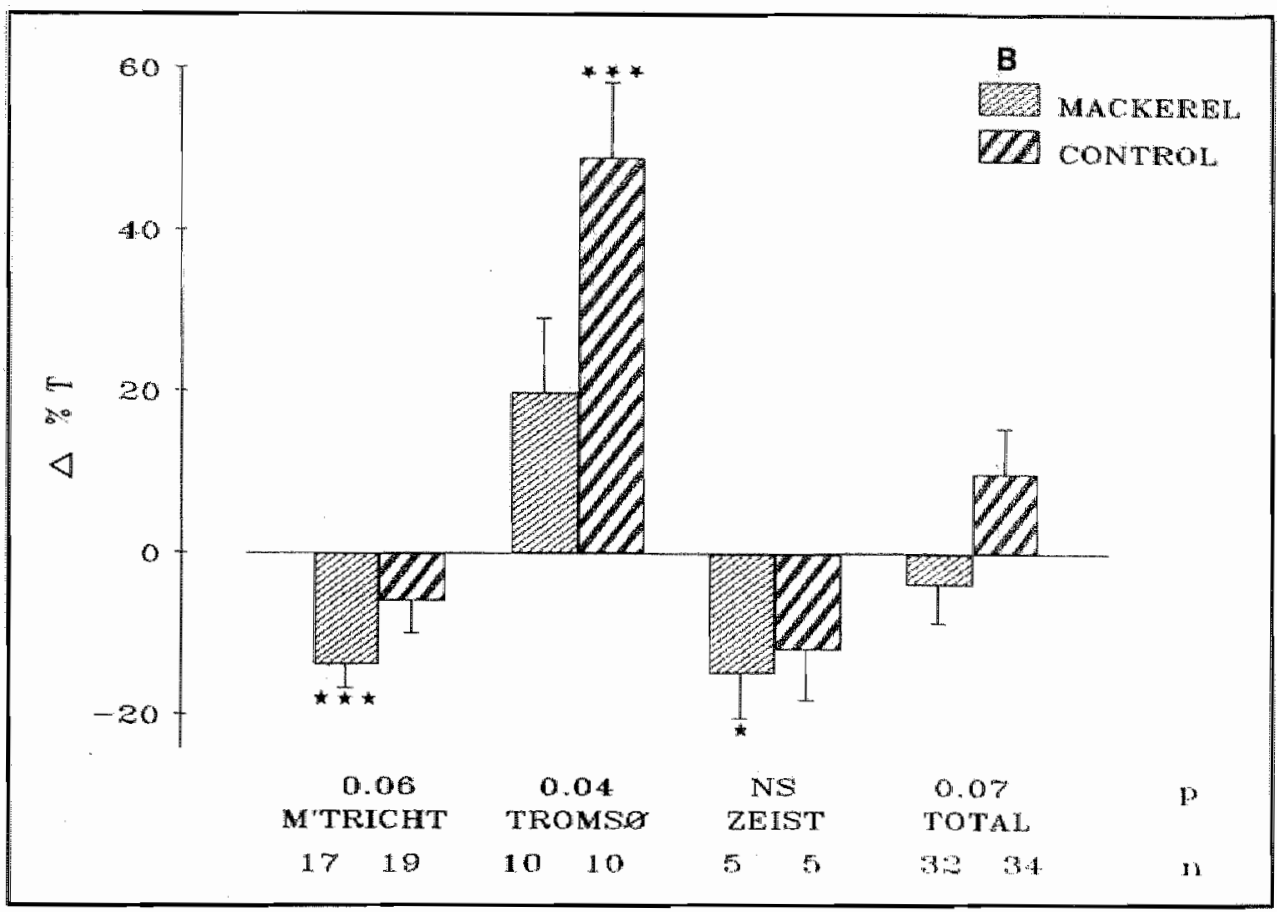

Fig 3 B. Effect of dietary supplements on the change in collagen-induced aggregation in PRP $(\triangle \% T$ and SEM) of the measurements which gave a maximum aggregation response of about 30\% (but always < 35\%). For further explanation see Fig. 3A.

well as for the control groups (Troms $\emptyset$ excluded). The decrease in the fish group always tended to be more pronounced than that in the control group. This difference reached statistical significance in the total group (Student's t-test $p=0.04$; analysis of variance $\mathrm{p}<0.02$, Fig $3 \mathrm{~A}$ ).

At the lower doses (response about 30\%), the change in maximum aggregation in the fish group was significantly different from zero in Maastricht and Zeist. Com pared with the control group the aggregation in the mackerel group tended to be more decreased, but these differences were not significant. Again in Troms $\emptyset$, different results were obtained: during the experimental period aggregation increased. This increase was significantly less for the mackerel group than for the control group ( $\mathrm{p}<0.04$, see Fig $3 \mathrm{~B}$ ). Using analysis of variance it appeared that, as compared with the control group, the mackerel supplement decreased platelet aggregation significantly $(\mathrm{p}<0.02)$.

Due to inter-individual differences in sensitivity of platelets towards collagen, the collagen dlose-range used for the various individuals differed substantially. However, in each center there was always one particular dose which was used most frequently. In Maastricht this collagen dose was $0.5 \mu \mathrm{g} / \mathrm{ml}$ (f.c.) and the 


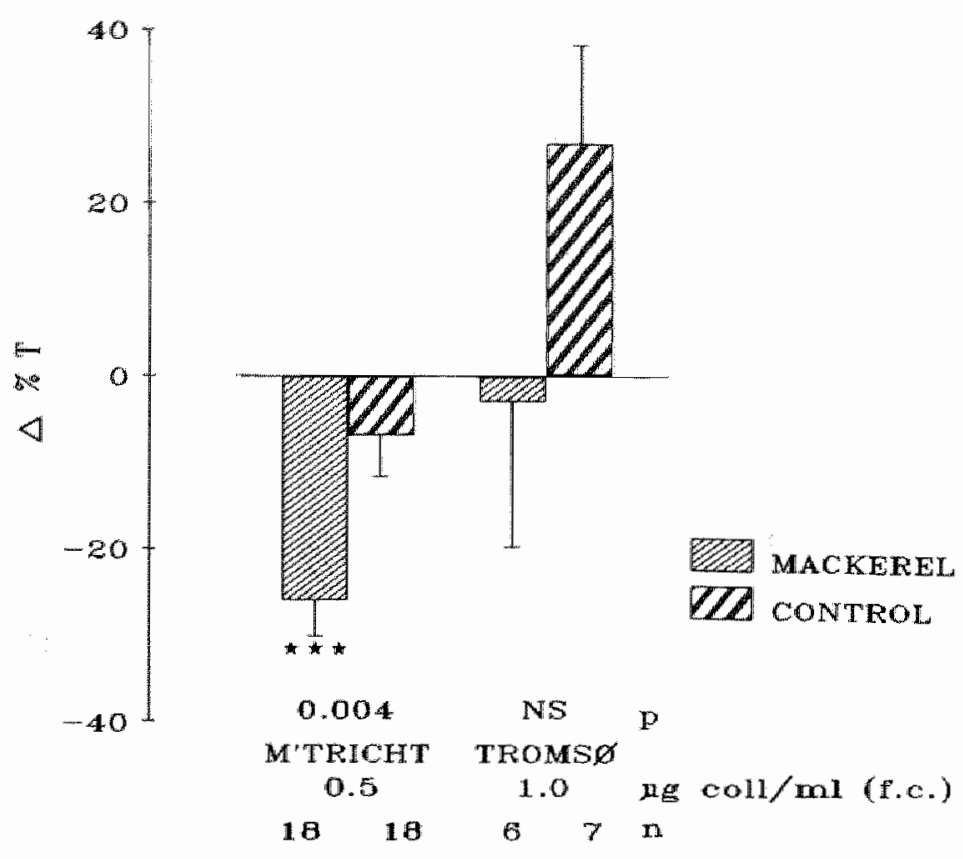

Fig 4. Effect of dietary supplements on the change in maximum aggregation in PRP ( $\triangle \%$ T and SEM) due to a specific dose of collagen (Maastrich and Troms between mackerel and control groups. NS. not significant. Values significantly different from zero: * $p<0.005$. Using analysis of variance the fish effect was significant $(p<0.04)$.

aggregation-inhibiting effect of the mackerel supplement after 6 weeks as measured with this amount of collagen was significantly more pronounced than that of the meat supplement ( $p=0.004$, Fig 4 ). In Troms $\emptyset$ the most frequently used collagen dose was $1.0 \mu \mathrm{g} / \mathrm{ml}$ (f.c.); no significant effect of the mackerel paste was observed. In Zeist the collagen dose used most often at week zero $(0.8 \mu \mathrm{g} / \mathrm{ml}$, f.c. $)$ scarcely gave a response at week 6: in 15 out of 16 cases no aggregation occurred at all. Therefore these measurements were disregarded. When the results of Maastricht and Troms $\emptyset$ were combined the inhibition of maximum aggregation by the mackerel group was significant as compared with the change in the control group (anova, $\mathrm{p}=0.04$ ).

The effect of the dietary supplements on the aggregation induction time was analysed in a similar manner to that described above for the maximum aggregation. Similar results were obtained (data not shown) which was to be expected because of the strong correlation between both aggregation variables at week $0(r=-0.74$, $\mathrm{p}<0.001, \mathrm{n}=65$ ).

All these results taken together, it can be concluded that the fish supplement lowered collagen-induced platelet aggregation in PRP slightly but significantly. No signifi- 
Table 7. Initial walues for maximum aggregation in PRP, induced by thrombin $10 \% \mathrm{~T}$ SEM).

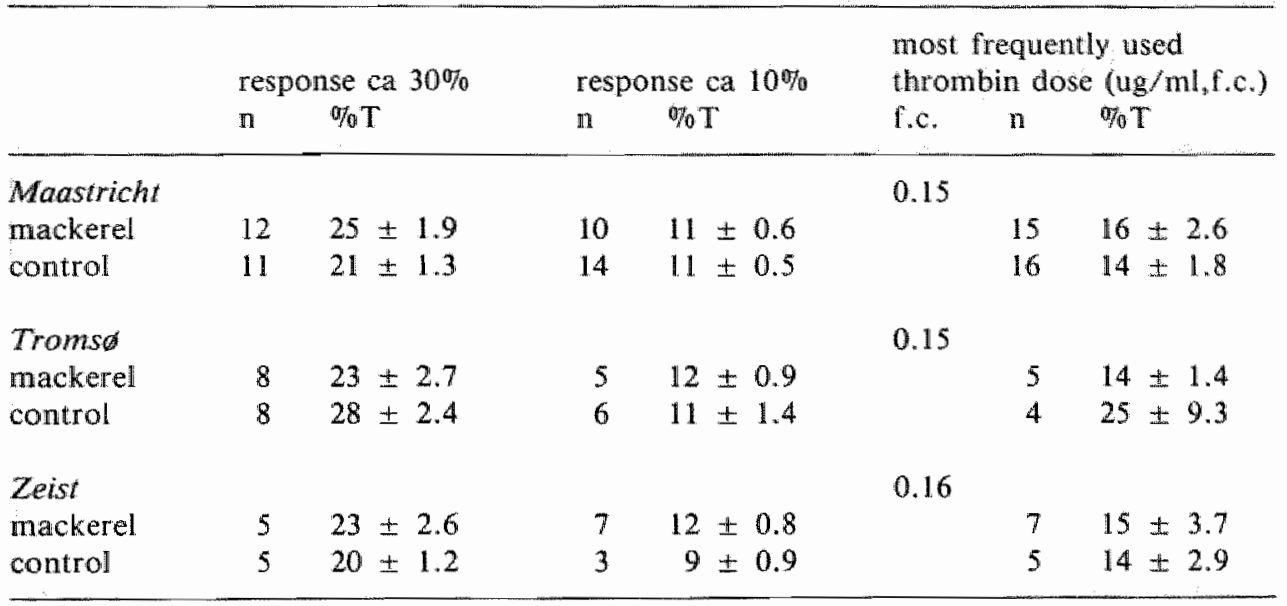

f.c.: final concentration

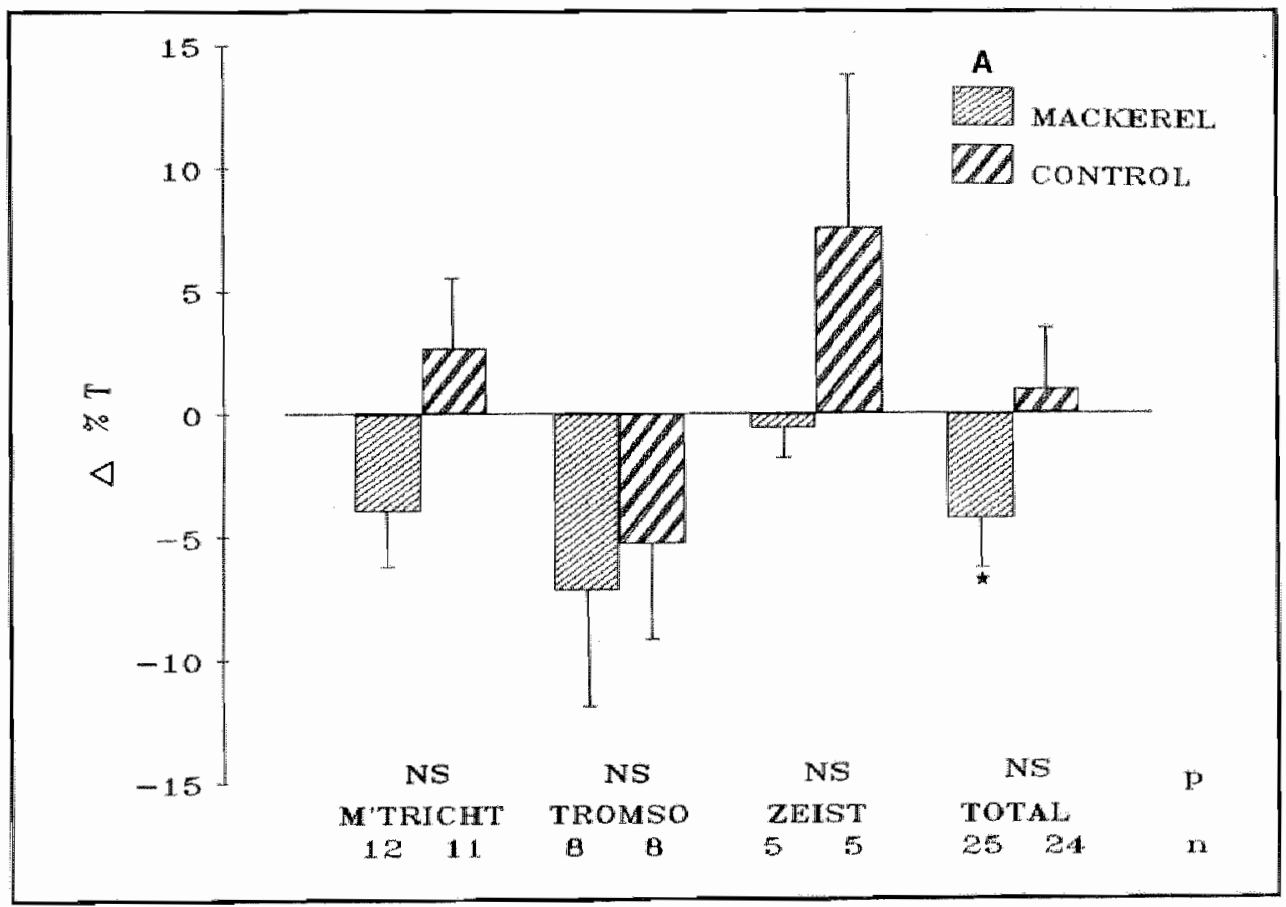

Fig 5.A. Effect of dietary supplements on the change in thrombin-induced aggregation in PRP $(\triangle \% T$ and $S E M)$ of the measurements which gave a maximum aggregation response of about $30 \%$. See Table 4 for initial values. $p$ : significance of differences between mackerel and control groups. NS: not sigmificant. Values significantly different from zero." * $p<0.05$, ** $p<0.005$. 


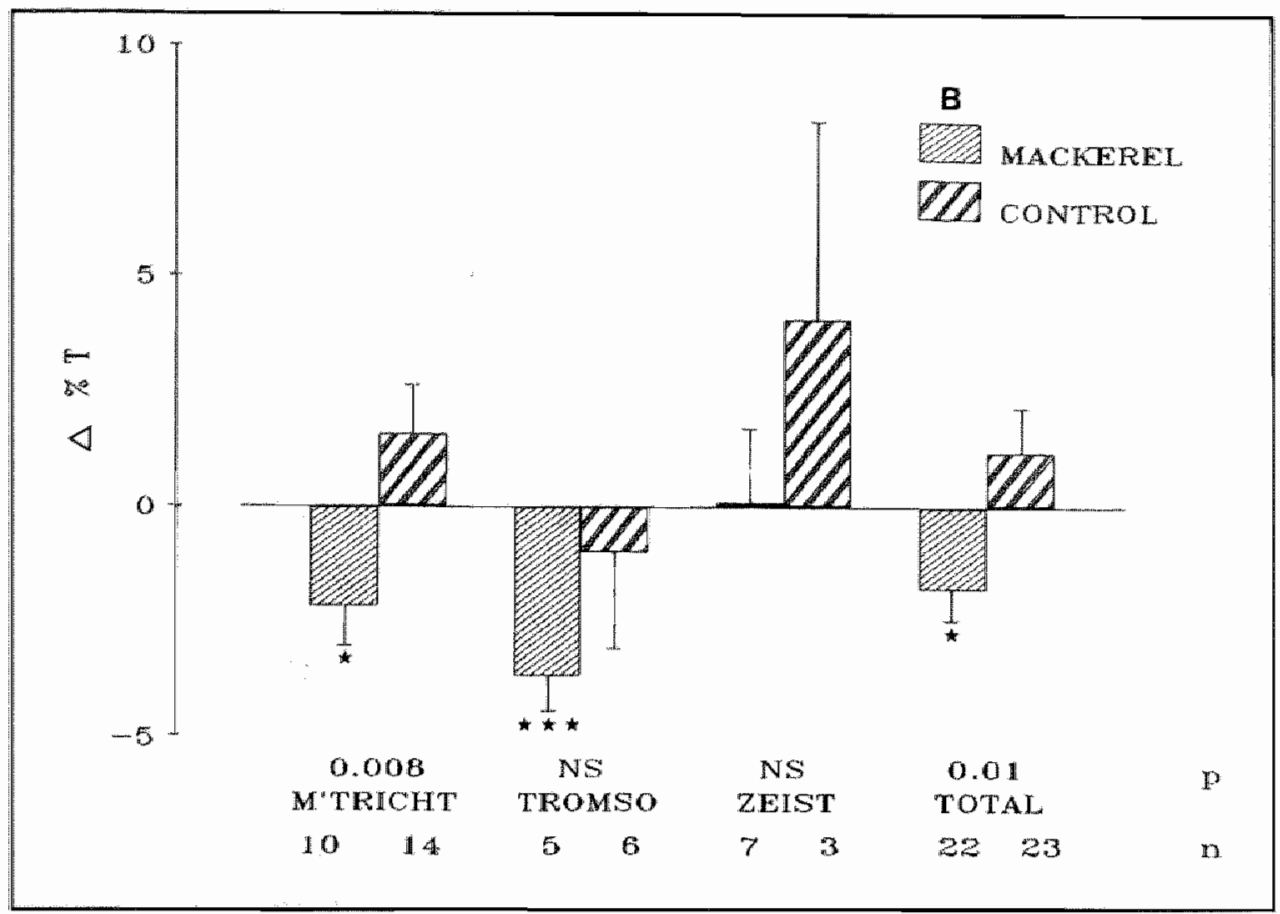

Fig 5 B. Effect of dietary supplements on the change in thrombin-induced aggregation in PRP $(\triangle \% T$ and $S E M)$ of the measurements which gave a maximum aggregation response of about 10\%. For further explanation see Fig. 5A.

cant correlation was observed between the dietary adherence and the extent to which the fish supplement inhibited the collagen-induced platelet aggregation. Moreover, within the experimental group the mackerel effect on platelet aggregation was similar in those $50 \%$ of the volunteers having the highest compliance as compared with the other $50 \%$ having the lowest compliance. Hence, the fish-induced changes in platelet aggregation were not significantly influenced by differences in dietary adherence.

\section{Thrombin-induced platelet aggregation in PRP}

In the three experimental centers, the inter-individual variation in aggregation response was far less for thrombin than for collagen as a platelet activator. However, the limited supply of PRP did not always enable us to obtain the required aggregation responses of 10 and $30 \%$ for each volunteer. Because of this the number of observations in each center was often too small to yield reliable results. At the higher doses of thrombin (giving a $\% \mathrm{~T}$ response of about $30 \%$ at week zero, see Table 7 ), no significant changes in aggregation occurred during the 6 experimental weeks in any of the centers. When the result from the three centers were taken together, a small decrease in aggregation was evident in the mackerel group which was significantly different from zero $(\mathrm{p}<0.05$ ), but which was not significantly different from the (non-significant) change in aggregation observed in the control group (Fig 5A). 
Results for the lower doses of thrombin (initial aggregation response about 10\%, see Table 7) are given in Fig 5B.

In the mackerel groups a significant decrease in aggregation was observed (Zeist excepted), whereas the changes in the control groups were not significantly different from zero. For Maastricht as well as for the three centers combined, this resulted in a significant mackerel effect as compared with the control groups. Based on analysis of variance, however, no significant mackerel effect could be confirmed for the three centers combined although a tendency was obvious $(\mathrm{p}=0.09)$.

Results obtained with the dose of thrombin most frequently used were analysed in a similar way; no significant differences were found between the mackerel and the control groups, either for each center separately, or for the three centers combined.

The effect of the mackerel supplement on the time to maximum aggregation was analysed in an identical way to that described for the maximum aggregation. In general, results were similar (data not shown), which can be explained by the correlation between both aggregation variables at week $0(r=0.64, p<0.001, n=40)$.

Clotting times (low thrombin dose: $200 \pm 11 \mathrm{~s}, \mathrm{n}=45$; high dose: $144 \pm 10 \mathrm{~s}, \mathrm{n}$ $=49$ ) were not affected by the dietary supplements (data not shown).

In general, the results did not change when corrections were made for dietary adherence. It can therefore be concluded that thrombin-induced platelet aggregation in PRP is only slightly affected by the mackerel supplement.

\section{Discussion}

In the present paper the effects of the daily administration of mackerel for 6 weeks on platelet aggregation in PRP are described.

The aggregation measurements were performed in three different experimental centers. Maximum care was taken to perform the measurements under identical conditions in each center. Detailed instructions were given to the research teams and identical equipment and reagents were made available. In spite of this, the response to the same amount of collagen was much higher in Maastricht than in Troms $\varnothing$ and Zeist (Table 5), although all volunteers consumed the meat supplement during the 2 weeks 'run-in period', which was intended to reduce the possible differences in starting conditions between the three centers. A difference in platelet sensitivity was not seen for thrombin-induced aggregation.

It should be pointed out here that the Maastricht volunteers were recruited from the general population and were, on average, significantly older (Table 1) than the participants in Tromsø and Zeist, who were all university students. 
Most probably, the difference in collagen-sensitivity of the platelets in the three centers did not interfere with our experimental results, since the effects of the diet were calculated in relation to a given, pre-determined response level of the platelets at week zero, irrespective of the collagen doses. Since this approach is quite uncommon, we also analysed a series of measurements obtained with one dose of collagen for each center. The results of both approaches were almost identical.

Our study indicates that the fish supplement had a slight but significant reducing effect on collagen-induced platelet aggregation in PRP, which might be due to the potency of activated platelets to produce thromboxane $A_{2}$ (25). Results on collagen-induced aggregation reported in the literature are not at all unanimous, which may be due to methodological differences between the various studies. Although most investigators used the same type and source of collagen we did (Hormon Chemie), the collagen doses applied to stimulate the platelets varied widely (range $0.1-70 \mu \mathrm{g} / \mathrm{ml}, \mathrm{f} . c$.). Moreover, the concentration of platelets in the PRP varied considerably (between $\left.200-400 \times 10^{9} / 1\right)$. The amounts and types of fish(products) investigated were by no means similar; daily doses of timnodonic acid varied between 0.15 to $6 \mathrm{~g}$ and the duration of supplementation ranged from one meal to daily for 20 weeks. However, the equivocal results of the studies are unlikely to be explained by this wide dose range. Finally, the populations under investigation were quite different, comprising healthy young individuals, elderly diabetics, hyperlipidemic patients, etc.

From our study it is evident that a proper control group is essential in this type of nutritional study. Unfortunately, of the 26 collagen-aggregation studies reported so far only 8 included a proper control group (7-14). In 5 (62\%) of these latter studies, fish(oil) administration was shown to reduce collagen-induced aggregation in PRP significantly. This percentage was higher $(72 \%)$ in the poorly - and non-controlled studies (15-32), but it can not be excluded that the positive effect in these studies is (partly) due to an artefact.

Thrombin induced platelet aggregation in PRP was scarcely affected by the fish supplement. This might due to the fact that thrombin-induced aggregation is very little affected by $T \times A_{2}$ formation (38), which may be diminished as a consequence of dietary fish (25). Our results are simular to those of two recently published wellcontrolled studies $(8,10)$ and one poorly-controlled investigation (21). In another poorly-designed experiment, thrombin-induced platelet aggregation appeared to be inhibited by the administration of cod-liver oil (39).

The importance of platelet aggregation as a risk factor for cardiovascular disease is poorly documented. Studies performed after myocardial infarction or in angina pectoris patients demonstrate that platelet aggregation may be enhanced or not altered $(40,41)$. So far, prospective studies to support the concept that increased 
platelet aggregability is a risk factor for the development of ischemic cardiovascular disease have not been reported. This implies that a decrease in platelet aggregation can, in fact, not be interpreted in terms of myocardial risk. Therefore, to investigate the potential of dietary fish for prevention and therapy of cardiovascular ischemia, a long term, prospective study is required, which should focus on incidence and mortality of atherosclerotic diseases.

\section{Acknowledgement}

The aggregometers were made available by the Chrono-log Corporation (Havertown, PA, USA).

\section{References}

1. Hornstra G. Dietary fats, prostanoids and arterial thrombosis. Chapter 7: Effect of fish oil feeding on arterial thrombosis, platelet function and blood congulation; Martinus Nijhoff Publishers, The Hague 1982; 106-137.

2. Hornstra G. The significance of fish and fish-oil enriched food for prevention and therapy of ischaemic cardiovascular disease. In: Crawford MA, Vergroesen AJ (eds). The role of fat in human nutrition II, Academic Press, London in press.

3. Ardlie NG, Han P. Enzymatic basis for platelet aggregation and release: the significance of the 'platelet atmosphere' and the relationship between platelet function and blood coagulation. $\mathrm{Br} J$ Haematol 1974; 26: 331-356.

4. Hornstra G. Platelet vessel wall interaction: role of blood clotting. Phil Trans R Soc Land 1981; B294: 355-371.

5. Mustard JF, Packham MA. Factors influencing platelet function: ad hesion, telease and aggregation. Pharmacol Rev 1970; 22: 97-187.

6. Weiss HJ. Platelets pathophysiology and antiplatelet drug therapy. Chapter 1. Alan R Liss Inc, New York 1982: 1-26.

7. Brox JH, Killie JE, Gunne S, Nordgy A. The effect of cod-liver oil and corn oil on platelets and vessel wall in man. Thromb Haemostas 1981; 46: 604-611.

8. Brox JH, Killie JE, Osterud B, Holme $\mathrm{S}$, Nordøy A. Effects of cod-liver oil on platelets and coagulation in familial hypercholesterolemia (Type Illa). Acta Med Scand 1983; 213: 137-144.

9. Driss $\mathbf{F}$, Vericel E, Lagarde $\mathbf{M}$, Dechavanne $\mathbf{M}$, Darcet $\mathbf{P}$. Inhibition of platelet aggregation and thromboxane synthesis after intake of small amount of icosapentaenoic acid. Thromb Res 1984: 36: $389-396$. 
10. Gevdnigh SH $3 r$, Marris Ws, Conuor WE. The effect of dietary n-3 fatty acids on platelet compostion and function in man; a prospective, controlled study. Blood 1981; 58: 880-885.

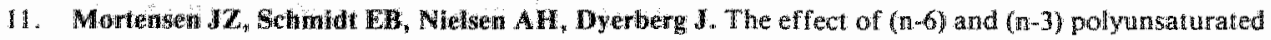
faty y acids on hemostasis ${ }_{i}$ blood lipids and blood pressure. Thromb Haemostas 1983; 50: 543-546.

12. Sanders TAD, Hochland MC. A comparison of the influence on plasma lipids and platelet function of supplentents of $n-3$ and $n-6$ polyunsaturated falty acids. Brit I Nutr 1983; 50:521-529.

13. Adam $O_{n}$ Wolfram $G$, Zoellner $\mathbb{N}$. Verglteich der Wirkung von Linolensaeure und Eicosapentaensature auf die Prostaglandinbiosynthese und Thrombozytenfunktion beim Menschen.(Comparison of the effect of lisolenic acid and cicosapentaenoic acid on prostaglandin biosynthesis and thrombocyte function in humans). Klin Wochenschr 1986; 64: 272-280.

14. Schacky $C$ won, Weber PC. Metabolism and effects on platelet function of the purifsed eicosapentaenoic and docosahexaenoic acids in humans. $\mathrm{J}$ Clin Invest $1985 ; 76: 2446-2450$.

15. Bollon-Smith C, Gibney MJ. The effect of a dietary supplement of marine oil in healthy volunteers on platelet lipids, platelet function and platelet plasma membrane fluidity. Proc Nutr Soc 1986; 45 : 12.

16. Dyerberg J. Platelet-wessel wall interaction: infuence of diet. Phil Trans R Soc Lond B 1980; 294: $373-381$.

17. Hirai A, Terano T, Hamazald T, Sajki J, Kondo S, Oxawa A, Fujita T, Miyamoto T, Tamura Y, Kamugai A. The effect of the oral administration of fish oil concentrate on the release and the metabolism of $\left[{ }^{14} \mathrm{Cl}\right.$ arachidonic acid and $\left[{ }^{14} \mathrm{Cl}\right.$ eicosapentaenoic acid by human platelets. Thromb Res 1982; 28: 285-298.

18. Hiral A, Terano T, Tamura $Y$, Yoshida S, Kamugai A. Eicosapentaenoic acid and thrombotic disorders - Epidemiological and clinical approach. Proceedings of the (n-3) fatty acid meeting. Reading, England, July 1984.

19. Lorentz R, Spengler U, Fischer S, Duhm $\boldsymbol{J}$, Weber P. Platelet function, thromboxane formation and blood pressure control during supplementation of the western diet with cod-fiver oil. Circulathon 1983; 67: 504-511.

20. Nagakawa Y, Orimo H, Harazawa M, Morita I, Yashïo K, Murot S. Effect of eicosapentaenoic acid on the platelet aggregation and composition of fatty acid in man. Atherosclerosis 1983; 47: $71-75$.

21. Nord $\phi$ y $\mathbf{A}$, Lagarde $\mathbf{M}$, Remand S. Platelets during alimentary hyperlipaemia induced by cream and cod-liver oil. Eur I Clin Invest 1984; 14: 339-345.

22. Sanders TAB, Lovat L, Mistry M, Upton K. Influence of a mackerel diet on plasma lipoproteins and platelet function. Proc Nutr Soc 1986; 45: 5 .

23. Sanders $\mathrm{r}$, Roshanai $\mathrm{F}$. The influence of different types of $\mathrm{n}-3$ poiyunsaturated fatty acids on blood lipids and platelet function in healthy volunteers. Clin Sci 1983; 64: 91-99.

24. Schacky $C$ von, Fischer $S$, Welber PC. Long-term effects of dietary marine $\mathbf{n}-3$ fatty acids upon plasma and cellular lipids, platelet function, and eicosanoid formation in humans. I Clin Invest 1985; 76: $1626-1631$.

25. Siess W, Scherer B, Böhlig B, Roth P, Kurzmann I, Weber PC. Platelet-membrane faity acids, platelet aggregation, and thromboxane formation during a mackerel diet. Lancet 1980; i: 441-444. 
26. Terano $\mathbf{T}$, Mirai A, Hamazaki T, Kobayashi S, Fujita T, Tamura $\mathbf{Y}$, Kumagai A. Effect of oral administration of highly purified eicosapentaenoic acid on platelet function, blood viscosity and red cell deformability in healthy human subjects. Atherosclerosis 1983; $46: 321-331$.

27. Thorngren $\mathbf{M}$, Gustafson $\mathbf{A}$. Effects of 11 -week increase in dietary eicospentaenoic acid on bleeding time, lipids and platelet aggregation. Lancet 1981; if: 1190-1193.

28. Thorngren M, Shafi S, Born GVR. Delay in primary haemostasis produced by a fish diet without change in local thromboxane $\mathrm{A}^{2}$. Brit I Haematol 1984; 58: 567-578.

29. Rylance PB, Gordge MP, Saynor $\mathbf{R}$, Parsons $\mathbf{V}$, Weston $\mathbf{M J}$. Fish oil modifies lipids and reduces platelet aggregability in haemodialysis patients. Nephron 1986; 43: 196-202.

30. Bradlow BA, Chetty $\mathbf{N}$, Westhuyzen $\mathbf{I}$ van de, Mendelsohn D, Gibson JE. The effects of a mixed fish diet on platelet function, fatty acid and serum lipids. Thromb Res 1983: 29:561-568.

31. Atkinson PM, Wheeler MC, Mendelsohn D, Pienaar N, Chetty N. Effects of a 4-week freshwater fish (troui) diet on platelet aggregation, platelet fatty acids, serum lipids, and coagulation factors. Am J Hematol 1987: 24: 143-149.

32. Tilvis RS, Rasi V, Vinikka L, Ylikorkala O, Mietlinen TA. Effects of purified fish oil on platelet lipids and function in diabetic women. Clin Chim Acta 1987; 164:315-322.

33. Houwelingen AC v, Nordøy A, Beek E wan der, Houtsmuller UMT, Melx M de, Hornstra G. Effect of a moderate fish intake on blood pressure, bleeding time, hematology and clinical chemistry. Am J Clin Nutr 1987; 46: 436-437.

34. Sanchez-Castill CP, James WPT. The use of lithium as a marker of sodium intake. Proc Nutr Soc $1983 ; 42: 168 \mathrm{~A}$.

35. Dixon WJ. Ratios involving extreme values.Ann Math Stat 1951; 22: 68-78.

36. Miller RG. Simultaneous statistical inference, 2nd ed; Springer Verlag New York 1981.

37. Houwelingen $\mathbf{A C} \mathbf{v}$, Hornstra $G$. Effect of a moderate fish intake on blood pressure, platelet function and safety aspects. Agents and Actions 1987; 22: 3-4.

38. Burck JW, Magerius PW. The role of prostaglandins in platelet function. Sem Haematol 1979: 16; 196-207.

39. Ahmed AA, Holub BJ. Alternation and recovery of bleeding times, platelet aggregation and fally acid composition of individual phospholipids in platelets of human subjects receiving a supplement. of codliver oil. Lipids 1984; 19:617-624,

40. Weiss HJ: Platelets pathophysiology and antiplatelet drug therapy. Chapter 4. Alan R Liss Inc, New York 1982: 76-94.

41. Kinlough-Rathbone RL, Packham MA, Mustard JF. Platelet aggregation; In: Measurements of platelet function. Harker LA, Zimmerman TS (eds). Chapter 4. Churchill Livingsione, Edinburgh 1983: 64-91. 


\section{EFFECT OF MODERATE FISH INTAKE ON PLATELET AGGREGATION AND ATP RELEASE IN HUMAN BLOOD}

\section{Summary}

A study to investigate the effect of a reasonable amount of dietary fish on collageninduced platelet aggregation and ATP release in citrated whole blood is described. Two groups of twenty healthy male volunteers were given a daily dietary supplement consisting of $135 \mathrm{~g}$ of tinned mackerel paste (experimental group) or meat paste (control group) for a 6 week period. Compliance, calculated on the basis of the urinary excretion of lithium added to the supplements, was about $80 \%$.

The mackerel supplement had a weak but significant inhibitory effect on collageninduced platelet aggregation (impedance method) and ATP rellease (firefly assay) in whole blood. Platelet release was significantly related to the compliance.

Key words: fish, diet, compliance, platelet aggregation, whole blood, collagen, ATP-release. 


\section{Introduction}

A diet rich in fish or fish products may be beneficial in the prevention of ischemic cardiovascular disease in man (1). This protective effect is likely to be due to an influence on certain functions of blood platelets involved in arterial thrombogenesis (2). In human intervention studies it has been demonstrated that diets enriched with fish or fish oils can reduce the aggregability of blood platelets. In most of these investigations platelet aggregation has been studied using the classical photometric method (3), which excludes measurements in whole blood and requires the separation of platelets from the other blood cells by differential centrifugation. Platelets are heterogeneous in size, density and metabolic activities $(4,5)$ and, therefore, the centrifugation procedure might cause a selection of certain subgroups of platelets, since the heavier ones and those sticking loosely together may not be recovered. Moreover, a possible contribution of red cells and leukocytes to the aggregation process (6) cannot be determined, when platelet rich plasma (PRP) is used. Another disadvantage of measuring platelet aggregation in PRP is the time lapse between blood collection and the measurements. During this period components, normally present in blood, but with a short half-life may disappear, which might influence platelet function in an unpredictable way. This hampers the interpretation of these in-vitro data with respect to the in-vivo effects of fish(oil)-enriched diets.

Some time ago, an aggregation technique was developed which enables the measurement of platelet aggregation in whole blood. This method is based on changes in electrical impedance of blood, resulting from platelet adhesion to an electrode followed by aggregation $(7,8)$. This aggregation method is possibly preferable to that in PRP because the platelet responses are determined in an environment that is much more physiological than PRP. For these reasons, a well-controlled study was conducted to investigate the effect of a reasonable amount of fish in the diet on collagen induced platelet aggregation in whole blood. Platelet ATP-release was also measured.

\section{Materials and methods}

The study was part of a more extensive investigation, the design of which lias been published comprehensively before (9). Experimental details will be given only insofar as they are related to the results in the present paper.

Forty healthy male volunteers (20-45 years of age) participated in the study. The experiment lasted 6 weeks and was preceded by a run-in period of 2 weeks. During this run-in period all volunteers were requested to consume one tin of meat paste $(135 \mathrm{~g})$ per day, after which they were randomized into a mackerel and a meat (control) group. During the 6 experimental weeks the volunteers of the mackerel group consumed one tin of mackerel paste $(135 \mathrm{~g})$ per day, while the controls continued the consumption of meat paste. The dietary supplements were given as a replace- 
ment for the fish, meat, cheese and eggs normally consumed during the main meal. The mackerel paste provided $1.7 \mathrm{~g}$ timnodonic acid (EPA, 20:5 $\mathrm{n}-3$ ) and $3.0 \mathrm{~g}$ cervonic acid (DHA, 22:6 n-3) per day.

Compliance was calculated on the basis of the daily urinary excretion ( $\%$ ) of a standard amount of lithium added to the supplements. The maximum lithium intake per day was about 100 times the amount naturally available in the diet and yet represented only one percent of the therapeutic dose (10). Compliance was also calculated on the basis of $\mu \mathrm{mol}$ urinary lithium per mmol urinary creatinine. To correct for a possible influence of inaccuracies during urine collection and to minimize the intluence of differences in body-mass and sudden changes in exercise level, both compliance indices were multiplied, resulting in a variable (the compliance index) which was used to investigate possible relationships between dietary adherence and dietinduced changes in platelet aggregation and release.

At week 0 (the end of the run-in period) and week 6 blood was drawn under fasting conditions after the volunteers had been resting for $20 \mathrm{~min}$ in a supine position. Under minimum stasis a forearm vein was punctured using a $19 \mathrm{G}$ butterfly-venisystem and a series of blood samples were taken for various measurements (9). For the measurement of platelet aggregation and ATP release in whole blood, $1.8 \mathrm{ml}$ blood was taken in a prewarmed $\left(37.5^{\circ} \mathrm{C}\right)$ syringe containing $0.2 \mathrm{ml}$ of the citrate solution. The blood was gently mixed with the anticoagulant and $1 \mathrm{ml}$ was immediately transferred into a prewarmed aggregometer cuvette (no. 68.750, Sarstedt, Numbrecht, FRG). The cuvettes had been slightly shortened to fit the thermostated cuvette holder of a Chronolog whole blood lumi-aggregometer (model 500, Chrono-log Corporation, Havertown, PA, USA). The cuvette already contained a tefloncoated stirbar for stirring at $1000 \mathrm{rpm}$ and $100 \mu \mathrm{l}$ of the luciferase-luciferin reagent Chrono-lume ${ }^{(n)}$ (no. 395, Chrono-log Corporation) to quantify the release of adenosine triphosphate (ATP), which reflects the platelet release reaction (11). All measurements were performed with 3 stirbars which had been pre-selected to give the same aggregation response when tested under standard conditions.

After 5 min of pre-incubation and calibration, aggregation was induced by adding $10 \mu 1$ of a diluted collagen suspension, which was freshly prepared each day from a stock solution (Collagen Horm ${ }^{2}$, Hormon Chemie, Munich, F.R.G., $1 \mathrm{mg} / \mathrm{ml}$ ) using the special dilution buffer. It provided an amount of collagen in the aggregation cuvette of $0.5 \mu \mathrm{g} / \mathrm{ml}$ citrated blood. After $15 \mathrm{~min}$ of aggregation, $10 \mu \mathrm{l}$ of an ATP (no. A 6144, Sigma, St. Louis, MO, USA) solution (133 $\mu \mathrm{mol} / 1)$ was added to the cuvette. The luminescence response to this standard dose was used to calculate the amount of ATP released by the platelets upon their activation with collagen. This approach is different from that advised by the manufacturers. However, in the discussion section our modification will be clarified. The aggregation and release signals were monitored on a dual channel flat bed recorder. Whole blood platelet aggregation and release were quantified as shown in Fig 1. The luminescence curve indicates the platelet release reaction (11) and is the resultant of occurring ATP 


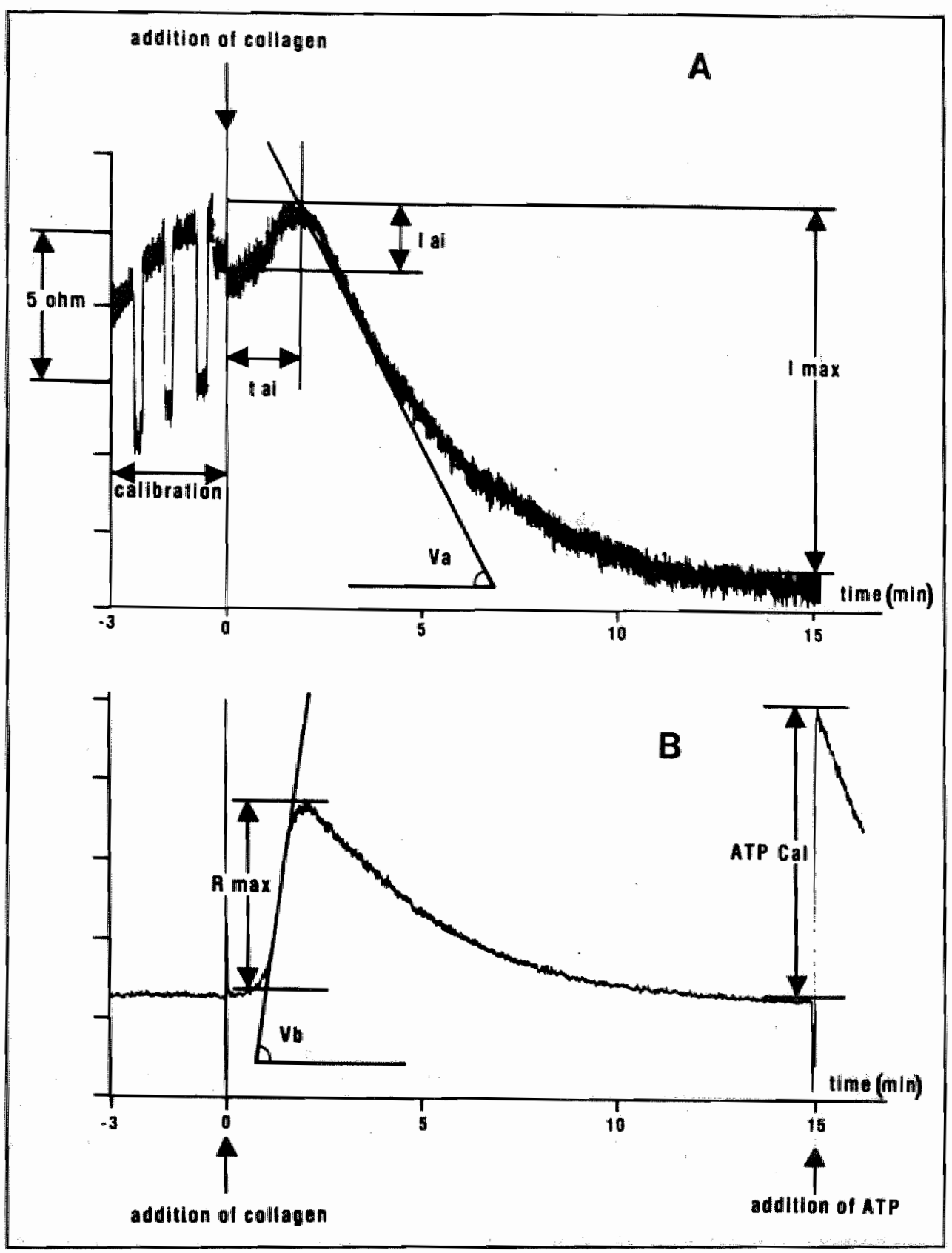

Fig 1. Schematic representation of the recorder tracings, showing platelet aggregation (A) and ATP release $(B)$ in whole blood.

A t-at: Aggregation induction fime (s): the time lapse between collagen addition and the moment the curve reached the lowest impedance value.

(-ai: Pre-aggregation response (ohm): the total decrease in impedance after administration of collagen.

(to be continued on next page) 
Va: Aggregation velocity: the tangent of angle a, which is formed by the steepest slope of the aggregation curve and the horizontal axis.

Imax. Maximum aggregation (ohm): the maximum change in impedance reached within 15 min after collagen addition.

$B$ Vb: Release velocity: the tangent of angle b, which is formed by the steepest slope of the release curve and the horizontal axis.

Rmax: Maximum ATP-release reached within 15 min after collagen addition (nmol ATP).

ATPcal: Calibration reaction: change in luminescence caused by adding a standard amount of ATP $(10 \mu l, 133 \mu$ mol $/ 1), 15$ min after the addition of collagen.

The release parameters ( $\mathrm{Vb}$ and $\mathrm{Rmax}$ ) were calculated laking into account the results of the calibration reaction (ATPcal).

release and breakdown and the decay of the luminescence signal following the reaction between the luciferase-luciferin system with the secreted ATP.

\section{Statistical evaluation}

All data were checked for their frequency distributions and when necessary, transformation of the data was applied to normalize this distribution. Subsequently significant outliers were omitted (12).

Differences between the mackerel-and control group were evaluated using Student's 2-sample t-test. To evalluate the changes in the mackerel-and the control group after 6 weeks the Student's t-test for paired data was used. Occasionally, other statistical methods were used which will be outlined when describing the results. Differences were considered significant when the two-sided $\mathrm{P}$ walue (p) was equal to or smaller than 0.05 .

\section{Results}

No side effects of the dietary supplements were observed during the study (9). The average dietary adherence at week 6 was $86 \%$ for the control group and $84 \%$ for the mackerel group. One volunteer was excluded because of very poor compliance. Transformation of the data was required for time related parameters only. For the sake of clarity, non-transformed values will be given only.

A the start of the experiment (week 0 ) there were no significant differences between the mackerel-and the control group for any of the variables measured. Unexpected$1 y$, at week six the responses to the same amount of collagen were greatly reduced in both groups. Therefore, the amount of collagen was gradually increased to find a dose which gave about the same response as at week 0 . Results for the aggregation velocity (Va) are given in Fig 2, from which it is evident that no significant differ- 


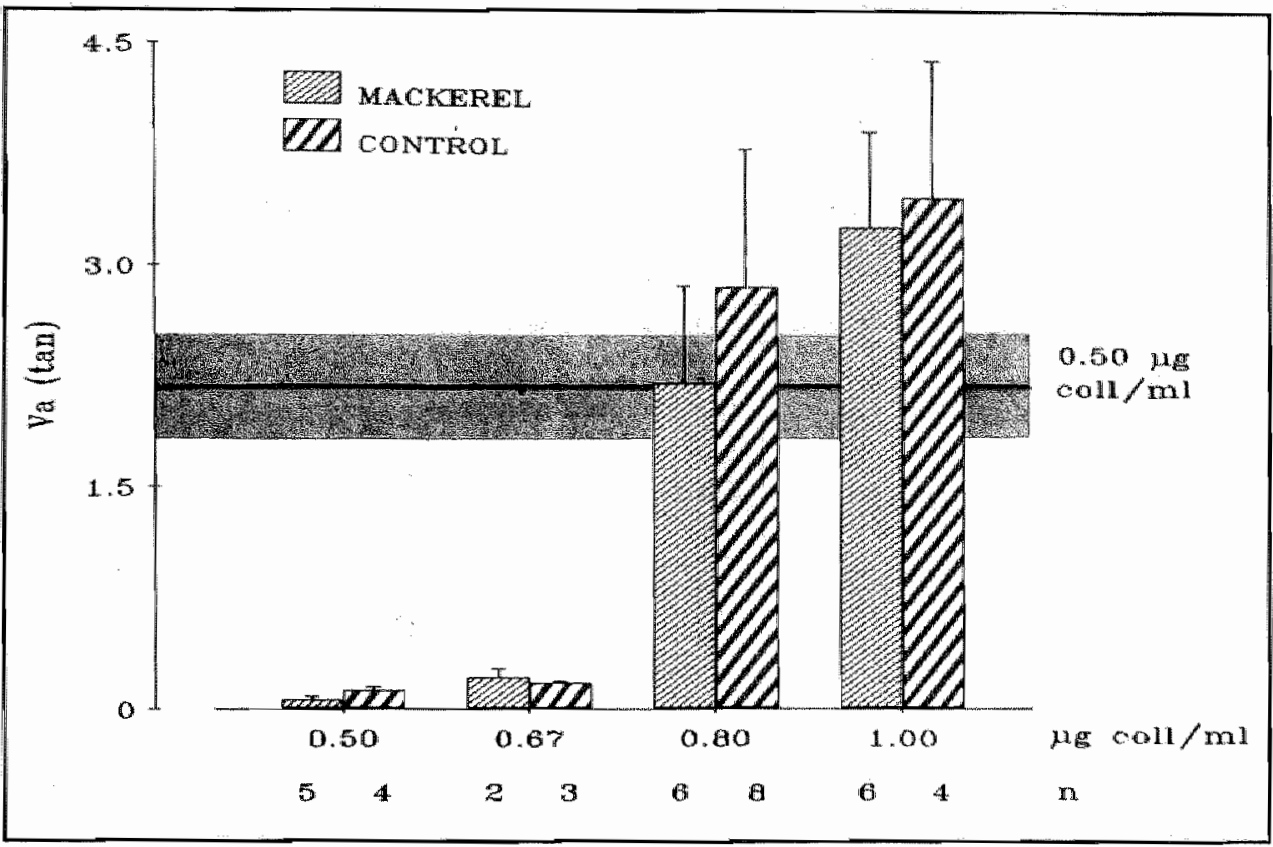

Fig 2. Collagen induced platelet aggregatian in cirrated whole blood (aggregation velocity (Va, tangent), mean and SEM) at week 6 (bars). The horizontal line and shaded area in the midale reflect the mean and SEM of the aggregation velocity at week zero $(n=39)$.

ences existed between the mackerel- and the control group. The same held for the other aggregation variables and for the results of the ATP release (data not shown).

The collapse of the platelet functions during the study, which forced us to increase the collagen dose at week 6, may have created an unfavourable situation for observing any effect of the dietary supplements. Therefore, about one year later we repeated the run-in period during which all volunteers again consumed one tin of meat paste per day. Before and after this second run-in period, platelet aggregation and release were measured using for each volunteer the same dose of collagen as had been applied at week 6 of the original experiment. Four volunteers were unable to participate. Using these post-experimental results as reference values, the changes in aggregation and release occurring at week 6 were analysed again. When the results were calculated separately for those samples activated with an identical collagen concentration, some significant changes occurred in the mackerel as well as in the control group. These data, however, are not very reliable because of the small number of observations for each of the doses. Therefore, the overall effect of the mackerel was evaluated applying analysis of variance on the total material. Because of the differences in variance between the results obtained with the lower and higher collagen concentrations respectively, logarithmic transformation was applied to stabilize the variance. According to Levene's test for equality of variances ( 13 ), this 


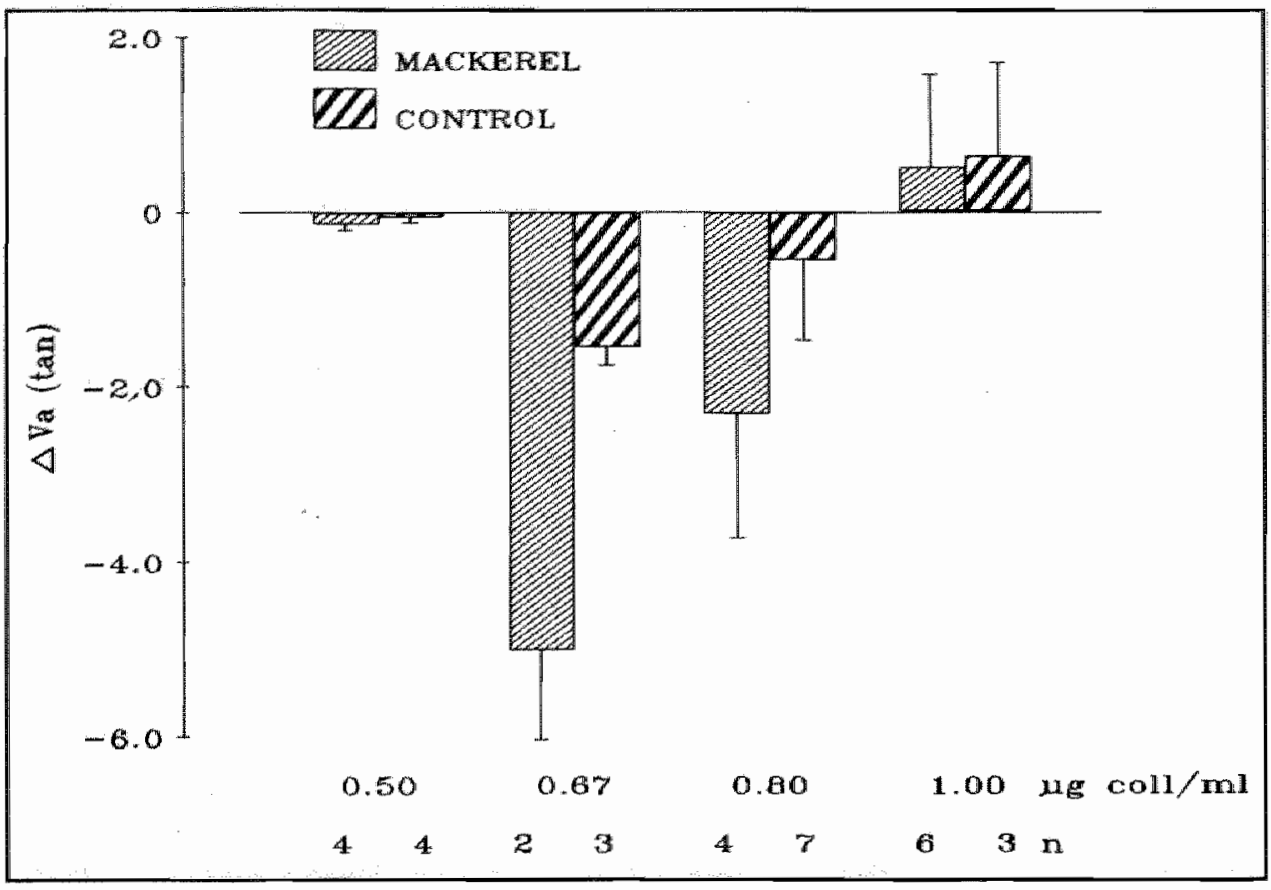

Fig 3. Change in aggregation velocity ( $\mathrm{Va}$ ) of collagen induced platelet aggregation in citrated whole blood (mean and SEM).

treatment appeared successful. Analysis of variance then demonstrated that the aggregation welocity (Va) was reduced more in the mackerel group than in the control group ( $\mathrm{p}<0.04$; Fig 3).

For the other variables used to quantify platelet aggregation and release, the differences between mackerel- and control group were not significant. However, when dietary adherence was taken into account, additional effects of the mackerel supplement were observed. Thus, within the experimental group the mackerel effect on platelet ATP release was significantly more pronounced in those $50 \%$ of the volunteers having the highest compliance, as compared with the $50 \%$ having the lowest compliance (release velocity, $\mathrm{Vb}: \mathrm{p}=0.035$; maximum release, $\mathrm{Rmax}: \mathrm{p}=0.006$ ). Within the control group no difference in release response was found between the volunteers belonging to the subgroups with the highest and lowest $50 \%$ compliance, respectively. No significant difference was seen between the mackerel-and the control group when the results were compared within each of these two compliance subgroups (Table 1).

Since four different collagen doses were used for the various volunteers, large variations occurred in the initial release values. To correct for a possible influence of the initial value on the diet induced effects, the responses after 6 experimental weeks were related to their reference values (obtained during the second run-in period) by 
Table 1. Effect of dietary supplements on change in platelet ATP release $($ mean $+S E M)$ for those $50 \%$ of the volunteers hawing the highest compliance as compared with the other $50 \%$ having the lowest compliance (n $=8$ per subgroup).

MAXIMUM RELEASE (Rmax, Anmol ATP)

\begin{tabular}{llcl}
\hline \multirow{2}{*}{ Group } & \multicolumn{2}{l}{ Compliance subgroup } & $\mathrm{p}$ \\
\cline { 2 - 3 } & lowest $50 \%$ & highest 50\% & \\
\hline Mackerel & $0.17 \pm 0.22$ & $-0.81 \pm 0.20^{\mathrm{a}}$ & 0.006 \\
Control & $0.08 \pm 0.20$ & $0.20 \pm 0.50$ & NS \\
\hline$p$ & NS & $0.090(\mathrm{NS})$ & \\
\hline
\end{tabular}

$\mathrm{a}: \mathrm{p}<0.002$

RELEASE VELOCITY $(\triangle \mathrm{Vb})$

\begin{tabular}{llll}
\hline \multirow{2}{*}{ Group } & \multicolumn{2}{l}{ Compliance subgroup } & $\mathrm{p}$ \\
\cline { 2 - 3 } & lowest $50 \%$ & highest $50 \%$ & \\
\hline Mackerel & $1.04 \pm 0.30^{\mathrm{a}}$ & $0.22 \pm 0.13$ & 0.034 \\
Control & $0.69 \pm 0.40$ & $0.27 \pm 0.09^{\circ}$ & $\mathrm{NS}$ \\
\hline $\mathrm{p}$ & $\mathrm{NS}$ & $\mathrm{NS}$ & \\
\hline
\end{tabular}

$\mathrm{a}: \mathrm{p}<0.01, \mathrm{~b}: \mathrm{p}<0.02$

taking the quotient of both values. To normalize the frequency distribution of this variable, logarithmic transformation was applied. It then appeared that within the mackerel group a significant correlation existed between dietary adherence (based on the compliance index) and the platelet release reaction ( $\mathrm{Vb}: \mathrm{r}=0.56, \mathrm{p}=0.02$; Rmax: $r=0.49, p=0.06$ ). Within the control group these correlations were not significant. The laypothesis of a common regression line $(\mathrm{Y}=\mathrm{R} \max , \mathrm{X}=$ compliance index) for both the mackerel- and the control group was tested against the alternative of two separate lines. After removal of an influential case from the mackerel group (Cook distance -ref. $14-1.14$ ), the $F$ test for equality of the regression lines yielded a $\mathrm{p}$ value of 0.01 . This implies that the two regression lines were significantly different from each other (Fig 4). The same holds for the release velocity ( Vb; $\mathrm{p}=0.03$ ).

This indicates that the effect of the fish supplement on release velocity and maximum ATP release was different from that of the meat supplement.

The conclusions concerning the aggregation variables did not change when dietary adherence was taken into account. All these results taken together, it can be concluded that the mackerel supplement had a weak inhibitory effect on collageninduced platelet aggregation and ATP release in citrated whole blood. 

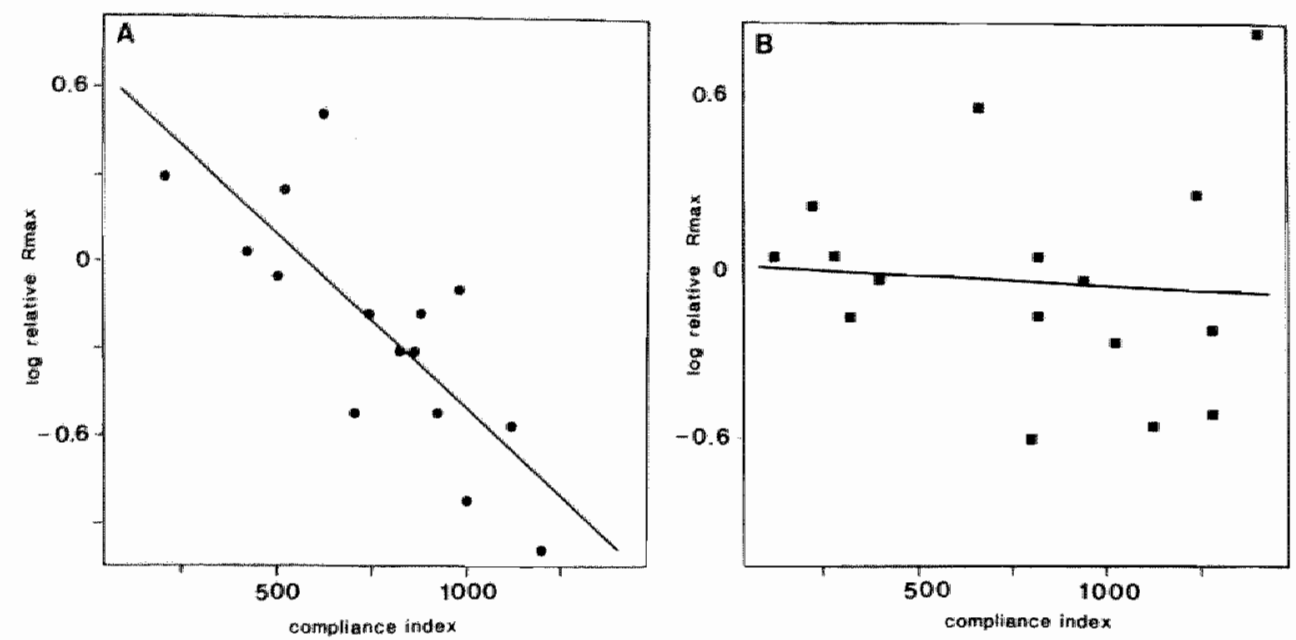

Fig 4. Relative change of platelet ATP release in relation to compliance.

A: mackerel group $(n=16), Y=0.683-119.10^{-5} X, r=-0.78, p<0.001$.

B: control group $(n=16), Y=0.174-668.10^{-7} X, r=-0.075, p=N S$.

\section{Discussion}

In the present paper collagen induced platelet aggregation and ATP release in citrated whole blood were measured using the Chronolog whole blood lumi-aggregometer, which has not previously been applied in dietary studies.

At the start of the experimental period no significant differences were observed between the mackerel- and the control group for any of the aggregation and release variables measured. For unknown reasons, however, the same dose of collagen (of the same batch) used at the end of the experimental period caused very poor platelet responses, both in the mackerel and in the control group (Fig 2). From comparison of the results obtained immediately before and at the end of the second run-in period, it could be concluded that the lithium-containing meat paste did not affect platelet aggregation and ATP release in a significant way (data not shown). Without a control group, we might have concluded that the decrease of aggregation was caused by the fish supplement. However, since the effects of the two dietary supplements were not significantly different from each other, no specific effect of the mackerel paste could be confirmed.

Because of the poor platelet responses at week 6 , the collagen dose was gradually increased and the results obtained in this way were compared with the aggregation responses obtained with the same collagen doses after a second 'run-in period' about one year later. It then appeared that the mackerel paste had a slight but significant decreasing effect on platelet aggregation and ATP release which (for release only) was more distinct the better the dietary adherence. This latter finding indicates that a more pronounced effect of dietary fish may be expected at a higher daily intake 
Table 2. Correlations between whole blood platelet aggregation and release parameters (week $0, n=36-39$ ).

\begin{tabular}{|c|c|c|c|c|c|c|}
\hline & \multicolumn{3}{|c|}{ Aggregation } & \multicolumn{3}{|l|}{ Release } \\
\hline & $x-a^{2}$ & $\mathrm{Va}$ & Imax & $\mathrm{Vb}$ & $R \max$ & ATPcal \\
\hline \multirow[t]{2}{*}{ t-aì } & $0.341^{b}$ & -0.533 & -0.444 & -0.481 & -0.458 & -0.044 \\
\hline & $0.036^{\mathrm{c}}$ & $<0.001$ & 0.005 & 0.003 & 0.004 & NS \\
\hline \multirow[t]{2}{*}{ I-ai } & & 0.156 & 0.293 & 0.074 & 0.181 & 0.006 \\
\hline & & NS & NS & NS & NS & NS \\
\hline \multirow[t]{2}{*}{$\mathrm{Va}$} & & & 0.894 & 0.707 & 0.733 & -0.220 \\
\hline & & & $<0.001$ & $<0.001$ & $<0.001$ & NS \\
\hline \multirow[t]{2}{*}{$\operatorname{Imax}$} & & & & 0.618 & 0.677 & -0.263 \\
\hline & & & & $<0.001$ & $<0.001$ & NS \\
\hline \multirow[t]{2}{*}{$\mathrm{Vb}$} & & & & & 0.765 & -0.013 \\
\hline & & & & & $<0.001$ & NS \\
\hline \multirow[t]{2}{*}{$\mathbb{R m a x}$} & & & & & & -0.196 \\
\hline & & & & & & NS \\
\hline
\end{tabular}

\footnotetext{
a: Abbreviations explained in Fig 1

b: coefficient of correlation

c: $p$ values
}

than could be achieved in the present experiment. It is very doubtful, however, whether this ever can be realized, since in our experiment the dietary adherence decreased significantly during the 6 week experimental period (9).

The course of the impedance response following the induction of platelet adhesion and aggregation in the Chronolog whole blood aggregometer is still poorly understood. From correlation studies (Table 2) it appeared that the release parameters $\mathrm{Rmax}$ (the maximal ATP release) and $\mathrm{Vb}$ (the release velocity) were not only significantly correlated with each other, but also with the aggregation induction time (t-ai), the aggregation velocity (Va) and the maximum degree of aggregation (Imax). These aggregation variables were also strongly interrelated.

The variable I-ai, which reflects the initial decrease in impedance which always precedes the aggregation-associated increase in impedance, was not significantly correlated with any of the aggregation and release parameters ( $t$-ai excluded). Although the curve suggests that this pre-aggregation response could reflect platelet shape change, this did not appear to be the case (7). The lack of correlation with all other platelet dependent variables indicates that 1 -ai does not reflect a known platelet function response.

The ATP calibration reaction (ATPcal) did not correlate with any of the aggrega- 
Table 3. Correlation of whole-blood platelet aggregarion and release variables with hematocrit (HCT) and white and red blood cell counts (WBC and RBC), and with platelet cownt (PC). $n=38-39$.

\begin{tabular}{|c|c|c|c|c|}
\hline & $\mathrm{HCT}$ & WBC & $\mathrm{RBC}$ & $P C$ \\
\hline$i-a i^{m}$ & $\begin{array}{r}-0.274^{b} \\
N S^{c}\end{array}$ & $\begin{array}{r}-0.159 \\
\mathbb{N S}\end{array}$ & $\begin{array}{r}-0.170 \\
N S\end{array}$ & $\begin{array}{r}-0.307 \\
\text { NS }\end{array}$ \\
\hline I ali & $\begin{array}{r}0.312 \\
\mathrm{NSS}\end{array}$ & $\begin{array}{r}0.074 \\
\mathrm{NS}\end{array}$ & $\begin{array}{r}0.079 \\
\text { NS }\end{array}$ & $\begin{array}{r}-0.014 \\
\mathrm{NS}\end{array}$ \\
\hline $\mathrm{Va}$ & $\begin{array}{r}-0.149 \\
\mathbb{N S}\end{array}$ & $\begin{array}{r}0.042 \\
\text { NS }\end{array}$ & $\begin{array}{r}0.299 \\
\text { NS }\end{array}$ & $\begin{array}{l}0.435 \\
0.005\end{array}$ \\
\hline$I \max$ & $\begin{array}{r}0.225 \\
\mathbb{N S}\end{array}$ & $\begin{array}{r}0.260 \\
\text { NS }\end{array}$ & $\begin{array}{r}-0.003 \\
\text { NS }\end{array}$ & $\begin{array}{l}0.432 \\
0.006\end{array}$ \\
\hline $\mathrm{Vb}$ & $\begin{array}{r}-0.137 \\
\text { NS }\end{array}$ & $\begin{array}{r}0.078 \\
\text { NS }\end{array}$ & $\begin{array}{r}-0.245 \\
N S\end{array}$ & $\begin{array}{l}0.448 \\
0.004\end{array}$ \\
\hline$R \max$ & $\begin{array}{r}-0.170 \\
\mathrm{NS}\end{array}$ & $\begin{array}{r}0.027 \\
\mathbb{N S}\end{array}$ & $\begin{array}{r}-0.316 \\
\text { NS }\end{array}$ & $\begin{array}{l}0.325 \\
0.046\end{array}$ \\
\hline ATPcal & $\begin{array}{r}-0.154 \\
\text { NS }\end{array}$ & $\begin{array}{r}-0.194 \\
\text { NS }\end{array}$ & $\begin{array}{r}-0.357 \\
0.027\end{array}$ & $\begin{array}{r}-0.183 \\
\text { NS }\end{array}$ \\
\hline
\end{tabular}

a: abbreviations explained in Fig 1

b: Coefficient of correlation

c: degree of significance

tion and release parameters, which suggest that the calibration response is not affected by the degree of platelet aggregation. Therefore, it is not necessary to perform the ATP calibration in a second non-aggregated blood sample, as is suggested by the manufacturer of the luminescent reagent (15).

As is indicated by Table 3, platelet aggregation and ATP release were independent of hematocrit and white cell counts. Although such correlations have been described before by others (16-19) this does not seem to hold for the physiological hematocritrange (16).

A significant negative relationship was observed between the erythrocyte count and the ATP calibration reaction (Table 3). This demonstrates that it is necessary to correct for the influence of the red cell number on the ATP release measurements, which we did by calibrating each blood sample with a standard amount of ATP. The platelet count in whole blood correlated significantly with various aggregation and release variables, indicating higher values at higher platelet counts. Since the fish supplement significantly lowered the platelet count $(20)$ we investigated whether 
the fish induced changes in platelet aggregation were caused by a drop in platelet count. Linear regression revealed no association between the changes in aggregation and ATP release indices and the change in platelet number.

We recently described (21) a significant decreasing effect of the fish supplement on collagen-induced platelet aggregation in PRP; in fact, the aggregation measurements in PRP and whole blood were performed at the same time. Although the fish effect on aggregation in PRP was comparable to that in whole blood, the two measurements did not correlate significantly with each other. This was investigated in detail at week zero for all 40 volunteers with $0.5 \mu \mathrm{g}$ collagen $/ \mathrm{ml}$ used for aggregation induction in whole blood as well as in PRP. The maximum aggregation measured in whole blood (Imax) did not correlate significantly with the maximum aggregation measured in PRP (\% light transmission). For unknown reasons this is not in agreement with results obtained by others $(16,22)$. The lack of correlation in our study points to the possibility that the results of platelet aggregation studied in whole blood reflect other platelet properties than those in PRP.

\section{References}

1. Hornstra $G$. The significance of fish and fish-oil enriched food for prevention and therapy of ischaemic cardilovascular disease. In: Crawford MA, Vergroesen AJl (eds). The role of fat in human nutrition II, Academic Press, Tondon in press.

2. Hornstra G. Dietary fats, prostanoids and arterial thrombosis. Chapter 7 : Effect of fish oil feeding on arterial thrombosis, platelet function and blood coagulation. In: Martinus Nijhoff Publishers, The Hague 1982: 106-137.

3. Borm GVR. Quantitative investigations into the aggregation of blood platelets. J Physiol London $1962 ; 162 ; 67-68$.

4. Frojmovic MM, Mülton JG. Human platelet size, shape and related functions in healti and disease. Physiolol Rev 1982; 62: 185-261.

5. Karpatkin S, Charmartz A. Heterogeneity of human platelets. J Clin Invest 1969; 48: 1073-1087.

6. Harrison MJG, Emmons PR, Mitchell JRA. The effect of white cells on platelet aggregation. Thromb Path Haem 1.966; 16: 105-121.

7. Cardinal DC, Flower RJ. The electronic aggregometer: novel device for assessing platellet behaviour in blood. J Pharmacol Meth $1980 ; 3: 135-158$.

8. Ingerman-Wojenski CM, Silver MJ. A quick method for screening platelet dysfunctions using the whole blood lumi-aggregometer. Thronb Haemostas 1984; 51: 154-156. 
9. Houwelingen AC W, Nordoy A, Beek Ean der, Houtsmuller UMT, Metz M de; Hornstra G. Effect of a moderate hish imtake on blood pressure, bleeding time, hematology and clinical chemistry. An J Clin Nite 1987: $46: 424-436$

10. Sanchez-Castill CP, James WPT. The use of lithum as a marker of sodium intake. Proc Nutr Soc $1983 ; 42$; 168A.

H1. Teinman RD, Lubowsky J, Charo I, Zabinski MP. The lumi-aggregometer: a mew instrument for simultaneous measurement of secretion and aggregation by platelets. J Lab Clin Med 1977; 90 : 125-127.

2. Dixon WJ. Ratios involwing extreme values. Amn Math Stat 1951; 22: 68-78.

13. Levene H. Robust tests for equality of variance. In: Olkin I (ed). Contributions to probability and statistics. Stanford Univ Press, Palo Alto, Calif 1960: 278-292.

14. Weisberg S. Applied linear regression. Wiley, New York 1985: 118-120.

15. Anonymotns. Instructions Chrono-log Corporation, Havertown; Nov. 1985.

16. Abbate $\mathbb{R}$, Favilla $\mathrm{S}$, Boddi M, Costanzo $\mathbf{G}$, Prisco D. Factors infuencing platelet aggregation in whole blood. Am I Clist Pathol 1986; $86 ; 91-96$.

17. Harrison JG, Pollock SS, Weisblatt E. Haematocrit and platelet aggregation, Lancet 1984; ji* $991-992$.

18. Samiabadi AR, Lowe GDO, Barbenal JC, Forbes CD. Haematocrit, bleeding time, and platelet aggregation. Lancet 1984; i: 1409-1410.

19. Mackie $\$$, Jones $\mathbb{R}$, Makin SJ. Platelet impedance aggregation in whole blood and uts inhibition by anti-platelet drugs, J Clin Pathol 1984; 37: 874-878.

20. Houwelingen AC , Hornstra $G$. Effect of a moderate fish intake on blood pressure, platelet functhon and safety aspects. Agents and actions 1987; 22: $371-372$.

21. Houwelingen AC , Henmissen AAM, Verbeek-Schippers G, Simonsen G, Kester ADM, Hornstrin G. Effect of a moderate fish intake on platelet aggregation in human platelet rich plasma. Thromb Haemost 1988; $59: 507-513$ (Chapter 6).

22. Ingerman-Wojenski CM, Smith JB, Silver MJ. Haw valution of electrical aggregometry: comparison with optical agregometry sectetion of ATP and accumulation of radiolabeled platelets. J Lab Clin Med 1983; $101: 44-52$. 


\section{CHAPTER 8}

\section{INFLUENCE OF DIETARY FISH ON EICOSANOID METABOLISM IN MAN}

\section{Summary}

Two groups of 40 volunteers were given a dietary supplement consisting of $135 \mathrm{~g}$ of mackerel or meat (control) paste per day for 6 weeks. Before and after this experimental period various aspects of eicosanoid formation and metabolism were measured. Compliance was about $80 \%$ in both groups and the daily intake of $20: 5$ n-3 and 22:6 n-3 from the mackerel supplement was about 1.4 and $2.4 \mathrm{~g}$, respectively. In collagen-activated platelet rich plasma the potency of blood platelets to produce cyclo-oxygenase and lipoxygenase-dependent monohydroxy fatty acids from endogenous arachidonic acid (HHT and HETE) was significantly reduced in the mackerel group as compared with the control group, whereas the formation of products derived from endogenous timnodonic acid (HHTE and HEPE) significantly increased. Changes in the formation of HHT and HHTE, measured by HPLC, correlated significantly with those of $\mathrm{TxB}_{2}$ and $\mathrm{TxB}_{3}$, respectively, measured by $\mathrm{GC} / \mathrm{MS}$.

Formation of ir $\mathrm{TxB}_{2}$ and 6-keto-PGF ${ }_{1, x}$ in clotting blood showed comparable, significant decreases in both the mackerel and the control group, leaving the ratio between the two compounds unchanged.

In collagen-activated, citrated whole blood, $\mathrm{TxB}_{2}$ formation tended to be reduced in the mackerel-supplemented volunteers, but the effect did not reach the $50 \%$ significance level. Mackerel consumption was associated with the formation of considerable amounts of $\mathrm{PGI}_{3}$, as judged from the appearance of 2,3-dinor$\Delta 17-6$ keto-PGF $_{\text {lix }}$ in urine. Moreover, the amount of the major metabolite of $\mathrm{PGI}_{2}$, 2,3-dinor-6-keto-PGF ${ }_{1 \alpha}$ increased considerably in the urine in striking association with of $\mathrm{PGI}_{3}-\mathrm{M}$. Since the total daily turnover of $\mathrm{PGE}$ and $\mathrm{PGF}$ (as reflected by the amount of tetranor prostanedioic acid in the urina) did not change in the mackerel-supplemented volunteers, the findings with respect to $\mathrm{POI}_{2}$-M may result from a change in the metabolic pathway of $\mathrm{PGI}_{2}$ due to fish consumption.

Key words: fish, diet, man, prostacyclin, thromboxane, prostaglandin, urine, hydroxy fatty acids, lipoxygenase, platelet. 


\section{Introduction}

Dietary fish(oil) has repeatedly been shown to modulate the fatty acid composition of tissue phospholipids: arachidonic acid (20:4 n-6, AA), the precursor of the 2-series eicosanoids, is partly replaced by timnodonic acid (TA, 20:5 n-3, eicosapentaenoic acid) the parent fatty acid of the eicosanoids of the 3-series (for a review, see ref. 1). Precursor availability is an important determinant of the eicosanoid formation in vitro $(2,3)$ and, consequently, fish(oil) consumption will lower the invitro formation of AA-derived eicosanoids and increase the synthesis of eicosanoids originating from TA. However, since TA is less readily converted into most eicosanoids than AA (4-8), the total production of both eicosanoid series can be expected to decrease upon fish(oil) consumption. Several investigators have found this concept to be true (9-12), although the evidence is equivocal (13-16).

The fatty acid composition of tissue fatty acids does not seem to be a major determinant of eicosanoid formation in vivo. Although the expected changes have been observed for prostaglandins, thromboxanes, prostacyclins and their respective urinary metabolites in some studies (17-24), this has not been confirmed under all circumstances $(21,22,23)$ and in other investigations $(3,11,25-28)$. In some cases an increase in total prostanoid turnover has even been reported after fish oil consumption $(18,19$, 20, 29). Many of the studies mentioned above were based on the administration of large amounts of fish, fish oil or fish oil concentrates with little or no resemblance to normal patterns of human nutrition. For this reason, in addition to the discrepancies mentioned above, we studied the influence of a reasonable amount of dietary fish on several aspects of eicosanoid formation and metabolism in human volunteers.

\section{Materials and methods}

The study was part of a trial conducted by the International Working Party 'Fish against thrombosis?'. The design of the study was published in detail before (30) and is briefly reiterated below. Experimental details will be given only insofar as they are related to the results to be presented in this paper.

In Tromsø (Norway) and in Maastricht and Zeist (The Netherlands) 84 healthy male volunteers (20-45 years of age) participated in the study. The experiment lasted 6 weeks, was preceded by a run-in period of 2 weeks. During this run-in period all volunteers were requested to consume one tin of meat paste $(135 \mathrm{~g})$ per day. Subsequently, they were randomized into a mackerel and a meat (control) group. During the 6 experimental weeks the volunteers of the mackerel group consumed one tin of mackerel paste $(135 \mathrm{~g})$ per day and the controls continued the consumption of meat paste. The dietary supplements were given as a replacement for the fish, meat, cheese and eggs normally consumed during the main meal. In Table 1 the fatty acid composition of the supplements is given. The mackerel paste provided $1.7 \mathrm{~g}$ timnodonic acid and $3.0 \mathrm{~g}$ cervonic acid $(22: 6 \mathrm{n}-3)$ per day. 
Table 1. Fatty actd composition (\% of total faty acids) of dietary supplements (mean $\pm S E M$ of 4 determinations).

\begin{tabular}{|c|c|c|}
\hline Fatty acid & Mackerel paste & Meat paste \\
\hline $12: 0$ & & $0.1 \pm 0.01$ \\
\hline $14: 0$ & $7.5 \pm 0.16$ & $2.3 \pm 0.04$ \\
\hline $16: 0$ dmat b & & $0.4 \pm 0.06$ \\
\hline $16: 0$ & $15.2 \pm 0.18$ & $24.3 \pm 0.16$ \\
\hline $16: 1 n-{ }^{2}$ & $0.8 \pm 0.10$ & \\
\hline $16: 1 \mathrm{n}-7$ & $3.8 \pm 0.10$ & $3.6+0.04$ \\
\hline $17: 0$ & & $0.6 \pm 0.03$ \\
\hline $18: 0$ & $2.4 \pm 0.04$ & 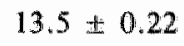 \\
\hline $18: 1 \mathrm{dma}^{\mathrm{a}}$ & $0.4 \pm 0.17$ & $0.5 \pm 0.02$ \\
\hline $18: 1 \mathrm{n}-9$ & $9.4 \pm 0.35$ & \\
\hline $18: 1 \mathrm{n}-7$ & $2.2 \pm 0.16$ & $41.7+0.39$ \\
\hline $18: 2 n-6$ & $2.2 \pm 0.03$ & $9.6 \pm 0.26$ \\
\hline $18: 3 n-3$ & $0.1 \pm 0.06$ & $1.0 \pm 0.02$ \\
\hline $18: 4 n-3^{i x}$ & $5.3 \pm 0.12$ & $0.1 \pm 0.01$ \\
\hline $20: 0$ & & $0.1 \pm 0.01$ \\
\hline $20: 1 n-11$ & $3.0 \pm 0.11$ & \\
\hline $20: 1 \mathrm{n}-9$ & $8.8 \pm 0.26$ & $0.7 \pm 0.02$ \\
\hline $20: 4 n-6$ & $1.2 \pm 0.03$ & $0.5 \pm 0.04$ \\
\hline $20: 5 n-3$ & $7.1 \pm 0.22$ & \\
\hline $22: 1 n-11$ & $15.5 \pm 0.27$ & \\
\hline $22: 1 \mathrm{n}-9$ & $0.9 \pm 0.02$ & \\
\hline $22: 4 n-6$ & $0.6 \pm 0.20$ & $0.1 \pm 0.01$ \\
\hline $22: 5 n-3$ & $0.7 \pm 0.24$ & $0.2 \pm 0.02$ \\
\hline $22: 6 n-3$ & $10.6 \pm 0.34$ & \\
\hline Unidentified & $2.3 \pm 0.12$ & $0.7 \pm 0.03$ \\
\hline
\end{tabular}

a: Tentative identification

$\mathrm{b}: \mathrm{dma}=$ dimethylacetal

Compliance was calculated on the basis of the urinary excretion ( $\%$ ) of a standard, subtherapeutic amount of lithium added to the supplements. The compliance index (30) was used to investigate possible relationships between dietary adherence and diet-induced changes in platelet aggregation.

\section{Blood sampling procedure}

At week 0 (the end of the run-in period), week 3, and week 6, blood was drawn under fasting conditions after the volunteers had been resting for $20 \mathrm{~min}$ in a supine position. Under minimum stasis a forearm vein was punctured using a $19 \mathrm{G}$ butterflyvenisystem (no. 4590, Luer, of no. 8488, Luer and Record; Abbott Ireland Ltd., Sligo, Republic of Ireland). 
After a small blood sample was taken for routine hematological measurements ( $3 \mathrm{ml}$, ref. 30) and for the measurement of fibrinolytic parameters $(5 \mathrm{ml}$, for results, see ref. $31), 18 \mathrm{ml}$ of blood were taken slowly into a $20 \mathrm{ml}$ syringe, prefilled with $2 \mathrm{ml}$ of citrate solution ( $109 \mathrm{mmol} / 1, \mathrm{pH} 7.2-7.4)$. The anticoagulated blood was mixed gently and used for the measurement of the cyclo-oxygenase and lipoxygenase-mediated production of monohydroxy fatty acids upon platelet activation with collagen.

Subsequently, $1.8 \mathrm{ml}$ blood was taken using a prewarmed $\left(37.5^{\circ} \mathrm{C}\right)$ syringe containing $0.2 \mathrm{ml}$ of the citrate solution. The blood was gently mixed with the anticoagulant and $1 \mathrm{ml}$ was used for the measurements of $\mathrm{TxB}_{2}$ and 6-keto-PGF $\mathrm{F}_{\mathrm{ix}}$, formed upon activation with collagen (Maastricht only). After another $20 \mathrm{ml}$ blood sample was taken for determination of the lipid profile of blood platelets (to be described elsewhere), an additional sample was collected in a $5 \mathrm{ml}$ Monovette ${ }^{-}$(Sarstedt, Numbrecht, FRG), for the preparation of serum which was used for the measurement of $\mathrm{TxB}_{2}$ and 6-keto- $\mathrm{PGF}_{1 a}$. Finally, a second serum sample was prepared in an identical way for the measurement of the fatty acid composition of serum lipids, described in detail elsewhere (32).

\section{Urine sampling}

Urine was collected over a 24 h period from 8:00 AM until 8:00 AM the next day, when the volunteers had to visit the laboratory for blood sampling. For the collection of urine, the volunteers were provided with a clean plastic bottle, containing no preservative. The volunteers were instructed to refrigerate the urine immediately after voiding. Because contamination of urine with seminal fluid will greatly affect the urinary prostaglandin content, the volunteers were requested to abstain from ejaculation during the $24 \mathrm{~h}$ collection period.

After measurements of the total urinary volume, $100 \mathrm{ml}$ of the urine was transferred into a small plastic bottle containing a few thymol crystals to prevent bacterial growth. These bottles were stored at $-20^{\circ} \mathrm{C}$ until transportation to Maastricht or Munich for prostanoid measurements. Ten $\mathrm{ml}$ of the urine was transferred into a clean plastic tube, capped, and stored at $-20^{\circ} \mathrm{C}$ until transportation to Maastricht for the compliance measurement as described elsewhere (30). The rest of the urine was discarded.

\section{Production of AA and TA-derived hydroxy fatty acids by collagen-activated blood platelets}

Twenty ml of citrated blood were used to prepare platelet rich and platelet poor plasma by differential centrifugation (33). The platelet rich plasma (PRP) was normalized to contain $220 \times 10^{9}$, platelet per liter by adding autologous platelet poor plasma. Aggregation induced by collagen $(0.8$ and $16 \mu \mathrm{g} / \mathrm{ml}$ final concentration) was measured as described in detail elsewhere (33) with a Chronolog aggregometer (model 430, Chrono-log Corporation, Havertown, PA, USA) and Collagen Horm $^{3}$, (Hormon Chemie, Munich, FRG). Exactly 5 min after the addition of col- 
lagen, the reaction was stopped by taking the cuvette out of the aggregometer and transferring the total content into a $10 \mathrm{ml}$ teflon screw-capped glass tube, containing $1 \mathrm{ml}$ Methanol (Uvasol ${ }^{\circledR}$, Merck No. 6002, Darmstadt, FRG). After thorough mixing, the tubes were stored at $-20^{\circ} \mathrm{C}$ until transportation to Vlaardingen on dry ice for determination of the hydroxy fatty acids. The method applied has been deseribed in detail before (34). Briefly, an appropriate amount of internal standard (15-(S)hydroxy-11,12-(Z,E)-eicosadienoic acid) was added to the samples, and after acidification and extraction with chloroform, the lipids were separated chromatographically. The monohydroxy fatty acid fraction was analyzed by RP-HPLC (Lichrospher $100 \mathrm{CH} \mathrm{18/2}$, particle size $5 \mu \mathrm{m}$, ex Merck, Darmstadt, FRG) with acetonitrile/tetrahydrofuran/water/acetic acid (30:15:55:0.05, v/v/v/v). Measurements were performed at $40^{\circ} \mathrm{C}$ at a flow rate of $1.5 \mathrm{ml} / \mathrm{min}$. The compounds of interest were detected at $234 \mathrm{~nm}$. Under these conditions we were able to resolve HHTE from an unknown, overlapping compound occurring after mackerel ingestion. In most samples, however, slightly different HPLC conditions were used which did not allow the quantification of HHTE. In these cases the eluent was a mixture of methanol/water/acetic acid $(80: 20: 0.05, \mathrm{v} / \mathrm{v} / \mathrm{v})$. The flow rate was $1.0 \mathrm{ml} / \mathrm{min}$ and separations were carried out at ambient temperature. The amounts of the hydroxy fatty acids of interest were calculated by comparing the relative areas of the corresponding peaks with that of the internal standlard, using the following molar absorbance values: HHT and HHTE: $32.0001 / \mathrm{mol} / \mathrm{cm}$; HETE and HEPE: 27.200 $1 / \mathrm{mol} / \mathrm{cm}$.

\section{Formation of $T x B_{2}$ and $T x B_{3}$ by collagen-activated platelets}

Measurements were carried out in a selection of the samples collected for hydroxy fatty acid determination, using gas chromatography in combination with mass spectrometry (GC/MS). $\mathrm{TxB}_{2}$ and $\mathrm{TxB}_{3}$ were quantified in 16 samples only, because of shortage of a deuterated internal standard. In an additional 20 samples the $\mathrm{TxB}_{2} / \mathrm{TxB}_{3}$ ratio which does not require an internal standard was determined.

After addition of $635 \mathrm{mg}$ of $\mathrm{D} 4-\mathrm{TxB}_{2}$ (16 samples), a total of 36 methanolic platelet preparations were extracted, pre-purified and fractionated in the same way as described for the hydroxy fatty acid measurements. Subsequently, the thromboxane-containing fractions were transported on dry ice to Munich for the measurement of $\mathrm{TxB}_{2}$ and $\mathrm{TxB}_{3}$ as described before (35). Briefly, the compounds to be determined were converted into the MO-PFBE-Me $\mathrm{Si}_{3} \mathrm{Si}$-ether derivatives (36), and fragments (MPFB) ${ }^{-}, \mathrm{m} / \mathrm{z} 612,614$ and 618 of $\mathrm{TxB}_{3}$ and $\mathrm{TxB}_{2}$ and $\mathrm{D}_{4}-\mathrm{TxB}_{2}$ were monitored in the NICI mode (isobutane). The GC/MS system was a Finnigan MAT $44 \mathrm{~S}$, equipped with a $30 \mathrm{~m}$ DB-1 fused silica capillary column (ex ICT, Frankfurt/Main, FRG).

\section{$T x B_{2}$ and 6-keto-PGF $F_{1 \alpha}$ in collagen-activated whole blood and in serum}

One $\mathrm{ml}$ citrated whole blood was transferred into the prewarmed cuvette of a Chrono-log ${ }^{\boxplus 1}$ whole blood lumi aggregometer (model 500, Chronolog Corporation, Havertown, PA, USA). The cuvette already contained a teflon-coated stirbar 
and $100 \mu$ of the luciferase-luciferin reagent Chrono-lume (no. 395, Chrono-log Corporation) to quantify the release of adenosine triphosphate (ATP) by the platelets after their activation. After $5 \mathrm{~min}$ of pre-incubation, aggregation of platelets was induced by adding $10 \mu \mathrm{l}$ of a diluted collagen suspension (Collagen Horm ${ }^{6}$ ) to a final concentration of $0.5 \mu \mathrm{g} / \mathrm{ml}$ citrated blood. After $15 \mathrm{~min}$ of aggregation $10 \mu \mathrm{ATP}$ was added to the cuvette (final concentration $3.6 \times 10^{-6} \mathrm{~mol} / \mathrm{l}$ ) in order to calibrate the luminescence detector. Results of these aggregation and ATP release measurements have been published elsewhere (37). About $10 \mathrm{~s}$ after the final ATP addition, the contents of the aggregation cuvette were transferred into a small cuvette and centrifuged with an Eppendorf centrifuge Type 5413 during 3 min at $9700 \times \mathrm{g}$. The plasma was collected carefully and stored at $-20^{\circ} \mathrm{C}$ until prostanoid determination.

The $5 \mathrm{ml}$ blood sample in the Monovette was immediately placed in a waterbath at $37.5^{\circ} \mathrm{C}$ and was allowed to clot for exactly $60 \mathrm{~min}$. Subsequently the Monovette was centrifuged for $15 \mathrm{~min}$ at approximately $3000 \mathrm{x}$ g. The serum was collected and stored at $-20^{\circ} \mathrm{C}$ until transportation on dry ice to Maastricht for prostanoid measurements.

Immunoreactive $\mathrm{TxB}_{2}$ and 6-keto-PGF $\mathrm{PG}_{1 \alpha}$ were measured by radioimmunoassay (RIA), using special kits from NEN, Dreieich, FRG (NEK 007A and 008A, respectively). For the $\mathrm{TxB}_{2}$ measurements plasma samples were diluted 33.3-fold: $30 \mu \mathrm{l}$ of plasma was mixed with $50 \mu \mathrm{l}$ of absolute ethanol and about 30 min later, $920 \mu \mathrm{l}$ assay buffer from the kit was added. After thorough mixing, the tubes were centrifuged with an Eppendorf Centrifuge, type 5413, for $5 \mathrm{~min}$. The supernatant was used for $\mathrm{TxB}_{2}$ quantification. The serum samples for $\mathrm{TxB}_{2}$ measurements were diluted 500-fold in a way comparable to that described for plasma, starting from $10 \mu \mathrm{l}$ plasma. Instead of assay buffer, however, $940 \mu \mathrm{l}$ double distilled water was used. The final dilution of 500 -fold was achieved by mixing $100 \mu \mathrm{l}$ of the supernatant with $400 \mu \mathrm{l}$ of the assay buffer. For the preparation of standards and blancs, prostanoid-free human plasma of the kit was used, also diluted 33.3 - (plasma) or 500 - fold (serum).

For the measurement of 6-keto-PGF ${ }_{1 a}$, plasma and serum were used undiluted. The prostanoid RIAs were carried out according to the kit instructions. Measurements were performed in $50 \%$ of the volumes mentioned in the instructions and were done in duplicate.

\section{Prostaglandin turnover in vivo}

These measurements were carried out as described in detail before (28). Briefly, after extraction from the urine by Sep Pak ${ }^{\text {(1) }}$ C18 RP columns (no 51910, Waters Associates, Milford, Massachusetts, USA), the numerous tetranor metabolites present in the eluent were first converted into two different compounds, tetranor prostane dioic acid (TPD) and tetranor prostanoic acid (TPM), by an analytical procedure including keto-reduction, iodination of hydroxyl groups, and replacement of iodine 
groups by a hydrogen atom. The resulting TPD and TPM were methylated and, after purification by thin layer chromatography, their amounts were measured by gas chromatography and flame ionization detection. In contrast to our earlier study, we now used capillary columns: for TPD a $25 \mathrm{~m}$ CP-Sil 5 CB column with a diameter of $0.24 / 0.35 \mathrm{~mm}$ and for TPM a $50 \mathrm{~m} \mathrm{CP-Sil} 88$ column, diameter $0.25 / 0.35 \mathrm{~mm}$. Both columns were obtained from Chrompack, Middelburg, The Netherlands. GC/FID was performed with a Perkin Elmer gas chromatograph, Type 8320 B (Perkin Elmer Ltd, Buckinghamshire, England).

The conditions for TPD were as follows. Carrier gas: He. Inlet pressure: $120 \mathrm{kPA}$, injection volume: 11 , split ratio: $1: 6$, injection temp.: $285^{\circ} \mathrm{C}$, detection temp.: $300^{\circ} \mathrm{C}$. Oven temp.: $185^{\circ} \mathrm{C}$ for $2 \mathrm{~min}$, after which it increased by $1^{\circ} \mathrm{C} / \mathrm{min}$ to $195^{\circ} \mathrm{C}$, followed by a further increase by $30^{\circ} \mathrm{C} / \mathrm{min}$ to $295^{\circ} \mathrm{C}$, until all components had been removed from the column. Total run time was about $30 \mathrm{~min}$, retention time of TPD about $9 \mathrm{~min}$. For the TPM measurements most conditions were similar. Temperature programming was slightly different, however. Starting at $160^{\circ} \mathrm{C}$, the temperature immediately increased by $5^{\circ} \mathrm{C} / \mathrm{min}$ to $240^{\circ} \mathrm{C}$, after which it remained constant for an additional $20 \mathrm{~min}$. Total run time was about $36 \mathrm{~min}$ and the retention time of TPM was about $10 \mathrm{~min}$.

An authentic TPD-standard was obtained from Dr. J.P. Ward, Unilever Research, Vlaardingen, The Netherlands. A TPM-standard was prepared by subjecting tretranor $\mathrm{PGB}_{1}$, (a gift of Dr. D.H. Nugteren, Unilever Research) to the analytical procedure described above.

To minimize the possible influence of differences and changes in physical activity, the results of the TPD and TPM measurements were not only expressed in $\mu \mathrm{g} / 24$ $\mathrm{h}$, but also related to urinary creatinine, measured with the Boehringer test combination No. 124192 ex-Boehringer Mannheim, FRG.

\section{Prostacyclin metabolites in urine}

In a limited number of urine samples this measurement was carried out by GC/MS after the urine samples had been transported on dry ice to Munich. The methodology has been described before (18).

\section{Statistical analysis}

All data were checked for their frequency distribution and when necessary, transformation of the data was applied to normalize this distribution. Subsequently, significant outliers were omitted (38). To evaluate the changes within the mackerel and the control group after 3 or 6 weeks the Student's-test for paired data was used. Differences between the two groups were evaluated using Student's 2 -sample t-test. Occasionally, other statistical methods were used, which will be outlined when the results are described. Differences were considered significant when the two-sided $P$ value (p) was equal to or smaller than 0.05 . 
Table 2. Effect of the dietary supplements on the formation of HHT (ex AA) and HHTE (ex TA) by collagen-activated platelets. Results are given in $n g( \pm S E M)$ per sample PRP. containing $99 \times 10^{\circ}$ platelets.

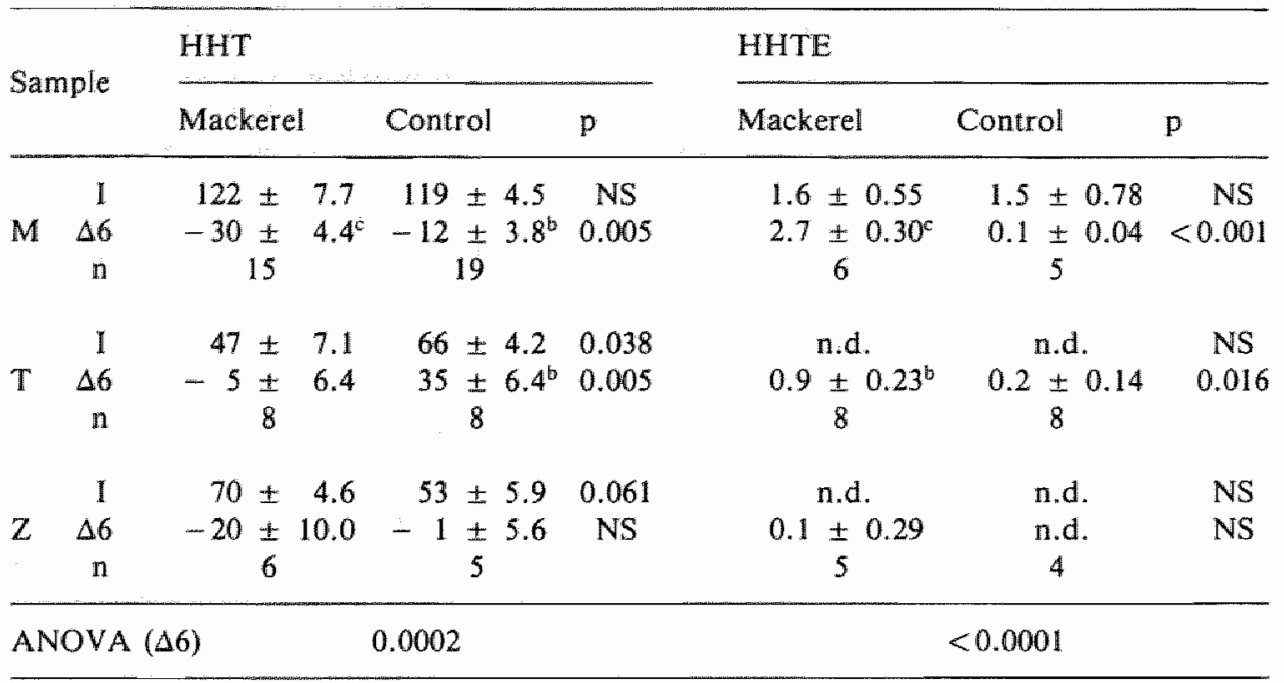

$\rrbracket \quad$ : Initial values

$\Delta 6$ : Changes during the 6 -week experimental period (week 6 - week 0 )

n : Number of obserwations

M : Maastricht; T: Troms $\phi ;$ Z: Zeist

n.d. : not detectable

p : Significance of difference between mackerel and control groups

Significance of response within each group: $b: p<0.01 ; c: p<0.001$

ANOVA: Analysis of Variance

\section{Results}

In general, the volunteers tolerated the dietary supplements quite well. Only one volunteer withdrew before the end of the experiment, after he developed a strong aversion against the mackerel paste. No side effects of the supplements were ob served during the study. The average dietary adherence, calculated on the basis of the urinary recovery of the added lithium salt, was $85 \%$ for the control group and $78 \%$ for the mackerel group. Data from one volunteer had to be removed because of very poor compliance (30).

Formation of monohydroxy fatty acids by collagen-activated platelets

Due to a considerable difference between the three experimental centers in the sensitivity of the platelets towards collagen (33), the production of monohydroxy fatty acid by these platelets also varied widely between the three centers. In all occasions, however, the collagen dose of $0.8 \mu \mathrm{g} / \mathrm{ml} \mathrm{PRP}$ was too low to result in the formation 
Table 3. Influence of the dietary supplements on the formation of HETE (eXAA) and HEPE (ex TA) by collagen-acrivated blood platelets. Results are given in ng ( \pm SEM) per sample PRP containing $99 \times 10^{\circ}$ platelets.

\begin{tabular}{|c|c|c|c|c|c|c|c|c|}
\hline \multirow{2}{*}{\multicolumn{2}{|c|}{ Sample }} & \multicolumn{4}{|l|}{ HETE } & \multicolumn{3}{|l|}{ HEPE } \\
\hline & & \multirow{2}{*}{$\begin{array}{c}\text { Mackerel } \\
\begin{array}{c}86 \pm 7.4 \\
-18 \pm 3.4^{c} \\
15\end{array}\end{array}$} & \multicolumn{2}{|l|}{ Control } & & $\frac{\text { Mackerel }}{3 \pm 0.6}$ & $\frac{\text { Control }}{2=0.4}$ & \multirow{2}{*}{$\frac{p}{\text { NS }}$} \\
\hline M & $\begin{array}{c}\mathrm{I} \\
\Delta 6 \\
\mathrm{n}\end{array}$ & & $\begin{array}{r}79 \pm \\
-\quad 6 \pm \\
19\end{array}$ & $\begin{array}{l}5.1 \\
3.2\end{array}$ & $\begin{array}{c}\text { NS } \\
0.018\end{array}$ & $\begin{array}{r}3 \pm 0.6 \\
11 \pm 1.3^{c} \\
15\end{array}$ & $\begin{array}{c}2=0.4 \\
0=0.43 \\
19\end{array}$ & \\
\hline $\mathrm{T}$ & $\begin{array}{c}1 \\
\Delta 6 \\
n\end{array}$ & $\begin{array}{r}40 \pm 4.8 \\
-8 \pm 4.5 \\
8\end{array}$ & $\begin{array}{r}41 \pm \\
17 \pm \\
8\end{array}$ & $\begin{array}{l}2.5 \\
3.6^{\circ}\end{array}$ & $\begin{array}{c}\text { NS } \\
<0.001\end{array}$ & $\begin{array}{c}1.6 \pm 0.2 \\
6 \pm 0.8^{\circ} \\
8\end{array}$ & $\begin{array}{c}2.5 \pm 0.4 \\
-1 \pm 0.5 \\
8\end{array}$ & $\begin{array}{r}0.004 \\
<0.001\end{array}$ \\
\hline $\mathbb{Z}$ & $\begin{array}{c}I \\
\Delta 6 \\
n\end{array}$ & $\begin{array}{r}47 \pm 3.3 \\
-9 \pm 9.2 \\
6\end{array}$ & $\begin{array}{r}40 \pm \\
-\quad 3 \pm \\
5\end{array}$ & $\begin{array}{r}6.0 \\
11.0\end{array}$ & $\begin{array}{l}\text { NS } \\
\text { NS }\end{array}$ & $\begin{array}{l}1 \pm 0.2 \\
5 \pm 1.8^{\mathrm{a}} \\
6\end{array}$ & $\begin{array}{l}1 \pm 0.2 \\
0 \pm 0.3 \\
5\end{array}$ & $\begin{array}{c}\text { NS } \\
0.034\end{array}$ \\
\hline
\end{tabular}

ANOVA $(\Delta 6)$

0.0140

$<0.0001$

Significance of response within each group: a : p $<0.05 ; \mathrm{b}: \mathrm{p}<0.01$; $: \mathrm{p}<0.0001$ For further explanations: see Table 2

of measurable amounts of HHTE, the cyclo-oxygenase-mediated hydroxy fatty acid derived from timnodonic acid. Therefore, it was decided to concentrate on the high collagen dose (16 $\mu \mathrm{g} / \mathrm{ml}$ PRP, f.c.).

Results for the cyclo-oxygenase products HHT (derived from AA) and HHTE (ex TA) are given in Table 2 . Within each center the mackerel consumption resulted in a decrease in HHT formation, which was significantly different from the response observed for the control groups (Zeist excluded). Analysis of variance demonstrated a highly significant fish effect: $p=0.0002$.

Formation of HHTE from TA was low in all cases. Since this measurement is very time-consuming, it was performed in a subset of the samples only. In Zeist, HHTE production was below the level of reliable detection in most cases; the same was true for Troms $ø$ at week 0 . In all other cases HHTE could be detected reliably, and a small but significant increase in HHTE production was observed in Maastricht and Troms $\emptyset$ (Table 2). Analysis of variance confirmed that the fish supplement resulted in a highly significant increase in the formation of HHTE. Nonetheless, this increase was by no means sufficient to compensate for the decrease in HHT formation. On average the HHTE production at the end of the 6-week experimental period was only $1.6-3.6 \%$ (mean $2.9 \%$ ) of the amount of HHT formed, whereas the average decrease in HHT formation was $21.6 \%$.

In Table 3 the results for the lipoxygenase products HETE (ex AA) and HEPE (ex 
Table 4. Influence of dietary supplements on the formation of $T \times B_{2}$ and $T \times B_{3}$ by collagen-activated platelets afler 6 experimental weeks. ng \pm SEM per sample of PRP containing $99 \times 10^{6}$ platelets $(n=8)$.

\begin{tabular}{llll}
\hline Compound & Mackerel & Control & $\mathrm{p}$ \\
\hline $\mathrm{TxB}_{2}$ & $49 \pm 4.4$ & $95 \pm 6.4$ & 0.0001 \\
$\mathrm{TxB}_{3}$ & $3.7 \pm 1.30$ & $0.8 \pm 1.46$ & 0.0009 \\
\hline
\end{tabular}

TA) are given. The changes caused by the dietary supplements were quite similar to those observed for the cyclo-oxygenase products: the mackerel consumption was associated with a reduction in HETE formation by activated platelets which was significant in Maastricht and Tromsø, but not in Zeist. Analysis of variance, which takes all data into consideration, demonstrated that the fish effect was indeed significant: $\mathrm{p}=0.0140$.

At the start of the study (week 0), some HEPE was formed, which for none of the control groups changed significantly during the experimental period. For the mackerel groups, however, the HEPE production increased significantly in each center ( $p<0.05$ for Zeist, $p<0.001$ for Maastricht and Tromsø).

The difference in response between mackerel and control groups was significant for each center and with all data taken together in an analysis of variance, the fish effect was highly significant $(\mathrm{p}<0.0001)$.

The lithium-recovery method, with which the compliance of all volunteers was estimated, enabled us to correct the eicosanoid responses for differences in dietary adherence. An almost significant relationship with compliance was observed for the HHT response $(p=0.08)$ and the HEPE response $(p=0.06)$ in the mackerel group. Correction for compliance, however, did not substantially alter the final results.

\section{Formation of $T \times B_{2}$ and $T \times B_{3}$ by collagen-activated platelets}

Because of the limited amounts of deuterated standards available, only a small selection of the samples could be measured quantitatively. Therefore, measurements were carried out in samples from Troms after 6 experimental weeks only (see Table 4). Analogous to the hydroxy fatty acids, consumption of the mackerel supplement was associated with a significant lower $\mathrm{TxB}_{2}$ formation, whereas the production of $\mathrm{TXB}_{3}$ was significantly higher as compared with that in the control group. Again, the decrease in the formation of the AA-derived product was only partly compensated for by the increase in production of the compound derived from TA.

For the Troms $\varnothing$ samples of week 0 the relative formation of $\mathrm{TxB}_{3}$ as percentage of $\mathrm{TxB}_{2}$ was also measured and compared with the results of week 6 . As is evident from Table 5 , the relative $\mathrm{TxB}_{3}$ formation at the start of the study did not differ significantly between the two groups. During the 6 week experimental period, 
Table 5. Formation of $T \times B_{3}\left(\%\right.$ of $T x B_{3} \pm$ SEM) by collagen-activated blood platelets $(n=8)$.

\begin{tabular}{lccc}
\hline Seimple & Mackerel & Control & $p$ \\
\hline 1 & $1.0 \pm 0.24$ & $0.6 \pm 0.16$ & N.S. \\
6 & $7.8 \pm 2.31$ & $1.0 \pm 0.65$ & $<0.001$ \\
$-\Delta 6$ & $6.8 \pm 0.82^{\mathrm{a}}$ & $0.4 \pm 0.66$ & $<0.001$
\end{tabular}

a: value significantly from zero: $p<0.001$

For further explanations: see Table 2

however, the relative $\mathrm{TxB}_{3}$ production significantly increased to a value that was significantly higher than that in the control group. The responses with respect to the relative $\mathrm{TxB}_{3}$ formation were significantly different for the two dietary supplements $(p=0.001)$.

These TxB-measurements were performed in samples in which the hydroxy fatty acids had also been determined. To investigate the relationship between these two sets of results, regression analyses were carried out for the absolute and relative values obtained. For these analyses all data were taken together, regardless of the week of sampling and the group of origin. Results are given in Table 6, from which it can be concluded that a good correlation exists between the thromboxane values determined by GC/MS and the amounts of monohydroxy fatty acids, measured by HPLC. This holds for products derived from AA as well as for the products originating from timnodonic acid, although the correlation is clearly less pronounced in this latter case.

Formation of ir $T X B_{2}$ and 6-keto-PGF $F_{1 \alpha}$ in collagen-activated whole blood These measurements were performed in Maastricht only. In all samples the levels of 6-keto-PGF lix $_{\text {ix }}$ were too low for reliable detection. Consequently, results for $\mathrm{TxB}_{2}$ will be given only.

Table 6. Regression analyses of the formation of thromboxanes and hydroxy fatty acids measured in the same PRP samples.

\begin{tabular}{llclcrr}
\hline$X$ & $Y$ & $a$ & $b$ & $r$ & $n$ & $p$ \\
\hline $\mathrm{TxB}_{2}$ & HHT & 18.3 & 0.82 & 0.77 & 16 & $<0.001$ \\
\hdashline $\mathrm{TxB}_{3}$ & HHTE(abs) & 0.69 & 0.167 & 0.54 & 16 & 0.031 \\
$\mathrm{TxB}_{3}$ & HHTE(rel) & 0.92 & 0.209 & 0.60 & 32 & $<0.001$ \\
\hline
\end{tabular}

$Y=a+b X$

$\mathbf{r}=$ correlation coefficient

$\mathbf{n}=$ number of cases

$\mathrm{p}=$ significance level 
Table 7. Effect of the dietary supplements on the change in formation of ir $T \times B_{2}$ in whole blood activated with collagen at week $0.0 .5 \mu \mathrm{g} / \mathrm{ml} / \mathrm{fc}$ ) and week 6 (various doses). Results are given in $\mathrm{ng} / \mathrm{m} /$ plasma $\pm S E M$.

\begin{tabular}{lrrrrr}
\hline $\begin{array}{l}\text { Collagen dose } \\
\mu \mathrm{g} / \mathrm{ml} \text { f.c. }\end{array}$ & \multicolumn{2}{l}{ Mackerel } & & \multicolumn{2}{c}{ Control } \\
\cline { 2 - 6 } & $\mathrm{n}$ & $\mathrm{ng} / \mathrm{m} \rrbracket$ & $\mathrm{n}$ & $\mathrm{ng} / \mathrm{ml}$ \\
\hline 0.50 & 4 & $-14.6 \pm 3.87$ & & 4 & $-10.5 \pm 2.11$ \\
0.67 & 2 & $-10.3 \pm 1.35$ & & 3 & $-8.2 \pm 3.90$ \\
0.80 & 6 & $0.2 \pm 4.14$ & & 9 & $3.4 \pm 4.33$ \\
1.00 & 5 & $5.0 \pm 4.11$ & & 4 & $11.0 \pm 3.31$ \\
\hline
\end{tabular}

f.c. = final concentration

At week 0 the collagen dose used for activation was $0.5 \mu \mathrm{g} / \mathrm{ml}$ f.c. No significant differences in $\mathrm{TxB}_{2}$ formation were observed between the two groups. The amounts determined were $21.2 \pm 1.77$ and $21.8 \pm 2.08 \mathrm{ng} / \mathrm{ml}$ plasma for the mackerel group $(n=17)$ and the control group $(n=20)$, respectively (mean $F \pm$ SEM). As described before (37), the same dose of collagen caused hardly any aggregation after 6 experimental weeks. Therefore, the collagen dose was gradually increased to an amount which caused a degree of aggregation comparable to that at the start of the study. $\mathrm{TxB}_{2}$ measurements were performed as planned; the changes in $\mathrm{TxB}_{2}$ formation between weeks 0 and 6 for each of the collagen doses administered are given in Table 7 . No significant differences in reponse were observed between the mackerel and the control groups, either for each of the collagen doses separately or for all collagen doses combined (analysis of variance). This indicates that the fish supplement did not significantly affect $\mathrm{TxB}_{2}$ formation in collagen-activated whole blood.

The collapse of platelet functions during the study, which forced us to increase the collagen close at week 6, may have created an unfavourable situation to observe any effect of the dietary supplements. Therefore, we repeated the run-in period about 1 year later, after which we again measured ir $\mathrm{TxB}_{2}$ production in whole blood activated with the same dose of collagen as used before in week 6 . This enabled us to calculate the $\mathrm{TxB}_{2}$ response for the two dietary supplements based on activation with the same dose of collagen. The results are given in Table 8. Because of the differences in variance between the results observed with the various collagen doses, logarithmic transformation of the date was required to stabilize the variance. Levene's test for equality of variances (39), was used to confirm the success of this procedure. All calculations and statistical tests were performed with the logtransformed data. For 3 of the 4 collagen doses the response in the mackerel group was more negative than that in the control group. However, due to the small number of observations and the wide variability of the results, the differences were not significant. Analysis of variance, nonetheless, indicated a trend for a reducing 
Table 8. Influence of dietary supplements on the formation of ir $T x B_{2}$ in whole blood actiwated by various amounts of collagen.

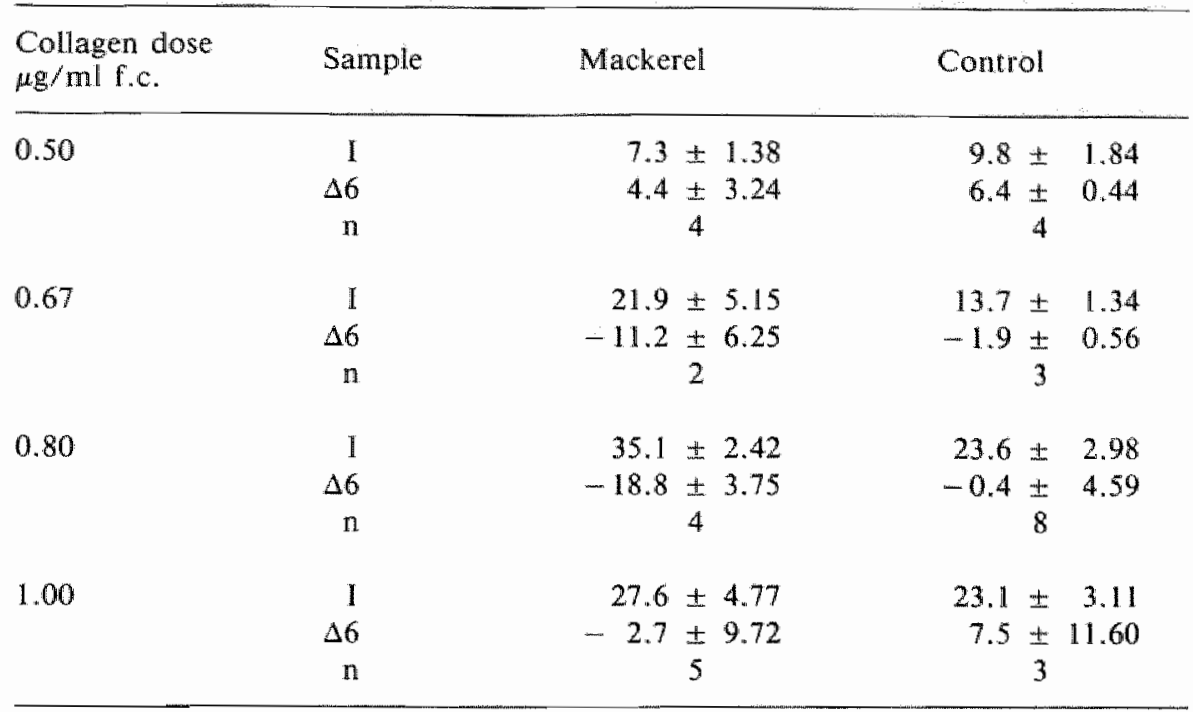

ANOVA (after log-transformation) 0.090

f.c. = final concentration

Initial data (1) refer to values obtained after the second run-in period. $\Delta 6$ : change during the 6 week experimental period when compared with the initial data. For further explanations: See Table 2.

effect by the fish supplement $(p=0.09)$. This trend was reinforced by the observation that in the mackerel group the $\mathrm{TxB}_{2}$-response $(=\mathrm{Y})$ and the dietary adherance $(=\mathrm{X})$ appeared strongly correlated with one another $(\mathrm{Y}=28.6-0.05 \mathrm{X}, \mathrm{r}=$ $-0.77, \mathrm{n}=14, \mathrm{p}<0.001$ ). This strongly suggests that a higher fish consumption than could be achieved in our study might significantly lower $\mathrm{TxB}_{2}$ formation in collagen-activated whole blood.

It should be remembered that the fish supplement had a significant lowering effect on the platelet count in whole blood (37). Since platelets can be expected to be the main source of $\mathrm{TXB}_{2}$ in collagen-activated blood, it seems likely that the trend for a lowering of the $\mathrm{TxB}_{2}$ formation by the fish supplement is secondary to the lower platelet counts in the blood. However, a multiple regression analysis demonstrated that, after taking into account differences in platelet count, the tendency for a reduced $\mathrm{TxB}_{2}$ production upon fish consumption persisted $(\mathrm{p}=0.11)$. 
Table 9. Effect of the dietary supplements on the amounts of ir $T \times B_{2}(\mathrm{mg} / \mathrm{ml})$ and $6-k e t o-$ $P G F_{l a x}(p g / m l)$ present in serum (mean $\left.\pm S E M\right)$.

\begin{tabular}{|c|c|c|c|c|c|c|c|}
\hline \multirow{2}{*}{\multicolumn{2}{|c|}{ Sample }} & \multicolumn{3}{|l|}{$\mathrm{TxB}_{2}$} & \multicolumn{3}{|l|}{ 6-keto-PGF ${ }_{\mathbb{1} \alpha}$} \\
\hline & & \multirow{2}{*}{$\begin{array}{l}\text { Mackerel } \\
\begin{array}{c}519 \pm 30 \\
-166 \pm 23^{\circ} \\
19\end{array}\end{array}$} & \multirow{2}{*}{$\begin{array}{l}\text { Control } \\
\begin{array}{r}42 \pm 28 \\
-19 \pm 16 \\
20\end{array}\end{array}$} & \multirow{2}{*}{$\begin{array}{l}p \\
\quad 0.067 \\
<0.0001\end{array}$} & \multirow{2}{*}{$\begin{array}{l}\text { Mackerel } \\
\begin{array}{r}392 \pm 21 \\
-128+21^{\circ}\end{array}\end{array}$} & $\begin{array}{l}\text { Control } \\
376 \pm 22\end{array}$ & \multirow{2}{*}{$\frac{\mathrm{p}}{\mathrm{NS}}$} \\
\hline$M$ & $\begin{array}{c}1 \\
\Delta 6 \\
n\end{array}$ & & & & & $\begin{array}{c}376 \pm 22 \\
2 \pm 17 \\
20\end{array}$ & \\
\hline $\mathrm{T}$ & $\begin{array}{r}1 \\
\Delta 6 \\
\mathbb{m}\end{array}$ & $\begin{array}{c}373 \pm 58 \\
-80 \pm 57 \\
11\end{array}$ & $\begin{array}{c}427 \pm 50 \\
-1 \pm 31 \\
12\end{array}$ & $\begin{array}{l}\text { NS } \\
\text { NS }\end{array}$ & $\begin{array}{c}310 \pm 35 \\
-33 \pm 47 \\
11\end{array}$ & $\begin{aligned} 312 & \pm 22 \\
49 & \pm 16^{a} \\
12 & \end{aligned}$ & $\begin{array}{l}\text { NS } \\
\text { NS }\end{array}$ \\
\hline Z & $\begin{array}{r}\mathrm{I} \\
\Delta 6 \\
\mathrm{~m}\end{array}$ & $\begin{array}{c}467 \pm 48 \\
-148 \pm 37^{0} \\
10\end{array}$ & $\begin{array}{r}494 \pm 37 \\
-65 \pm 37 \\
9\end{array}$ & $\begin{array}{l}\text { NS } \\
\text { NS }\end{array}$ & $\begin{array}{c}385 \pm 33 \\
-113 \pm 23^{b} \\
10\end{array}$ & $\begin{aligned} & 419 \pm 32 \\
&-62 \pm 22^{\mathrm{a}} \\
& 9\end{aligned}$ & $\begin{array}{l}\text { NS } \\
\text { NS }\end{array}$ \\
\hline
\end{tabular}

$\begin{array}{lll}\text { ANOVA } & 0.0010 \quad 0.0002\end{array}$

Significance of response within each group: $a: p<0.05 ; b: p<0.01 ; c: p<0.001$ For further explanations: see Table 2

Table 10. Effect of the dietary supplements on the amounts of ir $T \times B_{2}$ and 6-keto-PGF $F_{\text {lax }}$ in serum. Mean \pm SEM.

\begin{tabular}{|c|c|c|c|c|}
\hline Variable & Week & $\begin{array}{l}\text { Mackerel } \\
(n=40)\end{array}$ & $\begin{array}{l}\text { Control } \\
(\mathrm{n}=41)\end{array}$ & $\mathrm{p}$ \\
\hline $\begin{array}{l}\mathrm{TxB}_{2} \\
(\mathrm{ng} / \mathrm{ml})\end{array}$ & $\begin{array}{r}1 \\
6 \\
\Delta 6\end{array}$ & $\begin{aligned} & 465 \pm 26 \\
& 328 \pm 18 \\
&-137 \pm 22^{a}\end{aligned}$ & $\begin{array}{r}449 \pm 21 \\
425 \pm 23 \\
-24 \pm 14\end{array}$ & $\begin{array}{c}\text { NS } \\
0.0012 \\
<0.0001\end{array}$ \\
\hline $\begin{array}{l}\text { 6-keto-PGF } \\
(\mathrm{pg} / \mathrm{ml})\end{array}$ & $\begin{array}{r}\mathrm{I} \\
6 \\
\Delta 6\end{array}$ & $\begin{aligned} 368 & \pm 17 \\
269 & \pm 13 \\
-99 & \pm 18^{a}\end{aligned}$ & $\begin{array}{r}367 \pm 15 \\
369 \pm 13 \\
2 \pm 12\end{array}$ & $\begin{array}{c}\text { NS } \\
<0.0012 \\
<0.0001\end{array}$ \\
\hline$\frac{\mathrm{Tx} / 6 \text {-keto }}{1000}$ & $\begin{array}{r}1 \\
6 \\
\Delta 6\end{array}$ & $\begin{array}{r}1.28 \pm 0.06 \\
1.26 \pm 0.06 \\
-0.02 \pm 0.06\end{array}$ & $\begin{array}{r}1.27 \pm 0.06 \\
1.17 \pm 0.06 \\
-0.09 \pm 0.05\end{array}$ & $\begin{array}{l}\text { NS } \\
\text { NS } \\
\text { NS }\end{array}$ \\
\hline
\end{tabular}

a: value significantly different from zero: $\mathrm{p}<0.001$

$\Delta$ : Difference between week 6 and week 0

Formation of ir $T x B_{2}$ and 6-keto-PGF $F_{1 \alpha}$ in clotting blood

Because of the very powerful activation of platelets by thrombin formed during blood clotting, the amount of $\mathrm{TxB}_{2}$ in serum is thought to reflect the potency of blood platelets to produce $\mathrm{TxB}_{2}$. As can be seen in Table 9 , fish consumption in 
Table 11. Influence of the fish supplement on the amounts of the major metabolites of $\mathrm{PGI}_{2}$ and $P G I_{3}$ in the urine collected at the start of the siudy and after 6 weeks. Results are expressed in $n g / g$ creatimine, mean \pm SEM $(n=I I)$.

\begin{tabular}{lccc}
\hline Week & $\mathrm{PGI}_{2}-\mathrm{M}$ & $\mathrm{PGI}_{3}-\mathrm{M}$ & $\mathrm{PGl}_{\mathrm{N}} \mathrm{M}_{\text {total }}$ \\
\hline $\mathrm{I}$ & $73 \pm 6.6$ & $5 \pm 3.1$ & $78 \pm 7.8$ \\
6 & $130 \pm 6.3$ & $52 \pm 4.0$ & $183 \pm 9.7$ \\
$\mathrm{p}$ & $<0.0001$ & $<0.0001$ & $<0.0001$ \\
\hline
\end{tabular}

Table 12. Effect of the dietary supplements on the urinary content of tetranor prostaglandin metabolites, measured as tetranor prostanedioic acid (TPD). Results are given as mean \pm SEM.

\begin{tabular}{|c|c|c|c|c|c|c|c|}
\hline \multirow{2}{*}{ Sampl } & & \multicolumn{3}{|c|}{ TPD $(\mu g / 24 h)$} & \multicolumn{3}{|c|}{ TPD (mg/mol creatinine) } \\
\hline & & Mackerel & Control & $\mathrm{p}$ & Mackerel & Control & $\mathrm{p}$ \\
\hline \multirow[b]{2}{*}{$\mathbf{M}$} & I & $203 \pm 30$ & $243 \pm 36$ & NS & $15.5 \pm 2.15$ & $18.4 \pm 2.72$ & $\mathbb{N S}$ \\
\hline & $\begin{array}{r}\Delta 6 \\
\mathrm{n}\end{array}$ & $2 \pm 38$ & $\begin{array}{c}136 \pm 79 \\
19\end{array}$ & NS & $-0.6 \pm 1.99$ & $\begin{array}{c}9.9 \pm 5.64 \\
11\end{array}$ & NS \\
\hline \multirow[b]{2}{*}{$\mathrm{T}$} & 1 & $152 \pm 21$ & $212 \pm 53$ & NS & $10.4 \pm 1.39$ & $15.0 \pm 3.35$ & NS \\
\hline & $\begin{array}{r}\Delta 6 \\
\mathrm{n}\end{array}$ & $\begin{array}{c}51 \pm 33 \\
10\end{array}$ & $15 \pm 17$ & NS & $3.9 \pm 2.25$ & $0.5 \pm 1.54$ & NS \\
\hline \multirow[b]{2}{*}{$\mathrm{Z}$} & $\mathrm{I}$ & $160 \pm 33$ & $199 \pm 34$ & NS & $11.5 \pm 1.64$ & $12.6 \pm 2.10$ & NS \\
\hline & $\begin{array}{r}\Delta 6 \\
n\end{array}$ & $-30 \pm \frac{41}{7}$ & $-60 \pm \frac{ \pm 36}{5}$ & NS & $-1.9 \pm 2.06$ & $-3.3 \pm 2.47$ & NS \\
\hline \multirow[b]{2}{*}{ Total } & $\mathbb{I}$ & $174 \pm 16$ & $222 \pm 26$ & NS & $12.6 \pm 1.10$ & $15.9 \pm 1.86$ & $\mathrm{NS}$ \\
\hline & $\begin{array}{r}\Delta 6 \\
n\end{array}$ & $\begin{array}{c}12 \pm 22 \\
27\end{array}$ & $51 \pm 36$ & NS & $0.8 \pm 1.28$ & $\begin{array}{c}3.6 \pm 2.57 \\
27\end{array}$ & NS \\
\hline
\end{tabular}

For further explanations: see Table 2

Total: Three centers combined

variably led to a reduction of the $\mathrm{TxB}_{2}$ content in serum. For Maastricht and Zeist, this effect was highly significant. The small responses occurring in the control group were not significant. Due to a wide variability in the results, the differences in response between the mackerel and the control groups were not significant for Troms $\varnothing$ and Zeist. Analysis of variance, however, clearly demonstrated that the potency of blood platelets to produce $\mathrm{TxB}_{2}$ was significantly $(\mathrm{p}=0.0001)$ depressed following administration of the fish supplement. Results were similar when calculated per $10^{9}$ platelets. Moreover, multiple regression analysis revealed that the change in platelet count did not contribute significantly to this fish effect (data not shown). 
In Maastricht, $T \times B_{2}$ measurements were performed after 3 experimental weeks allso. At that time, the fish effect $(-179 \pm 18, \mathrm{p}<0.0001)$ was already maximum.

Results for 6-keto- $\mathrm{PGF}_{\mathrm{i} w}$ were comparable to those reported for $\mathrm{TxB}_{2}$ (Table 9). Analysis of variance demonstrated that consumption of the fish supplement was associated with a highly significant reduction in the content of 6-keto-PGF $F_{1 \alpha}$ in serum $(\mathrm{p}=0.0002)$, which had already been attained after 3 experimental weeks (Maastricht only, data not shown).

The ratio between $\mathrm{TxB}_{2}$ and 6-keto-PGF ${ }_{1 \alpha}$ did not change significantly during the study. This is illustrated in Table 10, in which the mean values are also given for the values of $\mathrm{TxB}_{2}$ and 6-keto-PGF $\mathrm{Pa}$. In this table the results of the 3 centers, which did not differ significantly from each other, are combined.

\section{Major metabolites of $\mathrm{PGI}_{2}$ and $\mathrm{PGI}_{3}$ in urine}

These measurements were carried out in samples from 10 Maastricht volunteers of the mackerel group at the start of the study and after 6 experimental weeks. Results are given in Table 11 from which it is evident that the urinary prostacyclin metabolites increased strikingly during the experimental period. This holds for the metabolites of both $\mathrm{PGI}_{2}$ as well as $\mathrm{PGI}_{3}$. In fact, a highly significant, positive, rectilinear relationship was observed between $\mathrm{PGI}_{2}-\mathrm{M}(=\mathrm{X})$ and $\mathrm{PGI}_{3}-\mathrm{M}(=\mathrm{Y})$, measured in the same samples. This relationship can be represented by the equation $Y=-36.05$ $+0.637 \mathrm{X}, \mathrm{n}=22, \mathrm{r}=0.86 ; \mathrm{p}<0.001$. The results of these measurements indicate that the fish supplement may double the daily turnover of $\mathrm{PGI}_{2}+\mathrm{PGI}_{3}$.

\section{Tetranor prostaglandin metabolites in urine}

Initially, TPD and TPM were both measured in each sample. However, the amounts of TPM were very low and could often not be quantified reliably. Therefore, it was decided to measure only TPD in the remainder of the samples; these results are given in Table 12.

Due to the complexity of the analytical procedure, the recovery was only $20-40 \%$ (32.6 \pm 0.71 , mean $\pm S E M, n=134)$. Unfortunately, no radioactive tetranor prostglandin metabolite was available as an international standard. Therefore, $1_{-14}$ $\mathrm{PGE}_{2}$ was used for this purpose, assuming that its recovery would reflect that of the PG-metabolites of interest. However, this assumption may not be totally correct, as is indicated by the significant rectilinear relationship observed between the recovery $(=X, \%)$ of the internal standard added to the samples and the daily urinary excretion of tetranor $\mathrm{PG}$-metabolites $(=\mathrm{Y}, \mu \mathrm{g} / 24 \mathrm{~h})$ as reflected by the TPD measured after correction for this recovery $(\mathrm{Y}=397-5.3 \mathrm{X}, \mathrm{n}=133, \mathrm{r}=-0.29$; $\mathrm{p}=<0.001)$.

This finding strongly indicates an 'overcorrection' for recovery; the results of the measurements were, therefore, calculated by analysis of covariance, taking into ac- 
count the recovery of the internal standard.

No significant effects were observed in any of the groups. Consequently, it can be concluded that the fish supplement did not affect the prostaglandin turnover in vivo as reflected by the urinary tetranor $\mathrm{PG}$ metabolites, measured as TPD.

\section{Discussion}

In this study the influence of dietary enrichment with on average ca. $80 \mathrm{~g}$ of mackerel per day for 6 weeks was investigated with respect to various aspects of the eicosanoid metabolism of blood platelets in vitro and some features of prostanoid turnover in wivo. The in-vitro studies were performed with platelets that had been activated with varying amounts of collagen, either in whole blood or in PRP, or with high amounts of thrombin, generated during blood clotting. These various conditions enabled us to evaluate the effect of the dietary fish on the maximum potency of blood platelets to produce pro-aggregatory $\mathrm{TxA}_{2}$ as well as on the prostanoid formation caused by more gentle platelet stimulation.

The results for the monohydroxy fatty acids derived from arachidonic acid and timnodonic acid (Table 2 and 3) were obtained after stimulation of the platelets with a high dose of collagen. Under this condition of supra-maximal stimulation, which resulted in maximum aggregation (data not shown), fish consumption was associated with significant reductions in the formation of HHT $(\mathrm{p}=0.0002)$ and $\mathrm{HETE}$ $(\mathrm{p}=0.0140)$, whereas the formations of TA-derived HHTE and HEPE was in. creased $(\mathrm{p}<0.0001)$.

Results for the cyclo-oxygenase products HHT and HHTE are likely to reflect the formation of $\mathrm{TxB}_{2}$ and $\mathrm{TxB}_{3}$, respectively. This can be concluded from the results of a series of samples in which both hydroxy fatty acids as well as thromboxanes were measured, demonstrating a significant correlation between the two sets of measurements (Table 6). The relationship between in $\mathrm{TxB}_{2}$ and HHT had been previously observed in a dietary study with rabbits $(\mathrm{r}=0.93, \mathrm{n}=122$, unpublished results); the additional observation of a relationship between $T \times B_{3}$ and $H H T E$, thus confirms and extends the suggestion, orginating from work by others $(40,41)$, that the formation of cyclo-oxygenase-dependent monohydroxy fatty acids by activated blood platelets reliably reflects thromboxane formation by those platelets.

The lowering effect of dietary fish on the formation of $\mathrm{Tx}_{2}$ by supramaximallystimulated platelets was also reflected in the lower amount of ir $\mathrm{TxB}_{2}$ in serum of volunteers consuming the fish supplement as compared with the control group, consuming a comparable amount of meat (Table 9). Moreover, a similar though smaller effect, was observed when the platelets were activated in a more gentle way, using rather low doses of collagen added to citrated whole blood (Table 7 and 8). Since 
Table 13. Relationship between the formation of it $T x B_{2}(=X)$ and various aspects of platelet function $(=Y$ ), measured simulianeously in collagen-activated whole blood.

\begin{tabular}{lllllrl}
\hline Y-variable & condition & $\mathrm{a}$ & $\mathrm{b}$ & $\mathrm{r}$ & $\mathrm{n}$ & $\mathrm{p}$ \\
\hline aggregation. & $\mathrm{a}$ & -0.46 & 0.12 & 0.71 & 106 & $<0.001$ \\
velocity (tan) & $\Delta$ & -0.62 & 0.11 & 0.66 & 32 & $<0.001$ \\
& & & & & & \\
maximum & $\mathrm{a}$ & 1.6 & 0.56 & 0.63 & 106 & $<0.001$ \\
aggregation (ohm) & $\Delta$ & -5.7 & 0.45 & 0.59 & 32 & $<0.001$ \\
& & & & & & \\
maximum ATP & $\mathrm{a}$ & 0.037 & 0.041 & 0.56 & 108 & $<0.001$ \\
release (nmol) & $\Delta$ & -0.180 & 0.037 & 0.83 & 31 & $<0.001$ \\
\hline
\end{tabular}

a: Actual values of all measurements combined: initial, after 6 experimental weeks and after the second run-in period

$\Delta$ : Difference in response between the second run-in period and the values after 6 experimental weeks

For further explanation: see Table 6

highly significant relationships were observed between $\operatorname{TxB}_{2}$-formation $(=X)$ and various aspects of platelet function ( $=\mathrm{Y}$, see Table 13), the lower $\mathrm{TxB}_{2}$-formation following fish consumption was the most probable explanation for the reduced platelet responses, which was simultaneously observed (37).

Lipoxygenase products from TA were readily formed following fish consumption (Table 3), although, again, the reduction in AA-derived products was not compensated for completely (average compensation was almost $65 \%$ ). It has been suggested that $H(P) E T E$ is essential for the formation of irreversible aggregates (42), and since, in general, lipoxygenase products of TA are less active than those derived from AA $(6,43,44)$, it may be speculated that the change in HETE/HEPE formation resulting from fish consumption may lower the thrombotic function of blood platelets. Others, however, have claimed that HETE has an aggregation-inhibiting effect $(45,46)$. Since no studies have been reported with HEPE in this respect, the possible implication of the HETE/HEPE exchange for platelet function and thrombosis remains to be elucidated.

Mackerel consumption seems to increase both $\mathrm{PGI}_{2}$ and $\mathrm{PGI}_{3}$ turnover in the body since the urinary amounts of their major metabolites increase significantly during the 6-week mackerel period (Table 11). The formation of $\mathrm{PGI}_{3}$ following fish consumption has been observed before (18) and is understandable, since precursor ( = timnodonic acid) availability greatly improves upon mackerel intake (results to be described elsewhere). The increased turnover of $\mathrm{PGI}_{2}$, on the other hand, is difficult to explain, since fish consumption is very often associated with a decreased AA availabilty $(1,12,47,48)$. Moreover, our studies in serum (Tables 9 and 10 ) indicate that the monocyte-associated (49) $\mathrm{PGI}_{2}$-production is significantly reduced 
upon fish consumption. This may be secondary, however, to the reduced capacity of platelets to produce endoperoxides, since it has been demonstrated that the $\mathrm{PGI}_{2}$-production of monocytes, depends at least partly on endoperoxides produced by, and escaped from, activated blood platelets (50). A higher $\mathrm{PGI}_{2}$ turnover in vivo has previously been observed following the ingestion of large amounts of mackerel (18), in traditionally-living Greenland Eskimos as compared to the Danes (19), and in inhabitants of a Japanese fishing village, as compared to Japanese farmers (20). This finding has been attributed to the effects of arachidonic acid that is often present in fish body fat. As is demonstrated in Table 1, the mackerel fat contained $1.2 \%$ AA, which can account for a daily intake of about $250 \mathrm{mg}$ of AA. The meat supplement, however, also contained some AA ( $0.5 \%$ of the total fatty acids), providing a daily intake of about $100 \mathrm{mg}$ of AA. Whether this was also associated with an enhanced turnover of $\mathrm{PGI}_{2}$ was not measured in the present study.

In a trial with cod-liver oil, containing no appreciable amounts of AA, no increase in $\mathrm{PGI}_{2}$ turnover was detected (22). In this latter study and in that by another research group (21), $\mathrm{PGI}_{2}$ turnover either did not change or was reduced upon fish oil ingestion. The highly significant correlation between $\mathrm{PGI}_{2}-\mathrm{M}$ and $\mathrm{PGI}_{3}-\mathrm{M}$, as found in the present study and as observed before (20), requires special attention since it may point to an influence of dietary fish on PGI metabolism in general. It should be realized that measurements were restricted to the major metabolites of $\mathrm{PGI}_{2}$ and $\mathrm{PGI}_{3}$, but 'major' still represents a small fraction only. For $\mathrm{PGI}_{2}$, for instance, as many as 16 different metabolites have been identified, the major one being only $10-15 \%$ of the parent compound (51-54). Moreover, the concept that the PGI turnover in vivo is reflected by the urinary excretion of its major metabolite is viable only if the treatment under investigation does not affect the metabolic pathway of the compound of interest and, consequently, does not modify the relative amounts of each member of the total spectrum of metabolites. Since fish oil has repeatedly been shown to affect peroxisomal and microsomal $\beta$-oxidation (55-60), changes in the urinary levels of the $\beta$-oxidation products of 6 -keto-PGF ${ }_{1 \alpha}$ and $\triangle 17-6-$ keto-PGF ${ }_{1 \alpha}$ do not necessarily reflect an altered turnover of $\mathrm{PGI}_{2}$ and $\mathrm{PGI}_{3}$, respectively, but may be the result of changes in the metabolic pathway of the parent compounds. Therefore, a more 'overall-method' seems indispensable to quantify PGI-turnover in vivo reliably.

It should also be mentioned that increasing amounts of PGI metabolites in urine do not necessarily reflect an increased vascular PGI production. A major source of $\mathrm{PGI}_{2}$ is the stomach fundus $(61,62)$, and recent evidence suggests that diet-induced PGI responses reflect gastro-intestinal changes in particular (63). Since $\mathrm{PGI}_{2}$ does not circulate as such in sufficient amounts to affect platelet aggregability (64-68), the importance of the possible, but by no means proven, increased PGI-turnover following fish consumption does not necessarily have cardiovascular implications. Finally, an increased prostanoid production can also reflect increased cell damage 
(69). In this context it is important to mention that the $\mathrm{PGI}_{2}-$ turnover in vivo, deduced from the urinary amounts of 2,3-dinor-6-keto-PGF $F_{1 a}$ is strikingly increased in heavy smokers (70) and in people with severe atherosclerosis (71). Moreover, recent evidence suggests that 'oxidative stress' may have an overall stimulating effect on basal prostaglandin turnover in vivo (72). In our present study, however, the urinary content of tetranor prostaglandin (PG) metabolites measured as tetranor prostanedioic acid, TPD, and thought to reflect the turnover of PGE and PGF, did not significantly change upon mackerel consumption (Table 12). Therefore, the increased PGI turnover possibly detected after mackerel consumption cannot be interpreted in terms of an adverse effect of the mackerel.

\section{Acknowledgements}

The skillful help of P. Moret in measuring the mono-hydroxy fatty acids is gratefully acknowledged. We thank Elsa Beckers for typing the manuscript.

\section{References}

1. Hornstra G. The significance of fish and fish-oil enriched food for prevention and therapy of ischaemic cardiovascular disease. In: Crawford MA, Vergroesen AJ (eds). The role of fats in human nutrition II. Academic Press, London 1988; in press.

2. Hornstra G. Dietary lipids, prostanoids and arterial thrombosis. Chapter 8: Relationship between dietary fat type, platelet fatty acid composition and eicosanoid formation by activated platelets. Martinus Nijhoff Publishers, the Hague 1982; 138-166.

3. Hornstra G. Regulation of eicosanoid production by fatty acid availability. Adv Inflamm Res 1985; 10: $1-6$.

4. Hamberg M. Transformations of 5,8,11,14,17 eicosapentaenoic acid in hunan platelets. Biochim Biophys Acta 1980; 618: $389 \% 398$.

5. Lands WEM, LeTeller PR, Rome LH, Vanderhoek JY. Inhibition of prostaglandin biosynthesis. Adv Biose 1973; 9: 15-28.

6. Needleman P, Raz A, Minkes MS, Ferrendelli JA, Sprecher H. Triene prostaglandins: prostacyclin and thromboxane biosynthesis and unique biological properties. Proc Natl Acad Sei USA 1979; 76: $944-948$.

7. Smith DR, Weatherly BC, Salmon JA, Ubatuba FB, Gryglewski RJ, Moncada S. Preparation and biochemical properties of $\mathrm{PGH}_{3}$. Prostaglandins 1979; 18: 423-438.

8. Struyck CB, Beerthuis RK, Pabon HJJ, van Dorp DA. Specificity of the enzymic conversion of polyunsaturated fatty acids into prostaglandins. Recl Trav Chim Pays Bas 1966; 85: 1233-1250. 
9. Brox JH, Killie JE, Gunne S, Nordgy $A$. The effect of cod-liver wil and corn oil on platelets and vessel wall in man. Thromb Haemostas 1981; 46: 604-611.

10. Driss $\mathbf{F}$, Vericel $\mathbf{E}$, Lagarde $\mathbf{M}$, Dechavanne $\mathbf{M}$, Darcet $\mathbf{P}$. Inhibition of platelet aggregation and thromboxane synthesis after intake of small amount of icosapentaenoic acid. Thromb Res 1984; 36: $389-396$.

11. Lorentz R, Spengler U, Fischer S, Duhm J, Weber P. Platelet function, thromboxane formation and blood pressure control during supplementation of the western diet with cod-liver oil. Circulation 1983 ; 67 : $504-511$.

12. Siess W, Roth P, Scherer B, Kurzmann I, Böhlig B, Weber PC. Platelet-membrane fatty acids, platelet aggregation and thromboxane formation during a mackerel diet. Lancet 1980; i: 441-444.

13. Beitz J, Schimke E, Liebaug V, Block HU, Beitz A, Honigmann G, Sziegoleit W, Mueller G, Mest H-J. Influence of a cod-liver oil diet in healthy and insulin-dependent diabetic volunteers on fatty acid pattern, inhibition of prostacyclin formation by low density lipoprotein (LDL) and platelet thromboxane. Klin Wochenschr 1986; 64: 793m 799.

14. Bolton-Smith C, Gibney MJ. The effect of a dietary supplement of marine oil in healthy volunteers on platelet lipids, platelet function and platelet plasma membrane fluidity. Proc Nuir Soc 1986; 45: 12.

15. Brox JH, Killie JE, Tosterud B, Holme S, Nordøy A. Effects of cod-liver oil on platelets and coagulation in familial hypercholesterolemia (Type 11a), Acta Med Scand 1983; 213: 137-144.

16. Sanders TAB, Hochland MC. A comparison of the influence on plasma lipids and platelet function of supplements of $n-3$ and $n-6$ polyunsaturated fatty aicds. Brit $J$ Nutr $1983 ; 50: 521-529$.

17. Adam O, Wolfram G, Zöllner N. Vergleich der Wirkung von Linolensäure und Eicosapentaensäure auf die Prostaglandinbiosynthese und Thrombozytenfunktion beim Menschen. Klin Wochenschir 1986; 64: 274-280.

18. Fischer $\mathrm{S}$, Weber PC. Prostaglandin $\mathrm{I}_{3}$ is formed in vivo in man after dietary eicosapentaenoic acid. Nature 1984; 307: 165-168.

19. Fischer S, Weber, PC, Dyerberg J. The prostacyclin/thromboxane balance is favourably shifted in Greenland Eskimos. Prostaglandins 1986, 32: 235-240.

20. Hamazaki T, Fischer S, Urakaze M, Sawazaki S, Yano S. Comparison of the urinary metabolitem of prostacyclin and thromboxane of the 2 -and 3. series in a Japanese fishing and a Japanese farm. ing village. Prostaglandins 1986; 32: 655-664.

21. Knapp HR, Rielly IAG, Allessandrini P, FizGerald GA. In vivo indexes of platelet and vascular function during fish-oil administration in patients with atherosclerosis. New Engl J Med 1986; 314 : 937-942.

22. Schacky $\mathbf{C}$ von, Fischer $\mathbf{S}$, Weber PC. Long-term effects of dietary marine n-3 fatty acids upon plasma and cellular lipids, platelet function, and eicosanoid formation in humans. J Clin Invest $1985 ; 76: 1626-1631$.

23. Sehacky $\mathbf{C}$ von, Weber PC. Metabolism and effects on platelet function of the purified eicosapentaenoic and docosahexaenoic acids in humans. J Clin Invest 1985; 76: 2446-2450.

24. Sinclair HM. Advantages and disadvantages of an Eskimo diet. In: R Fumigalli, D Kritchewski and R Paoletti (eds): Drugs affecting lipid metabolism. Elsevier/North Holland Biomedical Press 1980; 363-370. 
25. Houwelingen AC , Hemnissen AAHM, Sepberth H, Hornstra G. Effect of dietary fat type on PGE production in vivo. Adv Prost Thrombox Leukorr Res $1987 ; 17: 871-875$.

26. Thomgren M, Shafi S, Born GVR. Delay in primary haemostasis produced by a fish diet without change in local thromboxane $\mathrm{A}_{2}$. Brit J Haematol 1984; 58: 567-578.

27. Tilvis RS, Rasi V, Vïnikka L, Ylikorkala $O$, Miatimen $\mathbb{T}$ A. Eftects of purified fish oil on platelet lipids and function in diabetic women. Clin Chirn Acta 1987; 164: 315-322.

28. Zuccato E. Hornstra G, Dyerberg $\boldsymbol{J}$. Life-long 'marine diet' in Eskimos is not associated with altered urinary excretion of total tetranor prostaglandin metabolites. Prostaglandins 1985; 30: $465-478$.

29. Hormstra G, Zuccato E. Regulation of prostanoid production by dietary lipids: differences between in vifro and in viwo. In: Lagarde $M$ (ed). Biology of Icosanojds. Coll Inserm 1987; 152: 279-292.

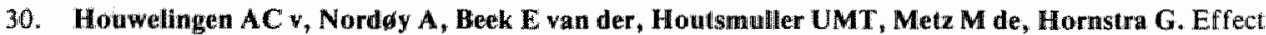
of a moderate fish intake on blood pressure, bleeding time, hematology, and clinical chemistry in healthy males. Am J Clin Nutr 1987; 46: 871-875. Chapter 4.

31. Emeis JJ, v Houwelingen AC, Hoogen CM wan den, Hornstra G. A moderate fish intake increases plasminogen activator inhibitor type-1 in human volunteers. Chapter 10.

32. Houwelingen AC w, Zevenbergen JL, Groot PHE, Kester ADM, Hornstra G. A controlled study on the effects of a fish-enriched diet on serum lipids and apoproteins. Chapter 5.

33. Houwelingen AC v, Hennissen AAHM, Verbeek-Schippers F, Simonsen T, Kester ADM, Hornstra G. Effect of a moderate fish intake on platelet aggregation in human platelet rich plasma. Throm. Haemostas 1988; 59: 507-513. Chapter 6.

34. Nugteren DH, Kivits GAA. Conversion of linoleic acid and arachidonic acid by skin epidermal lipoxygenases. Biochim Biophys Acta 1987; 921, 135-141.

35. Fischer $\mathbf{S}$, Weber $\mathbf{P C}$. Thromboxane $\mathbf{A}_{3}\left(\mathbf{T x} \mathbf{A}_{3}\right)$ is formed in lhuman platelets after dietary eicosapentaenoic acid (C 20:5 n-3). Biochem Biophys Res Comm 1983; 116: 1091-1099.

36. Waddell KA, Barrow SE, Robinson C, Orchard MA, Dollery CT, Blair IA. Quantitative analysis of prostanoids in biological fluids by combining capillary column gas-chronatography negative-ion chemicall ionisation mass-spectrometry. Biomed Mass Spectrom 1984; 11: 68-74.

37. Houwelingen AC v, Kester ADM, Hornstra G. Effect of a moderate fish intake on some platelet function in whole blood. Chapter 7.

38. Dixon WJ. Ratios inwolving extreme values. Ann Math Stat 1951; 22: 68-78.

39. Levene H. Robust tests for equality of variances. In: Olkin I (ed): Contributions to probability and statistics. Stanford University Press Palo Alto, Calif 1960; 278-292.

40. Dicafalusy U, Falardeau P, Hammarstrom S. Conversion of prostaglandin endoperoxides to $\mathrm{C} 17$. hydroxy acids catalyzed by human platelet thromboxane synthetase. FEBS Lett 1977; 84: 271-274.

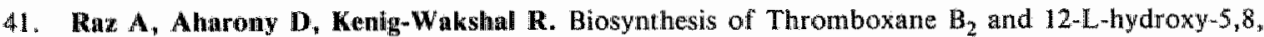
10-heptadecatrienoic acid. Evidence for a common enzymatic pathway. Eur J Biochem 1978; 86: $447-454$.

42. Dutilh CE, Haddeman E, Don JA, ten Hoor $\mathbf{F}$. The role of arachidonate lipoxygenase and fatty acids during irrewersible blood platelet aggregation in vitro. Prost and Med 1981; 6: 111-126. 
43. Prescoti SM. The effect of eicosapentaenoic acid on leukotriene B production by human neutrophils. I Biol Chem 1984; 259: 7615-7621.

44. Terano T, Salmon JA, Moncada S. Effects of orally administered eicosapentaenoic acid (EPA) on the formation of leukotriene $B_{4}$ and leukotriene $B_{5}$ by rat leukocytes. Biochem Pharmacol 1984; 33: $3071-3076$.

45. Alharony D, Smith JB, Silver MJ. Regulation of arachidonate induced platelet aggregation by the lipoxygenase product 12-hydroxy eicosatetraenoic acid. Biochim Biophys Acta 1982; 718: 193-200.

46. Gimeno MG, Shattner MA, Borda E, Gimeno AL, Lazzari MA. Lipoxygenase inhibitors alter aggregation and adhesiveness of human blood platelets from aspirin-treated patients. Prost Leukotr Med 1983; 11: 109-119.

47. Mori TA, Codde JP, Vandongen R, Beilin LJ. New findings in the fatty acid composition of individual platelet phospholipids in man after dietary fish oil supplementation. Lipids $1987 ; 22$ : 744-750.

48. Galloway, JH, Cartwright IJ, Woodcock BE, Greaves M, Russell GG, Preston FE. Erfects of dietary fish oil supplementation on the fatty acid compostion of the human platlet membrane: demonstration of selectivity in the incorporation of eicosapentaenoic acid into membrane phospholipid pool. Clin Sci 1985; 68: 449-454.

49. McGuire JC, Sun FF. Metabolism or arachidonic acid and prostaglandin endoperoxide by assorted leukocytes. Adv Prost Thromboxane Res 1980; 8: 1665-1667.

50. Defreyn $\mathbf{G}$, Deckmijn $\mathbf{H}$, Vermijlen $\mathbf{J}$. A thromboxane synthetase inhibitor reorients endoperoxide metabolism in whole blood towards prostacyclin and prostaglandin $\mathrm{E}_{2}$. Thromb Res 1982; 26: 389-400.

51. Brash AR, Jackson EK, Lawson JA, Branch RA, Oates JA, Fitzgerald GA. Quantitative aspects of prostacyclin metabolism in humans. Adv Prost Thrombox Leukotr Res 1983; 11: 119-122.

52. Rosenkranz B, Fischer C, Weimert KE, Fröhlich JC. Metabolism of prostacyclin and 6-ketoprostaglandin $F_{1, q}$ in man. J Biol Chem 1980; 255: 10194-10198.

53. Sun FF, Taylor BM. Metabolism of prostacyclin in cynomolgus monkeys. Prostaglandins 1981; 21: 307-314.

54. Sun FF, Taylor BM, Sutter DM, Weeks JR. Metabolism of prostacyclin III. Urinary metabolite profile of 6-keto-PGFi ${ }_{1 \alpha}$ in rat. Prostaglandins 1979; 17: 753-759.

55. Bergseth $\mathbf{S}$, Christiansen EN, Bremer J. The effect of feeding fish oils, vegetable oils and clofibrate on the ketogenesis from long chain fatty acids in hepatocytes. Lipids $1986 ; 21: 508-514$.

56. Neat CE, Thomassen MS, Osmundsen H. Effects of high-fat diets on hepatic fatty actd oxidation in the rat. Biochem J 1981; 196: 149-159.

57. Nilsson $\mathbf{A}$, Prydz $\mathbf{K}$, Rørtveit $\mathbf{T}_{*}$ Christiansen EN. Studies on the interrelated stimulation of microsomal beta-oxidation and peroxisonal beta-oxidation in rat liver with a partially hydrogenated fish oil diet. Biochim Biophys Acta 1987; 920: 114-119.

58. Osmundsen H, Bjornstad K. Inhibitory effect of some long-chain unsaturated fatty acids on mitochon-

drial beta-oxidation. Biochem I 1985; 230: 329-337. 
59. Thomassen MS, Christlansen EN, Norum K. Characterization of the stimulatory effect of high-fat diets on peroxisomal beta-oxidation in rat liver. Biochem J 1982;206: 195-202.

60. Yamazak RK, Shen $T$, Schade GB. A diet rich in ( $\mathrm{n}-3$ ) fatty acids increases peroxisomal betaoxidation activity and lowers plasma triacylglycerols without inhibiting glyathone-dlependent detoxication activities in the rat Hver. Biochim Biophys Acta 1987; 920: 62-67.

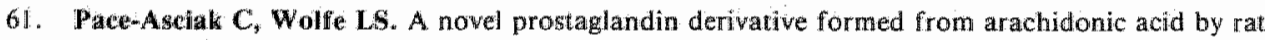
stomach homogenates. Biochemistry 1971; 10:3657-3664.

62. Kiwits GAA, Nugteren DH. The urinary excretion of prostaglandins $\mathrm{E}$ and their corresponding tetranor metabolites by rats fed a diet rich in eicosapentaenoate. Biochim Biophys Acta 1988; 958 : 289-299.

63. Grant HW, Palmer KR, Kelly RW, Wilson NH, Misiewicz JJ. Dietary linoleic acid, gastric acid and prostaglandin secretion. Gastroenterology 1988; 94: $955-959$.

64. Hassian RJ, McClenaghan MD. An assay for activators of platelet adenylate cyclase present in rabbit blood. Evidence that prostacyclin $\left(\mathrm{PGI}_{2}\right)$ is not a circulating hormone. Thromb Haemostas 1979; $42: 117$.

65. Haslam RJ, McClenaghan MD. Measurement of circulating prostacyclin. Nature 1981; 292: $364-366$.

66. Christ-Hazellhof $E_{1}$ Nugteren DH. Prostacyclin is not a circulating hormone. Prostaglandins 1981; 22: $739-746$.

67. FitzGerald GA, Brash AR, Falardleau P, Oates JA. Estimated rate of prostacyclin secretion into the circulation of man. J Clin Invest 1981; 68: 1271-1276.

68. Blair IA, Barrow SE, Waddell KA, Lewis PG, Dollery CT. Prostacyclin is not a circulating hormone in man. Prostaglandins 1982; 23: 579-589.

69. Brash AR. GC-MS analysis of urinary metabolites of eicosanoids. In: Lagarde M (ed): Biology of Icosanoids. Coll Inserm 1987; 15: 143-150.

70. Nowak J, Murray JJ, FitzGeralld GA, Wehr CJ, Hammon JW, Oates JA. Eicosanoids and sudden cardiac death. Adw Prosi Thrombox Leuktotr Res 1987; 17: 20-24.

71. FizGerald GA, Smith B, Pedlersen AK, Brash AR. Increased prostacyclin biosynthesis in patients with severe atherosclerosis and platelet activation. New Engl J Med 1984; 310: 1065-1068.

72. Hornstra G. Influence of dietary lipids on prostaglandin turnover in witro and in wivo. In: Lands WEM (ed): Polyunsaturated fatty acids and eicosanoids. American Oil Chemists' Society, Illinois $1987 ; 408-412$. 


\section{CHAPTER 9}

\section{EFFECT OF A MODERATE FISH INTAKE ON COAGULATION PARAMETERS IN HEALTHY MALES}

\section{Summary}

This chapter describes the results of a 6-week dietary intervention with a reasonable amount of fish on the coagulation tendency of blood and on the procoagulant activity of monocytes. Healthy male volunteers were given a daily dietary supplement consisting of $100 \mathrm{~g}$ of mackerel $(n=41)$ or meat $(n=42)$. Compliance was monitored on basis of urinary excretion of lithium, which was added to the supplements. We did not observe a significant effect of the fish supplement on the prothrombin time, or on the levels of factor VII, activated factor VII, antithrombin III, von Willebrand factor, fibrinogen, plasminogen and $\alpha_{2}$-antiplasmin. An indication of a slight transient prolongation in the partial thromboplastin time and a trend towards an increase in the factor $\mathrm{X}$ level with prolongation of the experimental period was noticed; no activated factor $X$ was found. A tendency towards a stimulation of monocyte procoagulant activity by the fish supplement was also found.

Key words: dietary fish, coagulation, factor VII, factor VII $\mathrm{a}_{\mathrm{a}}$ antithrombin III, von Willebrand factor, fibrinogen, plasminogen, $\alpha_{2}$-antiplasmin, prothrombin time, factor $\mathrm{X}$, factor $\mathrm{X}_{\mathrm{a}}$, monocyte procoagulant actity 


\section{Introduction}

Since cardiovascular ischemia has a complex etiology, the alleged preventive effects of a marine diet could be brought about by many possible mechanisms. In earlier publications we reported on the influence of a mackerel-containing dietary supplement on various aspects of the cardiovascular risk profile. The effects observed were marginal only and not in agreement with an important role of dietary fish in the prevention of ischemic heart- and vessel disease (Chapter 4-8 and 10).

Fibrin, the end product of the coagulation cascade, is one of the compounds found in the atherosclerotic plaque (1). Thrombin, the central enzyme in fibrin formation, is a powerful platelet activator $(2,3)$ and may be essential for the initiation of a local platelet thrombus $(4,5)$. Therefore, blood coagulation can be expected to play an important role in the onset, progression and complications of ischemic heart- and vessel disease.

In the present study we investigated the effect of a dietary enrichment with fish on a number of variables which reflect the coagulation tendency of blood and on monocyte procoagulant activity.

\section{Subjects, methods and materials}

The study was designed as an open, well-controlled intervention trial, carried out almost simultaneously under comparable conditions in three different centers: 1) Department of Medicine, University of Troms $\varnothing$, Norway, 2) TNO-CIVO Toxicology and Nutrition Institute, Zeist, The Netherlands and 3) Departments of Human Biology and Biochemistry, University of Limburg, Maastricht, The Netherlands. The experimental design has been extensively described in a previous publication (6).

Eighty-four healthy male volunteers (20-45 years of age) participated in the study. The trial lasted 6 weeks, preceded by a run-in period of 2 weeks. During this run-in period all volunteers were requested to consume one tin of meat paste $(135 \mathrm{~g})$ per day. Subsequently, they were randomized into a mackerel and a meat (control) group. During the 6 experimental weeks the volunteers of the mackerel group consumed one tin of mackerel paste $(135 \mathrm{~g})$ per day, while the control subjects continued the consumption of meat paste. The dietary supplements were given as a replacement of the fish, meat, cheese or eggs normally consumed during the main meal. The mackerel paste provided $1.7 \mathrm{~g}$ timnodonic acid $(20: 5 \mathrm{n}-3)$ and $3.0 \mathrm{~g}$ cervonic acid $(22: 6 n-3)$ per day. Compliance was calculated on the basis of the urinary excretion (\%) of a standard amount of lithium added to the supplements.

At week 0 (the end of the run-in period), week 3, and week 6 blood was drawn under fasting conditions.

Platelet poor plasma was prepared by centrifugation of blood for $10 \mathrm{~min}$ at 3000 
$\mathrm{x} \mathrm{g}$ and platelet free plasma by centrifugation of platelet poor plasma for $30 \mathrm{~min}$ at $12000 \times \mathrm{g}$. During blood sampling and plasma preparation procedures only plastic materials were used. A standard pool of platelet free plasma (PFP) was obtained from 50 healthy volunteers and stored in $1 \mathrm{ml}$ aliquots at $-80^{\circ} \mathrm{C}$ prior to testing. About one year later we repeated the run-in period during which the volunteers again consumed one tin of meat paste per day for 2 weeks. Before and after this second run-in period, blood samples were taken and plasma was prepared and stored as described above.

The following measurements were carried out:

- Prothrombin time (PT), activated partial thromboplastin time (APTT) and fibrinogen, according to van Dam-Mieras et al (7).

The PT and APTT values were compared to the corresponding values obtained with pooled standard plasma and expressed as:

PT (or APTT) of sample

PT(or APTT) of standard pool plasma

- Factor VII using the one stage clotting test, described previously (8).

- Factor $\mathrm{VII}_{\mathrm{a}}$ was determined by the ratio:

factor VII determined with bovine thromboplastin

factor VII determined with human thromboplastin

as described in the same report (8).

- Von Willebrand factor, according to Cejka (9).

The method applied is an enzyme linked immunosorbent assay (ELISA) performed in plasma, using commercially available peroxidase labeled antiserum and solid-phase support. This method had been validated before with the enzyme-immunoassay in which a phosphate-labelled antiserum was used and with an electroimmunoassay according to Laurell (10).

- Factor $X$ and factor $X_{a}$ were measured with an automated chromogenic substrate assay according to Bas et al (11). The reagent solution of the factor $\mathrm{X}$ assay contained a mixture of one volume of Russell's Viper Venom (RVV, $1 \mathrm{mg}$ lyophilized factor $X$ activating protein in $0.1 \mathrm{mmol} / 1$ sodium chloride, dissolved in 15 $\mathrm{ml}$ distilled water), one volume $\mathrm{CaCl}_{2}(0.1 \mathrm{~mol} / \mathrm{l})$, and two volumes $\mathrm{S} 2337$ solution $(30 \mu \mathrm{mol}$ lyophilized S 2337 dissolved in $20 \mathrm{ml}$ distilled water.

- Antithrombin III (AT-III) was determined by the method described by Bas et al (11). The starting reagent contained chromogenic substrate $S 2338$, polybrene and mannitol (Kabi Vitrum, Amsterdam), dissolved in distilled water, resulting in a chromogenic substrate concentration of $0.75 \mathrm{mmol} / 1$. The reagent solution 
contained 53 nKat lyophilized bovine thrombin, dissolved in $1.5 \mathrm{ml}$ distilled water, and $75 \mathrm{ml}$ heparin buffer, containing Tris $(62.5 \mathrm{mmol} / \mathrm{l})$, EDTA $(9.4$ $\mathrm{mmol} / \mathrm{l})$, heparin $(3.75 \mathrm{IU} / \mathrm{ml})$ and $1.25 \%$ polyethyleneglycol 8000 , pH 8.4.

- Alpha ${ }_{2}$-antiplasmin was measured according to Bas et al (11).

The starting solution contained $35 \mu \mathrm{mol}$ lyophilized chromogenic substrate $\mathrm{S}$ 2251 dissolved in $10 \mathrm{ml}$ distilled water and $22 \mathrm{nKat}$ lyophilized human plasmin, dissolved in $10 \mathrm{ml}$ sterile glycerol and $\mathrm{HCl} 2 \mathrm{mmol} / \mathrm{l}(\mathrm{w} / \mathrm{v})$. The reagent solution contained one volume of the $\mathrm{S} 2251$ starting solution and two volumes Tris buffer $(0.05 \mathrm{~mol} / \mathrm{l}, \mathrm{pH} 7.4)$.

- Plasminogen was quantified using a method described by Bas et al (11). The starting solution contained $35 \mathrm{mM}$ lyophilized chromogenic substrate $\mathrm{S} 2251$, dissolved in $10 \mathrm{ml}$ distilled water. The reagent solution (plasminogen activator) contained streptokinase $(100.000 \mathrm{U})$ dissolved in $35 \mathrm{ml}$ Tris buffer $(0.05 \mathrm{mmol} / 1 \mathrm{pH}$ 7.4)

- Monocyte procoagulant activity was measured in samples of the Maastricht group only. Human peripheral blood monocytes were isolated and cultured as described by Boyum (12), using Ficoll Paque Pharmacia. The purity of the monocyte preparations was at least $95 \%$; cell viability was $96 \%$, measured by trypsan blue exclusion. The measurement of monocyte procoagulant activity was performed according to Muller et al (13). Briefly: monocytes were separated by adhesion to the inner surface of small plastic tubes. After adherence absence of monocytes in the supernatant was verified. Procoagulant activity exposed at the cellular surface was determined in this plastic culture tube after replacing the culture medium by Michaelis buffer. After incubation for $15 \mathrm{~min}$ at $37^{\circ} \mathrm{C}, 0.1 \mathrm{ml}$ $\mathrm{CaCl}_{2}(33 \mathrm{mmol} / \mathrm{l})$ was addled and the clotting time was measured.

\section{Statistical evaluation}

Frequency distributions of all data were checked; when necessary, transformation of the data was applied to normalize this distribution. Subsequently significant outliers were omitted (14). Student"s-test for paired data was used to evaluate the changes within the mackerel and the control group after 6 weeks. Differences between the mackerel and control groups were evaluated using Student's 2-sample ttest. To compare these differences for the three experimental centers, combined analysis of variance (anova) was used. Occasionally, other statistical methods were used which will be outlined in the description of the results.

Differences were considered significant when the two-sided $P$ value (p) was equal to or smaller than 0.05 .

\section{Results}

In Table 1 the initial values (results of week 0 ) of the coagulation parameters are given. Within the centers no significant differences were observed between the 


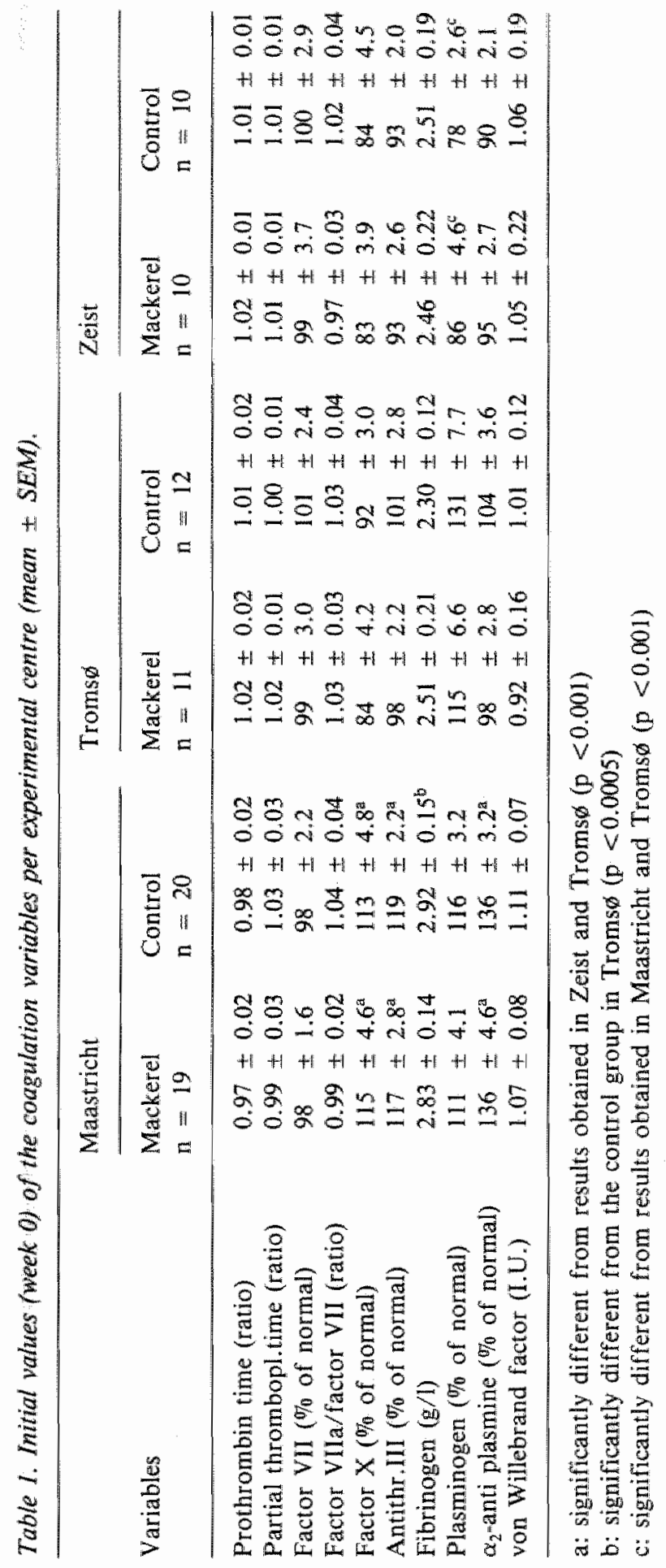




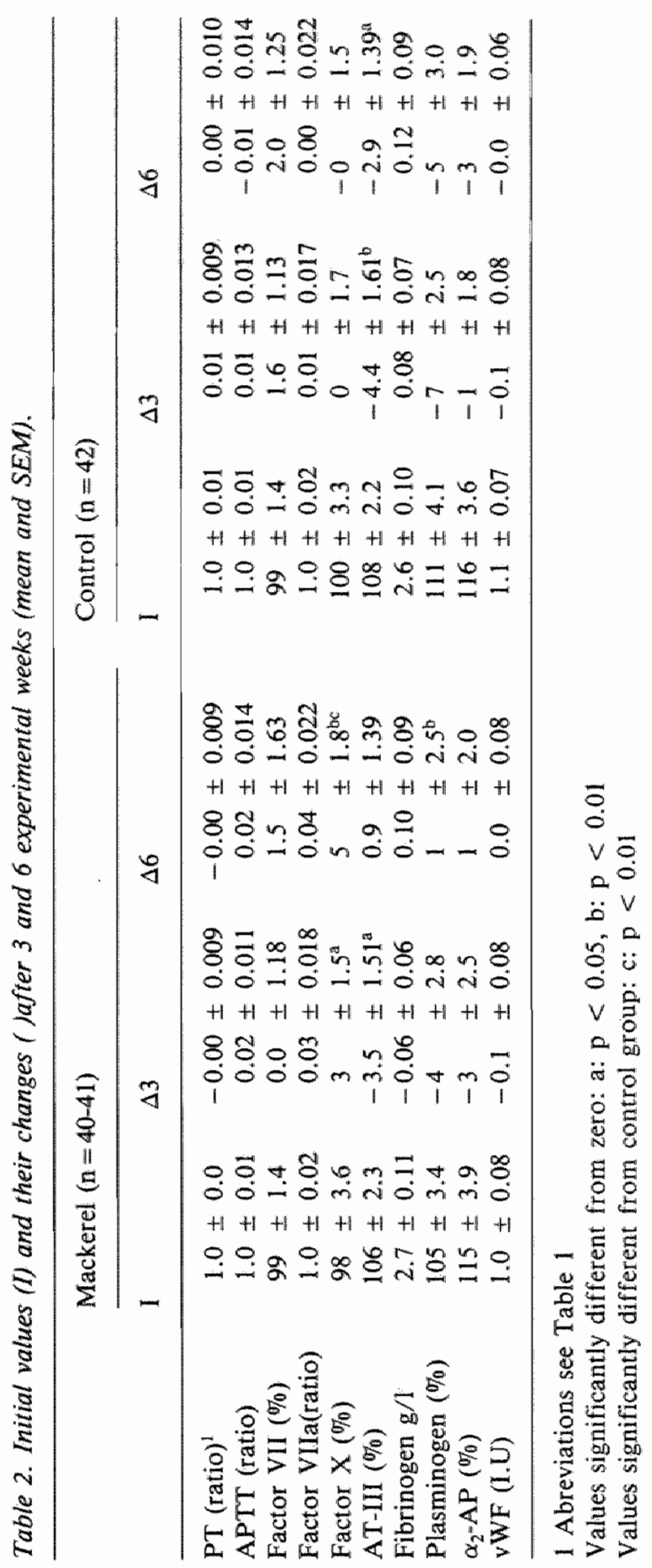




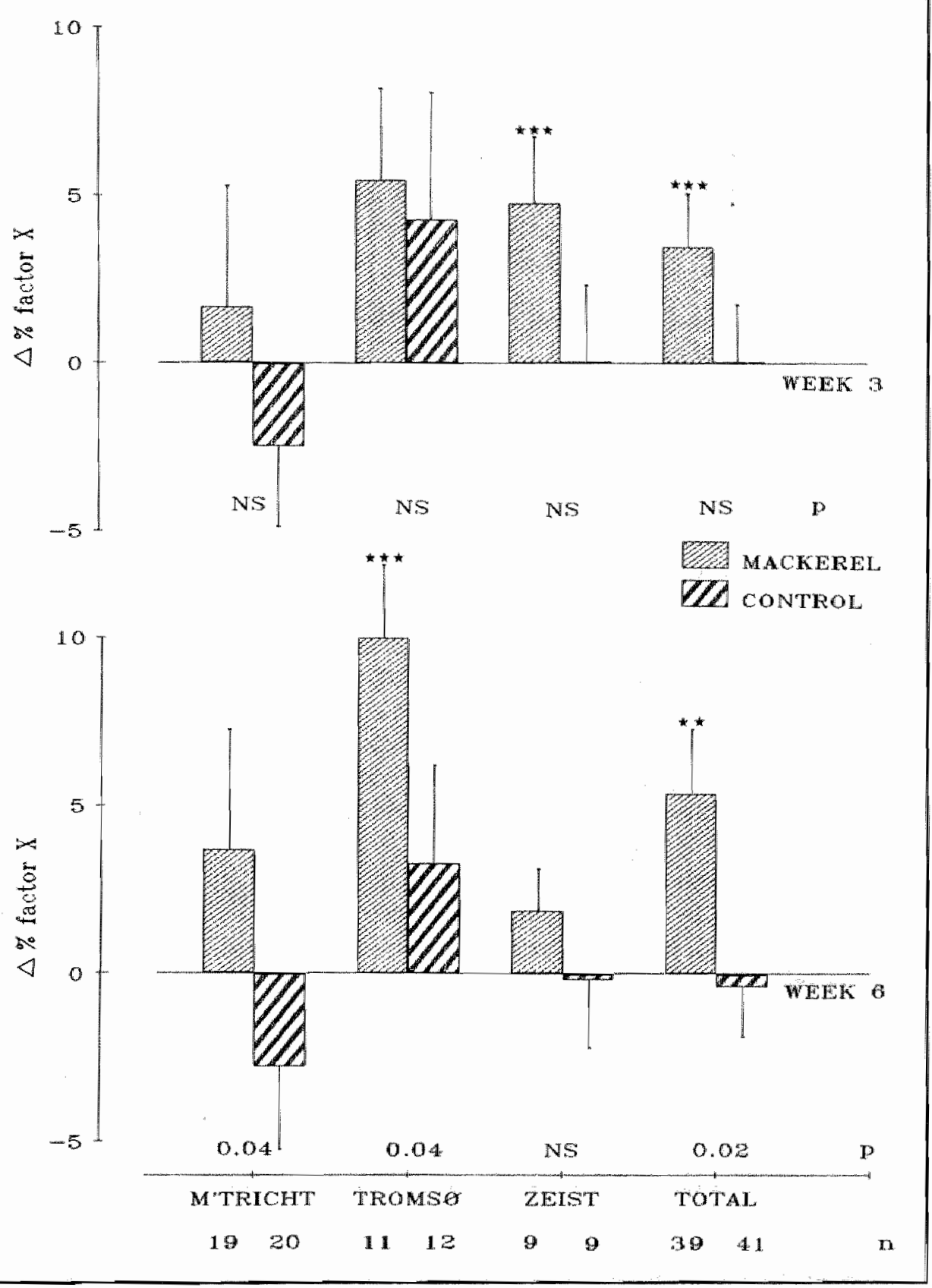

Fig 1. Effect of dietary supplemenis on the change in Factor $X(\Delta \%)$ after 3 and 6 experimental weeks (mean and SEM). NS: not significant. $p$ : significance of differences ber ween mackerel and control groups. Values significantly different from zero *p<0,05,**p<0.01,**p $<0.005$. Initial values given in Table 1 . 

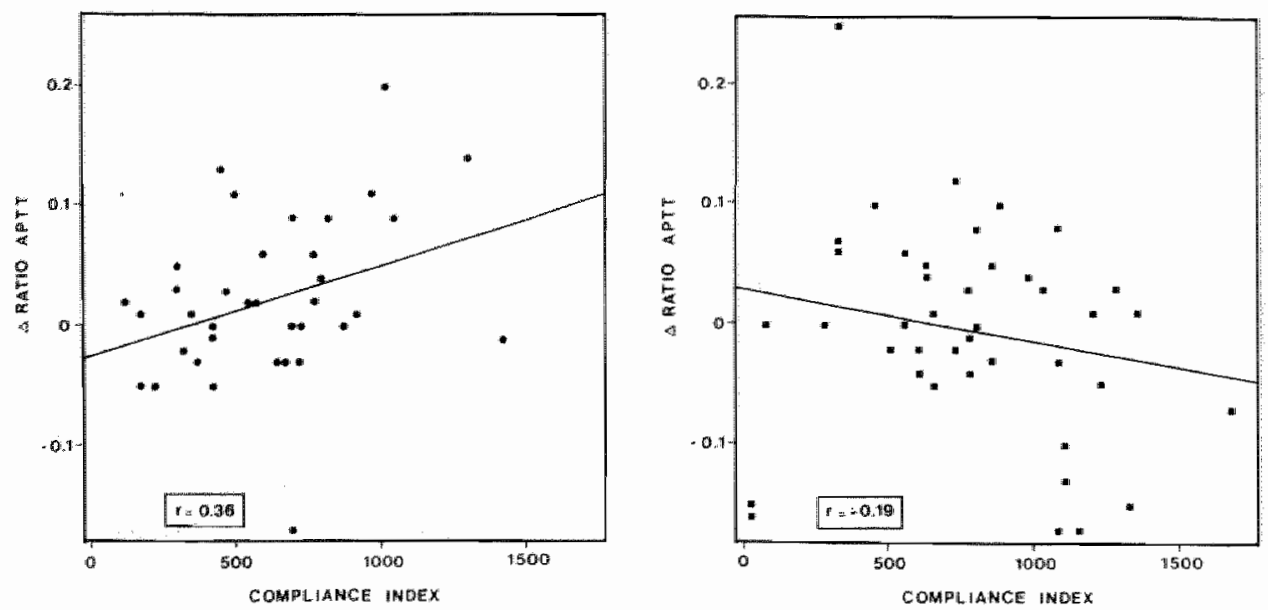

Fig 2. Change in APTT ratio $(Y)$ after 3 experimental weeks in relation with dietary complicance $(X)$.

- mackerel group: $Y=-0.025+8.10^{-5} X, n=38, r=0.36, p<0.03$.

- control group: $Y=0.029-4.10^{-5} X, n=42, r=0.19, N S$.

Difference between regression lines $p<0.05$.

mackerel and the control group. Plasminogen concentrations were significantly lower in Zeist than in the other two centers $(p<0.001)$. In Maastricht higher concentrations were found for factor $\mathrm{X}$, Anti-thrombin III and $\alpha_{2}$-antiplasmin $(\mathrm{p}<0.001$ in comparison with Zeist and Tromsø). The fibrinogen content in the control group of Maastricht was significantly higher than that in the control group of Troms $\varnothing$ $p<0.0005$. No other differences reached the $5 \%$ significance level.

In Table 2 initial values of the three centers combined are given, together with the changes occurring in the coagulation parameters during the experimental period. Except for factor $\mathrm{X}$, no significant differences were observed between the mackerel and control groups for any of the coagulation variables measured, either when evaluated for the combined material, using Student's 2-sample t-test, or when analysis of variance was applied in which the results within each of the 3 centers were taken into account.

For factor $\mathrm{X}$ activity, an increase occurred in the mackerel group as compared with the control group. This is illustrated in more detail in Fig 1, from which it was evident that in all instances the increase in the mackerel groups is higher than that in the control groups, although it was significant in a few instances only. When the 3 centers were taken together, the effect appeared more pronounced at week 6 (p $=0.02$ ) than at week 3 (NS). Moreover, analysis of variance revealed a significant effect of the fish supplement on factor $\mathrm{X}$ activity after 6 weeks $(\mathrm{p}<0.01)$ but not after 3 weeks. The activated form of factor $\mathrm{X}$ was undetectable in all samples. When differences in dietary adherence were taken into account most results did not change appreciably. However, at week 3 a significant, positive, rectilinear relationship was 
Table 3. Effect of dietary supplementis on moncyte procoagulant activily. Clotring time ( $s \pm S E M$ ).

\begin{tabular}{lcc}
\hline Sarnple & Mackerel $(\mathrm{n}=12)$ & Control $(\mathrm{n}=14)$ \\
\hline$I$ & $62.2 \pm 0.99$ & $62.4 \pm 0.62$ \\
6 & $58.2 \pm 2.16$ & $59.4 \pm 1.30$ \\
$\Delta 6$ & $-4.0 \pm 2.36$ & $-2.9 \pm 1.39$ \\
\hline
\end{tabular}

No significant effects
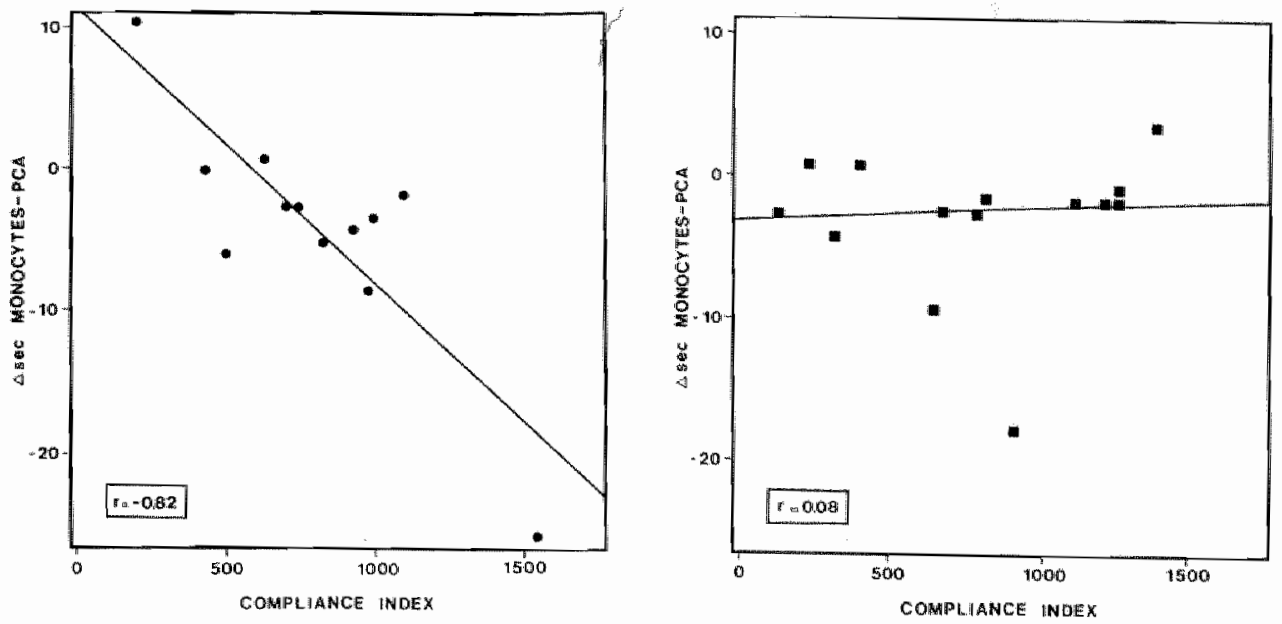

Fig 3. Change in monocyte procoagulant activity $(Y)$ in relation with dietary complicance $(X)$.

- mackerel group: $Y=11.2-0.02 X, n=12, r=-0.82, p<0.001$.

control group: $Y=-3.7+0.00 L X, n=14, r=0.08$, NS.

Difference between regression lines $p<0.005$.

observed between the compliance index $(=X)$ and the change in APTT ratio $(=Y)$. This relationship can be described by the equation $Y=-0.02+8.10^{-5}, \mathrm{X}, \mathrm{r}=$ $0.36, \mathrm{n}=38, \mathrm{p}<0.03$. For this regression analysis one volunteer was omitted because he was a significant outlier in the compliance index $(\mathrm{p}>0.01$, Dixon test, see ref 12). Moreover, this volunteer was very influential in the relation considered (Cook distance $<3.0$, see ref 15 ). As illustrated in Fig 2, the regression line for the mackerel group was significantly different from that calculated for the control group (F-test, $p<0.05$ ). After 6 experimental weeks no influence of the fish supplement on the APTT was still observed. This indicates that there might have been a transient effect of the fish supplement on the APTT, different from that of the meat supplement. Monocyte procoagulant activity (M-PCA) was measured in the samples of the Maastricht group only. When the result of week 6 were compared with the initial values obtained in the second run-in period, the change in $\mathrm{M}-\mathrm{PCA}$ was not signilicant. Moreover, no significant differences between the mackerel and the control groups 
were found (Table 3). However, dietary compliance seemed to have influenced the effect since in the mackerel group a significant, negative, rectilinear relationship was found between the compliance index at week $6(=X)$ and the change in M-PCA after 6 experimental weeks as compared with the second run-in period $(=\mathrm{Y})$. This relationship can be represented by the equation $Y=11.2-0.02 X, r=0.83, n=12$, $p<0.001$. As is evident from Fig 3, the relationship is largely determined by two subjects. However, since they were not significant outliers, they cannot be deleted from the calculations. The correlation between compliance index and change in M-PCA was not significant for the control group. In addition, the two regression lines differed significantly from one another ( $F$ test, $p<0.005$ ). In conclusion in this study the effect of the fish supplement on the procoagulant activity of monocytes may have differed from that in the control group.

\section{Discussion}

This study describes the effects of dietary fish on warious aspects of blood coagulation. The study was performed in three different centers to rule out any major local influence on these fish effects. In Maastricht, the initial values for factor $\mathrm{X}$, antithrombin III and $\alpha_{2}$-anti plasmin were significantly higher than for the participants in Zeist and Tromsø (Table 1). The fibrinogen level was also slightly higher in the Maastricht group. We do not have a straightforward explanation for this phenomenon, but it might be caused by the fact that the subjects in the Maastricht group had a higher alcohol consumption. Moreover, the Maastricht volunteers were recruited from the general population and were significantly older than the participants in Zeist and Troms $\emptyset$ (6), who were all university students.

Epidemiological data (which reflect long-term dietary habits) suggest only marginal effects of fish-oil enriched diet on blood coagulation. Traditionally-living Eskimos do not differ from a comparable Danish control group as to the coagulability of their blood plasma (PT and APTT), notwithstanding a higher fibrinogen content and a higher AT-III-content and activity $(16,17,18)$. These observations are in accordance with most human intervention studies. With a few exceptions $(19,20)$ the enrichment of human diets with fish, fish oil or a fish-oil concentrate did not have measurable effects on PT (21-26) or APTT $(20,21,22,24,25,27)$.

In our intervention study no effect of the fish supplement was observed on the prothrombin time. The activated partial thromboplastin time, however, reflecting the intrinsic pathway of blood clotting, tended to be prolonged after 3 experimental weeks (Fig 2). This effect was rather weak and only becomes manifest after correction for the inter-individual differences in dietary compliance. Moreover, the effect was no longer observed after 6 experimental weeks. 
The fish supplement did not affect the amounts of factor VII and VIla in a significant way (Table 2). In an earlier study in which the effect of a fish-oil concentrate was investigated in human volunteers, a significant decrease in factor VII activity was observed with a concomittant increase in the amount of VIIa (28). Our present results, as well as studies by others $(29,30,31)$, demonstrate that the activity of factor VII does not change upon fish(oil) consumption.

Our results strongly suggest an increasing effect of the fish supplement on the plasmatic content of factor $X$, measured by a chromogenic assay (Table 2, Fig 1). A comparable effect has been described by Haines et al (30) who gave 15 grams of MaxEPA per day for 6 weeks to insulin-dependent diabetics. Sanders and coworkers (31) studied the effect of $20 \mathrm{ml}$ cod-liver oil per day for 6 weeks in healthy volunteers and did not observe a significant effect. In our study the fish effect became more pronounced upon prolongation of the experimental period. The same trend was found by Haines and his group (30).

It should be realized that the physiological levels of all non-activated clotting factors are much higher than required for optimal blood coagulation. Consequently, any further increase of these supra-optimal levels is unlikely to cause an increased coagulability of the blood, especially since no circulating activated factor $\mathrm{X}$ was detectable in any case. However, the fact that an increased Factor $X$ activity after 6 experimental weeks appeared to coincide with a normalization of the initially prolonged APTT, is nonetheless suggestive of an increased clotting tendency of the blood following prolonged fish consumption.

In our study no significant effect of the fish supplement on antithrombin III (ATIII) was observed. In the literature $(16,17,18)$ results with regard to AT-III activity are not unanimous: a decrease of AT-III activity has been described following the administration of $20 \mathrm{ml}$ cod-liver oil per day for 6 weeks (31), whereas the administration of the fish-oil preparation MaxEPA $(10 \mathrm{ml}$ per day for 5 weeks $)$ did not have an effect (24). In another study with the same dose of MaxEPA for 4 weeks, the AT-III content (immunological activity) increased significantly but this did not result in a significant elevation of the AT-III activity. On the other hand, the AT-III content and activity did increase upon the daily administration of $10 \mathrm{ml}$ of a vegetable oil mixture rich in linoleic acid (27). Administration of the ethylester of a codliver oil concentrate increased the immunoreactive AT-III significantly but did not change AT-III activity (18). A comparable preparation given to normal volunteers in an amount of $0.9 \mathrm{~g}$ per day for 2-4 weeks did not change plasma AT-III content (26). No significant effect was seen on the chromogenic AT-III activity and/or the plasmatic AT-III antigen content, upon giving normal volunteers a fish-enriched diet (about $1.9 \mathrm{~g}$ timnodonic acid per day) for 4 weeks (21) or supplementing the diet of insulin-dependent diabetics with $15 \mathrm{~g}$ of MaxEPA per day for 6 weeks (30). These studies do not support the suggestion, derived from epidemiological data, that a fish(oil)-enriched nutrition will increase the physiological anti-coagulatory process via an increased AT-III activity $(27,18)$. As Eskimos who emigrated to Den- 
mark largely maintain their elevated AT-III activity (18), this elevation seems to be more determined by genetic than by environmental (nutritional) factors.

No significant influence of the fish supplement was observed on the plasma contents of von Willebrand factor and fibrinogen. This is in agreement with results reported by others for fish, fish oil or fish oil concentrates $(22,24-27,29,31-34)$, although in one studly (30) an increase was seen in the plasma fibrinogen content.

The effect of dietary fish(oil) on fibrinolysis has not been widely investigated. Sanders et al (31) did not observe an effect of the daily administration of $20 \mathrm{ml}$ codliver oil for 6 weeks to healthy man on the dilute clot-lysis time, suggesting that the fibrinolytic process is not affected by fish oil in a major way. Our results with respect to plasminogen and $\alpha_{2}$-antiplasmin seem to be in agreement with that suggestion. However, we recently demonstrated that in the fish group the total plasma plasminogen activator inhibitor activity increased by about $50 \%$ (Chapter 10). This finding may caution against the use of fish-enriched diets by subjects with a low endogenous fibrinolytic activity.

Although the evidence is very limited, the fish supplement possibly enhanced the procoagulant activity of monocytes (Table 3 , Fig 3 ). Since monocytes are now assumed to be important in the onset and progression of atherosclerosis (35), this observation needs confirmation and extension. Studies on rats demonstrated that high amounts (45 energy \%) of sperm whale oil lowered the procoagulant activity of spleen macrophages (36), whereas the same amount of mackerel oil had the opposite effect (37). This demonstrates that different fish oils may have different effects on this parameter. Therefore, more research is required to elucidate dietary influences on procoagulant activity of monocytes and macrophages.

\section{Acknowledgements}

Statistical analyses were performed by Dr. A. Kester, Department of Medical Information and Statistics, Limburg University, Maastricht, The Netherlands.

We wish to thank prof. dr. J.J. Sixma for the von Willebrand data and Mrs. M. Molenaar-van de Voort for typing the manuscript. 


\section{References}

1. Woolf N. Pathology of Atherosclerosis. Chapter 10: Thrombosis and atherosclerosis. Butterworth Seientific, London 1982: 217-259.

2. Davey MG, Luescher EF. Action of thrombin and other coagulant and proteolytic enzymes on blood platelets. Nature 1967; 216:857-858.

3. Majerus PW, Tollefesen DM, Shuman MA. The interaction of platelets with thrombin. In: Platelets in biology and pathology. Gordon JL. (ed) Vol. I. Elsevier Biomedical Press, Amsterdam 1976: $241-260$.

4. Ardlie NG, Han P. Enzymatic basis for platelet aggregation and release: The significance of the platelet atmosphere and the relationship between platelet function and coagulation. Brit J Haematol 1974; 26: 331-356.

5. Hornstra G. Platelet - wessel wall interaction: role of blood clotting. Philos Trans R Soc Lond [Biol] $1981 ; 294: 355-371$.

6. Houwelingen AC w, Nordoy A, Beek $\mathbf{E}$ vd, Houtsmuller U, Meta M de, Hornstra G. Effect of a moderate fish intake on blood pressure, bleeding time, hematology and clinical chemistry in healthy males. Am J Clin Nutr 1987; 46: 424-436.

7. Dam-Mieras MCE v, Muller AD, Hemker HC. Blood coagulation factors II, V, Vhl, VII, IX, X and XI. Determination by clotting assays.In: Methods of enzymatic analysis, vol. 5. Bergmeyer HU, Bergmeyer J, Grassl M (eds). Verlag Chemie GmbH, Weinheim, FRG 1984: 352-365.

8. Deijk WA v, Dam-Mieras MCE v, Muller AD, Hemker HC. Evaluation of a coagulation assay determining the activity state of factor VII in plasma. Haemostasis 1983; 13:192-197.

9. Cejka J. Enzyme immunoassay for factor VIII related antigen. Clin Chem $1982 ; 28: 1356-1358$.

10. Laurell CB. Quantitative estimation of protein by electrophoresis in agarose gel containing antibodies. Anal Biochem 1966; 15: 45-52.

11. Bas BM, Costongs CMPJ, Janson PCW. Rapid analysis of coagulation parameters by automated substrate methods with a Cobas Bio Centrifugation Analyser. Haemostasis. 1987; 17: 260-268.

12. Boyum A. Isolation of lymphocytes, granulocytes and macrophages. Scand If Immunol 1976; Suppl. 5: 9:15.

13. Muller AD, Dam-Mieras MCE $\mathbf{y}$, Hemker HC. Measurement of macrophage cellular procongulant activity. Haemostasis 1985; 15: 108-113.

14. Dixon WJ. Ratios inwolving extreme values. Ann Math Stat 1951; 22: 68-78.

15. Weisberg S. Applied linear regression. Willey, New York 1985: 1.18-120.

16. Dyerberg $\mathbf{J}$, Bang HO. Haemostatic function and platelet polyunsaturated fatty acids in Eskimos. Lancet 1979 ; ii: $433-435$.

17. Jorgensen KA, Nietsen AH, Dyerberg J. Haemostatic factors and renim in Greenland Eskimos. Acta Med Scand 1986; 219:473-479

18. Stoffersen E, Jorgensen KA, Dyerberg J. Antithrombin III and dietary intake of polysaturated fatty acids. Scand $\mathbf{J}$ Clin Lab Invest 1982; 42: 83-86. 
19. Dyerberg J, Jorgensen KA. Marine olls and thrombogenesis. Progr Lip Res 1982; 21: 255-269.

20. Terano $T$, Hrai A, Hamaxaki $T$, Kobayashi $S$, Fujita $T$, Tamura $X$, Kumagai $A$. Effect of oral administration of highly purified eicosapentatenoic acid on platelet function, blood wiscosity and red cell deformabilliy in healthy human subjects. Atherosclerosis 1983; 46: 321-311.

21. Atkinson PM, Wheler MC, Mandelsohn D, Pienaar $N$, Chetty $N$, Effect of a 4-week freshwater fish (rout) diet on platelet aggregation, platelet fatty acids, serum lipids, and coagulation factors. Am J Hematol $1987 ; 24: 143-149$.

22. Nagakawa $\mathbf{Y}$, Orimo H, Marazana M, Morita I, Yashiro K, Murota S. Effect of eicosapentaenoic acid on the platelet aggregation and composition of fatty acid in man. Atherosclerosis 1983; $47:$ $71-75$

23. Rylance $\mathbf{P B}$, Gordge $\mathbf{M P}$, Parsons $\mathbf{V}$, Weston $\mathbf{M J}$. Fish oil modifies lipids and reduces platelet aggregability in hamodialysis patients. Nephron 1986; 4: 196-202.

24. Saynor R, Verel D. Effect of a marine oil high in eicosapentaenoic acid on blood lipids and coagulation. IRCS Med Sci $1980 ; 8: 378-379$.

25. Thorngren M, Gustafson A. Effects of 11 -week increase in dietary eicospentaenoic acid on bleeding time, lipids and platelet aggregation. Lancet 1981; ii: 1190-1193.

26. Yoshimura $T$, Matsul $K$, Yumohara $T$, Kawasalki $N$, Nakamura $T$, Okamuara H. Erfects of highly purified efcosapentaenoic acid on plasma beta thromboglobulin level and vascular reactivity to angiotension IL. Artery 1987; 14:295-303.

27. Mortensen JZ, Schmid EB, Nielsen AH, Dyerberg $\mathbf{J}$. The effect of $(\mathrm{n}-6)$ and (n-3) polyunsaturated fatty acids on haemostasis blood lipids and blood pressure. Thromb Haemostas 1983; 50; 543-546.

28. Hornstra G. Dietary fats, prostamoids and arterial thormbosis. Chapter 7: Effect of fish oil feeding on arterial thrombosis, platelet function and blood coagulation. Martinus Nijhoff Publishers, The Hague 1982: 106-137.

29. Brox JH, Kullie JE, Osterud B, Holme S, Nordoy A. Effects of cod-liver oil on platelets and coagulation in familial hypercholesteremia (type Ila). Acta Med Scan 1983; 213: 137-144.

30. Haines AP, Sanders TAB, Ineson JD, Mahler RF, Martin J, Mistry M, Vichers M, Wallace PG. Effects of a fish oil supplement on platelet function, hemostatic variables and albuminuria in insullin-dependent diabetics. Thromb Res 1986; $43: 643.655$.

31. Sanders TAB, Vickers $\mathbf{M}$, Haines AP. Effect on blood lipids and haemostasis of a supplement of cod-liver oil, rich in eicosapentaenoic and docosahexaenoic acids, in healthy young men. Clin Sci $1981 ; 61: 317-324$.

32. Norris PG, Jones CIH, Weston MJ. Effect of dietary supplementation with fish oil on systolic blood pressure in mild essential hypertension. Brit Med J 1986; 293: 104-105.

33. Rogers S, James KS, Butland BK, Etherington MD, O'Brien JR, Jones JG. Effects of a fish oull supplement on serum lipids, blood pressure, bleeding time, haemostatic and theological wariables. A double blind randomised controlled trial in healthy volunteers. Atherosclerosis 1987; 63: $137-443$

34. Simons LA, Hickie JB, Ballesubramanian S. On the effects of dietary (n-3) fatty acids (MaxEPA) on plasma lipids and lipoproteins in patients with hyperlipidaemia. Atherosclerosis $1985 ; 54: 75-88$.

35. Ross R. The pathogenesis of Atherosclerosis - an apdate. New Engl J Med 1986; 314: $488-500$. 
36. Dam-Mieras MCE $v$, Muller AD, Rand ML. Hornstra $G$. Dietary lipids and macrophage procoagulant activity. Thromb Res $1986 ; 43: 133-137$

37. Bruggeman CA, Muilers WHM, Grauls G, Muller AD, Engels W, Hornstra G, Dam-Mieras MCE v. The effect of rat cytomegalowirus on the procoagulant activity and the arachidonic acid metabolism of macrophages: Role of dietary fats. 1988: Submitted. 


\section{A MODERATE FISH INTAKE INCREASES PLASMINOGEN ACTIVATOR INHIBITOR TYPE-1 IN HUMAN VOLUNTEERS}

\section{Summary}

For a period of six weeks, seventy-six healthy male volunteers consumed the contents of one tin (about $135 \mathrm{~g}$ ) of either fish (mackerel) paste or meat paste during their daily main meal. Fibrinolytic parameters were determined in plasma samples obtained at the beginning as well as at the end of the experimental period. No changes were found in plasminogen, $\alpha_{2}$-antiplasmin, tissue-type plasminogen activator ( $t-P A)$ antigen or euglobulin t-PA activity.

In the control group $(\mathrm{n}=39)$, no change in plasminogen activator inhibitor activity was found. In the fish group ( $\mathrm{n}=37)$, however, total plasma plasminogen activator inhibitor activity increased by $45 \%$, due to a $71 \%$ increase in plasminogen activator inlibitor type-1. This increase could not be ascribed to a diet-induced acute phasetype reaction and could also not be explained by changes in serum triglycerides or insulin. The results caution against the use of fish-enriched diets by people with low endogenous fibrinolytic activity.

Key words: fish, dietary intervention, fibrinolysis, plasminogen activator inhibitor, tissue-type plasminogen activator, triglycerides, insulin. 


\section{Introduction}

The consumption of fish may be of benefit in the prevention of ischemic cardiovascular disease. Kromhout et al (1) recently demonstrated that an average daily intake of $30 \mathrm{~g}$ of fish was associated with a reduced risk of coronary heart disease. Similar associations have been obtained by other $(2,3)$, but not all $(4,5)$, investigators. These epidemiological data suggest that the consumption of fish might protect against ischemic heart disease. The mechanisms involved have not yet been fully elucidated, but may include changes in blood lipids and lipoproteins (6-9) and a reduction of the interaction between blood platelets and the vessel wall (10).

Hamsten et al (11) have recently reported that, in myocardial infarction patients, the risk of reinfarction is positively related to the plasma level of plasminogen activator inhibit or (PAl) activity - a risk which may be associated with a reduced blood fibrinolytic activity.

Since the plasmatic PAI activity has repeatedly been shown to be correlated with the triglyceride concentration in the plasma (11-18), and since dietary fish and fish oil very consistently lower the plasma triglyceride level (6-9), the consumption of a fish-enriched diet might result in a decreased level of PAI and, thus, improve fibrinolysis. Such an effect would provide an additional explanation for the link between fish (oil) consumption and the reduced incidence of cardiovascular disease. We now report, however, that a diet moderately enriched in fish actually increased plasma PAI activity by some $45 \%$, due to a $70 \%$ increase in the plasma level of PAI type-1.

\section{Materials and methods}

The experimental design has been described in detail elsewhere (19). In brief: in three different centers, healthy, non-smoking male volunteers (20-45 years of age, with normal dietary habits) were assigned to either a control or an experimental group by stratified randomization, on the basis of serum triglyceride content and systolic blood pressure. In total 84 volunteers entered the study, 42 in each group. During a 6-week experimental period the volunteers consumed the contents of one tin (about $135 \mathrm{~g}$ ) of mackerel paste (fish group) or meat paste (control group) per day. The experimental period was preceded by a two-week run-in period during which all volunteers consumed one tin of meat per day. The dietary supplement had to replace the fish, meat, cheese or eggs normally consumed during the main meal. Compliance was checked by measuring the urinary excretion of lithium, added to the dietary supplements as a tracer (19). During the entire eight-week period no use of aspirin-like drugs was allowed. Each volunteer was requested to keep a diary and record any changes in physical condition, abnormal events, failure to comply, etc. 


\section{Composition of dietary supplements}

The dietary supplements were prepared by the Institute of Fishery Products. TNO, IJmuiden, The Netherlands (mackerel paste) and TNO-CIVO Toxicology and Nutrition Institute, Zeist, The Netherlands (meat paste). A detailed description of the dietary supplements has been given elsewhere (19). The fish paste provided 1.7 $\mathrm{g}$ of timnodonic acid (20:5 $\mathrm{n}-3$, eicosapentaenoic acid) and $3.0 \mathrm{~g}$ of cervonic acid (22:6 n-3, docosahexaenoic acid) per tin.

\section{Blood sampling and plasma preparation}

Blood sampling was performed between 8:00 and 12:00 AM, following an overnight fast and a $24 \mathrm{~h}$ period of abstinence from alcohol. Blood samples were obtained after a 10 min rest period in a recumbent position under minimal stasis from a cannula in a forearm vein. After a sample was obtained for basic hemotological measurements, $4.5 \mathrm{ml}$ of freely dripping blood was collected from the cannula into a precooled plastic tube, containing $0.5 \mathrm{ml}$ of ice-cold sodium citrate $(109 \mathrm{mmol} / 1, \mathrm{pH}$ adjusted to 7.2-7.4 with citric acid, $10 \% \mathrm{w} / \mathrm{v}$ ), and then put back into melting ice. Platelet-free plasma was prepared $\left(4^{\circ} \mathrm{C} ; 3000 \times \mathrm{g}\right.$ for $\left.15 \mathrm{~min}\right)$ and quick-frozen at $-20^{\circ} \mathrm{C}$. Blood samples were obtained at the end of the run-in period (week 0 ) and at the end of the experimental period (week 6).

\section{Plasminogen activator inhibitor (PAI assays)}

Total PAI activity of plasma was determined spectrophotometrically by titrating of a plasma sample $(10 \mu \mathrm{l})$ with tissuetype plasminogen activator (t-PA) and measuring the residual t-PA activity (20). PAI activity was then determined by graphical extrapolation. The thermostable PAI activity was determined by the same procedure, using plasma that had been incubated for $18 \mathrm{~h}$ at $37^{\circ} \mathrm{C}$.

To determine the contribution of PAI type-1 (PAI-1) (for nomenclature, see ref. 21) to total PAI activity, plasma samples $(10 \mu \mathrm{l})$ were preincubated with a quenching mouse monoclonal anti-PAI-1 $\operatorname{IgG}_{1}(22)$. This was done at a concentration of 20 $\mu \mathrm{g} / \mathrm{ml}$ in the assay buffer, at $37^{\circ} \mathrm{C}$, for $15 \mathrm{~min}$ prior to starting the assay procedure by the addition of t-PA, plasminogen and the substrate S-2251.

Preliminary experiments had shown that this amount of antibody gave maximal inhibition of plasmas containing as much activity as the sample with the highest PAI activity from this series $(21 \mathrm{IU} / \mathrm{ml})$. Controls without added antibodies were run in parallel. PAl-1 was then calculated by subtraction.

\section{Additional measurements}

Plasminogen was measured spectrophotometrically using Titertek equipment after activation with streptokinase (23). Procedural details were kindly made available by Dr. L. Engesser of the Gaubius Institute. Plasma $(10 \mu 1)$ was incubated with streptokinase (250 units) in $0.1 \mathrm{~mol} / 1$ Tris. $\mathrm{HCl}$ buffer, $\mathrm{pH} 7.5$, containing $0.1 \%(\mathrm{v} / \mathrm{v}$ ) Tween 80 (final volume $125 \mu l$ ) for $9 \mathrm{~min}$ at $37^{\circ} \mathrm{C}$. Then $125 \mu \mathrm{l}$ Tris/Tween buffer was added and $10 \mu l$ transferred to microtiterplate cups containing $170 \mu \mathrm{l}$ buffer and 
$30 \mu 1 \mathrm{~S}-2251(3.5 \mathrm{mmol} / \mathrm{l})$. The plates were incubated at $25^{\circ} \mathrm{C}$ and the absorbance at $405 \mathrm{~nm}$ measured at $15 \mathrm{~min}$ intervals for $60 \mathrm{~min}$.

$\alpha_{2}$-Antiplasmin activity was determined spectrophotometrically $(23,24)$ on Titertek equipment. To microtiterplate cups, containing $120 \mu \mathrm{l}$ buffer $(0.05 \mathrm{M} \mathrm{Tris.} \mathrm{HCl}$, $0.11 \mathrm{~mol} / \mathrm{l} \mathrm{NaCl}, 0.01 \%$ Tween 80 , Carbowax $1.4 \mathrm{mg} / \mathrm{ml}, \mathrm{pH} 7.4)$, were added 40 $\mu \mathrm{l} \mathrm{S}-2251(3.5 \mathrm{mmol} / \mathrm{l})$ and $10 \mu \mathrm{l}$ plasma (diluted $1: 20$ and $\mathrm{l}: 40)$. After equilibration for $5 \mathrm{~min}$ at room temperature, $40 \mu \mathrm{l}$ of plasmin $(0.15$ casein units $/ \mathrm{ml})$ was added and the absorbance at $405 \mathrm{~nm}$ determined at $5 \mathrm{~min}$ intervals for $15 \mathrm{~min}$. During this time span the change in absorbance was linear with time. Plasmin controls were run in the absence of plasma. With this assay procedure, no antiplasmin activity was detected in plasma taken from an $\alpha_{2}$-antiplasmin-deficient patient.

Plasma t-PA activity was determined in the plasma euglobulin fraction (dilution $1: 10, \mathrm{pH} 5.9$ ) by the method of Verheijen et al (25), using $25 \mu \mathrm{l}$ euglobulin sample, in the presence and the absence of $10 \mu \mathrm{l}$ rabbit anti-human t-PA IgC.

Plasma t-PA antigen was determined by an ELISA procedure, using a commercial test kit (Imulyse) in accordance with the manufacturer's instructions. DisodiumEDTA $(10 \mathrm{mmol} / \mathrm{l})$ had been added to the plasma samples (26).

Fibrinogen was measured by the method of Claus (27).

C-reactive protein (CRP) was measured by radial immunodiffusion using a commercial antiserum and a standard serum, according to the manufacturer's instructions. The lower limit of sensitivity of the assay was $1.1 \mu \mathrm{g} / \mathrm{ml}$.

Fasting serum triglycerides were analysed by a two-component kinetic method, using a Vitatron PA 800 automatic analyser and commercial kits in accordance with the manufacturer's instructions.

Insulin was determined in plasma by radioimmunoassay, using dextran-coated charcoal to separate bound from free insulin (28).

\section{Materials}

Human t-PA was provided by Dr. J.H. Verheijen of the Gaubius Institute. The activity of t-PA will be expressed in International Units (IU), as defined by the international standard of t-PA (batch $83 / 517$; ref. 29).

Mouse monoclonal anti-PAI-1 IgG 1 (22) was obtained from Monozyme (Charlottenlund, Denmark).

Rabbit-anti-human t-PA IgG was from Cappel-Organon Teknika (Turnhout, Belgium).

Rabbit-anti-human CRP and CRP standard serum were obtained from Behringwerke AG (Marburg, FRG). 
Streptokinase (Kabikinase), human plasmin and S-2251 were obtained from KabîVitrum (Stockholm, Sweden).

Imulyse t-PA kits for the determination of t-PA antigen concentrations were from Biopool (Umea, Sweden).

Kits for triglyceride determinations were from Boehringer (Mannheim, FRG), cat. nr. 644200 .

Reagents and equipment used in the spectrophotometric assays have been detailed before $(20,25)$. All other reagents used were of analytical grade.

\section{Statistics}

Differences between the values obtained in week 0 and week 6 were evaluated using Student's paired t-test or Wilcoxon's two-sample rank test, as will be indicated. A difference is considered significant if $p<0.05$.

\section{Results}

From 84 volunteers who entered the study, 76 complete sets of plasma were available for the analysis of fibrinolytic components ( 37 in the fish group and 39 in the meat group). Of the eight missing sets of plasmas, six were incomplete due to a technical failure during plasma preparation. One volunteer dropped out, while one volunteer had to be removed from the study because of low compliance (19).

\section{Fibrinolytic parameters}

The following fibrinolytic variables were determined in the plasma samples obtained at week 0 and week 6: plasminogen, $\alpha_{2}$-antiplasmin, t-PA antigen and t-PA activity. In four sets of plasma (two from the fish group and two from the control group), the t-PA antigen concentrations could not be determined, due to intractable high background absorbances in the ELISA test (compare ref. 26). Changes in the t-PA activity of euglobulin fractions were statistically evaluated by the non-parametric Wilcoxon two-sample rank test, as these values proved to be non-normally distributed. In all other cases Student's two-sample t-test could be applied. At week 0, no significant differences were observed between the control and the fish group for any of the fibrinolytic parameters measured (Figs 1-3, Table 1) showing that the two groups were adequately matched in these respects. A few, significant changes did occure during the 6-week experimental period; for none of these changes, however, did differences between the two groups prove to be significant. Consequently, the fish supplement did not have a specific effect on these fibrinolytic parameters.

\section{Plasminogen activator inhibitor (PAI) activities}

Preincubation of plasma with a monoclonal antibody, quenching the activity of PAI-1, allowed the subdivision of total PAl activity into two portions: a portion 


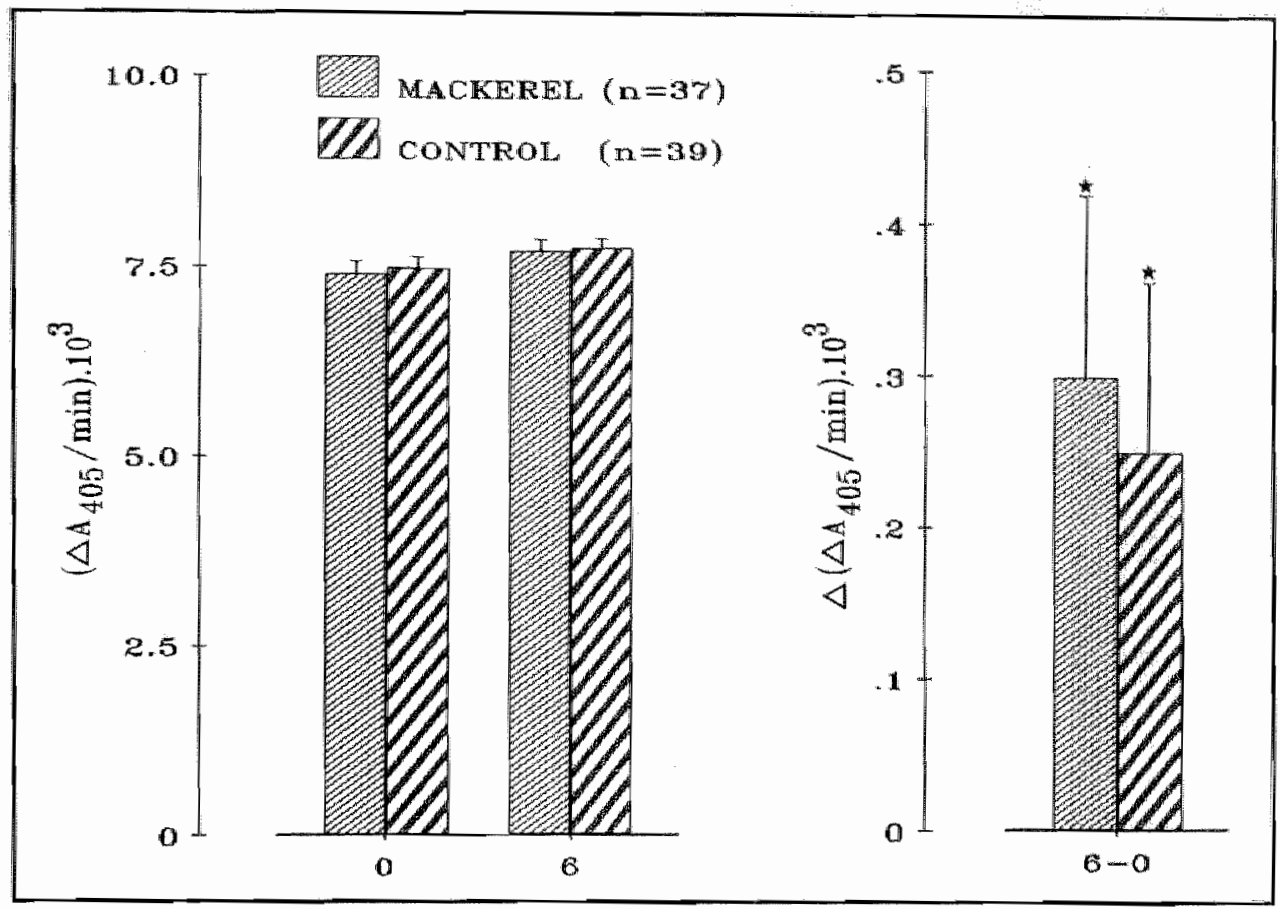

Fig 1. Plasma plasminogen activity at week 0 and week 6 , and the change from week 0 to week 6. Data shown are means \pm SEM. Plasma plasminogen activity is expressed as (A $\left.A_{405} / \mathrm{min}\right) .10^{3} ;$ for details see Materials and Methods. No significant differences between the fish and the control groups. The asterisks indicate values significantly different from zero tp $(0.025)$.

Table 1. Euglobulin t-PA activities ( $\mathrm{m} / \mathrm{U} / \mathrm{ml}$ ) at weeks $\square$ and 6

\begin{tabular}{llcc}
\hline & Week 0 & Week 6 & Change \\
\hline $\begin{array}{l}\text { Fish group }(\mathrm{n}=37) \\
\text { mean } \\
\text { median } \\
\text { range }\end{array}$ & 59 & 9 & -20 \\
Control group $(\mathrm{n}=39)$ & 16 & 7 & 0 \\
$\quad$ & $0-695$ & $0-263$ & $-622-084$ \\
mean & & & -12 \\
median & 69 & 57 & 0 \\
range & 16 & 17 & $-229-214$ \\
\hline
\end{tabular}

No significant changes during the experimental period (Wilcoxon's two-sample rank test) 


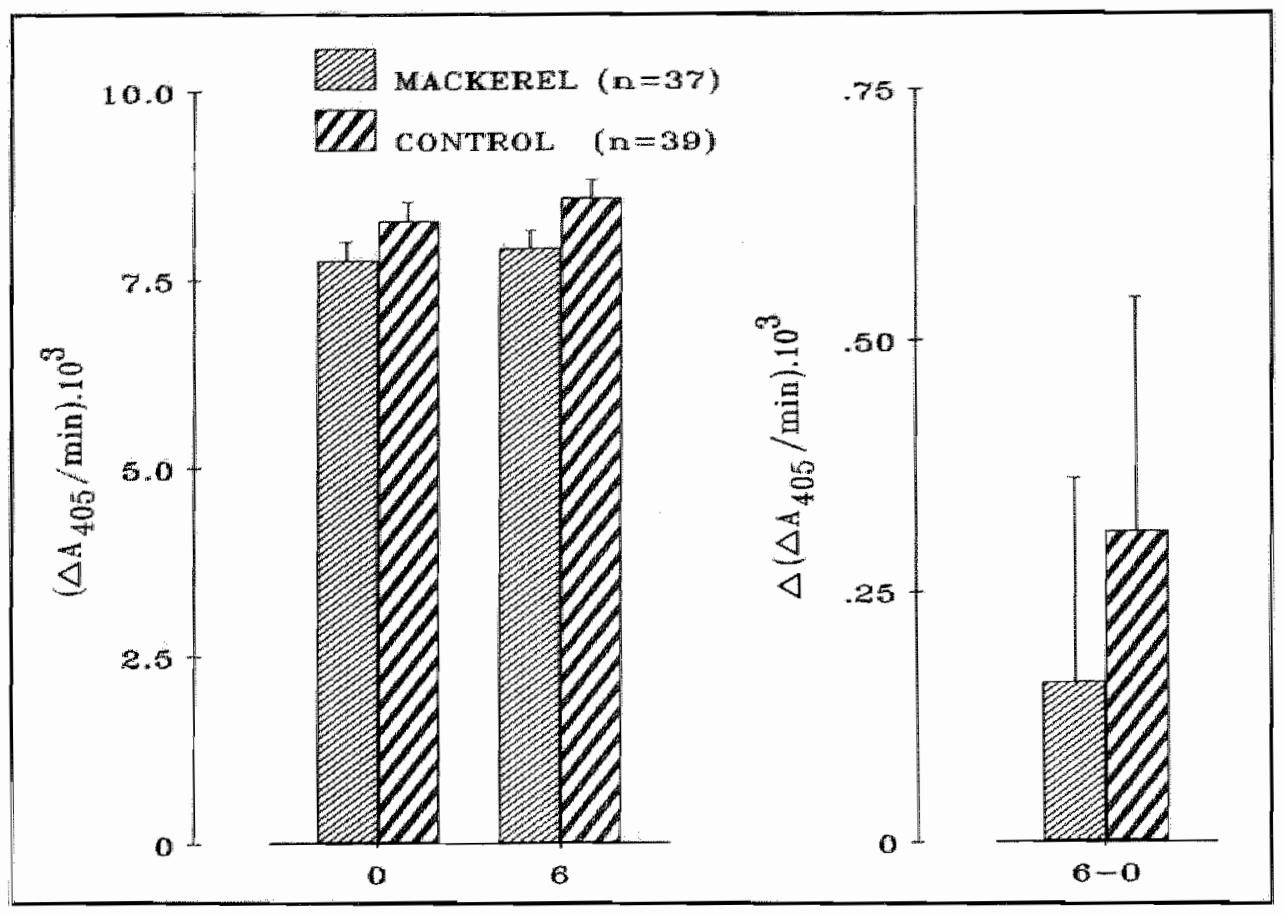

Fig 2. $\alpha_{2}$-Antiplasmin activity at week 0 and week 6 , and the change from week 0 to week 6. Data shown are means $\pm S E M ; \alpha_{2}$ antiplasmin activity is defined as the decrease in plasmin activity - expressed as $\left(\triangle A_{40.5} /\right.$ min). $10^{3}$ - in the presence of $0.5 \mu l$ plasma. For details see Materials and Methods. No significant differences between the fish and the control groups.

Table 2. Plasminogen activator inhibitor (PAI) activities (IU/ml) at weeks 0 and 6.

\begin{tabular}{lccc}
\hline & Week 0 & Week 6 & Change \\
\hline Fih group $(n=37)$ & & & \\
PAl-1 activity & $3.4 \pm 0.6^{\mathrm{a}}$ & $5.8 \pm 0.8$ & $2.4 \pm 0.7^{\mathrm{b}}$ \\
$\begin{array}{l}\text { Non-PAI-1 activity } \\
\text { Total PAI activity }\end{array}$ & $1.8 \pm 0.2$ & $1.7 \pm 0.2$ & $-0.1 \pm 0.1$ \\
& $5.1 \pm 0.6$ & $7.5 \pm 0.8$ & $2.3 \pm 0.7^{\circ}$ \\
Control group ( $=39)$ & & & \\
PAl-1-activity & $3.1 \pm 0.6$ & $2.9 \pm 0.4$ & $-0.2 \pm 0.3$ \\
Non-PAI-1 activity & $1.8 \pm 0.1$ & $1.4 \pm 0.1$ & $-0.5 \pm 0.1^{\mathrm{d}}$ \\
Total PAI activity & $4.9 \pm 0.6$ & $4.3 \pm 0.4$ & $-0.6 \pm 0.4$ \\
\hline
\end{tabular}

a: Mean \pm SEM

b: Significant increase from week 0 to week 6 (paired t-test, $\mathrm{p}<0.002$ ), and significantly different from control group ( $t$-test; $p<0.002)$

c. Significant increase from week 0 to week 6 (paired t-test, $p<0.01$ ), and significantly different from control group ( $\mathrm{p}<0.001)$

d: Significant decrease from week 0 to week 6 (paired t-test, $p<0.001$ ), and significantly different from fish group $(p<0.02)$. 


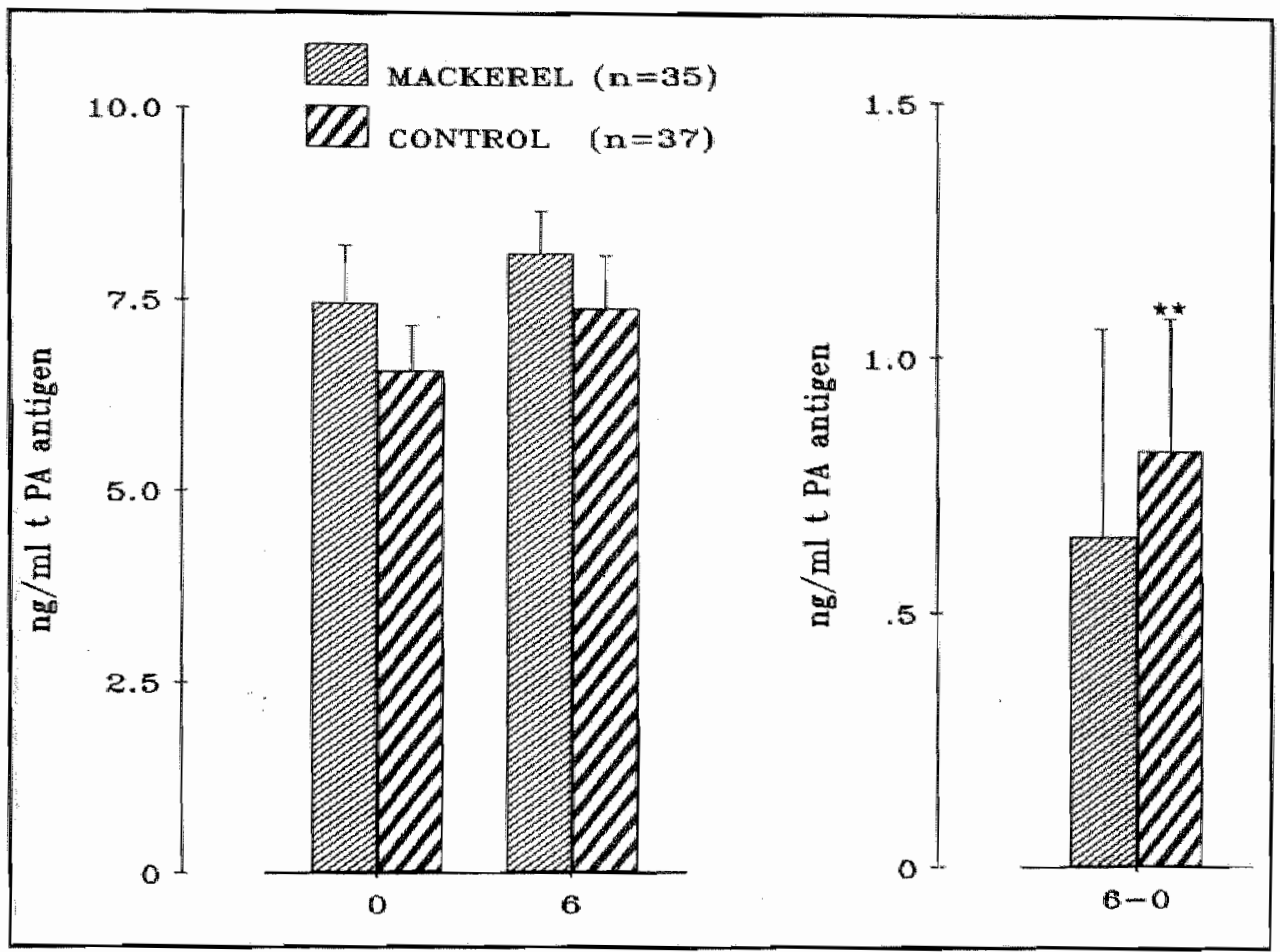

Fig 3. Tissue-type PA antigen concentrations $(n g / m l)$ at week 0 and week 6 , and the change from week 0 to week 6. Data shown are means \pm SEM. No significant differences bet ween the fish and the control groups. ** Value significantly different from zero $(p<0.01)$.

Table 3. C-reactive protein (CRP) at weeks 0 and 6.

\begin{tabular}{|c|c|c|c|c|}
\hline & \multicolumn{2}{|c|}{ Fish group $(n=37)$} & \multicolumn{2}{|c|}{ Control group $(n=39)$} \\
\hline & $\begin{array}{l}\text { No CRP } \\
\text { detectable } \\
(<1,1 \mu \mathrm{g} / \mathrm{ml})\end{array}$ & $\begin{array}{l}\text { CRP } \\
>1.1 \mu \mathrm{g} / \mathrm{ml}\end{array}$ & $\begin{array}{l}\text { No CRP } \\
\text { detectable } \\
(<1.1 \mu \mathrm{g} / \mathrm{ml})\end{array}$ & $\begin{array}{l}\text { CRP } \\
>1 . \| \mu \mathrm{g} / \mathrm{ml}\end{array}$ \\
\hline Week 0 & $\mathrm{n}=31$ & $2.0 \pm 0.4(6)^{4}$ & $\mathrm{n}=34$ & $3.8 \pm 1.1(5)$ \\
\hline Week 6 & $n=27$ & $4.8 \pm 2.0(10)$ & $\mathrm{n}=32$ & $3.2 \pm 0.9(7)$ \\
\hline
\end{tabular}

a: Mean $\pm S E M$ (number of volunteers)

No significant difference between the fish group and the control group in the change in CRP from week 0 to week 6 (Wilcoxon's two-sample rank tesit) 

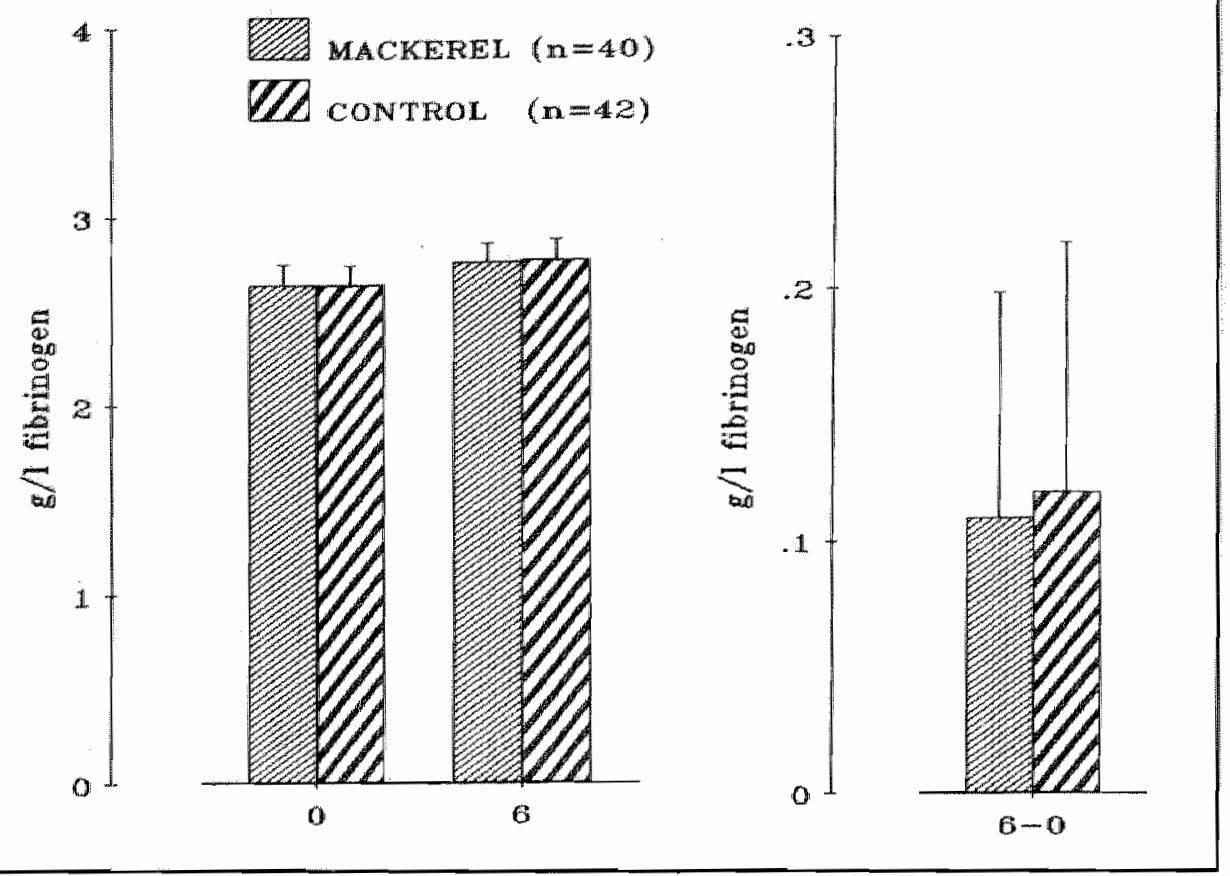

Fig 4. Plasma fibrinogen concentrations ( $g / l)$ at week 0 and week 6 , and the change from week 0 to week 6. Data shown are means $\pm S E M$. No significant differences between the fish and the control groups.

that was quenched by the antibody (designated as PAI-1 activity) and a residual portion (designated as non-PAI-1 related activity).

At week 0, none of measured PAI activities proved different for the control and the fish groups (Table 2). In the control group, total PAI activity as well as PAI-1 activity increased significantly, $+2.3 \mathrm{IU} / \mathrm{ml}(+45 \%)$ for total PAI activity $(\mathrm{P}<0.01)$, and $+2.4 \mathrm{IU} / \mathrm{ml}(+71 \%)$ for PAI-1 activity $(\mathrm{p}<0.002$; Table 2$)$.

As the PAI-1 unrelated activity did not change significantly in this group, the increase in PAl activity during the experimental period can be ascribed to an increase in PAI-1. Under base-line conditions, PAl-1 activity accounted for about $640 \%$ of the total PAl activity (63\% in the control group, 66\% in the fish group). As PAI-1 activity is known to be unstable during in vitro incubation at $37^{\circ} \mathrm{C}$ (half-life $2-3 \mathrm{~h}$; ref. 30), plasma samples were also assayed after overnight incubation at $37^{\circ} \mathrm{C}$. After this treatment, $67 \%$ (66\% in the control group and $68 \%$ in the fish group) of the PAI activity had disappeared in the week-0 samples, in agreement with the percentage quenched by the antibody $(64 \%)$. In the week 6 samples, the percentages of the antibody-sensitive and temperature-sensitive PAI activities were 77 and $78 \%$, respectively, in the fish group and 66 and $65 \%$ in the control group. 


\section{Acute-phase proteins}

To decide whether the increase in PAI- 1 activity in the fish group might have been caused by an acute-phase reaction, the rapidly reacting acute phase protein $C$ reactive protein (CRP) and the more slowly reacting acute phase protein fibrinogen were measured. Only minor, non-significant changes in CRP and fibrinogen were found in the two groups, as shown in Table 3 and Fig 4, respectively. In those volunteers where a change in CRP was observed, no significant correlation was found with the change in PAI-1 (fish group: $\mathrm{r}=-0.082, \mathrm{n}=10, \mathrm{n} . \mathrm{s} . ;$ control group: $\mathrm{r}=0.132, \mathrm{n}=11, \mathrm{n} . \mathrm{s}$. ).

\section{Discussion}

The fibrinolytic capacity of plasma is determined, to a large extent, by the balance between profibrinolytic factors such as plasminogen and plasminogen (pro)activators, on the one hand, and antifibrinolytic factors (eg. antiplasmins, plasminogen activator inhibitors) on the other. In this study we report that a fish-enriched diet influenced this balance unfavourably by causing a $71 \%$ increase of the plasma level of PAI-1, a fast-acting inhibitor of t-PA and of urokinase (31). No such change was found in the (meat-consuming) control group. The other fibrinolytic components showed either no significant change during the 6-weeks experimental period (Plasminogen, $\alpha_{2}$-antiplasmin, t-PA activity), or a similar small change in both the fish and the control groups (t-PA antigen).

Of the total PAI activity in plasma at week 0, about two-thirds was due to PAI-1, as determined by antibody quenching and temperature stability experiments. The remaining one-third was presumably due to the (still poorly defined) PA binding protein described by Kluft et al (32), as other known specific PA inhibitors (PAI-2; protease nexin-I) are not normally found in plasma (31). This non-PAI-1 related activity showed a small $(-27 \%)$, but significant decrease in the control group only.

In our control group individual PAI-1 activities at week 0 and week 6 showed a strong correlation $(\mathrm{r}=0.850, \mathrm{n}=39, \mathrm{p}<0.001)$, confirming the observation (33) that plasma PAI activity normally shows little intra-individual variability. Even in the fish group, this correlation persisted $(r=0.518, n=37, p<0.001)$ despite a $71 \%$ increase of mean PAl-1 activity. Individual levels of PAI-1 activity thus seem tightly regulated. This would also apply to PAI-1 antigen levels, as PAI-1 antigen and activity are strongly correlated (34). Still, little is known about factors involved in the regulation of PAI-1. Also, it is not yet known which cell type(s) synthetise PAl-1 in-vivo. Plasma levels of PAI-1 increase rapidly after surgery $(35,36)$ and trauma (37) and during septicemia $(38,39)$. No such acute phase-type reaction seemed to be involved in the increase in PAI-I induced by the fish diet, as the acute 
phase reactants CRP and fibrinogen showed no significant changes, and the small changes observed were not correlated with changes in PAI-1.

Under physiological conditions plasma PAl activity has been reported to be positively correlated with total serum triglycerides $(11,13,16-18)$, VLDL and LDL. triglycerides (11), oral glucose intolerance (11), body mass index $(11,14,16,17)$ and insulin $(14,17)$.

Also in this study, a highly significant correlation was found between fasting triglyceride and PAI-1 levels at week 0 for all volunteers $(r=0.382, n=75, p$ $<0.001$ ) and also (in the control group) between the change in triglycerides and the change in PAI-1 during the experimental period $(r=0.497, n=39, p<0.001)$. These positive correlations make the increase in PAI-1 for the fish group, in which triglyceride levels decreasedby $40 \%$, even more surprising. The opposite effects of the fish supplement on serum triglycerides and PAI-1 were not significantly related to each other, although there was a tendency towards a negative correlation between the change in PAI-1 and the change in triglycerides over the experimental period in the fish group ( $\mathrm{r}=-0.235, \mathrm{n}=36, \mathrm{p}=0.163$ ). At week zero we also observed a significant correlation between PAI-1 and the body mass index $(r=0.323, n=76$, $p=0.028$ ).

The changes in insulin values and PAI-1 values over the 6-week period were, however, not significantly correlated (control group: $\mathrm{r}=0.049, \mathrm{n}=38, \mathrm{p}=0.77$; fish group: $r=0.224, n=37, p=0.184)$. Our data thus confirm the previously reported data on the correlation between total PAI activity and body mass index $(11,14,16,17)$, as well as between total PAI activity and insulin $(14,17)$. Still, the increase in PAI-1 activity induced by the fish diet cannot be explained by changes in serum triglycerides and insulin in the fish group during the experimental period. In contrast to our data, Barcelli et al (40) reported that the consumption of 15 capsules of Max-EPA/day (providing about $5 \mathrm{~g}$ of $n-3$ fatty acids/day, similar to the n-3 falty acid content of one tin of fish) for two weeks decreased (in nine volunteers) the plasma PAI activity by about $15 \%$. It should be pointed out, however, that in this study no control group was included, as a result of which the data cannot be interpreted correctly. Moreover, direct comparison of their data and ours is difficult, as the assay procedures used show essential differences. The overnight procedure used by Barcelli et al (40) for measuring inhibition probably measured slow-acting low-affinity PA inhibitors such as $\alpha_{2}$-antiplasmin, $\alpha_{2}$-macroglobulin and $\mathrm{Cl}$-inhibitor as well, and is not necessarily specific for - presumably physiologically more relevant - fast-acting high-affinity PA inhibitors such as PAI-1. Also, we did not detect the reported (40) changes in $\alpha_{2}$-antiplasmin and t-PA activity. These discrepancies may, therefore, indicate that effects induced by whole fish and by a specially processed fish oil preparation are not necessarily identical. On the other hand, Fröschl et al (41) recently reported in an abstract an increase in PAI activity 
in diabetic patients taking fish-oil capsules. Moreover, PAI is higher in Greenland Eskimo"s compared to Danish controls (42).

Increased PAI activity has been found in patients with idiopathic deep vein thrombosis $(16,43)$ as well as and in young (13) and older (44-46) post-myocardial infarction patients, and is thought to be a risk factor for the occurrence of reinfarction (11) and the development of post-operative deep vein thrombosis $(33,47,48)$. Our observation that a fish-enriched diet increases PAI- 1 caution against the use of fishenriched diets by people with low endogenous fibrinolytic activity.

\section{Acknowledgements}

Fibrinogen measurements were performed by Mrs. A.D. Muller, Department of Biochemistry, Limburg University, Maastricht.

Triglyceride determinations were carried out by Dr. H. Zevenbergen, Unilever Research, Vlaardingen, The Netherlands.

Insulin determinations were performed in the Central Laboratory for Clinical Chemistry (Dr. M. Frölich) of the University Hospital Leiden, with the skillful technical assistance of Mrs. M. van Dijk-Besting.

This study was supported by grants 83.063 and 84.121 from The Netherlands Heart Foundation.

\section{References}

1. Kumhout D, Bosschieter EB, De Lezenne Coulander $C$. The inverse relation between fish con sumption and 20-year mortality from coronary heart disease. N Engl I Med 1985; 312: 1205-1209.

2. Shekelle RB, Missel LV, Oaul O, MacMillan Shyrock $A$, Stamler $\mathbf{J}$. Fish contsumption and mortality hrom coronary heart disease (Letter). N Engl J Med 1985; 313:820.

3. Norell SE, Ahlbom A, Feycliting M, Pedersen NL. Fish consumption and mortality from coronary heart disease. Br Med J 1986; 293: 426.

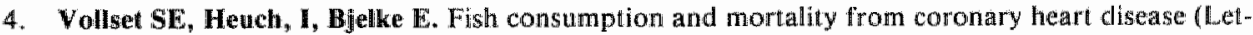
ter). N Engl J Med 1985; 313:820 821.

5. Curb ID, Reed DM. Fish consumption and mortality from cononary heart disease (Letter). N Engl II Med 1985; 313:821-822.

6. Lossonczy TO van, Ruiter A, Bronggeest-Schoute HC, Van Gent CM, Hermus RJ. The effect of a fish diet on serum lipids in healthy human subjects. Am J Clin Nutr 1978; $31: 1340-1346$. 
7. Harris Ws, Conmor WE, McMurry MP. The comparative reductions of the plasma lipids and lipoproteins by dietary unsaturated fats: salmon oil vs vegetable oils. Metabolism 1983; 32: $1764-184$.

8. Nestel PJ, Connor WE, Reardon MF, Comner S, Wong S, Boston R. Suppression by diets rich in fish oil of very low density lipoprotein production in man. J Clin Invest 1984; $74: 82-89$.

9. Phillipson BE, Rothrock DW, Connor WE, Harris WS, Ilingworth DR. Reduction of plasma lipids,

lipoproteins, and apoproteins by dietary fish oils in patients with hypertriglyceridemia. $\mathbb{N}$ Engl $J$ Med 1985; 312: 1210;1216.

10. Hornstra G. Dietary fats, prostanoids and arterial thrombosis. Chapter 7: Effect of fish oil feeding on arterial thrombosis, platelet function and blood coagulation. The Hague, Boston, Londion: Martinus Nijhoff Publishers, 1982, 106-137.

11. Hamsten A, De Faire U, Walldius G, Dahten G, Szamosi A, Landou C, Blombäck M, Wiman B. Plasminogen activator inhibitor in plasma: risk factor for recurrent myocardial infarction. Lancet 1987; ii: $3-9$.

12. Brommer EJP, Verheijen JH, Chang GTG, Rijken DC. Masking of fibrinolytic response to stimulation by an inhibitor of tissue-type plasminogen activator in plasma. Thromb Haemostas 1984; 52: 154-156.

13. Hamsten A, Wiman B, De Faire U, Blomliaick M. Increased plasma levels of a rapid inhibitor of tissue plasminogen activator in young survivors of myocardial infarction. $N$ Engl J Med 1985; 313: $1557-1563$.

14. Vague $\mathbf{P}$, Juhan-Vague I, Aillaud MF, Badier $\mathbf{C}_{\text {, Viard }} \mathbf{R}_{\text {, Alessi }} \mathbf{M C}$, Collen D. Correlation between blood filorinolytic activity, plasminogen activator inhibitor level, plasma insulin level, and relative body weight in normal and obese subjects. Metabolism 1986; 35: 250-253.

15. Vague P, Juthan-Yague I, Alessi MC, Badier C, Valadier J. Metrormin decreases the high plasminogen activator inhibition capacity, plasma insulin and triglyceride levels in non-diabetic obese subjects. Thromb Haemostas 1987; 57: 326-328.

16. Juhan-Vague I, Valadier J, Alessi MC, Aillaud MF, Ansaldy J, Philip-Joet C, Holvoet P, Serradimigni $\mathbf{A}$, Collen $D$. Deficient i-PA release and elevated $P A$ inhibitor levels in patients with spontaneous or recurrent deep venous thrombosis. Thromb haemostas 1987; 57:67-72.

17. Juhan-Vague I, Vague P, Alessi MX, Badier C, Valacher J, Alland MF, Atlan C. Relationships between plasma insulin, triglyceride, body mass index, and plasminogen activator inhibitor 1. Diabete \& Metabolism 1987; 13:331-336.

18. Mehta J, Mehta P, Lawson $\mathbf{D}$, Saldeen $\mathbf{T}$. Plasma tissue plasminogen activator inhibitor levels in coronary artery disease: correlation with age and serum triglyceride concentrations. J Am. Coll Cardiol $1987 ; 9: 263-268$.

19. Houwelingen AC v, Nordoy A, Beek E van de, Houtsmuller U, Metz M de, Hornstra G. Effect of a moderate fish intake on blood pressure, bleeding time, hematology, and clinical chemistry in healthy maies. Am J Clin Nutr 1987; 46: 424-436.

20. Verheijen JH, Chang GTG, Kluft C. Evidence for the occurrence of a fast-acting inhibitor for tissue-type plasminogen activator in human plasma. Thromb Haemostas 1984; $51: 392-395$.

21. Collen D. Report of the meeting of the subcommittee on fibrinolysis, Jerusalem, Israel, June 2 , 1986. Thromb Haemostas 1986; $56: 415-416$. 
22. Nielsen LS, Andreasen PA, Grondahl-Hansen J, Huang JY, Kristensen P. Danu K. Monoclonal antibodies to human 54,000 molecular weight plasminogen activator inhibitor from fibrosaicona cells - inhibitor meutralization and one-step affnity purifotion. Thromb Haenostas 1986; $55:$ 206-212

23. Fiberger P, Knös M, Gustavsson $S$, Aurell L. Claeson G. Methods for determimation of plasmin. antiplasmin and plasminogen by means of substrate S-2251. Hamostasis 1978: 7: 138 145.

24. Kuft $C$, Wijngaards $G$, Van Voorthuizen $H$. Revised reference curve for the ay antiplasmin assay by the addition of detergents. Thromb Haemostas 1984; $51: 297$.

25. Verheijen JH, Mullaart E, Chang GTG, KIuft C, Wingards G. A simple, sensitive spectrophotometric assay for extrinsic (tissue-type) plasminogen activator applicable to measurements in plasma. Thromb Haemostas $1982 ; 48: 266-269$.

26. Ränby M, Bergsdorf $\mathbf{N}$, Nilsson $T$, Mellbring $G$, Wimblad B, Bucht G. Age dependence of tissue plasminogen activator concentrations in plasma, as studied by an improved enzyme-linked immunosorbent assay. Clin Chem $1986 ; 32: 2160 \times 2165$.

27. Clauss A. Gerinnungsphysiologische Schnellmethode zur Bestimming des Fibrinogens. Acta Hae* matol 1957; $17: 237-246$.

28. Roelfsem F, Fröhlich M. Glucose tolerance and phasma immunoreactive insulin levels in acromegalics before and after selective transsphenoidal strgery. Clin Endocrinol 1985; 22:531 537.

29. Gaffney PJ, Curtis AD. A collaborative study of a proposedintemational standard for lissue plas. minogen activator (i-PA). Thromb Haemostas 1985; 53: 134-136.

30. Sprengers ED, Princen HMG, Koofstra T, Van Hinsbergh VWM. Intibition of plasmimogen activators by conditioned medium of human hepatocytes and hepatoma cell tine Hep G2, I Lab Clin Med $1985 ; 105: 751-758$.

31. Sprengers $\mathbb{E D}$, KIuft C. Plasminogen activator inhibitors. Blood 1987; 69:381-387.

32. Kluft C, Jie AFH, Sprengers WD, Verheijen $\mathbf{J H}$. Indentification of a reversible inhibitor of plasminogen actiwators in blood plasma. FEBS Lett 1985; 190: $315-318$.

33. Wuman B. The role of the fibrinolytic system in thrombotic disease. Acta Med Scanc 1986; Suppl 715:169-171.

34. Urden G, Hamsten, A, Wiman B. Comparison of plasmingen activator inhibitor activity and antigen in plasma samples. Clin Chim Acta 1987; 169: 189-196.

35. Juhan-Vague 1, Aillaud MF, De Cock F, Philip-Joet C, Arnaud C, Serradimigni A, Collen D. The fast-acting inhibitor of tissue type plasminogen activaton is an acute phase reactant protein. In: Davidson JF, Donati MB, Coccheri S, eds. Progress in fibrinolysis, Vol. VII. Edinburgla, Churchill Livingstone, 1985: 146-149.

36. D'Angelo A, KIuft C, Vertheijen JH, Rijken DC, Mozai E, Marnueci PM. Fibrinolytic shut-down after surgery: impaiment of the balance between tossue-type plasminogen actiwator and its specilic intubitor. Eur J Clin Invest 1985; 15: $308-312$.

37. Klaft C, Verheijen JH, Jie AFH, Rijken DC, Preston FE, Sue-Ling HM, Jespersen J, Aasen AO. The postoperative fibrinolytic shutiown: a rapidly reverting acule phase paitern for the fast-acting inlibiotor of tissue-type plasminogen activator after trauma. Scand $d$ Clin Lab lnvest 1985; 45: 605-610. 
38. Colwecl $M_{4}$ Paramo JA, Collen D. Generation in plasma of a fast-acting inhibitor of plasminogen actiwator in response to endotoxin stimulation. J. Clin Inwest $1985 ; 75: 818-824$.

39. Engebretsen LF, Kierulf P, Brandtzaeg P. Extreme plasminogen activator inhibitor and endotoxin values in patients with meningococcal desease. Thromb Res 1986; 42: 713-716.

40. Barcelli U, Gllas-Greenwall $P_{*}$ Pollak VE. Enhancing elfect of dietary supplementation eith $n-3$ fatty acids on plasma fibrinolysis in normal subjects. Throm Res 1985; 39: 307-312.

41. Fröschl H, Spannagl M, Drummer C, Landgraf-Leurs MMC, Iandgraf R, Schramm W. Effect of eicossupentaenoic acid diet on humoral clotting and fibrinolysus parameters in Type I diabetes mellitus. Haemostasis: 1988; 18 (suppl 2): 27-28.

42. Schmidt EB, Sqrensen PJ, Ernst E, Dyerberg J. PAl is higher in Greenland Eskimoes compared to Danish controls. Fibrinolysis 1988; 2 (suppl 1): 132.

43. Nilsson IM, Ljunger $\mathbf{H}$, Tengborn L. Two different mechanisms in patients with wenous thrombosis and defective fibritolysis: low concentration of plasminogen activator or increased concentration of plasminogen activator inhibitor. $\mathrm{Br}$ Med J 1985; 290: $1453-1456$.

44. Paramo JA, Colucci M, Collen D, Van de Werf F. Plaminogen activator inhibitor in the blood of patients with coronary artery disease. Br Med $J \downarrow 985 ; 291$ : $573-574$.

45. Nilsson TK, Johnson 0 . The extrinsic fibrinolytic system in survivors of myocardial infarction. Thromb Res 1987; 48: 621-630.

46. Verheugt FWA, Ten Cate JW, Sturk A, Imandt L, Verhorst PMJ, Vaneenige MJ, Verwey W, Roos JP. Tissue plasminogen activator activity and inhibition in acute myocardial infarction and angiographically normal coronary arteries. Am J Cardiol 1987; 59: 1075-1079.

47. Wiman B, Ljungberg B, Chmielewska J. Urden G, Blombäck M, Johnisson H. The role of the fibrinolytic system in deep vein thrombosis. J Lab Clin Med 1985; 105: 265-270.

48. Kluft C, Jie AFH, Lowe GDO, Blamey SL, Forbes DC. Association between postoperative hyperresponse in t-PA inhibition and deep vein thrombosis. Thromb Haemostas 1986; 56: 107. 


\section{GENERAL DISCUSSION AND SOME CONCLUDING REMARKS}

In this thesis results are presented of studies investigating the alleged relation between dietary fish and a number of variables associated with cardiovascular risk.

Firstly the hypothesis was tested that habitual fish consumption is related to coronary heart disease through an effect on bleeding time, platelet function and fibrinolysis. The study was performed in a selection of the study population which belonged to the Dutch cohort of the Seven Countries Study. Although we were not able to measure significant differences between the group with the highest fish consumption and the group with the lowest fish consumption, a trend was observed towards a decreased platelet function in the high-fish group. Therefore it cannot be ruled out that the minor differences observed, if they persisted life-long, could have lead to a lower thrombotic risk and may have contributed to the negative relation between fish consumption and mortality from coronary heart disease, observed in the Zutphen study (1).

The two groups investigated differed significantly with respect to the amount of fish-related fatty acids in the serum phospholipids, although an almost complete overlap was observed. This raised the question to what extent the amounts of ingested fatty acids, as calculated from the dietary history data, were reflected in the fatty acid composition of the serum lipid fractions. On an individual basis this appeared unreliable for $\mathrm{n}-3$ fatty acids. This is most probably due to the fact that on an individual basis, the amount of dietary n-3 fatty acids is difficult to assess, which may be caused by the large differences in amounts of n-3 fatty acids present in the same kind of foods.

Secondly, we performed an intervention study in which the influence of a moderate fish intake on some aspects of the cardiovascular risk profile was investigated. Blood pressure and serum cholesterol content are among the strongest predictors of ischemic cardiovascular disease $(2,3)$. In our study they did not change in response to dietary fish, nor, in general, do results from other studies permit the conclusion that fish consumption influences these variables in a beneficial way. Although a more pronounced decreasing effect of dietary $n-3$ fatty acids on total blood cholesterol concentration might be expected at a much higher daily intake $(4,5)$ than could be achieved in our intervention trial. It is very doubtful, however, whether 
this ever can be realised with dietary fish. In our experiment the dietary adherence, as calculated on the basis of urinary excretion of a standard amount of lithium added to the supplements, decreased during the 6-week study period, although our volunteers were very motivated.

The significant effects obserwed in our intervention trial were a prolongation of the bleeding time, a decrease in serum triglyceride content, a lower platelet aggregability in response to collagen, a diminished thromboxane $B_{2}$ production in clotting blood, a reduced $\mathrm{PGI}_{2}$ content of serum, a decrease in platelet count, and an increase in the activity of the major plasminogen activator inhibitor.

Bleeding time might be related to cardiovascular risk (6), but it has not been proven to be a risk factor in prospective studies. Plasma triglyceride values decreased upon fish consumption (7). However, the importance of this finding in terms of cardiovascular risk is not certain. It is said that hypertriglyceridemia (Type IV hyperlipidemia) is associated with an increased risk for cardiovascular disease (8). Type IV hyperlipidemia is found, among others, in patients with nephrotic syndrome, obesity, and in women using oral contraceptives. Under these conditions, hyperlipidemia is often associated with other strong risk indicators for cardiovascular disease such as hypertension and hypercholesterolemia. It is, therefore, questionable whether this increased risk is due to an enhanced serum triglyceride level per se or can be ascribed to accompanying risk factors (9). Moreover, Hulley et al (10) concluded from 27 epidemiological studies that hypertriglyceridemia is not a reliable risk factor for coronary heart disease.

Other significant alterations observed in our intervention study with dietary fish are changes in thrombotic functions of blood platelets. Collagen-induced platelet aggregation in platelet rich plasma and whole blood decreased slightly, but significantly, in the fish group. ATP release in whole blood was also significantly decreased. Prostanoid production climinished clue to the fish consumption. Platelet thromboxane production in clotting blood decreased by $30 \%$ and $\mathrm{PGI}_{2}$ production by $27 \%$. When compared with the influence of aspirin the effects of dietary fish on platelet function and prostanoid formation are very moderate. Bleeding time, as a measure for platelet vessel-wall interaction in-vivo, is prolonged about $100 \%$ by aspirin (11, 12); for fish this was only about $25 \%$. Prostacyclin synthesis by the vessel wall is less sensitive to inhibition by aspirin than platelet thromboxane A2 production because of a more rapid recovery of endothelial cyclo-oxygenase activity (11). Moreover, a single dose of 200 to $300 \mathrm{mg}$ of aspirin almost completely blocks the platelet thromboxane production and gives a maximum inhibition of platelet aggregation, with only a slight inhibition of vessel-wall prostacyclin production (13). Inhibition of thromboxane production without or with only a slight change in prostacyclin production may be favourable in terms of cardiovascular risk. However, the results of two prospective intervention trials of aspirin on cardiovascular risk have 
recently been published $(14,15)$, and, notwithstanding the pronounced effects of aspirin on platelet functions, the results are contradictory. In one of the studies a $23 \%$ decrease in cardiovascular risk was found, but the total number of cardiovascular deaths did not change (14). In the other study, however, no effect was found (15). It is thus not clear what might be expected from the influence of an enhanced fish consumption with only a marginal influence on platelet function.

In intervention trials, which are mostly performed during a short period, the beneficial effects of dietary fish on cardiovascular risk are marginal; on the other hand, a long-term influence of dietary fish cannot be excluded. Certain epidemiological studies are much more positive. In those studies the intake of n-3 fatty acids was high, and was thus thought to be the main reason for the low cardiovascular mortality. However, in the Faroe Islands the consumption of marine products is high (16), but the incidence of cardiovascular disease is also rather high (17). The same holds for the eastern part of Finland. In these countries the consumption of saturated fat is rather high as well. The intake of saturated fatty acids by the Eskimos, who have a low cardiovascular mortality, is, in contrast, very low. Moreover, in the Seven Countries Study a strong correlation was found between the intake of saturated fat ty acids and the 15 year mortality due to ischemic cardiovascular disease (18). The results of the Eskimo studies fit very well in this correlation (19). In intervention studies, only the amount of $\mathrm{n}-3$ fatty acids in the diet is increased, while the amount of saturated fat remaines unchanged. The beneficial effects of n-3 fatty acids in epidemiological studies may be confounded by a low intake of saturated fatty acids. Therefore, reducing the amount of saturated fat in the diet might be more effective than an isolated increase of the amount of dietary n-3 fatty acids.

In our study an increase of plasminogen activator inhibitor (PAI) after 6-weeks of moderate fish consumption is described. An increased PAI activity is thought to be a risk factor for the occurrence of reinfarctions (20). Although our results require confirmation by others, this finding implies that fish-enriched diets should not be advised to persons with a low fibrinolytic activity.

Due to dietary n-3 fatty acids the amount of platelets decreases. The meaning of this phenomenon in terms of human health in general or cardiovascular risk in particular is not known. The mechanism which underlies this decrease in platelet count is also not understood.

Although so far the effects of fish enriched diets on the onset and progression of ischemic cardiovascular disease are not convincing, other beneficial effects of these diets have been claimed, which are mainly thought to be due to modulatory influences of $\mathbf{n - 3}$ fatty acids on the formation of eicosanoids.

In patients with rheumatoid arthritis a subjective improvement was observed (21-24) due to a fish-enriched diet, but the investigators admit that no objective evidence 
of improvement of the active disease was found. In patients with asthma, contradictory results have been reported. Dietary n- 3 fatty acids may reduce the incidence of asthma (25). In mild asthma, however, a fish-oil enriched diet did not change the severity of asthma (26). Another study even suggested that fish diets may have a deleterious effect on patients with aspirin-intolerant asthma (27).

Dietary intervention trials in patients affected with psoriasis and atopic dermatitis showed that supplementation with n-3 fatty acids is useful particularly when itching is troublesome (28-31). In another trial, however, no change in objective clinical manifestation of psoriasis was found (32).

Supplementation with fish oil seemed to be a valuable adjunct therapy to ameliorate drug-induced hyperlipidemia secondary to therapy with etretinate (aromatic retinoid) (33).

Apart from beneficial effects of dietary n-3 fatty acids, negative influences have also been reported: in non-insulin dependent diabetics, dietary $n-3$ fatty acids might lead to metabolic deterioration with elevated basal hepatic glucose output and impaired insulin secretion but unchanged glucose disposal rates (34).

In several animal studies nephropathology has been mentioned to be favourably influenced by dietary fish (35-39), although, again, negative effects have also been reported $(40,41)$.

Dietary n-3 fatty acids effectively reduce the formation of $\mathrm{PGE}_{2}$, a tumor growthpromoting prostaglandin, and concomitantly decrease the incidence, growth and metastatic spread of a variety of experimental tumors in animals (42). However, no human data are available to support these last two findings.

In general, the effects of dietary n-3 fatty acids on human health are not very convincing. However, it cannot be ruled out that a long-term (life-long) influence of small amounts of dietary fish may contribute to a lower cardiovascular risk. Many of the published intervention trials showed serious shortcomings in their design and gave contradictory results. It should be realised that, in general, more problems are to be expected in getting inconclusive studies published than studies which present positive results. Therefore, the balance between studies with fishinduced beneficial effects on the cardiovascular risk profile and inconclusive studies may be expected to be less positive than can be concluded from the published literature (43). Moreover, the putative beneficial effects of n-3 fatty acids in epidemiological studies may be confounded by a low intake of saturated fatty acids. 


\section{References}

1. Krombout D, Bosschieter EB, Lezenne Coullander $\mathbf{C}$ de. The inverse ralation between ish consumption and 20-year mortality from coronary heart disease. New Engl J Med 1965 ; 312 : 1205-1209.

2. Kannel WB. Role of bloodpressure in cardiovascular morbidity and montality. Progr Cardiovasc Dis 1974; $17: 1-28$.

3. Assmann G. Lipid metabolism and atherosclerosis. Chapter l: Risk factors and atherosclerosis. Schattatuer Verlag $\mathrm{GmbH}_{3}$ Stutgart 1982:

4. Iliting worth DR, Harris WS, Connor WE. Inhibition of low density lipoprotein synthesis by dietary omega 3 fatty acids in humans. Arteriosclerosis $1984 ; 4: 270-275$.

5. Nestel PJ. Fish oil attenuated the cholesterol induced use in lipoprotein cholesterol. Am J Clin Nutr $1986 ; 43: 752-757$.

6. Milmer PC, Martin JF. Shortened bleeding time in acute myocardial infaretion and its relation to platelet mass. Br Med J (Clin Res) 1985; 290: 1767-1770.

7. Herold PM, Kinsella JE. Fish onl consumption and decreased risk of cardiovascular disease: com parison of findings from animal and human feeding trials. Am J Clin Nutr 1986: 43: 566-598.

8. Cabin HS, Toberts WC. Quantification of amounts of coronary arterial marrowing in patients with types II and IV hyperlipoproteinemia and in those with known normal lipoprotein patterns. Am Heart J 1981; 101:

9. Assmann G. Lipid metabolism and atherosclerosis. Chapter IV: Hypertriglyceridemia and atherogenesis. Schattauer Verlag GmbHt, Stutgart 1982: 67-75.

10. Hulley SB, Rosenman RH, Bawol RD, Brand RJ. Epidemiology as a guide to clinical decision. The association between triglyceride and coronary heart disease. New Engl J Med 1980; 302: 1383 1389.

11. Thorngren $\mathbf{M}_{4}$ Shafi $\mathbf{S}$, Born GVR. Thromboxane $\mathbf{A}_{2}$ in skin-bleeding-time blood and in clotted venous blood and after administration of acetylsalicylic acid. Lancet $1983 ; 1 ; 1075-1078$.

12. Weksler BB, Pelt SB, Alonso D, Richter RC, Stelzer P, Subramanian V, Tack-Goldman K, Gay WA Jr. Differential inhibition by aspirin of vascular and platelet prostaglandin synthes is in atherosclerotic patients. New Engl J Med 1983; 308:800-805.

13. Mielke CH Jr. Comparative effects of aspinin and acetaminophen on hemosiasis. Arch Intern Med $1981 ; 141: 305-310$.

14. The Steering Committee of the Pthysicans" Health Study Research Group. Preliminary report: findings from the aspirin component of the omgoing physicans' health study. N Engl J Med 1988; $318:$ 262-264.

15. Peto $\mathbf{R}$, Gray $R$, Collins $R$, Wheatley $K$, Hennelkens $C$, Jamrozik $K, W$ wriow $C$, Hafmer $B$, Thompm son $E_{\text {, Morton }} \mathrm{S}$, Gilliand $\mathbf{J}$, Doll $\mathrm{R}$. Randomised trial of prophilactic daily aspirin in British malle doctors. Br Med J 1988; 296:313-316.

16. Olsen SF, Hansen HS, Sorensen TI, Jensen B, Secher NJ, Sommer S, Kuwdsen LB. Intake of mai rine fat, rich in (n-3)-polyunsaturated fatty acids, may increase birthweight by prolonging gestation. Lancet 1986, ii: 367-369. 
17. Juel K. Dodeligheden of Kreds lobsygdomme pa Faerwerine 1960-1984 (Mortality of circulatory deseases athe Faroe Islands 1960-1984). In: Anmul report of the Chuer Medical oricer in the Faroe Islands:

18. Keys A. Menothi , Karvonne My, et al. Diet and 15-year death in the Seven Countries" Study. Am $J$ Epidemiol 1986; $124: 903-915$.

19. Kombout D. Personal communication.

20. Hamsten $A$, De Faire $U$, Walldus $G$, Dahlen $G$, Szamosi $A$, Landou $C$, Blombäck $M$, Wilman $B$. Plaminogen actiwator inhibitor in plasma: risk for recurrent myocardial infarction. Lancet 1987 ; ii: 3.9.

21. Kremer JM, Jubix W, Michalek A, Rynes RI, Bartholomew CE, Bigaouette $\mathbf{J}_{\text {, }}$ Tinchalk M, Beeler D, Lininger L. Fish oil fatty acid supplementation in active rheumatoid arthritis. A double-blind, controlled, cross-over situdy. Ann Int Med 1987; 106: 497-503.

22. Kromer JM, Bigaouette J, Michalek AV, Timchalk MA, Lininger L, Ryners RI, Huyck C, Zieminski J, Bartholomew LE. Effects of manipulation of dietary falty acids on clinical manifestations of thetumatoide arthriftis. Lancet $1985 ; \mathrm{i}$ : $184-187$.

23. Kremer $\mathfrak{J M}$, Lawrence $\mathbf{D}, J$ Jubix $\mathbf{W}$, et al. Different doses of fish-oil fatty acid supplementation in rheumatoid arthitis. A prospective double-blinded randomized study. Arthritis Rheum; abstract, in press..

24. Relch $\mathbf{J}$, Ansell D, Madhok R, O'Dowd A, Sturrock RD. Effects of altering dietary essential fatty acids on requirements for non steroidal anti inflammatory drugs in patients with rheumatoid arthritis: a double blind placebo controlled study. Ann Rheum Dis 1988; 47: 96-104.

25. Lee TH, Lewis RA, Robinson D, Drazen JM, Austen KF. The effects of a diel enriched in menhaden fish oil on the pulnonary response to antigen challerge. I Allergy Clin Immunol 1984; 73 : 150 .

26. Arm JP, Horton CE, Mencia-Hurta JM, House F, Liser NM, Clark TJ, Spur BW, Lee TH. Effect of dietary supplementation with fish oil lipids on mild asthma. Thorax 1988; 43: 84-92.

27. Picado C, Castillo MA, Schinca N, Pujades M, Ordinas A, Coronas A, Agusti-Vidal A. Effects of a fish oil enriched diet on aspirin intolerant asthmatic patients: a pilot study. Thorax 1988; 43: 93 97.

28. Maurice PDL, Allen HR, Barkley ASJ, Cockbill SR, Stammers J, Bather PC. The effects of dietery supplementation with fish oil in patients with psoriasis. Br J Dermatol 1987; 177: 599-606.

29. Zuboh VA, Cohen KA, Ellis CN, Miller C, Hamilton TA, Kraghalle K, Hydrick CR, Voorhees JJ. Effect of dietary supplementation of fish oil on neutrophil and epidermal fatty acids. Modulation of clinical contse of psoriatic subjects. Arch Dermatol 1986, 122: $1277-1282$.

30. Hutliner SB, Tucker WFG, Cartwright 1, Bleehen SS. A double-blind randomised placebo. controlled trial of fish oil in psoriasis. Lancet $1988 ; 1 ; 378.380$.

31. Djornebue A, Soyland E, Bjorneboe GE, Rajka G, Drevon GA. Effect of dietary supplementation with eicosapentaenoic acid in the treatment of atopic dermatitis. Br J Dermatol 1987; 117: 463-469..

32. Bjornebre A, Smeth AK, Bjormeboe GE, Thune PO, Dreven GA. Effect of dietary supplementation with $\mathrm{n}-\mathrm{J}$ fatry acids on clinical manifestation of psoriasis. $\mathrm{Br} \mathrm{J}$ Dermatol 1988; 118: $77-83$.

33. Low NJ, Borok ME. Fish oll consumption reduces hypertriglyceridemia in psoriatic patients receiving etritinate therapy. Arch Dermatol 1988; 124: 177-178. 
34. Glauber $\mathbf{H}$, Wallace $\mathbf{P}$, Griver $\mathbf{K}$, Brechtel $\mathbf{G}$. Adverse metabolic effect of omega-3 fatty acids in non-insulin diabetes mellitus. Ann Intn Med 1988; 108: 663-668.

35. Kelley VE, Rogers TS, Elzinga $\mathbf{L}_{\text {, }}$ Bennett WM. Fish oil protects from cyclosporine A induced nephrotoxicity. In Lands WEM, (ed). Polyunsaturated fatty acids and eicosanoids. American Oil Chemists. Society. Illinois 1987: 109-114.

36. Pricket JD. Robinson DR, Steinberg AD. Dietary enrichment with the polyunsaturated fatty acid eicosapentaenoic acid prevents proteinuria and prolongs survival in $\mathrm{N} 2 \mathrm{~B} \times \mathrm{NZW} \mathrm{F}_{1}$ mice. $1 \mathrm{Clin}$ Invest 1981; 68: 556-559.

37. Kelley VE, Ferretti A, Izui $\mathbf{S}$, Strom TB. A fish oil diet rich in eicosapentaenoic acid reduces cy. clooxygenase metabolites and suppresses lupus in MRL-1pr mice. J Immunol 1985; 134: 1914-1919.

38. Barcelli UO, Miyata J, Ito Y, Gallon L, Laskarzawski P, Weiss M, Hitzemann R, Pollak VE. Beneficial effects of polyunsaturated fatty acids in partially nephrectomized rats. Prostaglandins 1986; $32: 211-219$.

39. Ito $\mathbf{Y}$, Barcelli U, Yamashita $\mathbf{W}$, Weiss $M$, Glas-Greenwalt $\mathbf{P}$, Pollak VE. Fish oil thas beneficial effects on lipids and renal disease of nephrotic rats. Metabolism 1988; 37: 352-357.

40. Seharschmidt L, Gibbons N, McGarry L, Berger P, Axelrod M, Janis R, Ko H. Eicosapentaenoic acid, a poor substrate for rat renal cyclo-oxygenase, accelerates renal insufficiency in murine renoprival nephropathy. Adv Prostagl. Thrombox Leukotr Res 1987; 17B: 854-857.

41. Scharschmidt LA, Gibbons NB, McGarry L, Berger P, Axellod M, Janis R, Ko YH. Effects of dietary fish oil on renal insufficiency in rats with subtotal nephrectomy. Kidney Int 1987; 32: 700-709.

42. Karmali RA. Omega-3 faty acids and cancer: A review. In: Lands WEM (ed). Polyunsaturated fatty acids and eicosanoids. American Oil Chemists' Society. Illinois 1987; 68: 222-232.

43. Hornstra G. The significance of fish and fish-oil enriched food for prevention and therapie of ischaemic cardiovascular disease. In: Crawford MA, Vergoesen AJ (eds). The role of fats in human Inatrition II. London UK; Academic Press, London (in press). 


\section{Summary}

Atherosclerosis is the most important cause of cardiovascular death in Western industrialized countries and already since the beginning of this century a relation between cardiovascular disease and nutrition was suggested. Recent evidence suggest that diets rich in fish and fish-products (containing fatty acids of the n-3 type) are beneficial in the prevention of ischemic cardiac and vascular disease. A careful screening of the literature (Chapter 1) reveals, however, that the results of epidemiological studies on the relation between fish consumption and cardiovascular disease are ambiguous and inconclusive. These studies have, nevertheless, initiated many human intervention trials to investigate the effects of $n-3$ fatty acids on variables involved in the cardiovascular risk profile. The significance of these trials, however, is seriously reduced by several shortcommings in their design: in only one third of these studies an adequate control group had been included. Therefore, the results of the other two third cannot be interpreted correctly.

In this thesis first the hypothesis that habitual fish consumption might be related to coronary heart disease through an effect on platelet functions and fibrinolysis, was tested in a selection of the study population, which belonged to the Dutch cohort of the Seven Countries Study (Chapter 2).

Forty healthy elderly men were selected on the basis of their fish consumption over the last 26 years. In the high-fish group ( $n=25$ ) fish consumption was on average $33 \mathrm{~g}$; in the low-fish group $(\mathrm{n}=15)$ it was on average $2 \mathrm{~g}$ per person per day. This difference was reflected by significant differences in the concentrations of timnodonic acid (20:5n-3) and cervonic acid (22:6n-3) in the serum phospholipids of the participants. Between both groups no significant differences were observed in cutaneous bleeding time, platelet number, and collagen induced platelet aggregation and ATP-release in whole blood. The same holds for the actual as well as the potential $\mathrm{TxB}_{2}$-formation of activated platelets and for the activity of the plasminogen activator inhibitor. For most of the platelet-related variables a trend was found for a lower activity in the high-fish group. Therefore changes in platelet function might not explain, but may have slightly contributed to the inverse relationship between coronary heart disease and fish consumption, as observed in Zutphen.

To evaluate the validity of the cross-check dietary history method for the assessment of the habitual intake of polyunsaturated fatty acids from fish, as performed in the above mentioned study, the relationship was investigated between the estimated intake of these fatty acids and their relative amounts in the various serum lipid frac- 
tions. The fatty acid compositions of total lipids, phospholipids, triglycerides and cholesterolesters was determined in fasting serum samples. Although correlations between the calculated dietary intake of timnodonic acid (20:5 n-3, TA) and cervonic acid (22:6 n-3, CA), on the one hand, and the relative amounts of these fatty acids in the various serum lipid fractions on the other, appeared to be statistically significant, no more than about $20 \%$ of the variance in the serum values could be explained on the basis of dietary intake. For linoleic acid (18:2 n-6, LA) this was 55\%. It is concluded that the cross-check dietary history method is an acceptable technique for estimating the habitual intake of linoleic acid of a given individual. For the fish-related fatty acids, however, this method is less reliable. This most probably results from the large differences in TA and CA content in similar foods. In addition, a negative association with the calculated LA intake on the proportional amount of TA for most of the serum lipid fractions was demonstrated. This indicates an interference of dietary LA with the metabolism of TA (Chapter 3).

Secondly we performed a well-controlled intervention study in which the effect of a reasonable amount of dietary fish on a number of risk indicators of ischemic heart and vessel disease was investigated.

Chapter 4 describes the outline and first results of this international study which was performed within the framework of the international working party: "Fish against thrombosis?".

In Maastricht, Troms $\emptyset$, and Zeist healthy male volunteers were given a dietary supplement containing $100 \mathrm{~g}$ of mackerel or meat per day for a 6 week period. Compliance was monitored on the basis of the urinary excretion of lithium, added to the supplements. Average compliance was ca. $80 \%$, which resulted in a daily intake of $1.4 \mathrm{~g}$ timnodonic acid (20:5 $\mathrm{n}-3)$ and $2.4 \mathrm{~g}$ cervonic acid $(22: 6 \mathrm{n}-3)$ in the mackerel group. Compliance decreased slightly in time.

Systolic blood pressure decreased in both groups to a comparable degree; consequently no specific effect of the fish supplement was observed. The fish supplenent significantly prolonged the bleeding time. Hematology was hardly affected, but platelet counts decreased significantly. No indications were obtained for adverse effects of the fish supplement.

In Chapter 5 the effects of a fish enriched diet on serum lipids, apolipoproteins A-1 and $\mathrm{B}$, and the fatty acid compositions of serum triglycerides and cholesterolesters are described. LDL- and total serum cholesterol concentrations were unaffected. HDL cholesterol increased to a comparable degree in both the mackerel and the control group; thus no specific fish effect was observed. Triglyceride content of serum decreased in the fish group as compared with the control group. Apolipoproteins A-1 and B (Maastricht only) were only slightly affected. In the mackerel group the n-3 fatty acids increased significantly in the serum cholesterolesters and triglycerides; the $n-6$ fatty acids decreased in the cholesterolesters only. 
In Chapter 6 the effect of dietary fish on platelet aggregation in platelet rich plasma (PRP), induced by collagen and thrombin is reported. Platelet number in PRP decreased significantly in the fish group. Collagen-induced platelet aggregation in PRP differed widely between the three centres despite the attempt to use exactly the same conditions. Nonetheless, aggregation decreased significantly in the fish group. The mackerel effect on thrombin-induced aggregation was inconsistent.

In Chapter 7 the effect of a reasonable amount of dietary fish on collagen induced platelet aggregation and ATP release in citrated whole blood is described. These measurements were performed in Maastricht only. The mackerel supplement had a weak, but significant inhibitory effect on collagen induced platelet aggregation (impedance methody and ATP release (firefly assay) in whole blood. Platelet release was significantly related to the compliance.

In Chapter 8 the results are given of the influence of the dietary fish on the various aspects of eicosanoid formation and metabolism. In collagen-activated platelet rich plasma the potency of blood platelets to produce cyclo-oxygenase and lipoxygenasedependent monohydroxy fatty acids from endogenous arachidonic acid (HHT and HETE) was significantly reduced in the mackerel group as compared with the control group, whereas the formation of products derived from endogenous timnodonic acid (HHTE and HEPE) significantly increased. Changes in the formation of HHT and HHTE, measured by HPLC, correlated significantly with those of $\mathrm{TxB}_{2}$ and $\mathrm{TxB}_{3}$, respectively, measured by GC/MS. Formation of immono reactive $\mathrm{TxB}_{2}$ and 6-keto-PGF $\mathrm{Fax}_{\mathrm{a}}$ in clotting blood showed comparable significant decreases, both in the mackerel group and the control group, leaving the ratio between the two compounds unchanged. Mackerel consumption was associated with the formation of considerable amounts of $\mathrm{PGI}_{3}$, as judged from the appearance of 2,3-dinor17-6-keto-PGF ${ }_{3 \alpha}$ in urine. Moreover, the amount of the major metabolite of $\mathrm{PGI}_{2}$, 2,3-dinor-6-keto-PGF ${ }_{1 \alpha}$ increased considerably in the urine in striking association with $\mathrm{PGI}_{3}$. The total daily turnover of PGE and PGF (as reflected by the amount of tetranor prostanedioic acid in the urine) did not change in the mackerelsupplemented volunteers. Therefore the findings with respect to $\mathrm{PGI}_{2}-\mathrm{M}$ may result from a change in the metabolism rather than from an increase in turnover rate of $\mathrm{PGI}_{2}$ upon fish consumption.

In Chapter 9 the results of dietary fish on the coagulation tendency of blood and on the procoagulant activity of monocytes are reported. We did not observe a significant effect of the fish supplement on the prothrombin time or on the levels of factor VII, activated factor VII, antithrombin III, von Willebrand factor, fibrinogen. An indication of a slight, but transient compliance-related prolongation in the partial thromboplastin time was observed. Moreover, a significant increase of the factor X level with prolongation of the experimental period was noticed; no activated factor $\mathrm{X}$ was found. A tendency towards a stimulation of monocyte procoagulant 
activity by the fish supplement was also found, which was also related to the dietary adherence.

Fibrinolytic parameters (Chapter 10) were determined in plasma samples obtained at the beginning as well as at the end of the experimental period. No changes were found in plasminogen, $\alpha_{2}$-antiplasmin, tissue-type plasminogen activator (t-PA) antigen and euglobulin t-PA activity.

In the control group, no change in plasminogen activator inhibitor activity was found. In the fish group, however, total plasma plasminogen activator inhibitor activity increased by 45 percent, due to a 71 percent increase in plasminogen activator inhibitor type-1. This increase could not be ascribed to a diet-induced acute phase reaction and could not be explained by changes in serum triglycerides or insulin. The results caution against the use of fish-enriched diets by people with low endogenous fibrinolytic activity.

In general the effects of dietary n-3 fatty acids on human health are not very convincing. This is in contrast to the promising results of many epidemiological studies which, however, may have been confounded by a low intake of saturated fatty acids. From our study it is concluded that a reasonable amounts of dietary fish prolongs the bleeding time, decrease serum triglyceride content, lower platelet aggregability in response to collagen, diminish thromboxane $B_{2}$ production in clotting blood, reduce $\mathrm{PGI}_{2}$ content of serum, decrease platelet number, and increase the activity of the major plasminogen activator inhibitor. The meaning of these results in relation to a decrease in cardiovascular risk is dubious. It cannot be excluded, however that a long-term (life-long) influence of a small amount of dietary fish may contribute to a lower cardiovascular risk. 


\section{Samenvatting}

Hart- en vaatziekten zijn de bellangrijkste doodsoorzaak in geïndustrialiseerde landen. Sinds het begin van deze eeuw wordt er een verband verondersteld tussen voeding en hart- en vaatziekten. Uit epidemiologisch onderzoek is de indruk ontstaan dat voeding rijk aan vis en andere zee- en zoetwaterdieren van belang zou kunnen zijn bij de bestrijdling van deze ziekten. Een nadere bestudering van deze epidemiologische onderzoeken toonde echter aan dat de resultaten tegenstrijdig zijn (hoofdstuk 1). Desalniettemin hebben deze epidemiologische bevindingen veel onderzoek op gang gebracht naar de invloed van visvetzuren op de risicofactoren van hart- en vaatziekten. Het merendeel van deze onderzoekingen bleek echter niet betrouwbaar te zijn omdat een goede controlegroep ontbrak.

Hart- en vaatziekten zijn ondermeer het gevolg van trombose in de slagaders. Bloedplaatjes, de kleinste in het bloed voorkomende cellen, vervullen hierbij een essentiële rol doordat ze in staat zijn aan de wand van het bloedvat en aan elkaar te kleven (aggregeren). Op deze wijze dragen ze bij aan het langzaam dichtslibben van slagaders; zelfs kunnen ze een plotselinge verstopping daarvan veroorzaken.

In dit proefschrift worden twee eigen onderzoeken beschreven. In het eerste onderzoek wordt de hypothese getoetst dat langdurige (habituele) visconsumptie de sterfte aan hart- en vaatziekten beinvloedt door middel van een invloed op de funktie van bloedplaatjes en op de fibrinolyse. Voor dit onderzoek werden mensen uitgenodigd die reeds betrokken zijn bij een langdurig onderzoek in Zutphen. Veertig mannen met een stabiele visconsumptie gedurende de afgelopen 26 jaar werden in twee groepen verdeeld. In de groep met de hoge visconsumptie ( 25 personen) werd gemiddeld $33 \mathrm{~g}$ vis per dag per persoon gegeten. De groep met de lage visconsumptie (15 personen) at gemiddeld $2 \mathrm{~g}$ vis per dag per persoon. Dit verschil in visconsumptie was ook walar te nemen in het bloed van de vrijwilligers. De hoeveelheid visvetzuren (timnodonzuur (20:5 n-3) en cervonzuur (22:6 n-3)) in het bloed (serum fosfolipiden) was in de groep met de hoge visconsumptie hoger dan in de groep met de lage visconsumptie. Door middel van statistische berekeningen wordt aangetoond dat deze verschillen echt zijn (signifikant) en niet op toeval berusten. We konden echter geen verschil tussen beide groepen aantonen in bloedingstijd, aantal bloedplaatjes en functies van bloedplaatjes. Het leek er echter wel op dat de bloedplaatjes van de mannen in de hoge visgroep wat minder aktief waren. Op grond van deze resultaten kunnen we het verband tussen de sterfte aan hart- en vaatziekten en visconsumptie, zoals waargenomen in Zutphen niet verklaren. We kunnen echter niet geheel uitslui- 
ten dat een kleine hoeveelheid wis in de voeding op de lange duur toch een bijdrage levert aan een vermindering van het risico voor hart- en vaatziekten (hoofdstuk 2).

Op grond van een vragenlijst over het dieet is bij deze mensen berekend hoeveel timnodonzuur en cervonzuur per persoon per dag gegeten werd. In het bloed zijn de concentraties van deze beide vetzuren gemeten. Per persoon was de relatie tussen de berekende en de gemeten hoeveelheid visvetzuren niet duidelijk. Een van de redenen hiervoor zou kunnen zijn dat de hoeveelheid visvetzuren in dezelfde soort vis sterk kan varieren en het dus erg moeilijk is precies vast te stellen hoeveel van een bepaald vetzuur iemand binnen krijgt. Het lijkt dus beter dit in het bloed te meten.

Voor een ander onverzadigd vetzuur, linolzuur (18:2 n-6), was het verband tussen de hoeveelheid bepaald via de vragenlijst en de concentratie in het bloed veel duidelijker. Bovendien bleek dat de hoeveelheid linolzuur in de voeding van invloed is op de inbouw van timnodonzuur (hoodstuk 3 ). Bij het vergelijken van de berekende en de gemeten hoeveelheid timnodonzuur zullen we hiermee rekening moeten houden.

Het tweede onderzoek dat in dit proefschrift wordt beschreven is een study naar de invloed van een dagelijkse portie van $100 \mathrm{~g}$ vis in de voeding op een aantal risikofaktoren voor hart- en vaatziekten. Deze hoeveelheid vis kwam overeen met ca. $6 \mathrm{~g}$ visvetzuren per dag. In Maastricht, Zeist en het Noorse Troms $\emptyset$ werden ruim 80 gezonde mannen van 18-45 jaar voor het onderzoek geselecteerd. Aan ongeveer veertig mannen werd gevraagd om gedurende 6 weken dagelijks een blikje makreelpaté te eten. De andere veertig kregen als controle een blikje vlees. Aan het begin van de proef werd een serie metingen gedaan, die na 3 en 6 weken herhaald werd. De tijdens de proefperiode optredende veranderingen in de visgroep werden vergeleken met de veranderingen die in de controlegroep optraden.

Bij alle vrijwilligers werd regelmatig gecontroleerd of zij de voedingssupplementen ook werkelijk opaten. Dit werd gedaan door een bekende hoeveelheid van een geschikte merkstof (een lithiumzout) aan de supplementen toe te voegen, en de uitscheiding hiervan in de urine te bepalen. Gemiddeld bleek dat de vrijwilligers ongeveer $80 \%$ van de hoeveelheid die ze moesten eten ook werkelijk hebben gegeten (hoodfstuk 4).

Een van de belangrijkste risikofaktoren voor hart- en vaatziekten is een te hoge bloeddruk. We hebben in ons onderzoek dan ook nauwkeurig het bloeddrukverloop van de proefpersonen gevolgd, maar van enig specifiek effekt door het vissupplement was geen sprake (hoofdstuk 4).

Een bellangrijke risikofaktor voor hart-en vaatziekten is de hoeveelheid cholesterol in het bloed: een bepaalde cholesterolfraktie (het LDL-cholesterol) houdt direkt verband met het hart-vaat risiko. Dit LDL-cholesterol veranderde in de visgroep echter niet. 
Een andere vet-fraktie in het bloed, de triglyceriden, daalde wel signifikant bij de mensen die het vissupplement aten. Door sommige deskundigen wordt dit gezien als een daling van het hart-vaat risiko; anderen daarentegen, menen dat het triglyceridegehalte van het bloed geen betekenis heeft voor het ontstaan en verloop van harten vaatziekten (hoofdstuk 5).

De aggregatie-neiging van bloedplatatjes kan op verschillende manieren worden gemeten. Eén manier is het meten van de bloedingstijd (de tijd dat een klein huidwondje blijft bloeden): De bloedingstijd was na 6 weken in de visgroep signifikant verlengd (hoofdstuk 4).

Ook op andere wijze gemeten deed het eten van vis de aggregatieneiging van bloedplaatjes afnemen en dat zou op den duur een verminderd risiko voor hart- en vaatziekten kunnen betekenen. De waargenomen effekten waren echter gering, en het is dan ook de vraag of ze op zich voldoende zijn om ook inderdaad een risikovermindering tot stand te brengen (hoofdstuk 6 en 7).

In hoofdstuk 8 zijn de resultaten beschreven van de invloed van vis in het dieet op een aantal hormoonachtige stoffen die uit vetzuren worden gemaakt, de prostaglandinen. Dit zijn stoffen die allerlei processen in ons lichaam voortdurend regelen. Bloedplaatjes maken een soort prostaglandine (thromboxaan $\mathrm{A}_{2}$ dat de aggregatie doet toenemen; de vaatwand produceert een prostaglandine (prostacycline $I_{2}$ dat de aggregatie tegengaat. Onder invloed van de visvetzuren bleken de bloedplaatjes een andere soort thromboxaan (thromboxaan $A_{3}$ te maken. Deze stof doet de aggregatie veel minder toenemen dan het thromboxaan $\mathrm{A}_{2}$, dat onder invloed van visvetzuren in mindere mate gemaakt bleek te worden. De vaatwand maakt óók een ander soort prostacycline ten gevolge van het eten van vis: prostacycline $I_{3}$. Deze stof gaat de aggregatie in dezelfde mate tegen als het prostacycline $I_{2}$. In totaal betekenen deze veranderingen dat er onder invloed van de vissupplementen een afname van de aggregatieneiging plaatsvond.

Het dichtslibben van de slagaders, waarvan een groot deel van de hart- en vaatziekten het gevolg zijn, wordt niet alleen veroorzaakt door samenklonterende bloedplaatjes, ook het optreden van bloedstolling speelt hierbij een belangrijke rol. Het eindprodukt van het stollingsproces, fibrine, vormt als het ware een netwerk dat optredende verstoppingen verstevigt, waardoor deze nauwelijks nog te verwijderen zijn. In het bloed bevindt zich ook een systeem dat fibrine kan oplossen (fibrinolyse) en zolang bloedstolling en fibrinolyse elkaar in evenwicht houden, zijn er geen problemen te verwachten. Een toegenomen stollingsproces of een minder aktieve fibrinolyse kan echter wel bijdragen aan het ontstaan van hart- en vaatziekten en omgekeerd kumnen hart- en vaatziekten mogelijk worden tegengegaan door een verminderde stollingsneiging van het bloed en/of een sterkere fibrinolyse.

In ons onderzoek hebben wij de invloed van het vissupplement op zowel bloedstolling (hoofdstuk 9) als fibrinolyse (hoofdstuk 10) nauwkeurig bestudeerd. Beide pro- 
cessen verlopen in een groot aantal opeenvolgende stappen die op een ingewikkelde manier in elkaar grijpen. De meeste van die deelprocessen werden afzonderlijk bestudeerd. Daarnaast zijn bloedstolling en fibrinolyse ook als totaalproces bekeken. Het vissupplement bleek hierop nauwelijks enige invloed te hebben. Het fibrinolyseonderzoek is uitgevoerd in samenwerking met Dr. J. Emeis van het Gaubius Instituut te Leiden. Zoals gezegd, op het fibrinolyseproces als geheel had het vissupplement geen signifikante invloed, maar wel op de aktiviteit van een van de reguleringsfaktoren. Het bleek namelijk dat de aktiviteit van een natuurlijke, in het bloed voorkomende remmer van de fibrinolyse sterk was toegenomen bij mensen die het vissupplement gebruikten. Aangezien de fibrinolyse een belangrijk verdedigingsproces is tegen ongewenste bloedstolling, moet dit effekt van vis in de voeding als nadelig worden beschouwd.

De resultaten wan ons onderzoek overziende, moeten we tot de conclusie komen dat de dagelijkse consumptie van ongeveer 100 gram makreel gedurende 6 weken nauwelijks van invloed is op het risikoprofiel van hart- en vaatziekten. Het bloedcholesterolgehalte verandert niet, de bloeddruk evenmin. Wel neemt het triglyceridengehalte van het bloed af, maar de betekenis hiervan voor het hart-vaat risiko is niet duidelijk. De neiging van bloedplaatjes om samen te klonteren neemt enigszins af en dit kan inderdaad als gunstig worden geduid. Bloedstolling en fibrinolyse worden nauwelijks beînvloed; een negatieve invloed op de fibrinolyse kan echter niet worden uitgesloten.

Vis in de voeding is een uitstekende eiwitbron en uit het oogpunt van voedingsvariatie zeker aan te bevelen. Op basis van onze studie zijn er echter geen redenen om aan te nemen dat het eten van vis (of het slikken van visolie-capsules) wezenlijk bijdraagt tot een afname van het risiko voor hart- en vaatziekten. Dit komt niet overeen met de veelbelovend lijkende resultaten van verschillende epidemiologische onderzoekingen. Deze resultaten zouden weleens beinvloed kunnen zijn door een lagere hoeveelheid verzadigd vet in het dieet hetgeen dikwijls samen gaat met een visrijke voeding. Het is echter op dit moment niet uit te sluiten dat op de lange duur de consumptie van kleine hoeveelheden vis enig effekt heeft, maar het lijkt minstens zo belangrijk de hoeveelheid verzadigd vet in de voeding te verminderen. 


\section{Woorden van dank}

Promoveren doe je niet in je eentje. Dit proefschrift is dan ook tot stand gekomen door de samenwerking van een heel team van mensen. Allen die een bijdrage hebben geleverd aan de tot stand koming van dit proefschrift wil ik graag van harte bedanken.

Van hen wil ik met name noemen:

- Mijn coupromotor Dr. G. Hornstra. Gerard wat ik hier ook schrijf, ik doe je altijd te kort. Het is een voorrecht met je te mogen samenwerken en onder jouw begeleiding te kunnen promoveren. De vriendschap ondervonden van jou en Netty, heeft een bijzonder stempel gedrukt op de afgelopen jaren.

- Mijn promotor prof. dr. F. ten Hoor. Foppe, de stimulerende discussies die we regelmatig hadden zijn van grote waarde geweest. Bovendien kon ik als het nodig was altijd een beroep op je doen.

- Arnold Kester, jij hebt getracht mij wat statisch inzicht bij te brengen. Jouw inzet en vakkennis hebben een essentiele bijdrage geleverd aan de verwerking van de resultaten. In al die donderdagmorgenuurtjes heb ik veel van je geleerd.

- Jos Stegen. De laatste jaren ben je bijna onophoudelijk aan het analyseren geweest: vetzuurspektra, TPD's etc. Je hebt ontzettend veel werk verzet!

- Daan Kromhout, jij wist ons te verleiden tot het participeren in het Zutphen onderzoek hetgeen een boeiende en leerzame ervaring is geworden.

- Sjef Emeis, onder jouw leiding zijn alle fibrinolyse bepalingen uitgevoerd. Door jouw bijdrage heeft hoofdstuk 10 het licht gezien.

- Puck Muller, jij hebt alle coagulatie bepalingen gedaan; zonder jou was hoofdstuk 9 er niet geweest.

- Truus Dickhaut, die het meeste tikwerk en al die correcties heeft verzorgd. Dankzij jouw inzet en overuren was het toch altijd weer op tijd klaar.

- Adje Hennissen, Marianne Simonis, Rob Kalafusz, Sjef Roos, Marcel Theunissen, Elsa Beckers, Mariet Molenaar, die allen hun steentje hebben bijgedragen.

- De teams van onderzoekers en vrijwilligers in Troms $\emptyset$ en Zeist, die ervoor zorgden dat daar alles goed verliep.

- De Zutphense mannen die aan het onderzoek hebben meegedaan.

- De Maastrichtse vrijwilligers, die trouw dagelijks hun blikje hebben leeggegeten.

- Nancy Nicolson en Savithiri Ganesan die de engelse tekst corrigeerden. 
- De mensen die Andrea hebben opgevangen o.a. Marjan Vermeiden, Netty-, Marco en Silvio Hornstra, Mieke en Inge van Werkhoven, Mart Debets en Jan Jongenelen, José Aarts, Maria de Hoen, Opa's en Oma's.

- Andrea voor al het wachten als mamma weer eens moest schrijven.

- Mijn ouders die het fundament voor dit alles gelegd hebben.

- Tenslotte wil ik jou Kees bedanken voor je trouw, je kameraadschap... voor zoveel: Het is ontzettend fijn iemand als jij naast me te hebben. 


\section{Curriculum vitae}

Adriana Cornelia van Houwelingen,

13-8- 1950 geboren te Dordrecht.

1956-1962 lagere school te Sliedrecht.

1962-1965 huishoudschool te Eindhoven.

1965-1968 vooropleiding lerares N.O. aan de beroepenschool voor meisjes te Eindhoven.

1968-1969 opleiding lerares N XXI te Posterholt.

1969-1972 analiste-opleiding HBO-A analytische chemie; aan het Instituut voor Hoger Beroeps Onderwijs (IHBO), te Eindhoven.

sept 1972 in dienst getreden bij het klinisch chemisch laboratorium van het St Jozefziekenhuis te Eindhoven.

1973-1974 avondcursus klinisch chemisch analiste HBO-A aan het IHBO te Eindhoven (voor chemisch analisten werkzaam in ziekenhuizen).

mei 1976 in dienst getreden bij de afdeling Trombosedienst en Serologie van het St Annadalziekenhuis te Maastricht.

sept 1976 in dienst getreden bij het klinisch chemisch laboratorium van laatst genoemd ziekenhuis.

sept 1977 aanvang studie Geneeskunde aan de Rijksuniversiteit Limburg te Maastricht.

juni 1980 kandidaats-examen Geneeskunde.

1979-1981 lid studentenfractie van de faculteitsraad van de Faculteit der Geneeskunde.

sept 1982 doctoraal-examen Geneeskunde.

juli 1983 arts-examen.

aug 1983 aangesteld als wetenschappelijk ambtenaar (part-time) aan de Rijksuniversiteit Limburg bij de vakgroep Humane Biologie van de Faculteit der Gezondheids Wetenschappen.

sept 1986 aangesteld als universitair docent (part-time) bij bovengenoemde afdeling, waar zij sinds aug 1983, onder leiding van Dr. G. Hornstra, werkt aan een onderzoek naar de invloed van met vis verrijkte voeding op een aantal risiko factoren met betrekking tot hart- en vaatziekten. 